UNIVERSIDADE DE SÃO PAULO

FACULDADE DE ECONOMIA, ADMINISTRAÇÃO E CONTABILIDADE DEPARTAMENTO DE ADMINISTRAÇÃO PROGRAMA DE PÓS-GRADUAÇÃO EM ADMINISTRAÇÃO

CORRESPONDÊNCIA ENTRE USUÁRIOS E FUNCIONALIDADES DE BI: A INFLUÊNCIA DA PERSONALIDADE E DOS ESTILOS COGNITIVOS

Sergi Pauli

Orientador: Fernando Carvalho de Almeida

SÃO PAULO 
Prof. Dr. João Grandino Rodas

Reitor da Universidade de São Paulo

Prof. Dr. Reinaldo Guerreiro

Diretor da Faculdade de Economia, Administração e Contabilidade

Prof. Dr. Adalberto Américo Fischmann

Chefe do Departamento de Administração

Prof. Dr. Lindolfo Galvão de Albuquerque

Coordenador do Programa de Pós-Graduação em Administração 


\title{
SERGI PAULI
}

CORRESPONDÊNCIA ENTRE USUÁRIOS E FUNCIONALIDADES DE BI:

\section{A INFLUÊNCIA DA PERSONALIDADE E DOS ESTILOS COGNITIVOS}

\author{
Dissertação apresentada ao Departamento de \\ Administração da Faculdade de Economia, \\ Administração e Contabilidade da Universidade \\ de São Paulo, para obtenção do título de Mestre \\ em Ciências.
}

Orientador: Fernando Carvalho de Almeida

\section{Versão Corrigida}

(versão original disponível na Faculdade de Economia, Administração e Contabilidade)

\section{SÃO PAULO}




\section{Pauli, Sergi}

Correspondência entre usuários e funcionalidades de BI: a influência da personalidade e dos estilos cognitivos / Sergi Pauli Niubo. - São Paulo, 2012.

$200 \mathrm{p}$.

Dissertação (Mestrado) - Universidade de São Paulo, 2012.

Orientador: Fernando Carvalho de Almeida.

1. Sistemas de informação 2. Sistemas de apoio a decisão 3.

Personalidade 4. Estilo cognitivo I. Universidade de São Paulo.

Faculdade de Economia, Administração e Contabilidade II. Título.

CDD -658.4038011 
Ao meu avô Josep Niubo (in memorian) e ao mestre Ronaldo Zwicker (in memorian), fontes de inspiração e referências, hoje e sempre. 

Agradeço aos doutores da casa, em especial, Prof. Dr. Fernando Carvalho de Almeida pelo acolhimento e compreensão, Profa. Dra. Tânia Casado pela ajuda imprescindível e colaboração com Diagnóstico de Tipos Psicológicos, Prof. Dr. Nicolau Reinhard, pelos comentários enriquecedores e visão crítica, Prof. Dr. Cesar Alexandre de Souza, pelas orientações e colaborações ao longo do mestrado e Prof. Dr. Gilberto Perez, membro da banca de defesa.

Agradeço aos entrevistados e aos respondentes da pesquisa, em sua maioria anônimos, sem os quais não seria possível concluir com sucesso esta obra, e aquelas pessoas que permitiram e viabilizaram a pesquisa, inclusive dentro do Banco Alfa. Também agradeço aos colegas de trabalho e amigos por propiciar estes contatos, em especial, Mônica Tyszler, Fiorella Tierno e André Cristiano Borges.

Agradeço a meus familiares, particularmente meus pais, Jorge e Flora, pelo apoio incondicional e incentivo aos estudos, a minha namorada Tatiana Cardoso e a meus amigos mais próximos, em especial, Eduardo Martins e Luís Fernando Barreto, colaboradores, confidentes e pacientes amigos durante estes três anos de estudos. Agradeço também a Lícia Abe, Cátia Bicudo e Franciele Santos pela colaboração na execução da pesquisa.

Finalmente, agradeço a todos aqueles que participaram de uma forma ou de outra deste período de estudos, dedicação e tempo escasso.

Muito obrigado a todos. 

"Em algum lugar, algo incrível está a espera de ser descoberto" Carl Sagan (1934-1996) 



\section{RESUMO}

Para Rud (2009, p.3) o objetivo primordial do Business Intelligence é fornecer a informação certa para a pessoa adequada, dentro do tempo esperado e no formato correto, através do canal mais apropriado. Para cumprir este complexo desafio, Eckerson $(2009$, p.4) afirma que a questão central está em compreender quais as ferramentas e métodos são mais adequados para os diferentes grupos de usuários que usufruem das soluções analíticas. Assim, esta obra procura dar continuidade às observações de Eckerson (2009, p.4), aprofundando o entendimento dos usuários analíticos e de seu relacionamento com as ferramentas de BI disponíveis, avaliando uma nova variável: o estilo cognitivo dos usuários. Em outras palavras, procura avaliar se existe uma relação entre os estilos cognitivos dos usuários analíticos (representados neste caso pelos tipos psicológicos) e sua escolha por determinadas funcionalidades disponíveis em aplicações de Business Intelligence (como, por exemplo, painéis de informação, relatórios pré-configurados, relatórios ad hoc, relatórios OLAP, modelos preditivos e mineração de dados), além de outros aspectos relacionados com esta associação. No Estudo de Caso realizado com o Banco Alfa, as opiniões em relação a este assunto são variadas e parecem ser influenciadas pelo nível hierárquico do respondente; contudo, indicam a existência de alguma influência ainda que difícil de ser quantificada ou explicada. Por outro lado, no limitado levantamento executado com alguns usuários - cujos dados colhidos são avaliados com a ajuda do Teste Qui-Quadrado e do Teste Exato de Fischer, não é possível constatar a influência. De qualquer forma, mais do que negar de forma conclusiva a existência da relação, os resultados parecem indicar que uma das variáveis pode ser aprimorada, abrindo uma possibilidade de desenvolvendo para esta análise.

Palavras-chave: Sistemas de informação, Business Intelligence, Estilo Cognitivo, Tipos Psicológicos. 



\begin{abstract}
Rud (2009, p.3) states that the primary goal of Business Intelligence is to provide the accurate information to the right person within the expected timeframe and proper format, through the most suitable channel. To fulfill this complex challenge, Eckerson (2009, p.4) affirms that the key issue is to understand which tools and methods are the most suitable for the different groups of users who benefit from analytical applications. The key objective of this thesis is to continue the studies and observations of Eckerson (2009, p.4), understanding BI users and their relationship with these tools, investigating a new variable: the users' cognitive style. In other words, this thesis details the effort to verify if there is a relationship between cognitive styles (represented in this case by psychological types) of analytical users and their choice and preference for certain functionalities available in Business Intelligence applications (such as, dashboards, formatted reports, ad hoc reports, OLAP reports, predictive modeling and data mining), as well as other aspects of this association. In the Case Study conducted with Bank Alfa, the opinions on this matter are diverse and seem to be influenced by the hierarchical level of the respondent; however, they seem to indicate the existence of some influence even though it is difficult to quantify or explain. On the other hand, on the limited survey carry out with some BI users - the collected data was evaluated with Chi-Square Test and Fisher's Exact Test, is not possible to identify the influence. Nevertheless, instead of rejecting any type of relationship, the results indicate that one of the variables should be further improved and studied.
\end{abstract}

Key Words: Information Systems, Business Intelligence, Cognitive Styles, Psychological Types. 



\section{LISTA DE FIGURAS}

Figura 1. Os Quatro Principais Tipos de Sistemas de Informação......................................... 19

Figura 2. Formas de Coleta Externa de Informação............................................................ 38

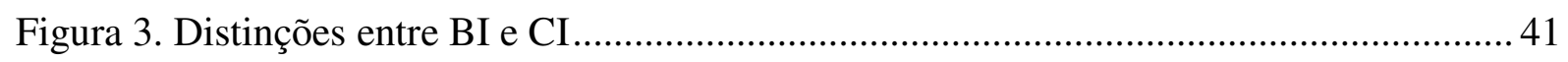

Figura 4. Componentes Genéricos de uma Solução de BI ................................................... 46

Figura 5. Complexidade vs Valor Agregado das Funcionalidades de BI ................................ 53

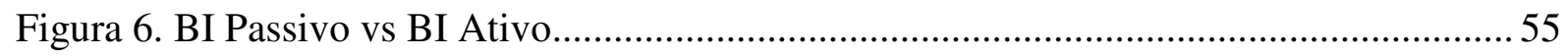

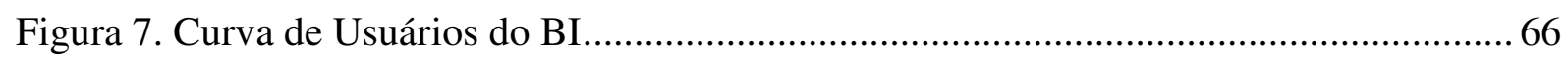

Figura 8. Mapeamento de Tipos de Usuários e Tipos de Ferramentas de BI .......................... 68

Figura 9. Fases da Automação Bancária no Brasil............................................................ 115

Figura 10. Características Demográficas da Amostra ........................................................ 130

Figura 11. Grau de Conhecimento por Funcionalidade ..................................................... 131

Figura 12. Freqüência de Utilização por Funcionalidade ................................................... 133

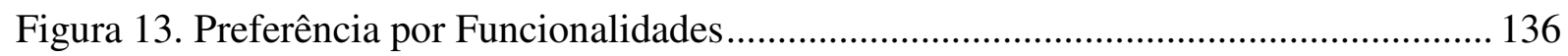

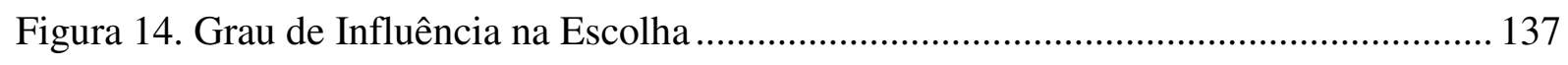

Figura 15. Distribuição dos Respondentes de acordo com as Funções Jungianas .................. 137 



\section{LISTA DE QUADROS}

Quadro 1. Características dos Sistemas de Informação ....................................................... 22

Quadro 2. Decisões Semi-Estruturadas: Escopo dos Sistemas de Apoio à Decisão................. 25

Quadro 3. Características dos Adaptadores e dos Inovadores ................................................ 74

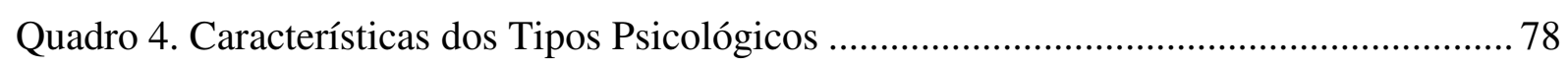

Quadro 5. Síntese dos Principais Temas do Marco Teórico ...................................................... 80

Quadro 6. Testes Fundamentais do Estudo de Caso ................................................................. 84

Quadro 7. Habilidades de um Pesquisador de Estudo de Caso ................................................ 91

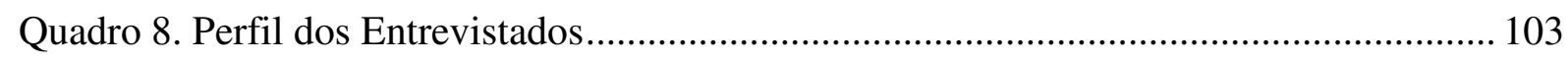

Quadro 9. Matriz de Variáveis e Indicadores do Questionário ............................................... 105 



\section{LISTA DE TABELAS}

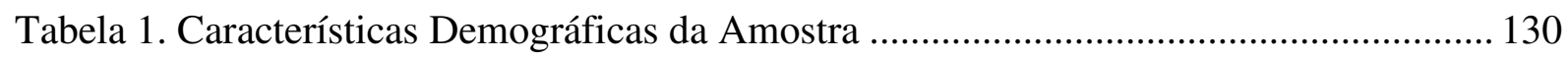

Tabela 2. Distribuição de Conhecimento por Funcionalidade ............................................... 131

Tabela 3. Distribuição de Utilização por Funcionalidade ..................................................... 132

Tabela 4. Teste de Normalidade de Conhecimento e Freqüência de Uso ............................... 134

Tabela 5. Coeficiente de Pearson entre Conhecimento e Freqüência de Uso ......................... 135

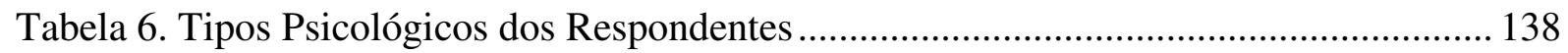

Tabela 7. Freqüências Observadas e Esperadas I...................................................................... 140

Tabela 8. Resultados Teste Qui Quadrado de Pearson........................................................ 141

Tabela 9. Freqüências Observadas e Esperadas II ........................................................... 142

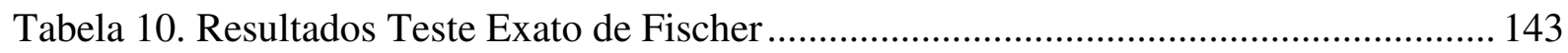





\section{SUMÁRIO}

1. INTRODUÇÃ

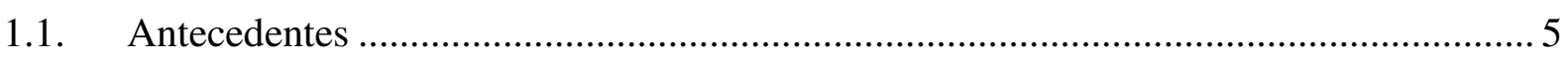

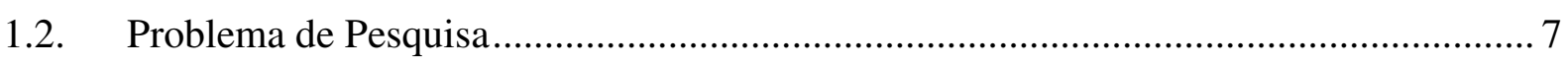

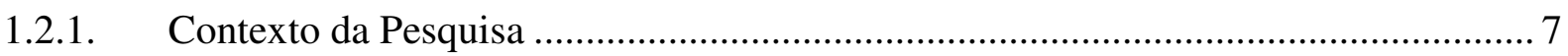

1.2.2. Questão-Problema e Objetivos de Pesquisa ........................................................... 9

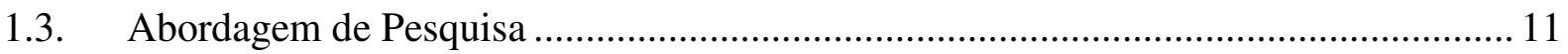

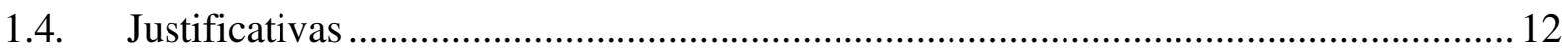

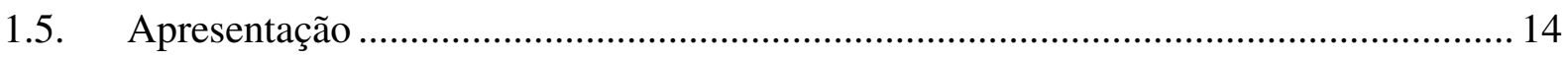

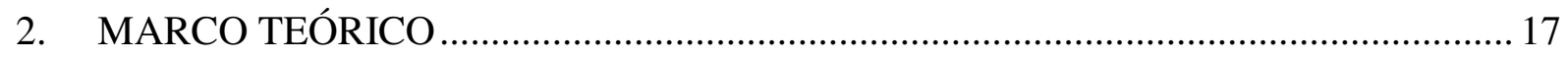

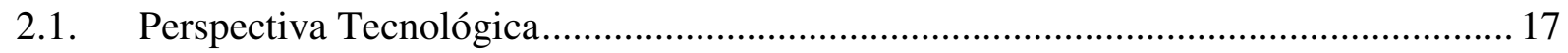

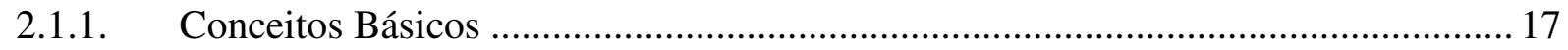

2.1.2. Classificação de Sistemas de Informação ............................................................... 19

Sistemas de Informação Gerenciais ................................................................. 22

Sistemas de Apoio à Decisão ............................................................................ 23

Sistemas de Informação Gerenciais vs Sistemas de Apoio à Decisão ................... 27

Sistemas de Informação Executivos................................................................ 28

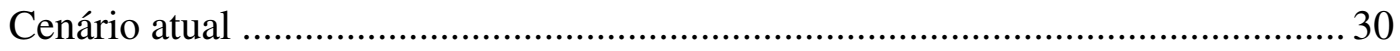

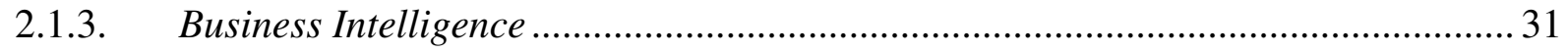

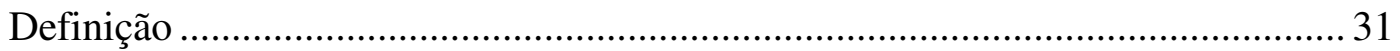

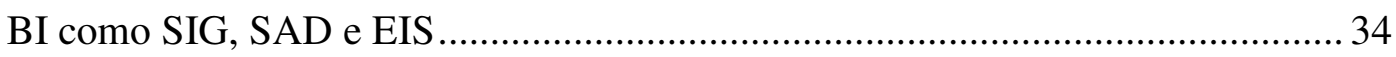

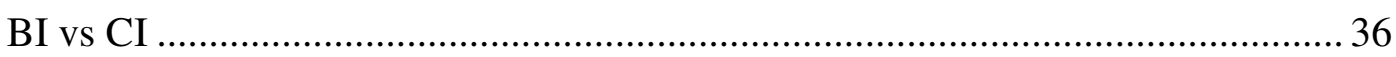

2.1.4. Componentes e Funcionalidades do BI........................................................... 41

Componentes de Arquitetura do BI.................................................................... 41

Funcionalidades de Apresentação e Análise de Dados do BI .................................46

Competição Analítica ........................................................................................ 54

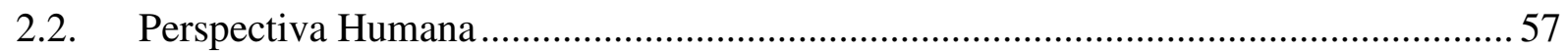

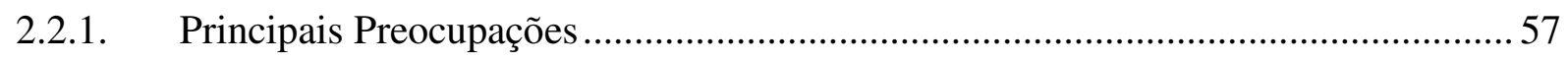

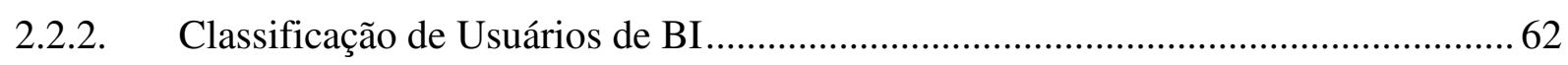

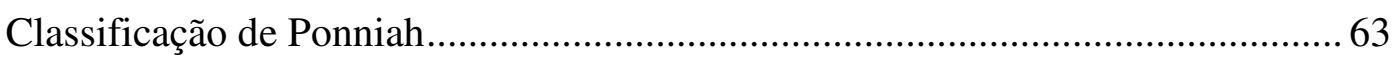

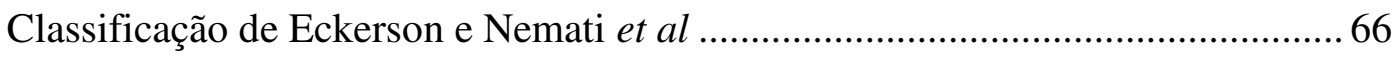




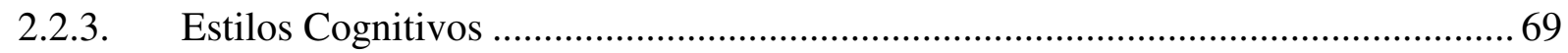

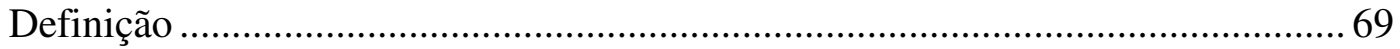

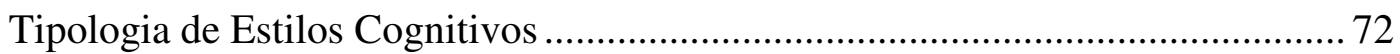

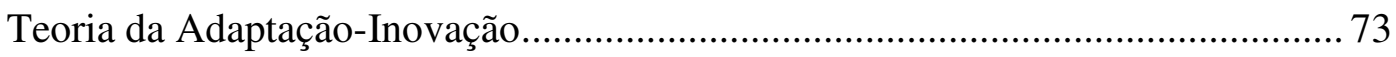

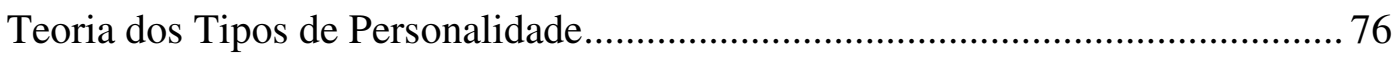

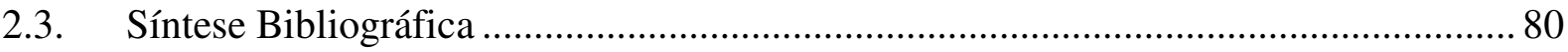

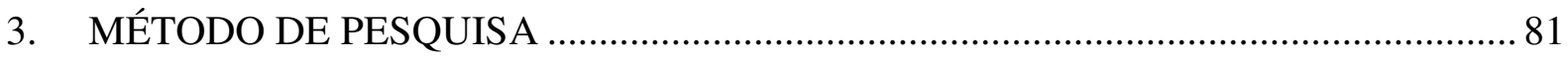

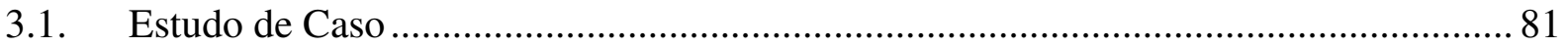

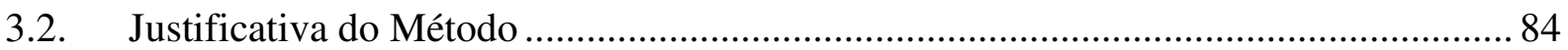

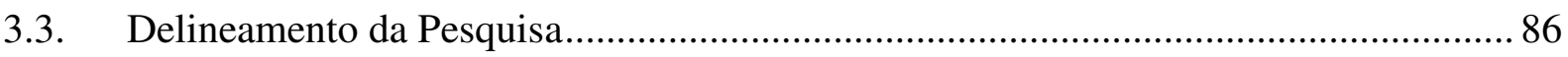

3.3.1. Questão de Pesquisa e Proposições de Pesquisa ..................................................... 86

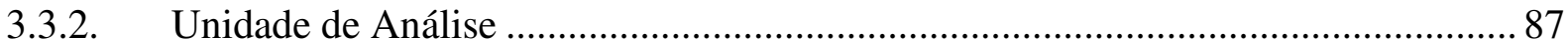

3.3.3. Ligação entre Dados e Proposições........................................................................... 88

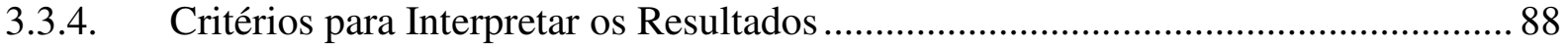

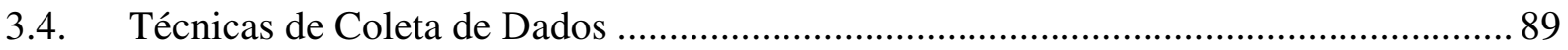

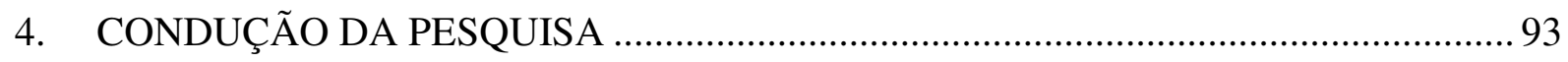

4.1. Questão-Problema e Proposições de Pesquisa .......................................................... 93

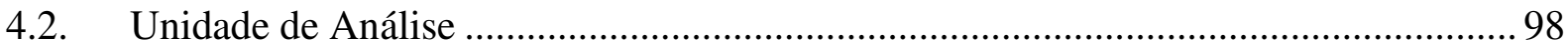

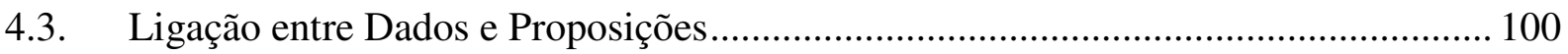

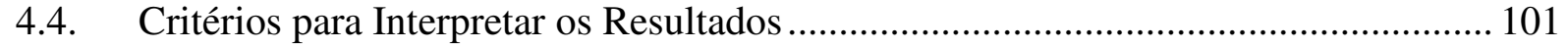

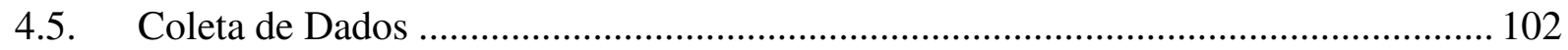

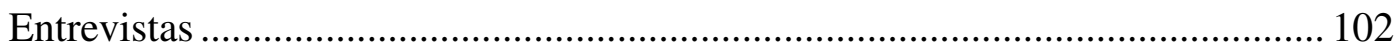

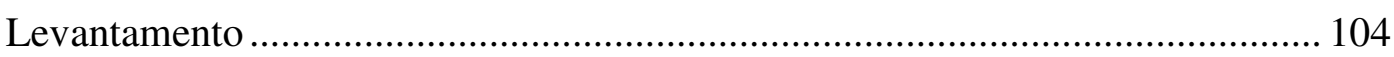

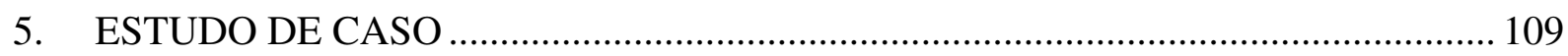

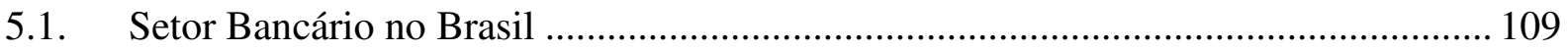

5.1.1. Histórico do Setor Bancário …............................................................................... 109

5.1.2. Tecnologia da Informação no Setor Bancário ...................................................... 112

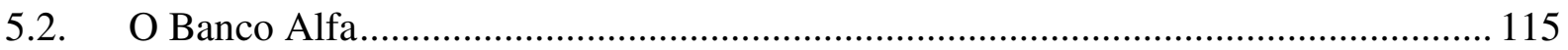

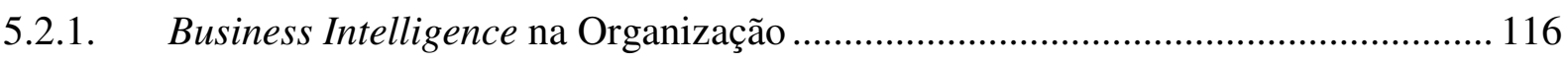

5.3. Caracterização e Distinção de Usuários de Soluções Analíticas................................ 120

5.4. Associação entre os usuários e as funcionalidades de BI.......................................... 123 
5.5. Relação entre Estilo Cognitivo e Preferência por Funcionalidades de BI 127

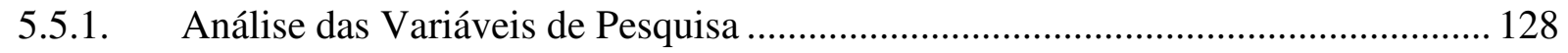

5.5.2. Análise da Relação entre Tipo Psicológico e Escolha por Funcionalidade ............ 138

5.6. Principais Preocupações com usuários no BI............................................................. 143

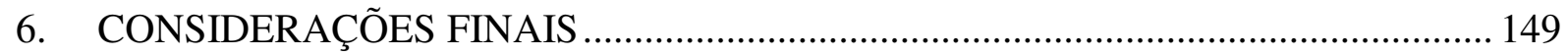

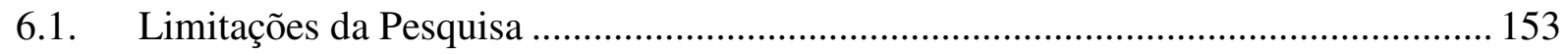

6.2. Implicações, Contribuições e Recomendações .......................................................... 154

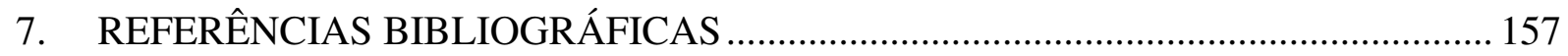

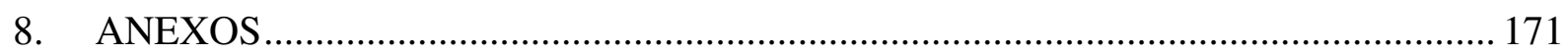

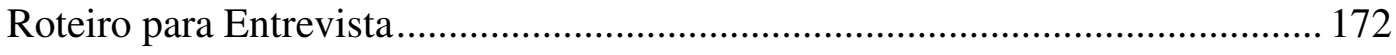

Questionário Business Intelligence ............................................................... 174

Carta de Apresentação da Pesquisa ..................................................................... 178

Orientação para Participação na Pesquisa ............................................................. 179

Resultado do Diagnóstico de Tipos Psicológicos ............................................... 180 


\section{INTRODUÇÃO}

A parte inicial desta dissertação tem como finalidade apresentar os antecedentes do estudo indicando campo, assunto e tema abordados, esclarecer o contexto, o problema de pesquisa e os objetivos, assim como sua abordagem, além de destacar as justificativas que motivaram o desenvolvimento deste trabalho. Finalmente, também é apresentada a disposição dos diversos assuntos dentro da obra.

\subsection{Antecedentes}

Apesar das pedras fundamentais terem sido estabelecidas aos poucos durante a primeira metade do século XX, a Revolução da Tecnologia da Informação propriamente dita teve início por volta dos anos 1960 e 1970 quando fatores ambientais adequados associados ao espírito inovador e empreendedor de gênios criativos permitiram o desenvolvimento sinergético, integrado, cíclico e contínuo do trinômio tecnológico composto pela microeletrônica, computação e telecomunicação (CASTELLS, 2005, p.76).

Desde então, esta revolução afetou indivíduos, organizações e sociedades de forma intensa, ininterrupta e irreversível, assim como suas antecessoras industriais, dando início a um novo paradigma econômico, social e cultural, organizado em torno da chamada Tecnologia da Informação (TI) (CASTELLS, 2005, p.67). Avanços como computadores pessoais, internet, telefonia móvel e redes sociais, dentre muitas outras, mudaram a forma como as pessoas se comunicam, se relacionam e se comportam, o modo como interagem, trabalham, estudam, consumem e pensam. As inúmeras inovações tecnológicas também foram aplicadas às organizações e, de modo equivalente, transformaram o mundo dos negócios, tornando a TI a espinha dorsal do comércio e da indústria dos séculos XX e XXI (CARR, 2003, p.5).

Particularmente no mundo das organizações, campo de estudo da Administração de Empresas, esta revolução tecnológica teve ampla aceitação e uma propagação acelerada na medida em que apoiou os objetivos estratégicos das empresas, trazendo benefícios para grande parte de seus stakeholders - atores que compõem o núcleo de interações de uma organização. Assim, as tecnologias desta revolução permitiram alcançar melhorias de desempenho e qualidade de 
produtos e de processos internos e externos (com clientes e fornecedores), expandir as fronteiras comerciais (consumidoras e fornecedoras) com a conseqüente conquista de novos mercados, difundir novos canais de distribuição e estabelecer novas formas de promoção, abrir oportunidades para a criação de novos produtos e serviços, dentre tantos outros benefícios que podem ser citados.

Tendo em vista este panorama, desde 1960 um novo assunto passou gradualmente a chamar a atenção de pesquisadores e acadêmicos, preocupando-se com uma série de questões válidas e extremamente pertinentes relacionadas com o emprego dessas tecnologias nas organizações. A Tecnologia da Informação como área de estudo dentro da Administração de Empresas concentrou-se, portanto, no entendimento da aplicação, uso, adoção e impactos de tecnologias diversas de microeletrônica, computação e comunicação nas organizações, nas pessoas e nos processos, assim como na definição, construção e gestão dessas soluções tecnológicas dentro das instituições privadas ou públicas. Ao contrário das disciplinas de cunho mais técnico como, por exemplo, a Engenharia Eletrônica ou de Telecomunicações, a Matemática ou a Computação (incluindo Processamento de Dados e Programação), a TI como parte de uma ciência social aplicada procurou atentar para o lado mais humano do tópico, assim como suas implicações nas várias instâncias sociais. De modo geral, pode-se dizer que se preocupou mais com os temas relacionados à informação, do que com aqueles relacionados à tecnologia por si só.

A evolução na computação também permitiu o desenvolvimento de um dos principais produtos da TI nas organizações, os Sistemas de Informação (SI), responsáveis por coletar, processar, armazenar e disseminar informações em grande volume de forma estruturada, rápida e segura em contraposição aos métodos manuais e arcaicos do começo do século XX. $\mathrm{O}$ aumento da capacidade de armazenamento e de processamento de dados associados ao barateamento dos custos ilustrados pela Lei de Moore (CASTELLS, 2005, p.77-78), assim como o desenvolvimento dos bancos de dados e das linguagens de programação promoveram o crescimento e amadurecimento destas poderosas ferramentas corporativas trazendo eficiência operacional e integração e automação de processos (WILLIAMS e WILLIAMS, 2003, p.2).

Por outro lado, aumentou sensivelmente o volume de dados a ser analisado, gerando empresas ricas em dados, mas pobres em informação, como sugerem Williams e Williams (2007, p.1), 
resultado que corrobora o estado de 'overdose de dados' em que se encontram muitas organizações nos dias atuais (BAWDEN e ROBINSON, 2009, p.182-183). Contudo, esta dificuldade de gerenciar tantas informações, agora importantes ativos da organização, associada à necessidade de novas ferramentas analíticas que pudessem auxiliar as pessoas a analisar os dados e convertê-los em conhecimento, acabou motivando o desenvolvimento de novas aplicações que receberam a denominação de Business Intelligence (BI), tema de estudo desta pesquisa.

\subsection{Problema de Pesquisa}

\subsubsection{Contexto da Pesquisa}

Apesar do enfoque essencialmente tecnológico dado ao Business Intelligence, principalmente por se tratar de um tema fundamentado na prática (YERMISH et al, 2010, p.48) e direcionado pelos fornecedores de TI (YEOH et al, 2008, p.81), diversos autores destacam a importância do lado humano para o sucesso destas aplicações. Howson (2008, p.1), por exemplo, afirma que sem pessoas capacitadas para interpretar a informação e agir sobre ela, o BI é incapaz de atingir qualquer resultado e enfatiza que a tecnologia é apenas o meio, mas nunca pode ser o fim. Brunson (2005, p.1) também alerta que nem a melhor das soluções tecnológicas é eficientemente aproveitada se seus usuários não são educados de forma adequada na sua utilização e entendimento.

Para Rud (2009, p.3) o objetivo primordial do BI é fornecer a informação certa para a pessoa adequada, dentro do tempo esperado e no formato correto, através do canal mais apropriado. Para cumprir este complexo desafio, Eckerson $(2009$, p.4) afirma que a questão central está em compreender quais as ferramentas e métodos são mais adequados para os diferentes grupos de usuários que usufruem das soluções de Business Intelligence. Entender os diferentes públicos alvo, os papéis que desempenham, as informações que demandam e as maneiras como consomem e analisam as informações permite que as estratégias e decisões em relação ao BI sejam aprimoradas dentro das organizações, garantindo resultados mais positivos, com menos frustração e insatisfação tanto pelo lado de TI, quanto pelo lado do negócio (ECKERSON, 2009, p.4). 
Esforços têm sido realizados neste sentido; Nemati et al (2010), por exemplo, realizaram em 2010 uma pesquisa onde procuram “(...) definir modelos de identificação de grupos de usuários dentro das organizações e mapear suas necessidades e requerimentos frente as funcionalidades oferecidas pelo Business Intelligence" (NEMATI et al, 2010, p.17). Com base nos ensaios de Eckerson (2002 apud NEMATI et al, 2010, p.17) (cujos estudos não têm um enfoque tão acadêmico e tampouco seguem fortes rigores metodológicos), os autores buscam neste estudo a correspondência entre os diferentes tipos de usuários definidos e as diversas funcionalidades de aplicações de BI. Estes pesquisadores concentram seus esforços de entendimento dos usuários avaliando principalmente suas necessidades de informação e capacidades técnicas, características essenciais no contexto organizacional.

Contudo, ignoram outros aspectos igualmente relevantes, dentre eles o estilo cognitivo dos usuários, uma variável que pode ser considerada pouco explorada até o momento, mas que, por outro lado, parece ser importante para o tópico em discussão. $\mathrm{O}$ estilo cognitivo trata das diferenças entre personalidades de usuários que resultam em distintas formas de interpretação de dados e de tomada de decisão e que, por conseguinte, podem significar distintas preferências por ferramentas de análise e apresentação de dados. Posteriormente esclarecida no marco teórico, uma premissa desta pesquisa é de que, apesar de depender de uma série de outras variáveis, o estilo cognitivo de um indivíduo pode ser representado de forma simplificada pelo seu tipo psicológico.

Evidentemente este relacionamento entre estilos cognitivos e ferramentas de SI não é uma novidade no mundo dos sistemas de informação. Pelo contrário, é o resgate dos estudos de autores conceituados que trataram da fase inicial dos Sistemas de Apoio à Decisão. Para Keen e Scott Morton (1978, p.73), por exemplo, as características, estratégias e habilidades particulares de cada pessoa fazem com que elas sejam mais eficientes em determinados contextos do que em outros, assim como em determinadas ferramentas do que em outras. Com isso em mente, os autores argumentam que "qualquer forma de auxílio analítico deve ser consistente [e coerente] com o estilo do usuário." Numa perspectiva similar, Mann et al (1991, p.142) mencionam pesquisas empíricas que avaliam que pessoas com diferentes estilos cognitivos têm preferências diferentes em relação quantidade de dados, nível de consolidação, tipo de informação (quantitativa ou qualitativa) e forma de apresentação, tópicos que fazem 
parte das diferentes funcionalidades dos sistemas de informação, principalmente no caso do Business Intelligence.

Tampouco é inteiramente novo o relacionamento entre estilos cognitivos e diferentes aspectos do mundo organizacional como comprova a literatura de referência. Apenas dentre aqueles autores avaliados mais a fundo nesta dissertação, Kolb (1984, p.81) procura relacionar os tipos psicológicos com os particulares estilos de aprendizagem vivencial (experiental learning), encontrando relações conclusivas e interessantes; Felder et al (2002, p.2), por outro lado, procuram explicar o sucesso dos alunos com determinados métodos de ensino (num curso de engenharia) com base nas diferenças de tipos psicológicos dos avaliados. No Brasil, Jacobsohn (2003, p.178) associa os tipos e a utilização do e-learning e afirma que "ao levar em consideração o estilo de aprendizagem [no caso, os tipos psicológicos] dos alunos, a pesquisa tende a confirmar que não são todas as pessoas que se adaptam ao e-learning, resultando em contribuições diferenciadas dependendo das preferências do aluno"; também no âmbito nacional, Lenzi (2008, p.106) relaciona tipos psicológicos e empreendedorismo, concluindo que para pelo menos cinco dos dezesseis tipos esta característica é comprovadamente mais marcante e intensa.

\subsubsection{Questão-Problema e Objetivos de Pesquisa}

Com base no contexto descrito, a primeira e mais fundamental intenção desta obra é dar continuidade às observações de Eckerson (2009, p.4), aprofundando o entendimento dos usuários das ferramentas analíticas e de seu relacionamento com as ferramentas de BI disponíveis. Assim, espera-se expandir os conhecimentos atuais no tópico, colaborando dentro das limitações para o êxito destas soluções, com resultados mais positivos e menos frustrantes tanto para usuários e organizações.

A fim de orientar o restante da obra e tendo em vista os objetivos de pesquisa descritos a seguir, a questão-problema proposta desta dissertação é:

\section{Existe uma relação entre os estilos cognitivos dos usuários analíticos e sua escolha por determinadas funcionalidades disponíveis em aplicações de Business Intelligence?}


Neste sentido, são objetivos deste esforço de pesquisa:

A. Analisar como as organizações caracterizam os usuários de soluções analíticas (como o Business Intelligence), isto é, como entendem, diferenciam e tratam os diferentes públicos alvo, considerando seus papéis, suas demandas e suas formas de consumir informações;

B. Entender como ocorre a associação entre estes grupos de usuários e as diversas ferramentas disponíveis, como as organizações lidam com este relacionamento e como o consideram em suas estratégias e ações de BI a fim de obter melhores resultados;

C. Verificar, dentro das limitações metodológicas, se existe a relação proposta entre os estilos cognitivos dos usuários analíticos e sua escolha por determinadas funcionalidades disponíveis em aplicações de Business Intelligence;

D. Avaliar se na opinião das organizações, o estilo cognitivo do usuário é de fato uma variável relevante para o entendimento dos usuários e para a definição de ferramentas adequadas, dentro das práticas e soluções de BI;

E. Examinar dentro das organizações como os temas relacionados a usuários são abordados e identificar a importância que elas outorgam às diversas preocupações relacionadas na literatura de referência;

Para o entendimento destes objetivos, é importante destacar as seguintes definições operacionais cujo detalhamento é realizado ao longo do marco teórico:

- Business Intelligence (BI): é o “(...) conjunto de metodologias e tecnologias para coleta, armazenamento, análise e acesso a dados para auxiliar usuários a tomar melhores decisões de negócio" (KEYES, 2006, p.155). É a janela de funcionalidades com ampla interação humana pela qual se pode ver a dinâmica da organização para acompanhar o desempenho, aprimorar a eficiência e descobrir oportunidades desconhecidas (HOWSON, 2008, p.1-2).

- Funcionalidades de BI: são as ferramentas de apresentação e análise de dados baseadas no referencial bibliográfico estudado, que correspondem genericamente à camada de interação do sistema com os usuários finais responsáveis pela interpretação analítica das 
informações dentro das organizações; são o ponto de contato das aplicações de BI, que apóiam o processo de transformação de dados em informação e conhecimento através da combinação de tecnologia e análise, fornecendo apoio para a tomada de decisão.

- Usuários analíticos (usuários de soluções analíticas ou usuários de BI): são todos aqueles indivíduos, produtores ou consumidores de informação, independente no nível hierárquico, da necessidade e do conhecimento, que utilizam ferramentas de inteligência como o BI para realizarem suas atividades do dia-a-dia, como, por exemplo, para acompanhamento do desempenho ou tomada de decisão.

- Estilos cognitivos: são as combinações das diferenças individuais de personalidade, habilidades e experiência que, conseqüentemente, resultam em diferentes modos de processar e interpretar informações, de resolver problemas e de tomar decisões; nesta obra, estilos cognitivos são utilizados como sinônimos de personalidade e tipos psicológicos abordados por Jung e Myers e Briggs, medidos por ferramentas como o MBTI e o DTP.

\subsection{Abordagem de Pesquisa}

Considerando a questão-problema, assim como os objetivos propostos, a abordagem escolhida para a pesquisa empírica é a qualitativa do tipo Estudo de Caso, isto é, pesquisa que “(...) investiga um fenômeno contemporâneo dentro de um contexto real de vida, especialmente quando os limites entre o fenômeno e o contexto não estão claramente definidos" (YIN, 2001, p.32).

Segundo Martins e Theóphilo (2009, p.62), o método de Estudo de Caso “(...) é caracterizado pela descrição, compreensão e interpretação de fatos e fenômenos (...) cujo objetivo é o estudo de uma unidade social que se analisa profunda e intensamente." Ao contrário do que se possa pensar, a pesquisa qualitativa não é o oposto da quantitativa, mas um método com forma e enfoque específicos que visam a contribuição acadêmica através de métodos racionais e indutivos com o objetivo de entender, analisar, interpretar e explicar os fenômenos de nosso dia-a-dia, uma forma de investigar que “(...) preserva as características holísticas e significativas dos eventos da vida real" (YIN, 2001, p.21). Genericamente, trata da observação não participativa e análise limitada, mas intensiva de uma ou múltiplas unidades 
sociais, procurando compreender o mecanismo de funcionamento e os motivos e as causas dos fenômenos observados (GODOY, 1995, p.25).

Com base nas demais particularidades desta pesquisa é possível ainda afirmar que este Estudo de Caso é do tipo explanatório, pois avalia situações nas quais a unidade de análise não apresenta um conjunto simples e claro de resultados; instrumental, pois a motivação está na crença de que este caso pode colaborar para o entendimento de uma idéia mais ampla; simples, pois tem apenas um sujeito sob análise que representa uma oportunidade única de estudo; típico, pois parece ser convencional e usual frente ao referencial adotado; e incorporado, pois são observadas diferenças entre os componentes de uma mesma unidade de análise, mas com a finalidade de obter maiores informações a respeito do todo.

A utilização do Estudo de Caso para esta pesquisa é fundamentada nas condições indicadas por Yin (2001, p.24), isto é, (a) o tipo de questão de pesquisa e os objetivos, (b) o controle do pesquisador sobre os eventos comportamentais efetivos e (c) o foco em fenômenos históricos (ou contemporâneos). De forma resumida, é o método “(...) mais adequado quando se procura responder questões do tipo 'como' e 'por que', quando o fenômeno estudado é contemporâneo (isto é, ainda está ocorrendo) e quando há pouca ou nenhuma possibilidade de controlar os fatores envolvidos" (SOUZA, 2000, p. 65-66).

De acordo com Godoy (1995, p.26), ainda que essencialmente qualitativos, os Estudos de Caso também podem comportar abordagens tipicamente quantitativas para esclarecer alguma questão ou tópico da investigação, mesmo que a análise estatística seja pouco sofisticada e robusta. Nesta pesquisa também é realizado um levantamento de proporções reduzidas com algumas limitações metodológicas abordadas posteriormente, cujo objetivo é explorar e avaliar a existência do relacionamento entre duas variáveis, isto é, o estilo cognitivo e a preferência por determinada funcionalidade de BI.

\subsection{Justificativas}

O Business Intelligence é um tema importante que tem recebido mais atenção recentemente, principalmente com o aumento dos investimentos dos últimos anos, reflexo direto do 
crescimento da importância estratégica de ferramentas analíticas no mundo dos negócios (ELBASHIR et al, 2008, p.136).

Contudo, apesar das inúmeras vantagens atribuídas às soluções de BI (defendidas principalmente por fornecedores desta tecnologia), aparentemente poucas organizações parecem ter usufruído plenamente delas (WILLIAMS e WILLAMS, 2007, p.1), o que tem gerado certo desconforto, descrédito e decepção. Em parte por esta insatisfação, segundo o Gartner Group (2011, p.1) nos últimos anos tem se observado que os “(...) usuários de negócio tem maior influência na compra de aplicações de BI, escolhendo muitas vezes novos fornecedores como uma alternativa aos tradicionais (...)". Ainda de acordo com Gartner Group (2011, p.3), o ano de 2010, por exemplo, “(...) foi marcado por um intenso choque entre as necessidades dos usuários por facilidade de uso e flexibilidade de um lado e as necessidades de TI por padrões e controles de outro."

Alguns motivos que explicam esta situação podem ser discutidos: as tecnologias sobre as quais uma ampla maioria das soluções se fundamenta, por exemplo, ainda são relativamente recentes e se encontram em desenvolvimento, num estágio de amadurecimento (principalmente no Brasil); o BI não é um simples sistema de informação, mas, pelo contrário, consiste de um conjunto de diferentes soluções de complexidade variada e que requer uma forte interação com usuários; também vivemos num mundo competitivo e extremamente dinâmico, onde os processos e as pessoas que decidem e participam do BI dentro das organizações mudam e se transformam numa velocidade muitas vezes difícil de acompanhar; finalmente, muitas organizações ainda são amadoras e bastante imaturas quando se trata de capacidades analíticas e, além disso, ainda dão pouca importância para questões da gestão de mudança e gestão de dados, prejudicando a adoção destas soluções. A outra explicação oferecida pela literatura de apoio para este cenário negativo é a abordada por Eckerson (2009, p.4) e Nemati et al (2010, p.16) em seus trabalhos, isto é, de que o sucesso das aplicações de BI dentro das organizações depende de aprimorar o entendimento dos usuários que utilizam estas ferramentas e de fornecer a melhor solução para cada grupo de usuários.

Tendo como base o cenário supramencionado, a principal razão que motivou a elaboração desta pesquisa foi apresentar uma abordagem diferente para o tópico, abordagem esta que desenvolva o corpo de conhecimento atual, que fomente a discussão e a crítica sob o ponto- 
de-vista científico e que, eventualmente, possa colaborar com o sucesso das soluções de BI nas organizações.

Além disso, este estudo atende aos predicados mais essenciais de um problema de pesquisa, o que por si valida o esforço de pesquisa. Em primeiro lugar, é relevante, pois se concentra em explorar e aprofundar um assunto atual e significante para a área de estudo dos Sistemas de Informação e de Administração de Empresas. Em segundo lugar, é original, pois mesmo sendo em parte uma replicação das pesquisas realizadas por outros autores e de se basear em conceitos (como estilos cognitivos) que também já foram abordados, a combinação destes dois elementos dentro de um mesmo problema de pesquisa é uma idéia nova, uma forma diferente de encarar um tema conhecido. Finalmente, é viável, pois tem referências estabelecidas e modelos testados que permitem encontrar evidências empíricas mínimas para observação, coleta, testes, análises e conclusões, mesmo que negativas.

\subsection{Apresentação}

Esta dissertação está dividida em mais quatro partes textuais, além da introdução ao tema de pesquisa realizada até este ponto.

Na segunda parte, Marco Teórico, são apresentadas as principais referências bibliográficas que servem de apoio e de motivação para o esforço de pesquisa em questão. Seu objetivo primordial é trazer uma fundamentação teórica que permita a sólida construção da pesquisa empírica, além de esclarecer questões essenciais abordadas ao longo desta dissertação.

A primeira seção da literatura revisada tratada da perspectiva tecnológica do Business Intelligence: são abordados os conceitos relativos à solução e são esclarecidas suas principais características, componentes e funcionalidades, assim como sua caracterização como um Sistema de Informação cujos objetivos primordiais são acompanhar o desempenho da organização e apoiar a tomada de decisão. A principal finalidade desta parte é elucidar o BI, fornecendo as variáveis para a pesquisa empírica, entretanto, sem aprofundar-se em discussões demasiado técnicas. 
A segunda seção do marco teórico aborda a perspectiva humana do BI: são avaliadas as principais preocupações, são detalhadas as diferentes classificações de usuários e também é contemplada a variável estilo cognitivo, principalmente suas definições e diferentes formas de abordá-la, com especial ênfase para os tipos psicológicos de Jung.

Na terceira parte, Método de Pesquisa, é abordado o referencial bibliográfico em relação à abordagem de pesquisa prática o escolhida para este trabalho. O objetivo desta parte é o esclarecer os motivos que contribuem para explicar a opção por esta estratégia, além de elucidar questões relacionadas ao método. Na quarta parte, Condução da Pesquisa, são detalhadas as características da pesquisa empírica propriamente dita, definindo técnicas de coleta, instrumentos, público-alvo e procedimentos de coleta.

$\mathrm{Na}$ quinta parte, Estudo de Caso, são apresentadas as evidências e informações levantadas durante a pesquisa, são relatadas as opiniões dos respondentes e as interpretações, buscando transformar as observações gerais em conclusões, evidências ou considerações em relação ao tema de pesquisa. Também é realizado um levantamento exploratório a fim de atingir um dos objetivos desta obra.

$\mathrm{Na}$ sexta e última parte deste manuscrito, Considerações Finais, são apresentados os principais produtos da dissertação, os resultados mais expressivos, além das respostas aos objetivos inicialmente propostos. Além disso, destacam-se algumas limitações da pesquisa, assim como suas implicações, contribuições e recomendações para futuros estudos.

Ao final da obra também são apresentadas as referências bibliográficas utilizadas na pesquisa, assim como os anexos pertinentes utilizados para a realização deste o trabalho, úteis para o entendimento da condução da pesquisa. 


\section{MARCO TEÓRICO}

\subsection{Perspectiva Tecnológica}

O objetivo desta perspectiva é esclarecer o tema Business Intelligence (BI) como ferramenta tecnológica analítica das organizações modernas, destacando as variáveis que posteriormente serão utilizadas na pesquisa empírica.

Inicialmente são apresentados alguns conceitos básicos com a finalidade de construir uma conexão lógica, histórica e evolutiva com o assunto, uma vez que as soluções de BI oferecerem reconhecidamente uma série de ferramentas que se encaixam nas diferentes classificações de Sistemas de Informação conhecidas.

Em seguida são abordadas as definições e características do Business Intelligence, assim como seus componentes básicos e funcionalidades de apresentação e análise. Neste tópico o foco está justamente no segundo conjunto; de qualquer forma, as ferramentas são avaliadas sob o ponto-de-vista técnico de modo objetivo, uma vez que se trata de um tema longo, denso e complexo.

Finalmente, ao longo desta perspectiva são debatidos temas relevantes, como, por exemplo, a evolução do BI como um Sistema de Informação múltiplo, a distinção entre o Business Intelligence e a Inteligência Competitiva, a análise da relação complexidade/valor agregado das funcionalidades e o papel do BI na competição analítica de Davenport.

\subsubsection{Conceitos Básicos}

Em primeiro lugar é importante conceituar ainda que brevemente o tema da Tecnologia da Informação, assim como o de Sistemas de Informação e procurar distingui-los, uma vez que, apesar de profundamente relacionados e utilizados em alguns casos como sinônimos, são termos que tratam de questões essencialmente diferentes. 
Dentro do campo da Administração de Empresas, a Tecnologia da Informação (TI) ou Information Technology (IT), trata de um universo mais amplo do conhecimento e considera todos os artefatos baseados em tecnologia, principalmente computacional, desenvolvidos para apoiar e viabilizar a execução das atividades de uma organização e, conseqüentemente, o cumprimento de seus objetivos estratégicos (LAUDON e LAUDON, 2012, p.15). Dentre estes artefatos temos os componentes básicos de infra-estrutura como hardware (objetos físicos), software (aplicações lógicas) e tecnologias diversas de comunicação, assim como os próprios Sistemas de Informação que fazem uso desta base instalada.

Dessa forma, a TI trata do conjunto de recursos de informação de uma organização, incluindo a própria informação, as diferentes ferramentas com que é abordada e todos aqueles que participam de alguma forma de sua criação e/ou utilização, além de também cuidar da gestão destes recursos, em sua definição, construção, aplicação, uso e adoção dentro da organização.

Parte fundamental da Tecnologia da Informação, os Sistemas de Informação (SI) ou Information Systems (IS) são, por outro lado, aplicações tecnológicas baseadas em um conjunto de componentes inter-relacionados que genericamente coletam, processam, armazenam, apresentam, analisam e distribuem dados e informações com alguma finalidade organizacional específica dentro do rol de atividades e decisões do processo administrativo, isto é, planejamento (definição de objetivos e recursos), organização (disposição dos recursos de forma estruturada), execução (realização dos planos) e controle (verificação dos resultados) (LAUDON e LAUDON, 2012, p.15; TURBAN et al, 2005, p.41; MAXIMIANO, 2006, p.27).

Os SI estão baseados em quatro pilares básicos: informações (dados processados), indivíduos (usuários e programadores), procedimentos (processos de negócio) e tecnologia (hardware, software, banco de dados, rede, etc.) (TURBAN et al, 2005, p.41-42). De forma genérica, a informação é o material essencial de qualquer Sistema de Informação, seu insumo e também seu produto que visa atender as necessidades e demandas dos indivíduos que trabalham ou interagem com ele. Os procedimentos são as instruções que devem ser realizadas de modo que a informação seja transformada e processada adequadamente para gerar o produto desejado, enquanto a tecnologia refere-se às ferramentas variadas que viabilizam os procedimentos e o acesso dos indivíduos às informações. 


\subsubsection{Classificação de Sistemas de Informação}

Levando em consideração a variabilidade dos quatro componentes básicos de um Sistema de Informação descritos (informações, indivíduos, procedimentos e tecnologia) é possível afirmar que os SI podem se apresentar de diferentes formas e com características bastante específicas. Assim, podem se concentrar em tipos de informações particulares, tratar com diferentes públicos, executar atividades voltadas para finalidades exclusivas e/ou utilizar conjuntos de artefatos tecnológicos bastante distintos.

Neste sentido, é comum observar esforços de classificação e agrupamento de Sistemas de Informação. A tipologia mais difundida talvez seja aquela proposta por Laudon e Laudon (2005, p.84), ilustrada a seguir pela figura 1. Ela leva em conta não só os níveis organizacionais que cada tipo de Sistema de Informação apóia, mas, indiretamente, o grau de estruturação (ou programação) das atividades e decisões que são executadas ou tomadas em cada um destes níveis, conforme os conceitos abordados por Simon (1960 apud KEEN e SCOTT MORTON, 1978, p.85-86).

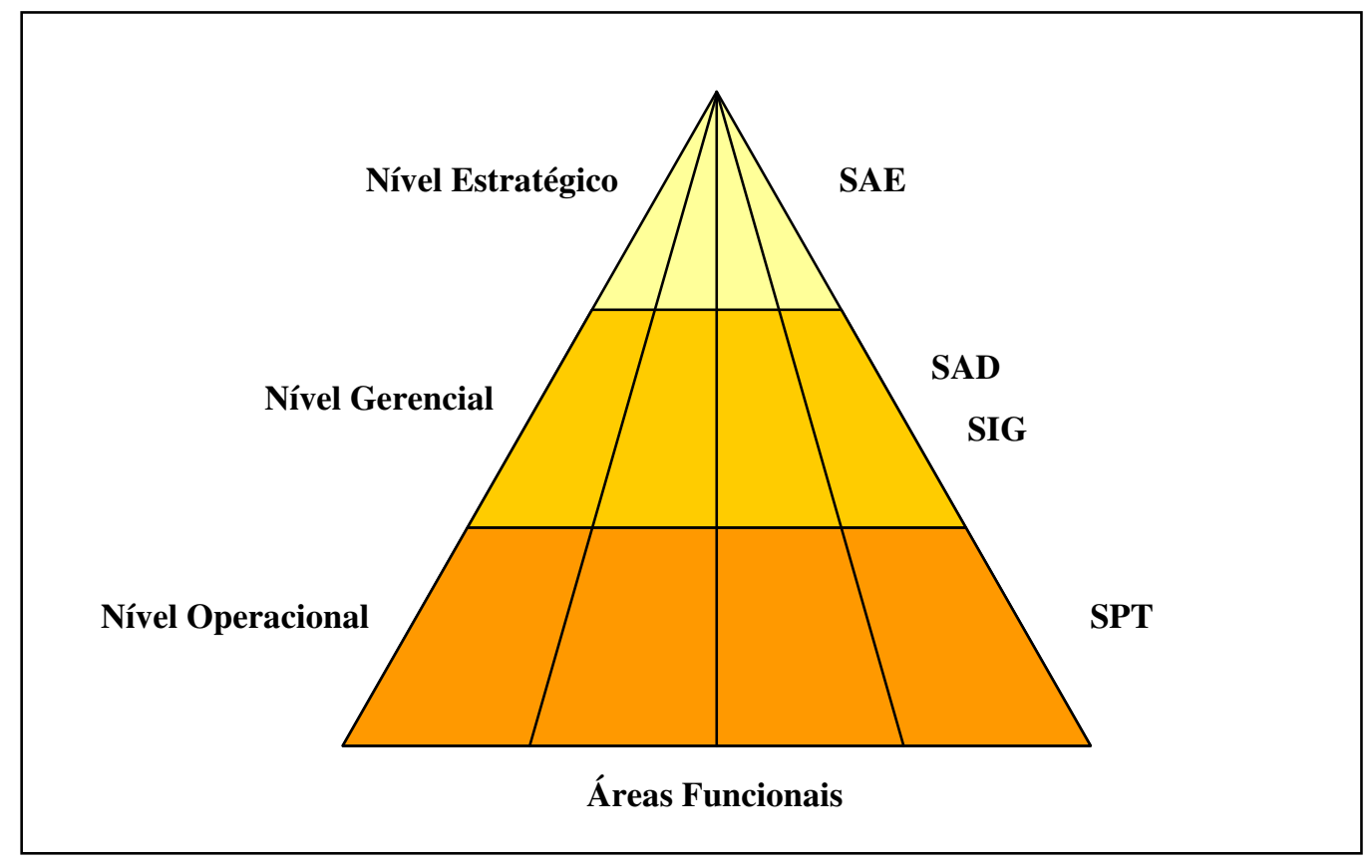

Figura 1. Os Quatro Principais Tipos de Sistemas de Informação

Fonte: Tradução e adaptação de Laudon e Laudon (2005, p.84) 
Concentrados no nível operacional estão os Sistemas de Processamento Transacional (SPT) ou Transactional Processing Systems (TPS), responsáveis por processar as operações cotidianas das diferentes áreas funcionais da organização como, por exemplo, transações de faturamento, recebimento de materiais, contas a pagar, dentre muitas outras. São sistemas com foco em alto desempenho e alta disponibilidade, concentrados em atividades rotineiras e repetitivas, trabalhando em tempo real no nível atômico do documento, com dados extremamente detalhados e sem redundância (INMON, 2002, p. 15). Tratam, portanto, de decisões bastante estruturadas, com variáveis conhecidas e que graças a sua complexidade limitada podem ser mais facilmente automatizadas.

O melhor e mais recente exemplo de SPT nas organizações é o Sistema de Gestão Integrada ou Enterprise Resource Planning (ERP). Segundo McGaughey e Gunasekaran (2007, p.24), os ERP são sistemas que integram processos de negócio com o objetivo de criar valor e reduzir custos, desenhados para promover a eficácia e a eficiência operacional através da integração entre áreas e processos, do estabelecimento de um fluxo de trabalho e dados explícito e da melhoria de processos de áreas administrativas e operacionais da organização.

Concentrados no nível gerencial estão os Sistemas de Informação Gerenciais (SIG) ou Management Information Systems (MIS) e os Sistemas de Apoio à Decisão (SAD) ou Decision Support Systems (DSS). Os SIG auxiliam os gerentes a monitorar e controlar de forma consolidada o desempenho e o andamento das atividades operacionais da organização (através dos dados fornecidos pelo SPT) frente aos referencias pré-estabelecidos (SOUZA, 2000, p.9). Os Sistemas de Informação Gerenciais são normalmente concentrados nas áreas funcionais e através do acompanhamento procuram garantir que as estratégias sejam cumpridas e de maneira eficiente (TURBAN et al, 2005, p.50). Os Sistemas de Apoio à Decisão, por outro lado, permitem simulações e análises mais complexas através de capacidades analíticas, inclusive com a aplicação de métodos quantitativos e a mineração de dados, dando apoio à tomada de decisões menos rotineiras e estruturadas.

Ao contrário dos Sistemas Transacionais, os sistemas do nível gerencial, principalmente os $\mathrm{SAD}$, estão concentrados nas análises das informações, normalmente consolidadas e de forma flexível, sem preocupações com alto desempenho e alta disponibilidade, onde, em alguns casos, não se tem um entendimento prévio do tema (INMON, 2002, p.15). Neste caso, os exemplos mais comuns são as ferramentas variadas que utilizam tecnologias de 
processamento analítico online (OLAP) como as aplicações de Business Intelligence e de Mineração de Dados (Data Mining).

Concentrados no nível estratégico estão os Sistemas de Apoio aos Executivos (SAE) ou Executive Support Systems (ESS). Seu objetivo básico é auxiliar nas decisões estratégicas da organização e, por este motivo, são bastante particulares e específicos, tratando com questões delicadas e até certo ponto sigilosas. As decisões neste caso também são menos estruturadas e podem ser únicas no sentido de não ter antecedentes ou não ter procedimentos pré-definidos (SOUZA, 2000, p.9-10). Em muitos casos se desconhecem as variáveis envolvidas, o ambiente onde a empresa está inserida tem um papel muito importante a ser considerado e o horizonte de tempo da decisão é mais extenso.

Neste nível as decisões dependem não só de avaliação e reflexão como nos outros casos, mas de julgamento e insights que permitam definir os objetivos da organização e a melhor forma para atingi-los (LAUDON e LAUDON, 2012, p.50). Por suas particularidades e dificuldades associadas, é possível afirmar que os SAE são sistemas menos difundidos que os demais e raramente são divulgados. Ferramentas de Inteligência Competitiva desenvolvidas pelas organizações normalmente estão concentradas neste nível hierárquico e podem ser consideradas exemplos práticos de Sistemas de Apoio aos Executivos. O quadro 1 da próxima página resume os pontos abordados em relação aos quatro sistemas de informação destacados.

Mesmo sendo amplamente utilizada e difundida, como é de se esperar numa generalização deste tipo, a classificação proposta por Laudon e Laudon tem uma série de limitações. Para alguns autores, por exemplo, ela ignora sistemas de informação que não atendem especificamente a nenhum dos três níveis ou, por outro lado, que atendem todos eles. Neste sentido, para Turban et al (2005, p.48-49) existiria um outro nível, o administrativo, relacionado com atividades de apoio diversas que são sustentadas por sistemas de correio eletrônico, fluxo de trabalho, dentre outros. Para Turban et al (2005, p.50-51) e Souza (2000, p.9) também existiria um quinto nível relacionado com o conhecimento, isto é, a administração das informações da organização e dos colaboradores, sejam elas documentos explícitos e formais ou conhecimentos tácitos. Estes duas limitações (sistemas de conhecimento e sistemas administrativos) foram em parte ajustadas nas últimas edições da obra de Laudon e Laudon. De qualquer forma, existem classificações alternativas que ao invés 
de considerar níveis hierárquicos, levam em consideração outras variáveis como áreas funcionais ou amplitude de suporte, como destacam Turban et al (2005, p.47).

\begin{tabular}{|c|c|c|c|c|}
\hline Sistema & Insumo & Processamento & Produto & Usuário \\
\hline SAE & $\begin{array}{l}\text { Dados } \\
\text { agregados; } \\
\text { externos ou } \\
\text { internos }\end{array}$ & $\begin{array}{l}\text { Gráficos; } \\
\text { simulações; } \\
\text { interatividade }\end{array}$ & $\begin{array}{l}\text { Projeções; } \\
\text { respostas a } \\
\text { questionamentos }\end{array}$ & Alta gestão \\
\hline SAD & $\begin{array}{l}\text { Pequenos } \\
\text { volumes de } \\
\text { dados ou } \\
\text { grandes bancos } \\
\text { de dados } \\
\text { otimizados para } \\
\text { análise de dados }\end{array}$ & $\begin{array}{l}\text { Interatividade; } \\
\text { simulações; } \\
\text { análises }\end{array}$ & $\begin{array}{l}\text { Relatórios } \\
\text { especiais; } \\
\text { análises de } \\
\text { decisão; } \\
\text { respostas a } \\
\text { questionamentos }\end{array}$ & $\begin{array}{l}\text { Profissionais; } \\
\text { gestores de } \\
\text { pessoas e } \\
\text { equipes }\end{array}$ \\
\hline SIG & $\begin{array}{l}\text { Dados } \\
\text { transacionais } \\
\text { sumarizados; } \\
\text { grande volume } \\
\text { de dados; } \\
\text { modelos simples }\end{array}$ & $\begin{array}{l}\text { Relatórios } \\
\text { rotineiros; } \\
\text { modelos } \\
\text { simples; análises } \\
\text { de baixa } \\
\text { complexidade }\end{array}$ & $\begin{array}{l}\text { Relatórios de } \\
\text { consolidação e } \\
\text { exceção }\end{array}$ & $\begin{array}{l}\text { Gestão } \\
\text { intermediária }\end{array}$ \\
\hline SPT & $\begin{array}{l}\text { Transações; } \\
\text { eventos }\end{array}$ & $\begin{array}{l}\text { Ordenação; } \\
\text { listagens; } \\
\text { combinações; } \\
\text { atualizações }\end{array}$ & $\begin{array}{l}\text { Relatórios } \\
\text { detalhados; } \\
\text { listagens; } \\
\text { sumários }\end{array}$ & $\begin{array}{l}\text { Equipe de } \\
\text { operações } \\
\text { (analistas); } \\
\text { supervisores }\end{array}$ \\
\hline
\end{tabular}

Quadro 1. Características dos Sistemas de Informação

Fonte: Tradução e adaptação de Laudon e Laudon (2005, p.87)

\section{Sistemas de Informação Gerenciais}

O surgimento dos Sistemas de Informação Gerenciais teve início na década de 1960 e foi um resultado direto das inovações e desenvolvimento dos grandes computadores (mainframes). Até aquele momento, as baixas capacidades de processamento e armazenamento de computadores impossibilitavam a construção de sistemas de grande porte, restringindo sua aplicação às tarefas extremamente operacionais das grandes organizações (POWER, 2003, p.2). Contudo, com os avanços tecnológicos, os SIG puderam ser concebidos e começaram a ser uma realidade, concentrando-se principalmente no auxílio e controle gerencial através de relatórios periódicos e estruturados, onde grande parte dos dados era oriunda dos SPT.

Segundo Venkatraman (1989, p.4), os Sistemas de Informação Gerenciais (SIG) ou Management Information Systems (MIS) são sistemas integrados baseados em computadores 
capazes de prover as informações necessárias para a gestão da operação, sistemas que permitem o gerenciamento, processamento e uso de informações como forma de aprimorar a coordenação e o desempenho da organização (SPRAGUE, 1980, p.4). Eles representam um método que “(...) apóia o planejamento, controle e as funções operacionais de uma empresa com informações (...)” (KENNEVAN, 1970 apud VENKATRAMAN, 1989, p.4).

Para Sprague (1980, p.4), as principais características do SIG são o foco sobre os dados, a orientação para a gerência intermediária, a integração com os STP, o fluxo de informações estruturado e a geração de relatórios e consultas com suporte de banco de dados. Sob o pontode-vista do trinômio impacto, retorno e relevância (para gestores), Keen e Scott Morton (1978, p.1-2) entendem que os SIG estão concentrados em tarefas totalmente estruturadas, portanto, na operação e no dia-a-dia da organização, onde procedimentos, regras e fluxos de informação podem ser pré-definidos com confiança; o principal retorno dos SIG é o aprimoramento da eficiência em busca da excelência operacional e sua relevância para os gestores está no acompanhamento e controle, auxiliando apenas indiretamente as diferentes decisões a serem tomadas (KEEN e SCOTT MORTON, 1978, p.2).

Em muitos casos, os Sistemas de Informação Gerenciais foram considerados grandes fracassos de TI nas organizações, uma vez que prometeram muito mais do que puderam cumprir de acordo com Venkatraman (1989, p.5). Já na década de 1960, este cenário de desconfiança e frustração resultou numa visão particularmente cética em relação aos benefícios do SIG. Este panorama talvez possa ser justificado pelo otimismo exagerado provocado pelas contínuas evoluções tecnológicas ou pelos objetivos ambiciosos e irreais que muitas organizações estabeleceram para os SIG, quando na verdade as tecnologias e metodologias de base ainda eram imaturas e pouco exploradas.

\section{Sistemas de Apoio à Decisão}

Para Power (2003, p.2), com base nos Sistemas de Informação Gerenciais e evoluindo sobre os estudos teóricos sobre tomada de decisão e de interação entre humanos e computadores, no início da década de 70 foram desenvolvidos os primeiros protótipos de sistemas de informação concentrados na utilização de computadores e modelos analíticos para o auxílio à tomada de decisões. A visão de Power é similar a de Keen e Scott Morton (1978, p.3) que 
conceituam os Sistemas de Apoio à Decisão como a evolução natural dos SIG, respondendo parte das críticas e pontos fracos destes sistemas, principalmente a falta de apoio para a resolução de problemas, a estrutura inflexível para atender às demandas de negócio e a falta de apoio interativo. Venkatraman (1989, p.5), por outro lado, tem uma visão mais crítica e considera o termo SAD apenas como uma forma de desviar a atenção das frustrações e insucessos dos SIG, uma vez que, segundo o autor, em suas essências ambos tratam dos mesmos aspectos.

De qualquer forma, os Sistemas de Apoio à Decisão (SAD) ou Decision Support Systems (DSS) consistem em “(...) modelos computacionais interativos ou assistentes de informação concebidos para auxiliar (ao invés de substituir) o julgamento gerencial em tarefas semiestruturadas" (KEEN, 1979, p.1), visão similar àquela proposta por Sprague (1980, p.1), que também inclui no escopo dos SAD as tarefas não-estruturadas.

Para Keen e Scott Morton (1978, p.1), os Sistemas de Apoio à Decisão representam o lado tecnológico da tomada de decisão e implicam no uso de computadores (linguagens, modelos, programas, sistemas, etc.) para três premissas básicas: (1) auxiliar gerentes no processo decisório de tarefas semi-estruturadas, (2) apoiar (ao invés de substituir) o julgamento gerencial e (3) melhorar a eficácia (em detrimento da eficiência) da tomada de decisão. Desta explicação, em que se destaca principalmente o lado tecnológico, outros tópicos importantes relacionados com SAD ficam subentendidos, como o próprio processo de tomada de decisão e as características dos tomadores de decisão (como inteligência, intuição e julgamento).

Em relação à primeira premissa, Keen e Scott Morton (1978, p.86) explicam que decisões semi-estruturadas são aquelas que tratam de problemas de maior porte e complexidade, que exigem maior precisão e/ou mais recursos de processamento para sua solução, como, por exemplo, comercialização de títulos, definição de orçamento de promoção para produtos, análise de aquisição de bens e capital. Em outras palavras, são problemas que não podem ser resolvidos de modo trivial apenas por pessoas e tampouco podem ser totalmente automatizados porque demandam análise e julgamento (muitas vezes subjetivos, sem motivos aparentemente racionais). Por estas características, são decisões que devem ser elaboradas de forma complementar por homem e máquina, onde o primeiro sempre controla o segundo. 
Ainda a respeito desta primeira premissa, Keen e Scott Morton (1978, p.85-87) oferecem o quadro 2 a seguir cujo objetivo é esclarecer e explicitar o foco dos Sistemas de Apoio à Decisão. Para isso, os autores se baseiam nas dimensões e taxonomias propostas por Anthony (1965 apud KEEN e SCOTT MORTON, 1978, p.81-82) sobre atividades e decisões nos diferentes níveis organizacionais (estratégico, gerencial e operacional) e por Simon (1960 apud KEEN e SCOTT MORTON, 1978, p.85-86) sobre tipos de decisão (estruturada, semiestruturada e não estruturada).

\begin{tabular}{|l|l|l|l|}
\hline $\begin{array}{l}\text { Nível Organizacional / } \\
\text { Tipo de Decisão }\end{array}$ & Operacional & Gerencial & Estratégico \\
\hline Estruturada & $\begin{array}{l}\text { Reordenação de } \\
\text { inventário }\end{array}$ & $\begin{array}{l}\text { Programação linear } \\
\text { de produção }\end{array}$ & $\begin{array}{l}\text { Definição de } \\
\text { localização de } \\
\text { planta/fábrica }\end{array}$ \\
\hline Semi-estruturada & $\begin{array}{l}\text { Comercialização de } \\
\text { títulos }\end{array}$ & $\begin{array}{l}\text { Definição de } \\
\text { orçamento para } \\
\text { produtos }\end{array}$ & $\begin{array}{l}\text { Análise de } \\
\text { aquisição de capital }\end{array}$ \\
\hline Não estruturada & $\begin{array}{l}\text { Escolha da capa de } \\
\text { uma revista }\end{array}$ & $\begin{array}{l}\text { Contratação de } \\
\text { gerentes }\end{array}$ & $\begin{array}{l}\text { Desenvolvimento } \\
\text { de portfólio de P\&D }\end{array}$ \\
\hline
\end{tabular}

\section{Quadro 2. Decisões Semi-Estruturadas: Escopo dos Sistemas de Apoio à Decisão}

Fonte: Adaptação de Keen e Scott Morton (1978, p.87)

Quanto à terceira premissa, isto é, o foco na eficácia ao invés da eficiência na tomada de decisão, os autores defendem que por tratar de questões semi-estruturadas, os Sistemas de Apoio à Decisão têm preocupações como aprendizagem, interação (inclusive com redundâncias e riscos), adaptação e evolução, ao invés de substituição, procedimento, automação e desempenho, escopo típico dos sistemas operacionais. Deste modo, os SAD não poderiam ser julgados pelos mesmos critérios de produtividade e, portanto, eficiência dos demais sistemas, mas por critérios de efetividade, relevância e utilidade (KEEN e SCOTT MORTON, 1978, p.12).

Ampliando o debate, Keen (1981, p.1) afirma que "análises tradicionais de custo/benefício não se aplicam adequadamente aos SAD" uma vez que "os benefícios que oferecem são raramente quantitativos (...)", o que os torna difíceis de apreciar e valorizar monetariamente. Além disso, devido à característica peculiar de contínua evolução destes sistemas, a atribuição 
de custos também não é uma tarefa trivial (KEEN, 1981, p.1-2). Mesmo mais recentemente essa linha de raciocínio ainda parece aceitável, como sugere Kumar (1999, p.295) ao afirmar que “(...) avaliar benefícios resultantes de investimentos em TI é importante (...), mas muitos Sistemas de Apoio à Decisão produzem benefícios relativamente intangíveis" que são ainda mais difíceis de quantificar e medir seus retornos.

Indo além das premissas destacadas, Venkatraman (1989, p.5) utiliza a abordagem de Sprague para avaliar as características particulares dos Sistemas de Apoio à Decisão, principalmente aquelas que os distinguem dos demais sistemas de informação. Assim, os SAD são sistemas orientados a problemas pouco especificados ou menos estruturados, que procuram combinar o uso de modelos e técnicas analíticas às funções básicas dos sistemas de informação, priorizam a facilidade de uso e interatividade - pois nem sempre seus usuários são especialistas em computação - e enfatizam a flexibilidade, escalabilidade e adaptabilidade aos ambientes dinâmicos em que são aplicados.

Em relação aos resultados esperados, diferentes estudos (IGBARIA et al, 1996, p.224) comprovam os êxitos na aplicação de Sistemas de Apoio à Decisão descritos por Keen (1981, p.6-8), isto é:

- Aumento no número de propostas alternativas que podem então ser examinadas;

- Melhor entendimento das relações entre as variáveis do negócio;

- Respostas mais rápidas para situações inesperadas;

- Capacidade de configurar análises instantâneas com independência;

- Geração de novas idéias, abordagens e conhecimentos;

- Melhor comunicação e poder de convencimento;

- Maior controle e monitoramento de tendências;

- Redução de custos e de tempo;

- Melhores decisões com possibilidades de análises mais detalhadas;

- Maior eficiência nos trabalhos;

- Melhor uso dos recursos de informação da organização;

Devido à expansão e aplicação de diferentes tipos de SAD nas organizações, Power (2007, p.5-9) oferece uma tipologia de acordo com o objetivo e escopo de atuação do sistema: 
1. SAD direcionados a Modelos: primeiras aplicações neste campo, tratam da manipulação de dados limitados e parâmetros através de modelos quantitativos de simulação e otimização;

2. SAD direcionados a Dados: Tratam do acesso e manipulação de dados internos e externos à organização, baseados em bancos de dados e ferramentas de consulta e relatórios com processamento analítico;

3. SAD direcionados a Comunicação: Tratam das tecnologias e uso de redes para viabilizar a colaboração e comunicação na tomada de decisão;

4. SAD direcionados a Documentos: Tratam do armazenamento e processamento de documentos, assim como sua análise;

5. SAD direcionados a Conhecimento: Tratam de sistemas interativos homem-máquina com expertise especializado em resolução de problemas visando a recomendação ou sugestão de ações para os gestores, fortemente baseados em Inteligência Artificial.

\section{Sistemas de Informação Gerenciais vs Sistemas de Apoio à Decisão}

O debate das diferenças e similaridades entre Sistemas de Informação Gerenciais e Sistemas de Apoio à Decisão é antigo, mas não por isso há consenso no tópico. Este cenário é uma conseqüência de uma série de conceituações distintas e de opiniões diferentes (com relação ao escopo, por exemplo) dos autores e pesquisadores que abordaram os temas ao longo dos anos.

De um lado temos autores como Venkatraman que entendem que o “(...) escopo dos SAD é muito mais restrito do que o dos SIG” e que os primeiros são um subconjunto dos segundos, isto é, “(...) Sistemas de Informação Gerenciais são um universo maior dentro do qual os Sistemas de Apoio à Decisão residem e operam" (VENKATRAMAN, 1989, p.6 e 9). A opinião do autor é baseada na análise comparativa de quatro critérios de análise: ambiente (onde são avaliadas características da tarefa e padrões de acesso ao sistema), funções, componentes e recursos (onde são avaliados aspectos tecnológicos, dados e pessoas). Além disso, em seu levantamento bibliográfico o autor destaca definições de SIG segundo Dickson, Davis e Kenneva que, invariavelmente, consideram o processo e a função da tomada de decisão como parte do escopo dos Sistemas de Informação Gerenciais (VENKATRAMAN, 1989, p.4), o que denota uma área de intersecção e de sobreposição. 
Por outro lado, temos a linha de pensamento dos autores de SAD que, apesar de concordarem com a proximidade entre os dois termos, entendem os Sistemas de Apoio à Decisão como uma evolução natural dos Sistemas de Informação Gerenciais e diferentes em sua essência. Apesar de algumas definições de SIG considerarem a tomada de decisão, Keen e Scott Morton (1978, p.3) justificam a distinção entre os termos afirmando que os desenvolvimentos de sistemas como o SIG tem em geral um foco no processamento de dados, melhorando apenas tímida e indiretamente a tomada de decisão, sem trazer resultados significantes neste processo.

Além disso, os autores supramencionados utilizam três aspectos - área de impacto, retorno e relevância para gestores - para esclarecer de forma sólida a distinção entre os termos. Ao contrário dos SIG, os SAD se concentram especificamente na área da tomada de decisões, tarefa onde o apoio do computador ainda é possível e razoável, mas o julgamento e discernimento dos gestores são fundamentais. Seu principal retorno está no aprimoramento da eficácia das respostas e, além do mais, sua relevância para os gestores é muito maior, pois servem de auxílio direto e basal para a tomada de decisão (KEEN e SCOTT MORTON, 1978, p.2). Sprague (1980, p.4) tem uma visão similar destacando que os Sistemas de Apoio à Decisão têm como características particulares o foco na decisão, a orientação para alta gerência e executivos (apesar de auxiliar outros recursos), a ênfase na flexibilidade e adaptabilidade e a capacidade de adequação ao usuário, inclusive ao seu estilo pessoal.

Outro autor que colabora com este ponto-de-vista é McLeod (1990 apud VENKATRAMAN, 1989, p.5). De acordo com ele há uma diferença fundamental entre os sistemas sob o pontode-vista do público-alvo e da forma como a informação é utilizada. Neste sentido e baseado nas idéias de McLeod, Venkatraman (1989, p.5-6) afirma que os SIG são “(...) sistemas organizacionais designados para auxiliar um grande grupo de gerentes (...)” e “(...) seus produtos têm natureza mais genérica (...)”, ao contrário dos SAD que “(...) apóiam gerentes individualmente ou em pequenos grupos (...)” e “(..) seus produtos são mais customizados para decisões específicas."

\section{Sistemas de Informação Executivos}


Segundo Power (2003, p.3), a partir do desenvolvimento e aplicações dos Sistemas de Apoio à Decisão começaram a surgir iniciativas de sistemas que pudessem auxiliar a tomada de decisão do público executivo. De acordo com o autor, os Sistemas de Apoio ao Executivo (SAE) ou Executive Support Systems (ESS) foram inicialmente sugeridos por Rockart no final da década de 1970 e representam um subconjunto particular dos SAD concentrados em apoiar o nível estratégico da organização, opinião análoga a de Venkatraman $(1989$, p.6).

Apesar da possibilidade de um debate similar ao descrito acima entre SIG e SAD, alguns autores, como Turban e Schaeffer (1991, p.345), Power (2007, p.3) e, inclusive Venkatraman (1989, p.6), entendem que o termo SAE tem um sinônimo conceitual, os Sistemas de Informação Executivos (SIE) ou Executive Information Systems (EIS). De fato, a definição é praticamente a mesma: são sistemas cujo objetivo é atender as necessidades de informação do público executivo (eliminando em muitos casos os intermediários), de modo a auxiliar no acompanhamento, controle e tomada de decisão, fornecendo dados críticos consolidados e prontos para o uso, através de uma interface com recursos gráficos, mas ágil e fácil de usar (TURBAN e SCHAEFFER, 1991, p.347).

Para McLeod e Jones (1990, p.156), independente da forma do SIE, um de seus principais papéis é agregar coerentemente o conteúdo dos dados de modo a fornecer informação que permita observar um panorama geral da organização e não pedaços separados e individuais que afetem a interpretação dos executivos, gerando decisões incompletas e equivocadas ou, em último caso, que levem a inação. Para os autores, os Sistemas de Informação Executivos colaboram para o entendimento da organização e permitem que seu desempenho possa ser monitorado. Matthews e Shoebridge (1992, p.101) concordam com esta abordagem, afirmando que os SIE “(...) são tanto pacotes de software que auxiliam os executivos a lidar eficientemente com os grandes volumes de dados quanto sistemas de informação que se concentram no uso interativo das informações para monitorar e controlar as operações."

Warmouth e Yen (1992, p.192) oferecem ainda uma definição complementar importante. Para os autores o EIS é um sistema informação no sentido convencional, portanto, que coleta, armazena, processa e apresenta dados, mas que deve combinar atributos como imaginação e julgamento do usuário. Além dos dados internos, os Sistemas de Informação Executivos devem tratar dos fatores externos à organização, incorporando dados do ambiente associados a competidores, consumidores, fornecedores, governos, tendências econômicas e assim por 
diante (WARMOUTH e YEN, 1992, p.193), possibilitando a chamada análise competitiva (INMON, 2002, p.248).

\section{Cenário atual}

No final da década de 1980, McLeod e Jones (1990, p.158) afirmaram que havia toda a razão para acreditar que no futuro SIG e SAD seriam cada vez mais parecidos com os SIE. Para os autores, após a adoção dos Sistemas de Informação Executivos pelo público estratégico, a camada gerencial da organização também passaria a utilizar os sistemas, usufruindo de seus benefícios, exigindo, porém, a expansão de funcionalidades para atender suas necessidades específica. Na prática isso representaria a ruptura da principal diferenciação entre estes sistemas.

Se não acertaram na forma ou nos motivos, talvez seja possível afirmar que McLeod e Jones previram o resultado final corretamente. De fato, aplicar tipologias e classificações dos sistemas resulta difícil nos tempos atuais, pois cada vez mais os Sistemas de Informação analíticos têm se transformado em poderosas ferramentas que englobam funcionalidades e características diversas de todos os tipos de sistemas e que atingem diversos públicos em diferentes níveis hierárquicos. Em outras palavras, observa-se hoje nas organizações sistemas que combinam e complementam as definições, objetivos e particularidades acima descritas, auxiliando tanto no controle e monitoração quanto na tomada de decisão, impossibilitando uma clara distinção ou classificação entre Sistemas de Informação Gerenciais, Sistemas de Apoio à Decisão e Sistemas de Informação (ou Apoio) aos Executivos.

Vários motivos podem corroborar esta afirmação, mas o mais forte talvez seja a pressão que os grandes fornecedores do mercado de TI têm aplicado através de fusões e aquisições recentes e a conseqüente busca por soluções analíticas integradas e completas que ofereçam numa mesma plataforma as diferentes funcionalidades associadas ao SIG, SAD e SIE. Segundo Yong (2009, p.21), "a diversidade de produtos e de nomes de produtos é certamente uma estratégia de marketing (...)”, mas, “(...) com o tempo, a aceitação no mercado acabará por unir todo o conjunto de softwares numa só categoria, que é prover informações de gestão para executivos, gerentes e profissionais especializados em análise de informações." 
Para outros autores, foram os SAD que expandiram sua linha de atuação e aos poucos começaram a agrupar os vários tópicos tecnológicos que, no início do século XXI, convergem para oferecer apoio integrado aos gerentes, seja individual ou coletivamente, de modo a auxiliá-los a administrar adequadamente as organizações e a aprimorar seu desempenho através de melhores decisões (POWER, 2003, p.1).

Neste sentido a década de 1990 foi transcendental na evolução dos Sistemas de Apoio à Decisão, representando uma guinada tecnológica. O desenvolvimento das redes internas de corporações promoveu uma melhora sensível na troca de informações e na gestão do conhecimento e os avanços tecnológicos viabilizaram os conceitos de armazenamento de dados, a modelagem multidimensional e o Processamento Analítico Online ou Online Analytical Processing (OLAP), abrindo espaço para os SAD direcionados a dados (POWER, 2003, p.5). Aos poucos, a pesquisa, a prática e o desenvolvimento de Sistemas de Apoio à Decisão continuam a explorar novas tecnologias e, usufruindo dos volumosos bancos de dados, começam a viabilizar a aplicação dos conceitos da inteligência artificial e dos sistemas especialistas (POWER, 2007, p.10).

\subsubsection{Business Intelligence}

A aplicação dos conceitos de modelagem dimensional, armazenamento de dados e processamento analítico online (em contraposição ao processamento transacional) revolucionaram os SIG, SAD e SAE e implicaram no desenvolvimento de sistemas "produto" que puderam ser comercializados. Estes pacotes, passíveis de customização e adequação às necessidades da organização, receberam o nome genérico de Business Intelligence (BI), um termo bastante “(...) popularizado e agregador (...) que descreve um conjunto de conceitos e métodos para aprimorar a tomada de decisão através do uso de sistemas de apoio baseados em fatos" (POWER, 2003, p.5), tema que será explorado a seguir.

\section{Definição}

O termo Business Intelligence (BI) (traduzido como Inteligência de Negócios ou Inteligência Empresarial), remonta ao final da década de 1950 quando Hans Peter Luhn (1958, p.314) 
sugeriu um sistema baseado em dispositivos eletrônicos para apoio e comunicação na condução dos negócios de uma organização, capaz de capturar relações entre fatos que permitissem orientar ações em direção a determinados objetivos. Em outras palavras, para o cientista da computação alemão a finalidade deste sistema era a de “(...) oferecer informações adequadas para apoiar atividades específicas executadas por indivíduos, grupos, departamentos, divisões ou organizações”, preocupando-se com a aquisição, armazenamento, recuperação e transmissão das informações (LUHN, 1958, p.314-315).

Tendo em vista a maturidade das diversas tecnologias disponíveis na época em que foi redigido o artigo, ao mesmo tempo em que as idéias de Luhn podem ser consideradas precoces e bastante genéricas, elas também são visionárias e inovadoras. Até certo ponto, elas são avaliadas como as pedras fundamentais dos conceitos que hoje definem o Business Intelligence atual, ainda que a orientação do autor fosse mais concentrada a documentos e conhecimento, assuntos atualmente abordados por temas tão atuais como o Knowledge Management ou o Content Management.

Talvez por sua antecipação, o termo BI permaneceu ignorado por algum tempo. Somente depois de 40 anos o conceito foi recuperado, reciclado e popularizado por Howard Dresner (POWER, 2007, p.4). Apenas no início dos anos 1990, o BI pôde ser finalmente viabilizado graças à rápida evolução da TI, caracterizada pelo aprimoramento da capacidade de armazenamento e da velocidade de processamento, pelo desenvolvimento de linguagens de programação, pelos bancos de dados e interfaces homem-máquina, pelo amadurecimento das fontes de dados e pela crescente aplicação de métodos quantitativos no mundo das organizações.

Mas o Business Intelligence da virada do milênio acabou tornando-se um termo agregador que “(...) descreve um conjunto de conceitos e métodos para aprimorar a tomada de decisão através do uso de sistemas de apoio baseados em fatos" (POWER, 2007, p.4), visão bastante similar a de Watson (2009, p.491) e também de Keyes (2006, p.155), que propõe o BI como “(...) um conjunto de metodologias e tecnologias para coleta, armazenamento, análise e acesso a dados para auxiliar usuários a tomar melhores decisões de negócio.” Em outras palavras, é um conceito genérico empregado para descrever a utilização de dados e informações internas à organização (principalmente) através de soluções baseadas em tecnologias computacionais com a finalidade de apoiar e, dentro de suas limitações, aprimorar a tomada de decisão. 
Para Rud (2009, p.3), entretanto, as idéias por trás do Business Intelligence são mais ambiciosas. Para a autora, o BI “(...) abrange todas e quaisquer capacidades e habilidades necessárias pra transformar dados em inteligência", competências que permitam às organizações fornecerem as informações corretas no formato correto às pessoas corretas, dentro do tempo correto e através do canal correto de modo a estimular melhores decisões (RUD, 2009, p.3; KAHN et al, 2009, p.2). O BI representa então um sistema que apóia o processo de transformação de dados variados do negócio em informação e conhecimento através de capacidades analíticas dos usuários e desenvolvedores (isto é, inteligência em conjunto com experiência), permitindo assim dar sentido ao grande volume de dados coletados e armazenados pela organização (ROZE, 2002, p.4). A escolha das palavras business (negócio) e intelligence (inteligência), portanto, não é fortuita e tem sentido lógico, apesar de muitos fornecedores de tecnologia aproveitarem-se delas, alimentando em alguns casos expectativas ilusórias.

Cabe então uma importante observação: seja pelo fato de fundamentar-se sobre um sistema de informação, por ter se beneficiado das evoluções e desenvolvimentos das várias tecnologias supramencionadas ou pelo enfoque técnico dos fornecedores deste mercado, o BI ainda hoje é um termo confuso, pouco intuitivo, que em muitos casos é erroneamente interpretado sendo associado a um assunto puramente tecnológico. Devido à profusão e particularidades das ferramentas e técnicas que o compõem, não raro a própria definição do BI é confundida com seus componentes e funcionalidades, dificultando ainda mais o entendimento do tema (KEYES, 2006, p.155). Para Davenport (2006, p.3), por exemplo, Business Intelligence é o termo que o "pessoal" de TI utiliza para descrever os processos, aplicações e infra-estrutura dedicadas a relatórios e análises. Outros autores são mais restritivos: de acordo com Arnott (2008, p.55), o BI se restringe a camada de análise e apresentação de dados.

Contudo, o BI é uma solução mais ampla e bastante particular que está essencialmente baseada na interação com indivíduos e sobre as capacidades cognitivas humanas. Assim, independentemente da tecnologia utilizada, o Business Intelligence “(...) permite que usuários construam aplicações que auxiliem organizações a aprender e entender seus negócios" (GARTNER GROUP, 2011, p.10). Como explicam Williams e Williams (2007, p.2), o BI não se trata apenas de produtos, tecnologias ou metodologias isoladas, mas da combinação destes elementos com o objetivo de melhor organizar informações chave que as pessoas necessitam 
para melhorar o desempenho de suas organizações. Ou, mais além, "o BI não é nem um produto nem um sistema; é uma estratégia, visão e arquitetura em constante evolução que continuamente busca o alinhamento entre a operação e o direcionamento da organização com seus objetivos estratégicos de negócio" (ATRE, 2003, p.2).

\section{BI como SIG, SAD e EIS}

Não há dúvidas de que o BI é um exemplo clássico de sistema de informação na medida em que se trata de uma aplicação (computacional) de coleta, armazenamento, processamento, análise e distribuição de dados, empregada em atividades variadas das organizações. Por sistema de informação entende-se então que o BI envolve não só tecnologia (como a miopia mercadológica tende em insistir), mas indivíduos, informação e procedimentos, além da essencial interação harmoniosa e balanceada entre estes quatro elementos.

Mas, apesar de ser um termo recente que tem ganhado visibilidade e relevância no mundo dos negócios (BAARS e KEMPER, 2008, p.132), pode-se dizer que o BI capturou expectativas antigas e reciclou conceitos que já existiam dentro da literatura da área de sistemas de informação. Assim como defendem Venkatraman (1989, p.5) e Yong (2009, p.21), o BI parece ser de fato apenas um novo nome com uma nova estratégia de marketing que procura evitar associações negativas com outras soluções do passado. No fundo, os objetivos, características, ferramentas, público-alvo e demais particularidades do Business Intelligence são extremamente similares as de SIG, SAD e SIE abordados anteriormente. Como sugere Negash (2004, p.177) de forma mais enfática e conclusiva, "o termo BI substituiu os [conceitos] Sistemas de Suporte à Decisão, Sistemas de Informação Executivos e Sistemas de Informação Gerencial."

Em primeiro lugar, o BI é um típico exemplo de Sistema de Apoio à Decisão, como sugere Scheps (2008, p.11), porque ele é uma “(...) atividade, ferramenta ou processo usado para obter a melhor informação para apoiar o processo de tomada de decisão" da organização. Baars e Kemper (2008, p.132) também corroboram esta afirmação, indicando que dentre várias outras capacidades, o BI incluí funcionalidades necessárias para suportar decisões. Muitos outros autores, de uma forma ou de outra abordam o Business Intelligence como um sistema de suporte à decisão, como são os casos de Cody et al (2002, p.698), Steiger (2010, 
p.29-30), Negash (2004, p.177), Kimball e Ross (2002, p.398) e Williams e Williams (2007, p.5).

Além disso, quando avaliado sob a ótica dos tipos de decisão de Simon (1960 apud KEEN e SCOTT MORTON, 1978, p.85-86), o BI novamente se ajusta no mesmo universo dos SAD proposto por Keen e Scott Morton (1978, p.97) uma vez que auxilia tomadores de decisão nas questões semi-estruturadas (e, em alguns casos extremos, até nas não-estruturadas), decisões menos rotineiras ou repetitivas, sem um processo definido para execução. Esta opinião e as supramencionadas são corroboradas por Turban et al (2008 apud KHAN et al, 2009, p.2), que explicam que as muitas funcionalidades do BI emergiram das ferramentas e técnicas sobre as quais ele foi constituído, especialmente dos Sistemas de Apoio à Decisão.

Não obstante, Turban et al (2008 apud KHAN et al, 2009, p.2) também destacam a proximidade com os Sistemas de Informação Executivos. De fato, determinadas soluções de Business Intelligence atendem exclusivamente as necessidades estratégicas de organização, assumindo propriedades de Sistemas de Apoio aos Executivos. Williams e Williams (2007, p.5) e Arnott (2008, p.55) também consideram que em muitas formas o BI é o sucessor dos SIE, porque é a camada de análise e apresentação intermediária entre os bancos de dados e os tomadores de decisão executivos. Elbashir et al (2008, p.149) compartilham desta idéia, argumentando que o BI era inicialmente uma ferramenta de uso exclusivo para o apoio à tomada de decisão estratégica, mas que aos poucos conquistou mais interessados, expandindose para os níveis gerenciais e inclusive operacionais.

De qualquer forma, a análise do ambiente externo (baseada em informações pouco estruturadas) pode ser considerada para alguns uma lacuna entre o BI e o conceito por trás dos antigos Sistemas de Informação Executivos. Para Warmouth e Yen (1992, p.193), os SIE também deveriam auxiliar as decisões de nível estratégico associadas às informações do ambiente externo, informações que reflitam as pressões dos diversos fatores exógenos à organização. Em muitos casos este não é o escopo do BI, mas da Inteligência Competitiva.

Finalmente, assim como explicam YERMISH et al (2010, p.48), também é possível conceber o BI como “(...) a última encarnação dos Sistema de Informação Gerencial”, isto porque ele também apresenta características como estruturação, eficiência e acompanhamento sugeridas por Keen e Scott Morton (1978, p.1-2). Em outras palavras, o BI também trata das decisões 
estruturadas, com enfoque no monitoramento e controle e com o público-alvo gerencial, onde são envolvidas mais variáveis de análise, conforme a abordagem dos tipos de decisão de Simon (1960 apud KEEN e SCOTT MORTON, 1978, p.85-86). Os relatórios e outras ferramentas do BI colaboram diretamente na condução das atividades da organização e permitem avaliar o desempenho frente aos referencias pré-estabelecidos, outra característica dos SIG de acordo com Souza (2000, p.9).

A proximidade do BI com os SIG é ainda mais pertinente quando avaliamos o contexto dos sistemas de informação dentro das organizações nas últimas décadas. Com o desenvolvimento e disseminação de SPT, em particular dos Sistemas de Gestão Integrada (ERP), as mais variadas corporações puderam se aproveitar da convergência e estruturação de informações num mesmo banco de dados, da redução de discrepâncias entre informações de diferentes departamentos e da melhoria na qualidade dos dados (SOUZA e SACCOL, 2003, p.21). Por outro lado, os ERP aumentaram sensivelmente o volume de informação disponível e possível de ser analisada, uma contribuição direta para a chamada 'overdose de dados' ou 'sobrecarga da informação' defendida na literatura de TI (BAWDEN e ROBINSON, 2009, p.182-183). Esta nova realidade resultou em novas necessidades gerenciais de relatórios, consolidações e análises, demandas típicas dos SIG, que em nome da performance e de suas especificidades foram deslocadas para as aplicações de BI.

Enfim, considerando os pontos expostos, a afirmação de Negash (2004, p.177) de que o Business Intelligence é o novo termo que substituiu os antigos não parece infundada. De fato, por ajustar-se às definições de mais de uma tipologia de sistemas, é cada vez mais difícil distinguir ou rotular o BI nestes termos. Por este motivo talvez as tipologias alternativas sejam mais relevantes, como é o caso daquela sugerida por Inmon (2002, p. 15), que separa os sistemas operacionais, concentrados em transações, dos sistemas analíticos, concentrados em análises.

\section{BI vs CI}

No levantamento bibliográfico do tema Business Intelligence observam-se um grande número de definições e conceitos relacionados com outro termo comumente utilizado como sinônimo, a chamada Competitive Intelligence (CI) ou Inteligência Competitiva (IC). 
A CI também é um tópico relativamente recente dentro da Administração de Empresas, tendo surgido no começo dos anos 80 (FLEISHER e BENSOUSSAN; 2002; p.5), com poucas pesquisas empíricas (SAAYMAN et al, 2008, p.384) e que, seja por sua maturidade ou evolução, ainda apresenta conceituações desencontradas e controversas com diversas linhas de pensamento diferentes na bibliografia de referência, como abordam Santos e Almeida (2009, p.47). Não raro pode ser observada uma infinidade de nomes para descrever, de modo genérico, os mesmos conceitos ou idéias abordados pela Inteligência Competitiva, dentre eles, Strategic Foresight, Marketing Intelligence, Defensive Intelligence, Key Intelligence Topics, Antecipatory Management, Early Warning Signals, FAROUT System, Environmental Scanning dentre outros.

Para a SCIP (Profissionais de Inteligência Competitiva e Estratégia), a CI refere-se a um "(...) processo sistemático e ético para coleta, análise e administração de informações externas [à organização] que podem afetar os planos, decisões e operações da empresa" (SCIP, 2009, p.1). Ela é o processo sistemático - e também o produto - que apóia e aprimora a tomada de decisão e que ajuda a desenvolver melhores estratégias uma vez que promove o entendimento dos concorrentes, do ambiente onde a organização e as tendências da indústria, gerando respostas mais sintonizadas às oportunidades ou ameaças que se apresentam (BERNHARDT, 1994, p.13; FLEISHER e BENSOUSSAN; 2002; p.6).

Em parte por esta definição, que descreve um processo sistêmico relacionado com a tomada de decisão (principalmente estratégica), é justificável que alguns autores compreendam o BI e a CI como temas correlatos ou até correspondentes, como é o caso de Vedder et al (1999, p.109). Isso é particularmente verdade quando a abordagem segue o ponto-de-vista de autores como Hering e Mayer, dois ex-funcionários da Agência Norte-Americana de Inteligência (CIA); a linha clássica sugerida por estes autores procura aplicar os conceitos de inteligência no mundo dos negócios (SANTOS e ALMEIDA, 2009, p.47), tratando especificamente da coleta de informações sobre competidores e forças do ambiente com o objetivo de fornecer insumos que permitam a organização se adiantar às mudanças do ambiente (MODY, 2005, p.17).

$\mathrm{Na}$ escola francesa (principalmente os autores que seguem a linha de Humbert Lesca), também é comum observar a utilização do termo BI para referir-se ao processo de 
monitoramento e prospecção do ambiente externo com o objetivo de criar oportunidades e reduzir incertezas para a organização (BLANCO e LESCA, 1998, p.1; BLANCO et al, 2003, p.81). Porém, quando os conceitos de Blanco et al são analisados a fundo, é possível verificar que não tratam das mesmas características e objetivos que o BI convencional e com o enfoque discutido anteriormente. Na verdade, para estes autores o Business Intelligence deveria se concentrar em propósitos antecipatórios, procurando tratar com decisões únicas e não rotineiras, deveria contemplar informações que lidem com os sinais fracos sugeridos por Ansoff e deveria ser um processo de iterações que permita o aprendizado (BLANCO et al, 2003, p.81), todas particularidades abordadas por outros autores dentro do rótulo da Inteligência Competitiva.

Choo (2001, p.86-93) também colabora no debate das terminologias de inteligência e propõe uma diferenciação de acordo com o escopo da coleta (externa) e o horizonte de tempo em que esta captação é realizada que pode ser visualizada na figura 2 a seguir. A princípio o autor não entende CI e BI como sinônimos, mas, ao contrário, defende que a primeira é uma parte da segunda e esta, por sua vez, um subconjunto de algo mais amplo chamado de Monitoramento Ambiental (Environmental Scanning ou ES), um termo cunhado pelo próprio autor.

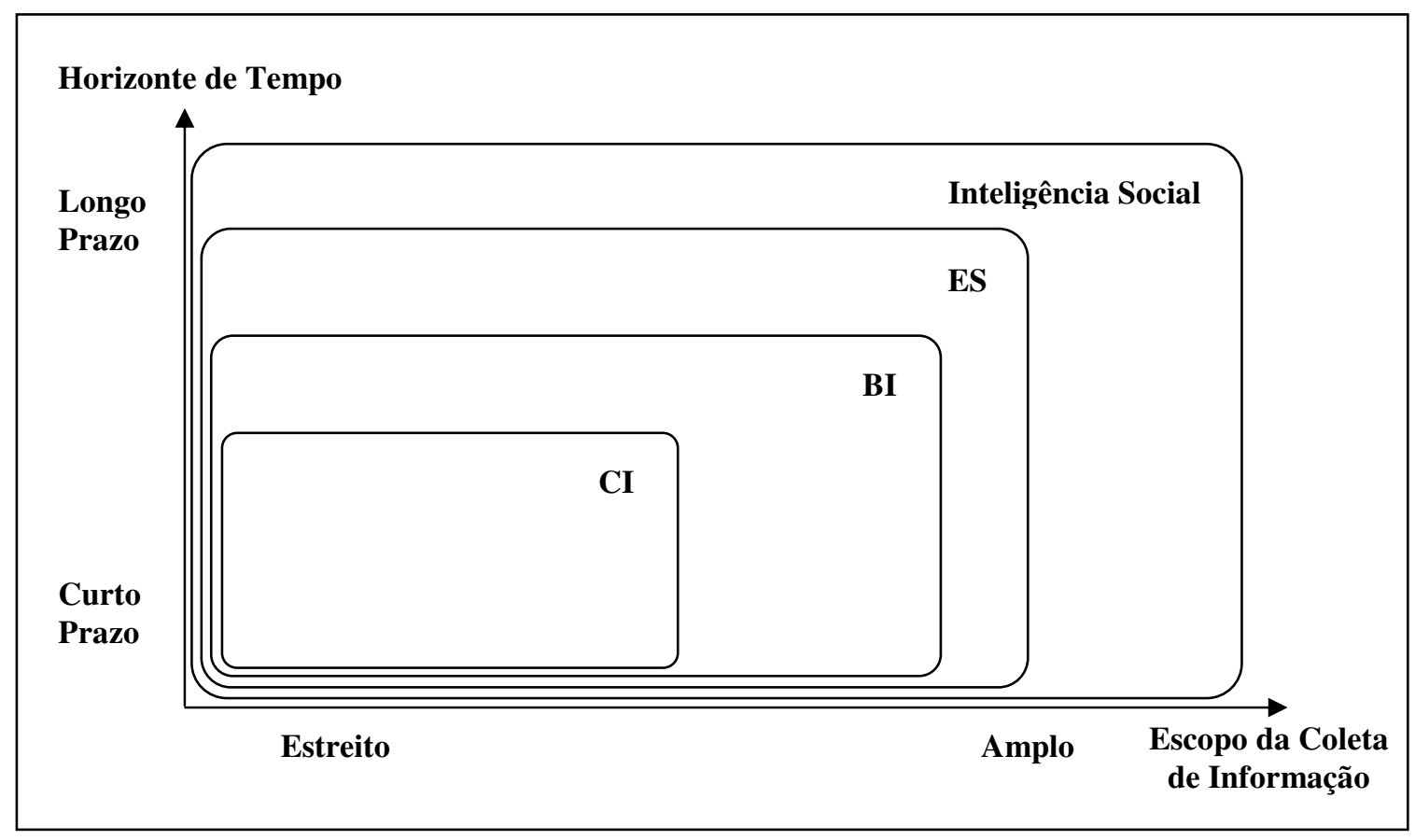

Figura 2. Formas de Coleta Externa de Informação

Fonte: Tradução de Choo (2001, p.88) 
Contudo, uma análise superficial aos conceitos de Choo pode ser enganosa. Na visão do autor, por exemplo, a CI trata apenas da análise da concorrência e do ambiente concorrencial seguindo as Forças Competitivas de Porter, isto é, ameaça de novos entrantes, concorrência entre empresas, ameaça de bens substitutos, poder de barganha dos compradores, poder de barganha dos fornecedores (CHOO, 2001, p.88-89). Esta abordagem é bastante restrita e não corresponde ao sentido mais da Inteligência Competitiva segundo a SCIP, por exemplo.

$\mathrm{Na}$ verdade, no trabalho de Choo o termo que mais se assemelha em significado ao CI proposto pela SCIP e por outros autores como Bernhardt, Vedder et al, Santos e Almeida e Mody, dentre outros, é justamente o Monitoramento Ambiental, termo fundamentado sobre a pesquisa de Aguilar e que corresponde ao processo de “(...) aquisição e uso da informação sobre eventos, tendências e relacionamentos no ambiente externo da empresa, conhecimento que pode auxiliar executivos no planejamento das ações futuras da organização" (CHOO, 2001, p.94). Além disso, para o autor, o domínio da ES é similar ao do BI (que é baseado sobre as idéias de Meyer) e, assim como os seguidores de Lesca, os termos são utilizados como sinônimos.

Uma linha diferente de pensamento, que se fundamenta principalmente no apoio que a CI deve promover ao planejamento estratégico e que de certa forma sustenta o gráfico proposto por Choo, entende a Inteligência Competitiva no sentido da SCIP como uma parte integrante do BI. Seu objetivo é fomentar a criação e a manutenção de vantagens competitivas através das informações externas coletadas de competidores, clientes, fornecedores, tecnologias e ambientes. (SAAYMAN et al, 2008, p.384-385). Keyes (2006, p.159), Ranjan (2009, p.60) e Negash (2004, p.186) compartilham desta abordagem ao indicar a CI como um subconjunto do BI, um campo especializado com a monitoração não só do competidor, mas de todos os envolvidos na dinâmica da organização para evitar perigos e capturar oportunidades, trabalhando de forma alinhada com o Planejamento Estratégico e garantindo que sua execução possa ser controlada.

Considerando o debate das terminologias e as definições até o momento abordadas, é importante destacar que, nesta obra, BI e CI não são considerados sinônimos, mas termos independentes e específicos, certamente relacionados entre si, não obstante complementares e com pouca ou nenhuma sobreposição (ao contrário do que sugerem alguns autores). Esta distinção entre os termos está fundamentada em três premissas básicas: o tipo de informação, 
a origem da informação e o escopo ou nível organizacional considerado por cada um dos termos.

Em primeiro lugar, o CI trata do processamento analítico de informações não estruturadas e qualitativas (inclusive aquelas chamadas de sinais fracos por Ansoff) que suportam decisões únicas e não rotineiras (BLANCO et al, 2003, p.81). Por outro lado, apesar de também ser essencialmente um processo analítico, o BI lida principalmente com informações estruturadas e semi-estruturadas e quantitativas (NEGASH, 2004, p.180), sobre as quais podem ser aplicadas diferentes técnicas de manipulação e apresentação.

Em segundo lugar, as informações coletadas pela Inteligência Competitiva vão além das fronteiras da organização (BAARS e KEMPER, 2008, p.133), estando relacionadas exclusivamente ao ambiente externo em que a organização está inserida (FLEISHER e BENSOUSSAN; 2002; p.6; RANJAN, 2009, p.60) e esta parece ser uma opinião unânime entre todos os autores abordados. Em contraposição, o Business Intelligence está concentrado majoritariamente nos dados internos à organização, principalmente o grande volume de dados oriundo de sistemas operacionais. Estas duas distinções relacionadas com a informação são dois dos principais motivos que explicam porque o BI é um termo normalmente associado a sistemas de informação e soluções tecnológicas, como esclarece Davenport (2006, p.3), enquanto esta ênfase não é tão presente no CI e gera inclusive debates interessantes como o proposto por Gilad (2008, p.22) sobre a escola de "relatórios" e a escola de "interpretação".

O último ponto de distinção entre BI e CI sugerido trata do nível organizacional para o qual cada tema dá maior ênfase e apoio. Enquanto a CI é tem foco puramente estratégico e está intimamente relacionado com “(...) os esforços em aprimorar a competitividade da organização e seu processo de Planejamento Estratégico" (SAAYMAN et al, 2008, p.385), o BI parece se concentrar no apoio da tomada de decisão dos diferentes níveis organizacionais (estratégico, gerencial e, em alguns casos, operacional). Existe neste aspecto, portanto, uma intersecção entre o BI e o CI no nível estratégico, porém ela é limitada e diferenciada pelas características de cada um. A figura 3 na próxima página procura ilustrar estas distinções conceituais entre $\mathrm{BI}$ e $\mathrm{CI}$ descritas. 


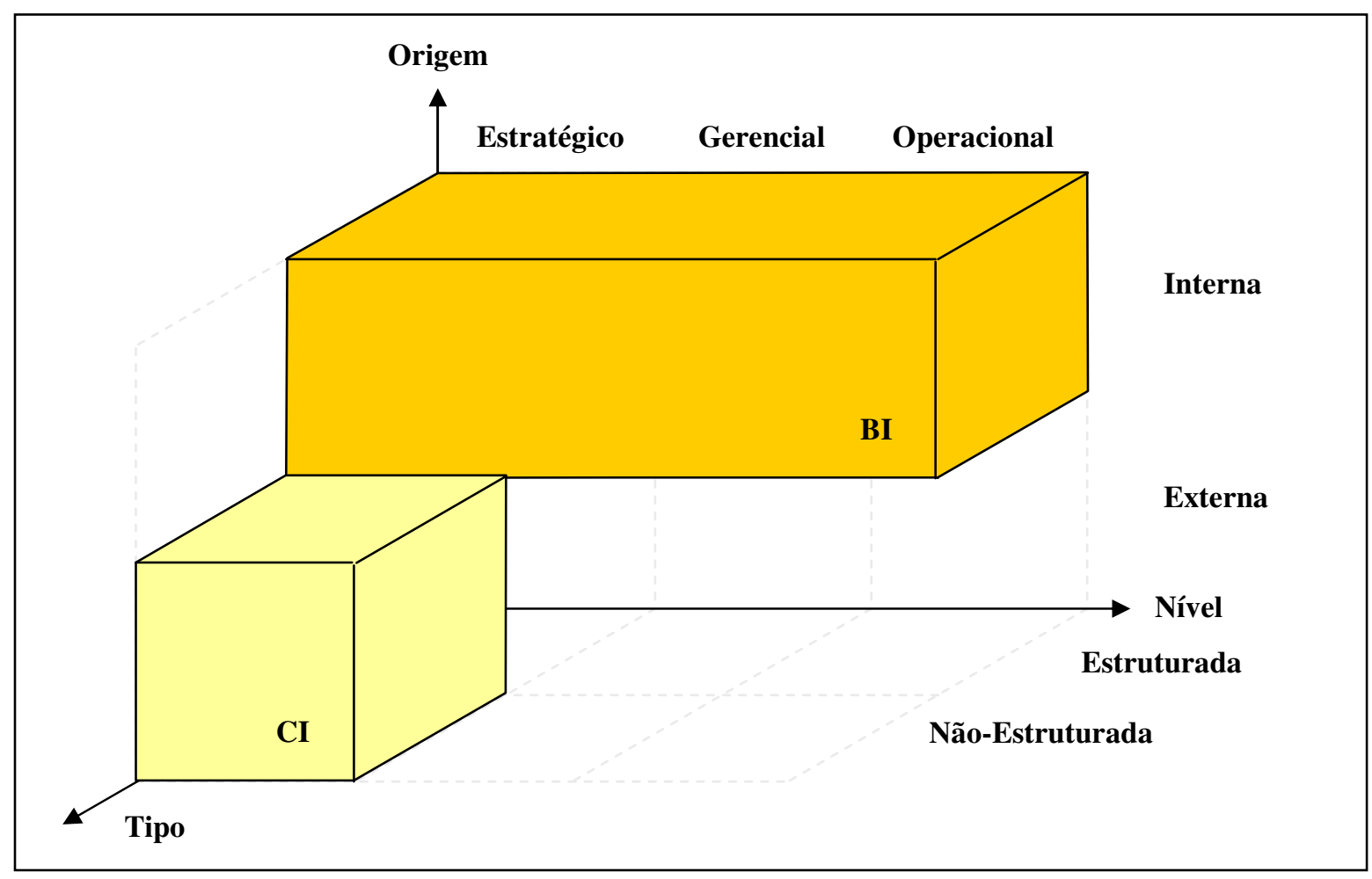

Figura 3. Distinções entre BI e CI

Fonte: Adaptação de Pauli (2010, p.4)

\subsubsection{Componentes e Funcionalidades do BI}

A seguir são abordados os componentes e funcionalidades do BI, principalmente aqueles relacionados com a apresentação e análise de dados.

\section{Componentes de Arquitetura do BI}

De forma genérica, observando as referências avaliadas (TURBAN et al, 2008 apud KHAN et $a l$, 2009, p.2; ARNOTT 2008, p.1; HOWSON, 2008, p.21), as funcionalidades de uma plataforma de BI podem ser divididas em três camadas básicas de acordo com a função que exercem: (1) Aquisição (corresponde à extração, transformação e carga dos dados), (2) Armazenamento (corresponde ao banco de dados e sua particular modelagem) e (3) Acesso (corresponde às facilidades de visualização, análise e disseminação das informações da organização). 
Dando maior ênfase para a apresentação e utilização dos dados, assim como para as questões de infra-estrutura e desenvolvimento, o Gartner Group (2011, p.10-11) propõe 13 capacidades organizadas também em três grupos, mas de maneira distinta: (1) Integração (corresponde à infra-estrutura que suporta o BI, assim como a administração dos metadados, as ferramentas de desenvolvimento e as possibilidades de colaboração), (2) Entrega (corresponde às facilidades de visualização mais simples, como relatórios, painéis, consultas ad hoc, além da integração com planilhas eletrônicas e facilidades de busca) e (3) Análise (corresponde às capacidades mais complexas de apresentação, como relatórios OLAP, visualização interativa, modelos preditivos e mineração de dados, além de scorecards).

Outra categorização aceitável, ainda relacionada com a função exercida e elaborada com o apoio da definição de um Sistema de Informação proposta por Turban et al (2005, p.41) é detalhada a seguir.

A. Coleta: Para a aquisição e transferência dos dados nos diferentes sistemas fonte da organização, o BI utiliza aplicações conhecidas como ETL (sigla em inglês para Extract, Transform e Load). Elas têm diversas funcionalidades que em conjunto são responsáveis pela extração (busca e captura dos dados em sua origem), transformação (inspeção, limpeza e modificação nos dados coletados) e transferência (carga) para dentro do banco de dados base do BI (atualização dos dados transformados) (SILVERS, 2008, p.139).

Como explica Inmon (2002, p.122), o ETL é um passo importante que deve converter, reformatar e, idealmente, integrar dados provenientes dos múltiplos sistemas operacionais de forma automatizada. De acordo com Silvers (2008, p.140), existem vários princípios e metodologias para desenvolver uma aplicação de ETL de sucesso, mas a atividade mais importante é analisar os requisitos do sistema de destino e as restrições das informações nos sistemas de origem. Como o ETL faz parte do que se pode chamar de infra-estrutura de BI, ela normalmente é relacionada como uma atividade sob responsabilidade de equipes técnicas (mesmo que se faça necessário conhecer o negócio para definir as regras coerentemente).

B. Processamento: Dentro do BI o processamento dos dados pode ser considerado difuso uma vez que ocorre em diferentes momentos e em diferentes funcionalidades, com objetivos particulares em cada caso. Talvez o processamento de dados mais próximo do 
conceito convencional seja aquele realizado justamente na transformação e transferência das informações pelas aplicações de ETL, conforme abordado no tópico acima. De qualquer forma, os dados também são processados em sua apresentação, por exemplo, através do processamento analítico online (OLAP).

Em contraposição ao processamento transacional online (OLTP) que é utilizado nos sistemas transacionais e que se preocupa com a entrada de dados, a tecnologia OLAP se concentra em sua análise (KIMBALL e ROSS, 2002, p.408). Aplicável em bancos de dados multidimensionais (e muitas vezes confundidos com eles), o OLAP permite a apreciação de dados com mais profundidade, com maior velocidade e numa interface mais amigável, portanto, mais compreensível, através de uma série de técnicas como o slice and dice e o drilling (drill down, drill up, drill through, etc) (SILVERS, 2008, p.210-213; KEYES, 2006, p.180).

Além disso, também há processamento de dados na mineração de dados, neste caso com o apoio (em geral) de modelos matemáticos complexos que em conjunto tem como objetivo de “(...) descobrir e interpretar padrões previamente desconhecidos (...), convertendo dados em informação e potencial conhecimento acionável” (NEMATI et al, 2010, p.19). ETL, OLAP e mineração são apenas três exemplos que demonstram a característica difusa do processamento dentro do $\mathrm{BI}$.

C. Armazenamento: Para o armazenamento dos dados transformados, o BI utiliza bancos de dados baseados em modelos de tabelas estruturados que visam a melhor organização das informações, tanto para guardá-la, quanto para acessá-la. Existem diferentes formas de definir e desenvolver o armazenamento dentro do BI que refletem diferentes conceitos e possibilidades; neste aspecto, não há consenso nem mesmo entre os dois principais ícones do tema (Bill Inmon e Ralph Kimball). De qualquer forma, uma vez tratados no ETL, os dados são hipoteticamente armazenados num depósito central, corporativo, granular, integrado, histórico, construído sobre um modelo relacional (portanto, normalizado), chamado de Data Warehouse (ou DW) (INMON, 2002, p.137). O objetivo do DW é armazenar dados de forma flexível e detalhada, servindo de ponto central dos dados da organização e mantendo apenas uma versão da verdade (SILVERS, 2008, p.18). 
Arranjados desta forma, porém, os dados não atendem as demandas dos usuários de negócio. Neste caso as informações devem ser consolidadas, reorganizadas e alinhadas de maneira compreensível de acordo com suas necessidades. Estes pequenos conjuntos de dados, normalmente separados pelos temas funcionais e orientados a assuntos, são chamados de Data Marts ou cubos. Ao contrário do DW, os Data Marts têm como objetivo fundamental preparar os dados para a apresentação aos usuários e, por este motivo, é necessária uma abordagem diferenciada chamada de multidimensional, onde os fatos centrais estão associados às várias dimensões que os caracterizam e os detalham. Nesta modelagem há pouca normalização e muita redundância, já que o foco é fornecer aos usuários um modelo intuitivo, fácil de utilizar, com bom desempenho de acesso e rápida resposta, que seja adaptável, extensível e padronizável (KIMBALL e ROSS, 2002, p.3).

D. Apresentação: Para a visualização dos dados, o BI tem normalmente diferentes ferramentas que oferecem diferentes artifícios e técnicas cuja finalidade comum é disponibilizar as informações com opções mínimas de parametrização, permitindo aos usuários da comunidade de negócios responderem e interpretarem por si só os dados e tomar melhores decisões (KIMBALL e ROSS, 2002, p.10; NEMATI et al, 2010, p.21). Algumas destas técnicas são mais simples e estão concentradas na facilidade de uso por parte dos usuários finais, que normalmente não têm conhecimentos técnicos suficientes.

Assim, as ferramentas de relatórios utilizadas pelos usuários finais são aplicações técnicas com uma interface amigável que convertem de modo transparente os requisitos de negócio em sintaxes complexas, como linguagem estruturada de consultas (SQL) (SILVERS, 2008, p.207), sem a necessidade de que os usuários tenham conhecimentos avançados em construção de consultas, mas oferecendo assim mesmo opções mais interessantes como agrupamentos, seleções e filtros (NEMATI et al, 2010, p.21). A visualização dos dados é normalmente feita por interface web (SILVERS, 2008, p.214) ou por planilha eletrônica. Esta orientação para padrões de outras ferramentas com as quais os usuários têm mais intimidade e conhecimento (principalmente no caso das planilhas) visa alavancar a familiaridade do usuário com o instrumento, aproveitar as opções de manipulação e de construção de gráficos, construir e atualizar conjuntos integrados de planilhas e diminuir a necessidade de licenças exigidas por muitos produtos de BI (HOWSON, 2004, p.1). 
A camada de apresentação, representada por painéis de informação, relatórios préconfigurados e relatórios ad hoc é talvez a faceta do BI mais próxima aos Sistemas de Informação Gerenciais (SIG) abordados anteriormente, pois seu foco é mais concentrado no controle e no acompanhamento do desempenho da organização. Tendo em vista estas particularidades, dentro deste grupo de componentes, portanto, também podem ser classificadas as funcionalidades normalmente baseadas em relatórios que são utilizados para planejamento e controle orçamentário.

E. Análise: Uma parte da camada de apresentação, a análise refere-se às capacidades normalmente mais complexas do BI que, além de significarem maiores dificuldades técnicas de definição e construção, exigem maior interação do usuário e, portanto, mais habilidades analíticas que permitam a viabilização da contextualização e interpretação das informações. Apesar de mais complexas, porém, estas ferramentas de análise são aquelas que oferecem recursos mais poderosos e diferenciados, que podem resultar em novas descobertas e idéias e na real possibilidade de criação de vantagens competitivas (BRYDON e GEMINO, 2008, p.604), principalmente no cenário atual, onde organizações oferecem produtos muito similares, utilizam tecnologias comparáveis e têm dificuldades de se distinguir no mercado ou indústria (DAVENPORT, 2006, p.1). Em parte por este motivo é que o interesse nestes componentes vem obtendo uma massa crítica considerável desde o começo da década (KIMBALL e ROSS, 2002, p.384), aumentando de forma sensível e re-direcionando o foco original em medição para análises, previsões e otimizações em 2011 (GARTNER GROUP, 2011, p.5).

Seja pela complexidade ou pelas diferenças técnicas, as soluções do rótulo de análise são mais heterogêneas do que as de apresentação. Os relatórios OLAP, por exemplo, seguem o padrão dos outros dois casos de relatórios supramencionados sob o ponto-de-vista de usabilidade, interatividade e integração com ferramentas já usuais. Por outro lado, as funcionalidades que envolvem modelos preditivos ou mineração de dados são bastante particulares, com características próprias. Neste caso, além do tema tecnológico e de sua aplicação ao negócio, ainda existe uma complicação adicional relacionada com as dificuldades inerentes às aplicações de modelos matemáticos e estatísticos que sustentam as funcionalidades. De qualquer forma, são estes os componentes que acabam justificando o BI como um Sistema de Apoio a Decisão (SAD). 
F. Distribuição: Para a disseminação das informações e dos relatórios para a organização, parceiros e demais stakeholders, o BI utiliza uma infinidade de formas e ferramentas diferentes. Em primeiro lugar, a distribuição pode ser física (como cópias impressas dos relatórios) ou eletrônica (arquivos ou acesso instantâneo). Neste segundo caso, além dos próprios aplicativos de relatórios que podem ser acessados virtualmente em qualquer computador da organização, é possível disponibilizar os relatórios (ou o próprio acesso) em redes corporativas (em intranets, por exemplo), em aparelhos móveis (como celulares e PDAs) ou diretamente em correios eletrônicos (SILVERS, 2008, p.213-215).

A distribuição pode ser automatizada e agendada, assim como outros processamentos dentro do BI, e pode seguir critérios específicos que sejam demandados pelo negócio.

Como explica o Gartner Group (2011, p.10), uma solução de BI é uma plataforma única ou um conjunto de ferramentas que, em conjunto, apresentam as funcionalidades listadas acima. A figura 4 abaixo procura representar todos os componentes supramencionados.

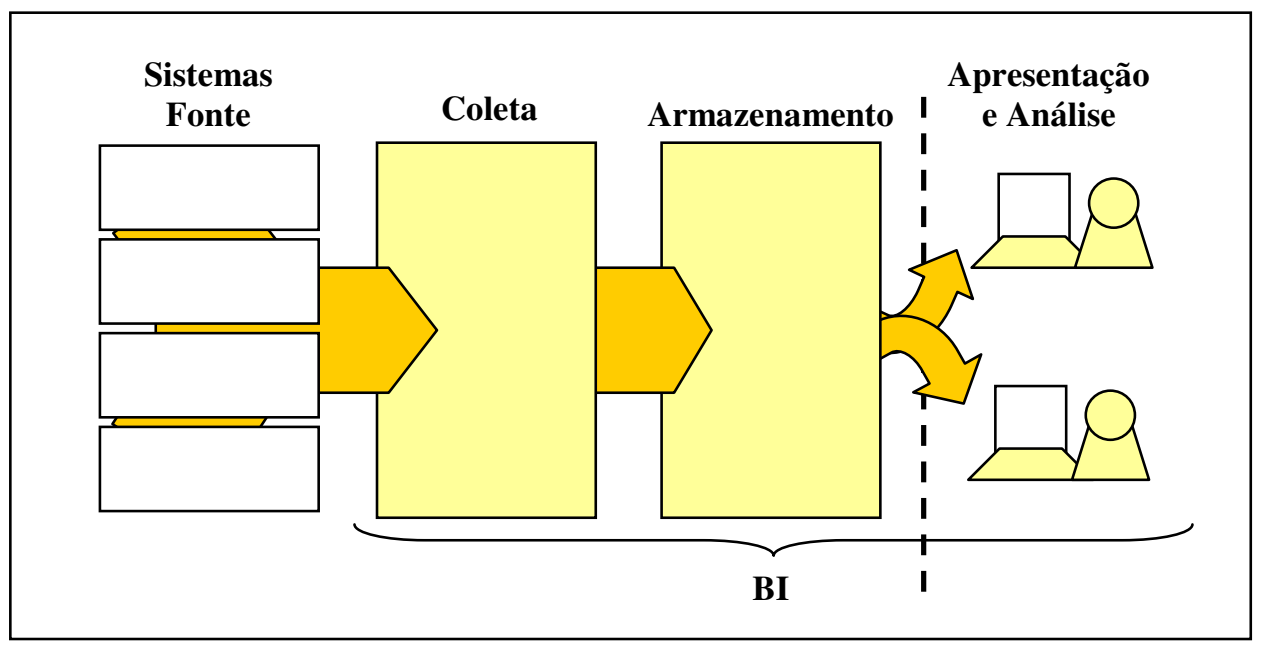

Figura 4. Componentes Genéricos de uma Solução de BI

Fonte: Tradução e adaptação de Silvers (2008, p.3)

\section{Funcionalidades de Apresentação e Análise de Dados do BI}

Apesar da necessidade essencial de uma infra-estrutura de integração (incluindo hardware, software, arquitetura, modelos, sistemas e aplicações variadas) que armazene e permita o acesso a dados, não raro o BI é entendido apenas como a camada de apresentação e análise 
para os usuários finais. Para Howson $(2008$, p.1), por exemplo, o BI “(...) é um conjunto de tecnologias e processos que permitem pessoas de todos os níveis de uma organização a acessar e analisar dados". Nesta linha, Silvers (2008, p.199) entende o BI como a face explícita do Data Warehouse, aquilo que os clientes da informação vêem e com quem interagem de fato. De certa forma, é possível afirmar que as visões de Howson e Silvers fortalecem o argumento já apresentado de que um dado só se torna uma informação - ou inteligência de negócios de fato - quando é colocado num contexto através da interação e envolvimento analítico das pessoas.

As observações de Nemati et al (2010, p.16) seguem esta lógica, considerando o BI como as diversas ferramentas da camada de apresentação, utilizadas por usuários finais para entrega de informações que forneçam bases sólidas para a tomada de decisão. Além disso, para os autores, a aplicação que fornece o acesso do cliente aos dados é a que o usuário final associa ou percebe como sistema. Assim, mesmo que os dados (com qualidade) possam ter sido coletados e organizados corretamente, é a interface de apresentação com o usuário que determina o sucesso de uma solução de BI (NEMATI et al, 2010, p.16). Certamente este é um dos fatos que colabora para a observação do Gartner Group (2011, p.10) de que a camada de apresentação tem sido o foco da maioria dos projetos de implantação de BI na atualidade.

Tendo como base as diferentes técnicas de apresentação e análise de BI sugeridas por diversos autores, dentre eles Gartner Group (2011, p.10-11), Nemati et al (2010, p.19-21), Silvers (2008, p.209-218) e Turban et al (2008 apud AGHA KHAN et al, 2009, p.2) e complementada por outros autores da bibliografia de referência, a seguir são detalhadas as soluções mais relevantes para o estudo, seja pela aplicação já em larga escala ou pela maturidade do conceito dentro das organizações. Estas técnicas são descritas por ordem de complexidade (daquelas mais simples e limitadas para as mais complexas) sob o ponto-devista de facilidade de uso e amplitude de análise para o usuário final, sendo desconsideradas as dificuldades de desenvolvimento.

A. Painel de Informação (Dashboard): É a técnica de apresentação de dados mais intuitiva e, conseqüentemente, mais simples do BI, com gráficos, tabelas, velocímetros, alertas, dentre outros, pois se preocupa com conjuntos de informações consolidadas e com poucas variáveis de análise, além de oferecer funcionalidades limitadas que limitam a interação com o usuário. Os painéis têm como objetivo principal a rápida compreensão de um 
conjunto de informações cujo acesso é contínuo, por isso sua apresentação é padronizada e raramente alterada. Os painéis devem ser intuitivos e de fácil entendimento uma vez que este tipo de aplicação normalmente atende um público-alvo com conhecimentos heterogêneos tanto sob o ponto-de-vista técnico, quanto de negócio. O tempo de resposta também é uma exigência importante, portanto, os painéis devem ter um bom desempenho com rápidas respostas.

Assim como os EIS (Executive Information Systems) descritos por Keyes (2006, p.164), os Painéis visam reduzir a quantidade de dados expostos ao usuário sem afetar o entendimento dos problemas, aumentando a relevância, a rapidez e o foco dos usuários nas informações realmente críticas. Além disso, eles procuram promover sua usabilidade e interação através da melhora de comunicação, acompanhamento e rastreamento de mudanças. O exemplo clássico desta aplicação são os chamados Painéis Executivos Corporativos, que apresentam informações consolidadas (sem detalhes específicos), do conjunto de áreas que compõe a organização, fornecendo os principais indicadores com alertas de desvios e pontos de atenção para que os executivos possam vislumbrar num "piscar de olhos" a situação da empresa. Outro exemplo, tratado separadamente pelo Gartner Group (2011, p.11) e considerado no agrupamento de análise, são os Balanced Scorecard (BSC), um estágio mais avançado de painel, que aplica as informações ao mapa estratégico da organização, alinhando indicadores de desempenho com os objetivos estratégicos, permitindo um melhor acompanhamento destes temas (BALLARD et al, 1996, p.98).

B. Relatório Pré-Definido (Reporting): É a técnica de apresentação de dados em formatos pré-configurados, mas com possibilidades mínimas de parametrização que respondem a questões que podem ser consideradas convencionais e até certo ponto repetitivas. Sua interface é orientada para padrões de outras ferramentas com as quais os usuários têm mais intimidade e praticidade (por exemplo, planilhas eletrônicas), ao mesmo tempo em que oferecem opções avançadas de agrupamento, seleção e filtros (NEMATI et al, 2010, p.21).

Os relatórios pré-definidos podem apoiar temas operacionais, gerenciais ou estratégicos, de forma detalhada e em diversos temas funcionais específicos como finanças, vendas, produção. De certa forma, o público usuário desta funcionalidade tampouco tem 
conhecimentos técnicos avançados, mas é mais restrito, pois estes relatórios atendem necessidades particulares do negócio. Exemplos de relatórios pré-configurados podem ser encontrados na área de finanças, controladoria e contabilidade das organizações nas versões eletrônicas e automatizadas de DRE (Demonstração dos Resultados do Exercício), Balanço Patrimonial ou Fluxo de Caixa. Eles têm formatos padrões e apresentam informações de temas particulares.

Para alguns autores, inclusive Nemati et al (2010, p.21) e Gartner Group (2011, p.10), os painéis de informação são um sub-tipo de relatório pré-definido. Esta afirmação é coerente e apropriada, mas tendo em vista as particularidades dos painéis (tanto de público, quanto de objetivo e formato) e sua disseminação nas organizações, esta funcionalidade é tratada individualmente nesta pesquisa.

C. Relatório Ocasional $(a d h o c)$ : É uma técnica de apresentação que, normalmente está baseada nas mesmas funcionalidades dos Relatórios Pré-Configurados, mas que permite ao usuário a criação por conta própria de relatórios flexíveis (com mais possibilidades de formatação e parametrização), sem formatos específicos e que respondem a questões ou necessidades pontuais de um tema especifico. É uma forma mais aprimorada de análise do negócio, pois permite buscar respostas para problemas inesperados sem a necessidade de que os usuários tenham conhecimentos avançados em construção de consultas (NEMATI et al, 2010, p.21) e sem depender da ajuda de desenvolvedores.

De qualquer forma, o preço da flexibilidade é o aumento da complexidade na utilização da ferramenta, já que o usuário deve ter algum conhecimento técnico e uma boa idéia do modelo de dados por trás da aplicação, caso contrário, pode criar relatórios redundantes, ineficientes e/ou incorretos (SILVERS, 2008, p.210). Em muitas ferramentas deste tipo, o usuário pode optar por utilizar as opções padrão pré-moldadas ou fazer uso da linguagem [de construção] de consultas estruturadas, o chamado SQL, para definir os relatórios, o que exige determinadas habilidades técnicas.

Ainda em relação à complexidade, segundo Kimball e Ross (2002, p.14) apenas uma pequena parcela de usuários de negócio pode entender satisfatoriamente a ferramenta $\mathrm{ad}$ hoc, estando apta para utilizá-la. Para o autor, a maioria esmagadora dos usuários (80\%) normalmente acessa os relatórios pré-configurados que não requerem habilidades 
minimamente diferenciadas. Os relatórios ad hoc também podem apoiar todos os níveis organizacionais, apesar do detalhamento acabar motivando o uso principalmente nas áreas de negócio, nos níveis operacionais e gerenciais.

D. Relatório OLAP: É uma técnica de apresentação típica de modelagem multidimensional e que utiliza o processamento OLAP abordado anteriormente. Como a informação está disponível em cubos onde os dados encontram-se pré-calculados, pré-agregados e intuitivamente organizados, este tipo de relatório possibilita uma apresentação de melhor desempenho, maior compreensão e maior interatividade e consistência, pois oferece diferentes alternativas de navegação e análise sem prejudicar o entendimento dos dados (NEMATI et al, 2010, p.21; SILVERS, 2008, p.210; OLAP COUNCIL, 1997, p.1).

Dentre as alternativas de análise oferecidas pelo OLAP estão a possibilidade do (1) slice and dice (fatiar e detalhar) que trata da análise concentrada num sub-conjunto de dados através do filtro de uma ou mais dimensões e o seu posterior detalhamento por outras dimensões de análise (BALLARD et al, 1996, p.87-89); (2) pivoting (rotação) que trata da mudança dos eixos, isto é, das informações das colunas pelas informações das linhas e vice-versa (BALLARD et al, 1996, p.90); e (3) drilling (exploração) que trata da navegação pelo detalhamento de um dado, isto é, pelos níveis de granularidade ou hierarquia da dimensão de análise (SILVERS, 2008, p.212). Assim, o drill-down trata da exploração no sentido de detalhar o dado, enquanto o drill-up é oposto, consolida-o. $\mathrm{O}$ drill-across trata da exploração de uma dimensão a partir de outra (desde que previamente definida) (BALLARD et al, 1996, p.92) e o drill-through trata da exploração de um dado até eventualmente seu registro conforme origem.

Como explica Silvers (2008, p.211), os relatórios que utilizam OLAP “(...) são ferramentas tipicamente analíticas" e, mais do que a noção técnica, quem as utiliza “(...) deve ter um conhecimento profundo do negócio e da empresa para poder seguir uma corrente de pensamento coerente." Em outras palavras, com as funcionalidades investigativas disponíveis pelo OLAP, os relatórios permitem encontrar respostas para as perguntas variadas do negócio, mas, para utilizar esta potencialidade é preciso saber o que perguntar. De certa forma é possível dizer que este tipo de relatório é a grande marca registrada de uma aplicação de DW e Data Mart e, portanto, do Business Intelligence e é 
considera um exemplo de ferramenta de análise (e não meramente de apresentação), porque depende da interação e da interpretação do usuário.

E. Modelos Preditivos: Como explica Inmon (2002, p.53), além de o BI preparar dados para a apresentação, ele também pode disponibilizá-los para exploração a partir de aplicações que utilizam diferentes modelos matemáticos e estatísticos (técnicas como regressões, análises fatoriais e clusters, dentre outros). Modelos preditivos não tratam da apresentação dos dados em si, mas de sua análise com o objetivo de realizar previsões e extrapolações tomando por base dados históricos do BI. Os resultados, desde que coerentes e compreensíveis sob o ponto-de-vista de negócio, podem então ser posteriormente oferecidos aos demais usuários através das técnicas de apresentação abordadas anteriormente.

Os modelos preditivos são considerados um componente de análise do BI com maior complexidade porque exigem não só conhecimentos de negócio e tecnologia, mas também de matemática e estatística de modo a construir modelos minimamente aceitáveis, em primeiro lugar, e avaliar os resultados destes modelos com propriedade e segurança, em segundo lugar.

F. Mineração de Dados (Data Mining): Concentrada nos grandes conjuntos de dados armazenados pelas organizações modernas, a mineração de dados é a forma mais complexa de análise e tem como objetivo primordial encontrar conhecimentos que $a$ priori não podem ser identificados pelas outras funcionalidades do BI. Ela pode ser definida como a capacidade de descobrir padrões, tendências, relações inesperadas e/ou quaisquer outras informações relevantes e valiosas que estejam escondidas nos bancos de dados (KEYES, 2006, p.176-177; INMON, 2002, p.389; SILVERS, 2008, p.217; JACKSON, 2002, p.267), fornecendo meios de apoio para “(...) transformar peças discretas e desconectadas de informação em inteligência real” (KEYES, 2006, p.176).

Para Silvers (2008, p.217), a mineração de dados é um exercício dinâmico e investigativo, baseado em duas abordagens complementares: as análises exploratórias (a busca por novas hipóteses) e as análises confirmatórias (a validação e verificação das hipóteses). É um exercício complexo que vem sendo viabilizado para as organizações graças à comercialização de pacotes de soluções específicas e a grande quantidade de dados e 
informações que as empresas armazenam (BRYDON e GEMINO, 2008, p.614), mas que dependem de pessoas extremamente capacitadas. De qualquer forma, segundo os autores, ainda permanece a lacuna entre a sofisticação e o poder da mineração de dados dos produtos de mercado e as técnicas de tomada de decisão utilizadas regularmente pelas organizações (BRYDON e GEMINO, 2008, p.614), um dos inúmeros desafios relacionados com a mineração de dados.

A relação entre este tipo particular de análise e o BI é controversa, pois a mineração de dados tem vida própria e não necessariamente depende do BI (JACKSON, 2002, p.268). Entretanto, além de fornecer dados integrados e prontos para o uso e técnicas citadas anteriormente como alternativa para a apresentação das informações geradas, existe um convergência entre os dois temas que inclusive recebe o nome de OLAM ou mineração analítica online (JACKSON, 2002, p. 270). Além disso, para Kohavi (2002, p.48), funcionalidades de mineração têm sido embutidas em plataformas tecnológicas (inclusive de $\mathrm{BI})$ graças à facilidade de uso e a entrega mais eficiente, o que agrega mais valor ao usuário final. Na verdade, organizações e pessoas devem compreender que a mineração de dados, assim como as demais ferramentas de BI e os sistemas de apoio a decisão, é apenas uma peça na grande engrenagem do processo de tomada de decisão (BRYDON e GEMINO, 2008, p.614), um componente que deve trabalhar em harmonia e em conjunto com o restante da arquitetura apoiando as pessoas em suas necessidades.

Uma ressalva importante é que para a maior parte dos autores estudados não parece existir uma distinção evidente entre modelos preditivos e mineração de dados, pois todas são técnicas de análise baseadas na matemática cujo objetivo principal é trabalhar os dados e descobrir novos conhecimentos. A diferenciação sugerida pelo menos nesta categorização está fundamentada em dois argumentos: o da complexidade e o do conhecimento a priori. No caso dos modelos preditivos, por exemplo, as técnicas empregadas normalmente são mais simples e a priori se tem um conhecimento mínimo sobre o assunto, o que resulta em questões explícitas e linhas de pesquisa mais direcionadas. Por outro lado, a mineração é uma folha em branco aonde respostas vêm antes das perguntas, derivadas de aplicações que são “(...) uma extensão das abordagens tradicionais de análise e estatística, que incorporam técnicas analíticas derivadas de uma série de disciplinas incluindo análise numérica, aprendizagem computacional, inteligência artificial, redes neurais e algoritmos genéticos" (JACKSON, 2002, p.267-268). 
Esta separação das funcionalidades em seis grupos é ligeiramente diferente da sugerida por Nemati et al (2010, p.29), que, apesar de explorar o mesmo conteúdo, destacam nove funções no artigo que serve de referência para esta dissertação. Em primeiro lugar, os autores consideram separadamente as opções de crosstab, drill e OLAP e as opções de dashborads e scorecards; na classificação sugerida nesta dissertação, as três primeiras estão inseridas sob a mesma categoria de Relatórios OLAP e as duas últimas sob a de Painéis de Informação. Em segundo lugar, os autores tratam o SQL como função específica, mas na classificação sugerida a possibilidade de utilização desta linguagem faz parte das opções dos Relatórios ad hoc (ou ocasionais). Além disso, dentro de sua pesquisa, Nemati et al (2010) consideram o ETL e a camada de integração de dados como uma funcionalidade, porém, como elas não têm funções de apresentação e análise e como não são utilizadas convencionalmente por usuários finais, não foram incluídas dentro dos seis agrupamentos destacados. Finalmente, uma categoria não detalhada pelos autores é a de modelos preditivos.

Considerando as características descritas acima para as funcionalidades de BI, é possível sugerir o gráfico da figura 5 a seguir para ilustrar a relação entre a complexidade de utilização e o nível de dificuldade de análise de um lado e o potencial valor agregado do outro (sob o ponto-de-vista de diferenciador estratégico e gerador de vantagens competitivas).

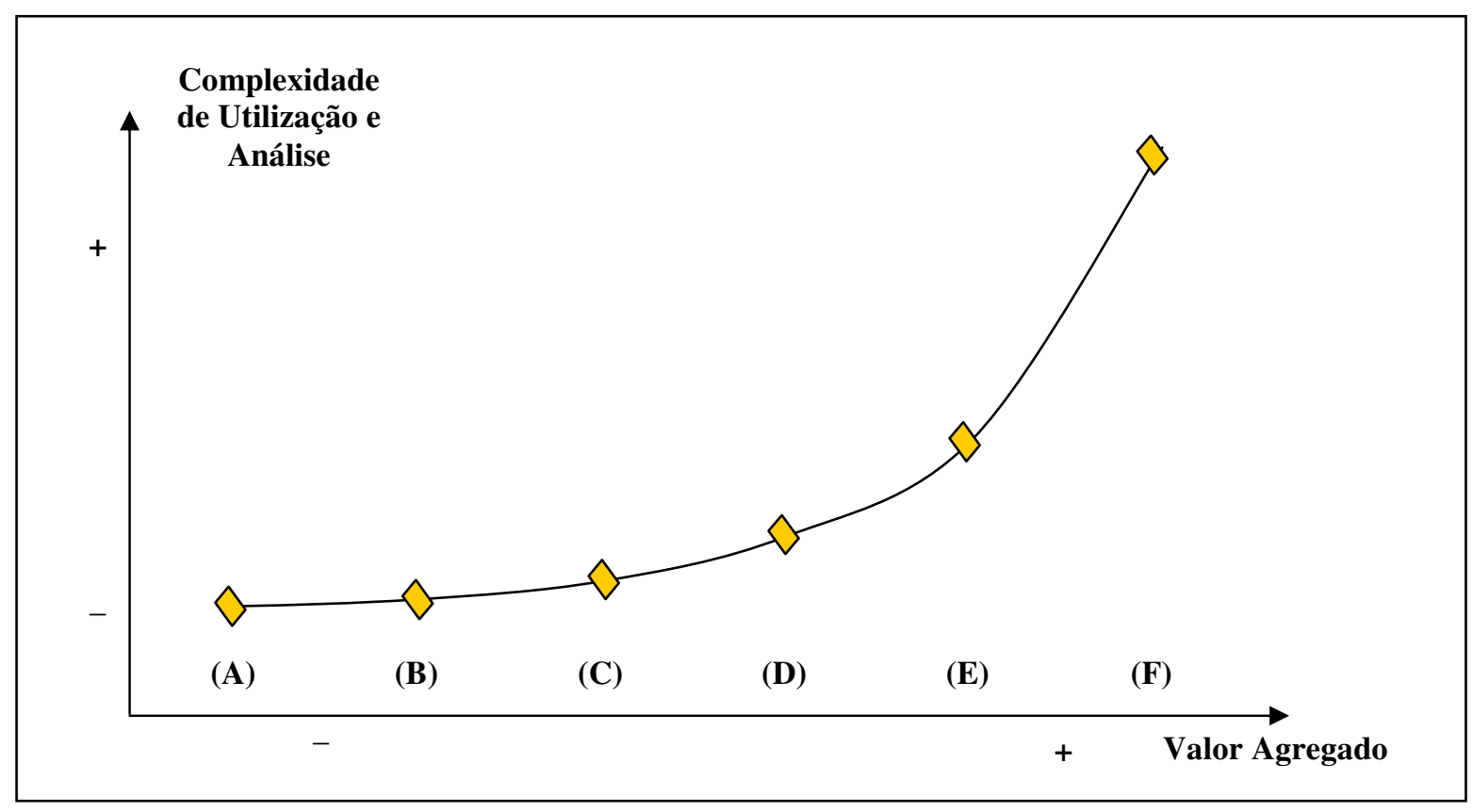

Figura 5. Complexidade vs Valor Agregado das Funcionalidades de BI 
Enquanto os painéis situam-se no canto inferior esquerdo como funcionalidades de menor complexidade e de valor agregado, pois são ferramentas analíticas muito limitadas e que tratam de informações conhecidas, a mineração está no canto superior direito como uma funcionalidade de alta complexidade, mas de mais potencial estratégico e gerador de vantagens competitivas. A relação, portanto, é direta e crescente, sendo que a inclinação da curva vai se acentuando em termos de complexidade.

\section{Competição Analítica}

As diferenças evidentes entre funcionalidades de Business Intelligence além de permitirem a categorização descrita anteriormente, também fornecem insumos para um debate em relação ao foco principal destas ferramentas, a dualidade apresentação/análise. Esta distinção trata, portanto, do nível de participação das pessoas e da interatividade delas com os dados e ferramentas e tem dois conjuntos básicos: o primeiro é o BI Passivo (ou Reativo), concentrado principalmente na apresentação, tendo interações e análises bastante limitadas e o segundo é o BI Ativo, concentrado fundamentalmente na análise, onde reflexão, interpretação, intuição, experiência e conhecimento do usuário são requisitos fundamentais e compõem a habilidade analítica da organização.

O BI Reativo está baseado sobre ferramentas como os painéis e os relatórios pré-formatados ou adhoc e preocupa-se com as perguntas mais básicas de uma análise, isto é, deseja saber o "quanto" detalhado pelo "quando", "quem", “onde" e "o quê", de forma muito similar ao objetivo dos Sistemas de Informação Gerenciais (SIG). Ele é então mais disseminado, tem maior amplitude de usuário e se converte em ação com mais freqüência e facilidade; além disso, refere-se aos estágios iniciais de maturidade analítica, onde a organização obtém aos poucos maior consciência das suas necessidades de informação, para em seguida aumentar paulatinamente o entendimento e, no limite, gerar conhecimento.

O BI Ativo, por outro lado, está baseado sobre a tecnologia OLAP e sobre os modelos matemáticos até a mineração; concentra-se em perguntas mais elaboradas como "por quê", “como" e "e se...?", de forma análoga a muitos Sistemas de Apoio à Decisão (SAD). Apesar do volume de ações práticas ser limitado (assim como sua amplitude), as decisões costumam ser transcendentais, pois além do conhecimento, o BI Ativo, através do insight humano e das 
ferramentas tecnológicas, cria inteligência e gera novas descobertas. Mesmo com sua alta complexidade, riscos maiores e retornos nem sempre garantidos, este tipo de BI é uma forma de estabelecer diferenciais estratégicos da organização em relação aos seus concorrentes.

Como sugere Eckerson (2005, p.11), o BI Ativo é o enfoque analítico e a verdadeira essência da inteligência de negócios, mas só pode ser atingido após certa evolução e maturidade. A figura 6 a seguir resume esta dicotomia.

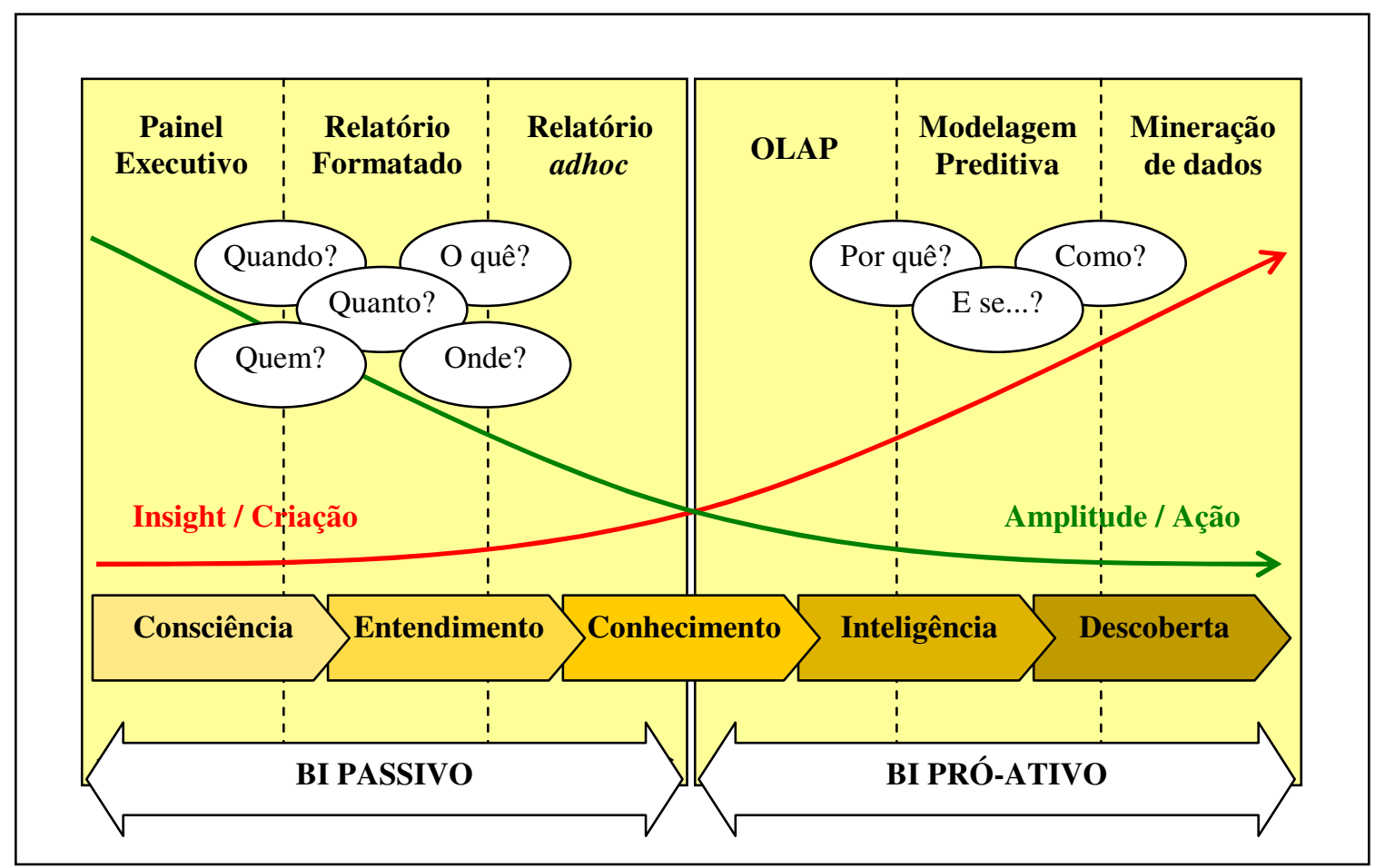

Figura 6. BI Passivo vs BI Ativo

Fonte: Baseado em Eckerson (2005, p.11)

Em relação a esta "filosofia analítica" e a segregação entre BI Reativo e Ativo, Thomas Davenport é provavelmente um dos autores mais influentes que já escreveu sobre o tema. Em 2006 publicou um interessante manuscrito com grande repercussão na comunidade acadêmica e profissional norte-americana tratando do tema. Em parte por este motivo, o artigo intitulado Competing On Analytics (traduzido em português para Competição Analítica) foi republicado pela Harvard Business Review numa edição especial do periódico com outros nove trabalhos considerados leituras essenciais e obrigatórias pelo corpo editorial da revista, títulos de autores renomados como Peter Drucker, Robert Kaplan, Michael Porter, Coimbatore Prahalad, Gary Hamel, dentre outros. 
Neste artigo, Davenport (2006, p.1) explica que no momento atual onde “(...) companhias de muitas indústrias oferecem produtos similares e utilizam tecnologias comparáveis, processos estão entre os últimos pontos de diferenciação remanescentes" e destaca, neste sentido, a importância das capacidades analíticas na tomada de decisão para a diferenciação e a criação de vantagens competitivas. Para Davenport et al (2005, p.1), as capacidades analíticas referem-se justamente à aplicação intensiva de modelos quantitativos e estatísticos sobre os dados com a finalidade de analisar problemas de negócio e encontrar conhecimento que auxilie a tomar decisões melhores, mais rápidas, de modo constante e eficiente.

Organizações que usufruem dos benefícios da filosofia (e sem dúvida da ação) analítica estão em indústrias variadas e em busca de diferentes conhecimentos. Davenport (2006, p.5) cita exemplos como Amazon, Harrah's, Capital One, Boston Red Sox, Marriott, UPS e Procter \& Gamble como competidores analíticos, organizações que buscam, por exemplo, aprimorar cadeias de suprimento, reduzir inventários, evitar perdas, identificar preços ótimos, detectar problemas de qualidade, etc. Num exemplo detalhado, Loveman (2003, p.113) destaca a utilização das capacidades analíticas pela Harrah's Entertainment na busca de um melhor entendimento de seus clientes e, como direta consequiência, na definição de uma estratégia de satisfação e de fidelização.

Apesar de muitas organizações terem embarcado nesta filosofia analítica, poucas atingiram o nível avançado e a maturidade suficiente (DAVENPORT, 2006, p.2), principalmente no Brasil, onde as capacidades analíticas ainda são insipientes. Almejar a excelência analítica exige uma mudança significativa da organização, uma transformação que requer alguns prérequisitos importantes como ambiente tecnológico sustentável (pois, segundo o autor, competir analiticamente ainda significa competir em tecnologia), acúmulo maciço de dados confiáveis e de qualidade, estratégias globais para administração dos dados, experiência e conhecimento quantitativo dos recursos, comprometimento explícito e inabalável da liderança, estimulo da demanda pelos produtos analíticos, mudanças de mentalidade e de cultura (como as pessoas pensam, trabalham e são tratadas) (DAVENPORT, 2006, p.2; DAVENPORT et al, 2005, p.7-9). 


\subsection{Perspectiva Humana}

Genericamente os Sistemas de Informação estão fundamentados em quatro pilares básicos: informações, indivíduos, procedimentos e tecnologia (TURBAN et al, 2005, p.41-42). Até este ponto da dissertação foram abordados aspectos do BI relacionados com o último destes pilares, em especial para suas definições, componentes e funcionalidades mais comuns.

Apesar de informações e procedimentos serem aspectos igualmente importantes para qualquer aplicação de Business Intelligence, o objetivo desta perspectiva é abordar o pilar humano das soluções analíticas ou de inteligência, ponto fundamental para Howson (2008, p.1), uma vez que sem pessoas para interpretar a informação e agir sobre ela, as aplicações de BI são incapazes de atingir qualquer resultado. "Por esta razão (...)”, destaca a autora, “(...) Business Intelligence é muito mais sobre cultura, criatividade e (...) informação como recursos críticos [do que tecnologia]" (HOWSON, 2008, p.1).

Inicialmente são apresentadas as principais preocupações em relação ao tema humano dentro do BI, sendo abordados pelo menos cinco aspectos: a associação entre usuários e informações e entre usuários e ferramentas, a importância da capacitação, a discussão da facilidade de uso e, por último, o fomento da filosofia e cultura analítica. Em seguida são avaliadas as definições e características das principais classificações de usuários de Business Intelligence encontradas na literatura de referência, esclarecendo o significado de usuário analítico descrito ao longo desta perspectiva. Por fim, é destacado o tópico dos estilos cognitivos, sua definição e a derivação para os tipos psicológicos de Jung com o objetivo de permitir a associação com as ferramentas analíticas propostas na parte anterior do marco teórico.

\subsubsection{Principais Preocupações}

É surpreendente observar que até certo ponto os problemas tratados neste tópico são antigos. Em suas discussões iniciais sobre Sistemas de Apoio à Decisão, por exemplo, Keen e Scott Morton (1978, p.6) alertam para seu foco em “(...) engrenar o poder analítico e as capacidades de processamento dos computadores com as necessidades e os processos de resolução de problemas dos gerentes." Na obra do final da década de 1970, os autores destacam que os temas técnicos (ou tecnológicos) estavam, sob seu ponto-de-vista, em um segundo plano, 
sendo o objetivo primordial de seus esforços aprimorar a eficácia dos gerentes, dada a frustração destes com as soluções tecnológicas em geral.

Este lado humano é particularmente relevante na atualidade porque a tendência que se espera para os próximos anos (e que tem se observado nos últimos anos) é a de crescimento do número de usuários do BI dentro das organizações (NEMATI et al, 2010, p.17). Ao mesmo tempo e ao contrário de outros sistemas de informação, principalmente os de Gestão Integrada (ERPs), o BI tem uma abordagem menos técnica, direta, planejada e racional, tem uma personalidade exploratória (em algumas ferramentas) e seus resultados são difíceis de identificar e quantificar, o que aumenta a influência dos fatores humanos. Além disso, as aplicações de Business Intelligence são menos sujeitas a pressões de coerção para sua adoção e, portanto, não raro enfrentam mais complicações na sua institucionalização nas organizações, pois é mais difícil convencer, motivar e incentivar a adoção deste tipo de instrumento, o que resulta invariavelmente num panorama desafiador para as organizações.

Diversos autores abordam temas relacionados com indivíduos dentro da literatura que trata de Sistemas de Informação, sejam SIG, SAD ou SIE. Também são contemplados na literatura de Business Intelligence e assuntos relacionados como Data Warehouse e Mineração de Dados, mas geralmente a discussão é superficial, talvez por ser um tema complexo ou abstrato. Consequiência ou causa, este ponto não raro também parece ser menosprezado ou até ignorado pelas organizações e pelos seus responsáveis.

A seguir são abordadas algumas das principais preocupações levantadas na bibliografia.

A. Informações e Usuários: Já em sua fase embrionária em meados dos anos 1950, uma das principais preocupações do Business Intelligence era fornecer dados adequados para os usuários apropriados. Para Luhn (1958, p.315), um dos problemas fundamentais que um sistema de BI deve solucionar é o da comunicação, isto é, compreender e associar cada tipo de informação a seu público adequado, pois segundo o autor a disseminação genérica de dados sobrecarrega as pessoas com informações (muitas vezes desnecessárias) e prejudica o entendimento do que é realmente essencial.

Assim, o BI deve “(...) prover meios de disseminação seletiva para cada um dos pontos de ação" e, além disso, deve permitir a distribuição de informações particulares baseada 
numa relação com os requerimentos, desejos e interesses dos usuários e com as atividades que estes executam dentro da organização (LUHN, 1958, p.315). O não atendimento destes aspectos, segundo o autor, significa pessoas tomando decisões impróprias e ações equivocadas ou duplicadas.

Associar a informação certa para as pessoas adequadas talvez seja uma das principais preocupações do BI, assim como para a maioria dos demais sistemas de informação. De qualquer forma, é um assunto bastante genérico, pois inclui uma série de discussões que por si só são temas de grande debate. A informação adequada, por exemplo, é uma questão subjetiva e que depende de vários aspectos como a relevância (apresentação no tempo apropriado, conforme o contexto e a circunstância enfrentada), entendimento (deve ser compreensível e clara), valor agregado (deve conter interpretações que permitam tomar decisões e melhores ações) e qualidade (deve ser correta, coerente e confiável) conforme sugerem Scheps (2008, p.11) e Brunson (2005, p.1).

B. Ferramentas e Usuários: Keyes (2006, p.100) oferece outra preocupação extremamente pertinente que é combinar adequadamente as diversas ferramentas que o BI oferece com os usuários finais certos, algo que conforme comprovado por D'Addario (2002 apud NEMATI et al, 2010, p.17) é uma das razões comuns para o insucesso de projetos de implantação de Business Intelligence, opinião similar a de Keen e Scott Morton (1978, p.73) que alertam que as incompatibilidades entre usuários e sistemas resultam invariavelmente em fracassos.

Como abordado, o BI fornece funcionalidades que variam em complexidade desde simples painéis de informações à utilização de métodos quantitativos e seu expoente máximo, a mineração de dados. Segundo Nemati et al (2010, p.17), uma das tarefas mais desafiadoras para os desenvolvedores é justamente a de identificar usuários de acordo com suas capacidades e necessidades provendo a melhor ferramenta, isto é, a que fornece a cada grupo os melhores meios de desempenhar seu trabalho de forma eficiente e eficaz. Eckerson (2009, p.4) corrobora estas afirmações, assegurando que um erro clássico na compra e implantação de aplicações de BI é que as “(...) ferramentas são muito complexas para usuários casuais, mas pouco sofisticadas para usuários avançados”. 
Disponibilizar ferramentas avançadas de criação de relatórios ad hoc, assim como de análise de dados utilizando funções OLAP nas mãos de usuários capacitados permite que eles possam extrair muito mais dos dados, fazendo perguntas mais pertinentes e encontrando respostas mais relevantes. Contudo, uma ferramenta não se ajusta a todos. Cada funcionalidade tem suas particularidades, vantagens e desvantagens e nenhuma delas responde a todas as demandas e habilidades dos usuários. Para Silvers (2008, p.209), é justamente a estratégia de combinação e distribuição dos componentes do BI e a correspondência com o público-alvo adequado que determina o sucesso de uma solução de BI, ou seja, um dos principais objetivos desta pesquisa.

C. Capacitação: Brunson (2005, p.1) alerta que nem a melhor das soluções tecnológicas é eficientemente aproveitada se seus usuários não são educados de forma adequada na sua utilização e entendimento, se não tem o conhecimento mínimo do trinômio ferramenta, dado e negócio. E Eckerson (2009, p.4) complementa a questão afirmando que encontrar recursos com o conhecimento no trinômio descrito é um verdadeiro desafio para as organizações, pois a "alfabetização analítica" em grande parte das organizações é falha e os poucos recursos capacitados são escassos e/ou extremamente valorizados.

Scheps (2008, p.22) destaca que o BI também é uma forma de dar as pessoas da organização não só novas ferramentas, mas novas perspectivas para as decisões e ações do cotidiano. Porém, esta nova filosofia só funciona com sucesso quando os tomadores de decisão são capazes não só de utilizar essas funcionalidades, mas quando estão preparados e têm a experiência suficiente para fazer as perguntas certas e entender as respostas (SCHEPS, 2008, p.22). Assim não basta apenas promover o treinamento básico dos usuários na ferramenta, é preciso orientá-los satisfatoriamente em como analisar as informações de modo que possam ser contextualizadas e produzam o resultado analítico esperado, evitando a desilusão e a frustração (BRUNSON, 2005, p.1).

Além disso, também é fundamental capacitar os usuários em matemática e métodos quantitativos como defende Davenport (2006, p.7), difundindo o respeito corporativo pela medição, teste e avaliação de evidências, incentivando a tomada de decisão com base em fatos, aspectos fundamentais de um competidor analítico de ponta segundo o autor. $\mathrm{Na}$ verdade, para Davenport, os colaboradores analíticos são profissionais especiais e raros que contam com aptidões quantitativas, habilidades de resolução de problemas, histórico 
em áreas funcionais, facilidade em expressar problemas complexos em termos simples, além de competências de comunicação para relacionamento e interação com os tomadores de decisão e postura crítica e ativa (DAVENPORT, 2006, p.7).

D. Facilidade de uso: Profundamente relacionada com a questão da capacitação está a facilidade de uso das inúmeras opções que o BI oferece, talvez uma forma de contornar as dificuldades envolvidas em treinamento e aprimoramento de pessoas. Segundo o Gartner Group (2011, p.7), usuários de negócio de Business Intelligence têm demandado cada vez mais experiências de uso similares as de outras tecnologias pessoais que tiveram grande difusão nos últimos anos como iPhone, iPad, Google e Facebook, direcionando as ferramentas de BI para aplicações que devem ser simples, móveis, intuitivas e inclusive "divertidas" tendo em vista a expansão do uso e valor das aplicações de Business Intelligence.

Esta preocupação não é nova, mas vem ganhando força mais recentemente. De acordo com relatório atual do Gartner Group, tem-se acentuado nas organizações a disputa interna entre as demandas por facilidade e flexibilidade dos usuários de negócio e os padrões e controles dos responsáveis de TI (GARTNER GROUP, 2011, p.3). Em 2010, a pesquisa realizada pela entidade apontou pela primeira vez que o critério de compra "facilidade de uso" superou o critério "funcionalidade" (GARTNER GROUP, 2011, p.3), evidenciando que as organizações identificam maior utilidade em poucas ferramentas que possam trazer resultados práticos com mais facilidade, do que muitas ferramentas (algumas delas mais complexas) que não se traduzem facilmente produtos relevantes.

A facilidade de uso é uma preocupação relevante atualmente porque pode reorientar profundamente o mercado de fornecedores de aplicações de BI. Apesar de ainda manter a participação de mercado elevada, os grandes players têm dificuldades para responder às demandas e desafios dos usuários de negócio e, além disso, seu tempo de resposta é lento, o que tem provocado uma insatisfação crônica dos clientes com os principais fornecedores de BI (GARTNER GROUP, 2011, p.4). Isto tem aberto espaço para fornecedores de nicho, que têm apresentado soluções inovadoras de descoberta e análise, interativas e com interfaces gráficas aprimoradas (GARTNER GROUP, 2011, p.4). 
E. Cultura Analítica: Brunson (2005, p.1) acredita que uma parte do sucesso do BI não está associada somente a capacitação dos recursos e as correspondências adequadas com os usuários, mas também a aptidão e disposição da organização (representada por seus recursos humanos) em convencer a si própria da confiabilidade e da relevância do BI. O autor critica assim a visão prepotente de muitas empresas que consideram que, uma vez construído o sistema, os usuários automaticamente e pró ativamente o adotam. Davenport (2006, p.2) também aborda esta questão da cultura organizacional e alerta que é preciso vontade de mudar a forma como as pessoas pensam, trabalham e são tratadas, implantando uma nova filosofia de trabalho.

Para Howson (2008, p.183), uma companhia pode ter uma arquitetura de BI perfeita, mas se não tiver uma cultura que a apóie e a fomente, os resultados são limitados, locais e têm um impacto reduzido. De acordo com a autora, a cultura é uma força intangível, mas que afeta profundamente a forma como as pessoas vêem e valorizam o Business Intelligence (HOWSON, 2008, p.183).

A preocupação da cultura é por si só difícil de balancear. De qualquer forma, o desenvolvimento e o uso de tecnologias são intimamente conectados com o lado social da organização, são emergentes, incrementais e melhor caracterizados pela improvisação do que pelo planejamento e não seguem apenas normas racionais e técnicas, o que reforça a importância da administração da mudança e o respeito pelas particularidades do contexto organizacional (AVGEROU, 2001, p.48).

\subsubsection{Classificação de Usuários de BI}

Nemati et al (2010, p.18) defendem que através do conhecimento dos tipos de usuário é possível mitigar algumas das preocupações supramencionadas, principalmente aquelas que tratam da combinação de informações e funcionalidades com os usuários adequados. Assim, entender os diferentes públicos alvo, os papéis que desempenham, as informações que demandam e as maneiras como consomem e analisam (ECKERSON, 2009, p.4) permite que as estratégias e decisões em relação ao Business Intelligence sejam aprimoradas dentro das organizações, garantindo resultados mais positivos, com menos frustração e insatisfação tanto pelo lado de TI, quanto pelo lado do negócio. Ou como explica Ponniah (2001, p.323), "para 
fazer com que o mecanismo de apresentação de informação seja o mais adequado para o seu ambiente, é preciso ter um entendimento profundo das classes de usuários".

Neste sentido, alguns autores procuraram definir categorizações de pessoas de acordo com o papel que desempenham, com suas necessidades (demandas, requerimentos, interesses) e/ou com suas habilidades (principalmente técnicas) na esperança de amadurecer o assunto. A seguir são detalhadas duas das classificações encontradas na literatura de apoio.

\section{Classificação de Ponniah}

Uma das primeiras classificações de usuários finais (portanto, excluindo os desenvolvedores propriamente ditos) encontradas na literatura de apoio é aquela oferecida por Ponniah (2001, p.325). Mais do que uma simples classificação, o autor proporciona um modelo de identificação de usuários que procura consolidar pelo menos três aspectos de diferenciação (conhecimento técnico, necessidade da informação e papel desempenhado), servindo como uma alternativa que, apesar de genérica, é simples e aceita nas organizações.

O primeiro aspecto considerado por Ponniah (2001, p.324-325) é o conhecimento técnico do usuário, ou seja, a forma como ele interage com a informação e a ferramenta (o "como"). Neste sentido são oferecidos três tipos de usuários: casual (ou novato), que utiliza esporadicamente o BI e necessita de interfaces intuitivas, regular, que utiliza regularmente, tem intimidade com computação e precisa de recursos mais intermediários do BI, ou avançado, que é proficiente na tecnologia empregada, pode executar, construir e utilizar as ferramentas mais complexas. O segundo aspecto é o da necessidade do usuário, isto é, o que ele deseja fazer com a informação (o "o que" e "por quê") e neste caso o autor não oferece uma diferenciação de usuários, mas descreve as próprias funcionalidades do BI, o que pode ser um ponto fraco na divisão sugerida. Finalmente, o terceiro e último aspecto é o do papel de cada usuário (o "quem"). Neste sentido o autor entende que existem quatro tipos de usuários: executivos e gerentes, que trabalham com informação consolidada e personalizada com objetivo de tomada de decisão; analistas técnicos, que exercem atividades analíticas complexas com forte viés técnico; analistas de negócio, que trabalham informações disponíveis através de ferramentas de complexidade intermediária; ou usuários orientados a negócios, público variado e ponta final no fluxo da informação. 
Com base nestes aspectos e utilizando analogias, Ponniah (2001, p. 325) oferece então os seguintes tipos de usuários: (1) turistas (tourists): são aqueles usuários cujo comportamento é acanhado, o acesso é esporádico e está concentrado em determinados tópicos, (2) operários (operators): são a base da organização e necessitam de informações específicas para realizarem suas atividades burocráticas rotineiras, (3) fazendeiros (farmers): são os usuários analíticos que conhecem o terreno do negócio e sabem exatamente o que necessitam colher, (4) aventureiros (explorers): assim como os fazendeiros, também são analistas, mas com procedimentos pouco claros e que estão preocupados em responder questões pontuais, oportunidades ou ameaças do negócio e (5) garimpeiros (miners): são aqueles usuários que buscam novas informações e conhecimentos que não estão explicitamente disponíveis e que necessitam de uma investigação aprofundada.

Com base nas características descritas por Ponniah (2001, p. 326-329), complementadas pelas observações de Imhoff e Pettit (2004, p.2) e Assis (2010, p.47-49), é possível detalhar um pouco mais as características de cada grupo.

A. Turistas: Conhecimento técnico: nenhum. Características e Necessidades: acesso e visualização de dados de forma aleatória, requisitos pouco claros ou imprecisos, uso esporádico, mas consolidado, verificação de indicadores em intervalos rotineiros, identificação de pontos de interesse sem dificuldades, seleção das necessidades com facilidade e alto desempenho, obtenção de informações adicionais para maior detalhamento; navegação intuitiva com customizações para cada indivíduo. Exemplos: executivos e gerentes, tomadores de decisão em geral.

B. Operários: Conhecimento técnico: limitado. Características e Necessidades: preocupação com dados atuais; uso regular e com maior nível de detalhe; respostas imediatas e confiáveis; análise rápida dos dados mais convencionais; interfaces e relatórios claros e simples. Exemplos: equipe administrativa/suporte da organização (com forte orientação operacional).

C. Fazendeiros: Conhecimento técnico: intermediário. Características e Necessidades: acesso regular e previsível aos dados e modelos/relatórios; requisitos conhecidos e claramente identificados; dados com qualidade e integrados; facilidade para executar relatórios 
convencionais e pré-formatados; capacidade de visualizar tipos de resultado padrão; tempo de resposta mais maleável; resultados pequenos, mas precisos; dados correntes e dados históricos para comparações; possibilidade de criação de relatórios. Exemplos: analistas de negócio concentrados em atividades rotineiras.

D. Aventureiros: Conhecimento técnico: avançado. Características e Necessidades: solicitações mais imprevisíveis e uso de relatórios para questões pontuais; capacidade para desenvolver análises complexas; facilidade para recuperar grandes volumes de dados; tempo de resposta maleável, utilização de diferentes ferramentas de análise. Exemplos: analistas de negócio com necessidades mais complexas.

E. Garimpeiros: Conhecimento técnico: expert, inclusive em matemática e estatística. Características e Necessidades: acesso irregular e imprevisível aos dados e modelos; requerimentos e necessidades desconhecidas ou indefinidas; muitos fracassos e poucos sucessos; possibilidade de diferentes formas de análises matemáticas; capacidade de interpretação de resultados das análises; disponibilidade de grandes volumes de dados (principalmente históricos); habilidade para trabalhar em pesquisa exploratória e confirmatória; disponibilidade de dados no formato necessário para mineração. Exemplos: analistas de negócio focados na descoberta de novos conhecimentos.

Sobre esta classificação e baseados em parte dos aspectos abordados, Imhoff e Pettit (2004, p.10) oferecem uma representação gráfica ilustrada pela figura 7 da página a seguir que procura resumir a discussão, demonstrando a relação entre a complexidade analítica e o volume de dados, assim como as áreas de atuação de cada um dos grupos avaliados. De certa forma esta ilustração complementa a relação entre valor agregado e funcionalidades de BI sugerida anteriormente na figura 5, pois, juntamente com as observações dos autores, permite estabelecer uma relação entre estes grupos de usuários e cada uma das ferramentas.

Dessa forma, turistas seriam os usuários típicos de painéis; operários, os usuários habituados com relatórios pré-formatados; fazendeiros, mais acostumados com relatórios ad hoc; aventureiros, usuários dos relatórios OLAP; e, finalmente, garimpeiros seriam experts dos métodos preditivos e mineração. Esta correspondência não é definida, pois existem diversas exceções, mas é uma combinação aceitável das duas proposições. 


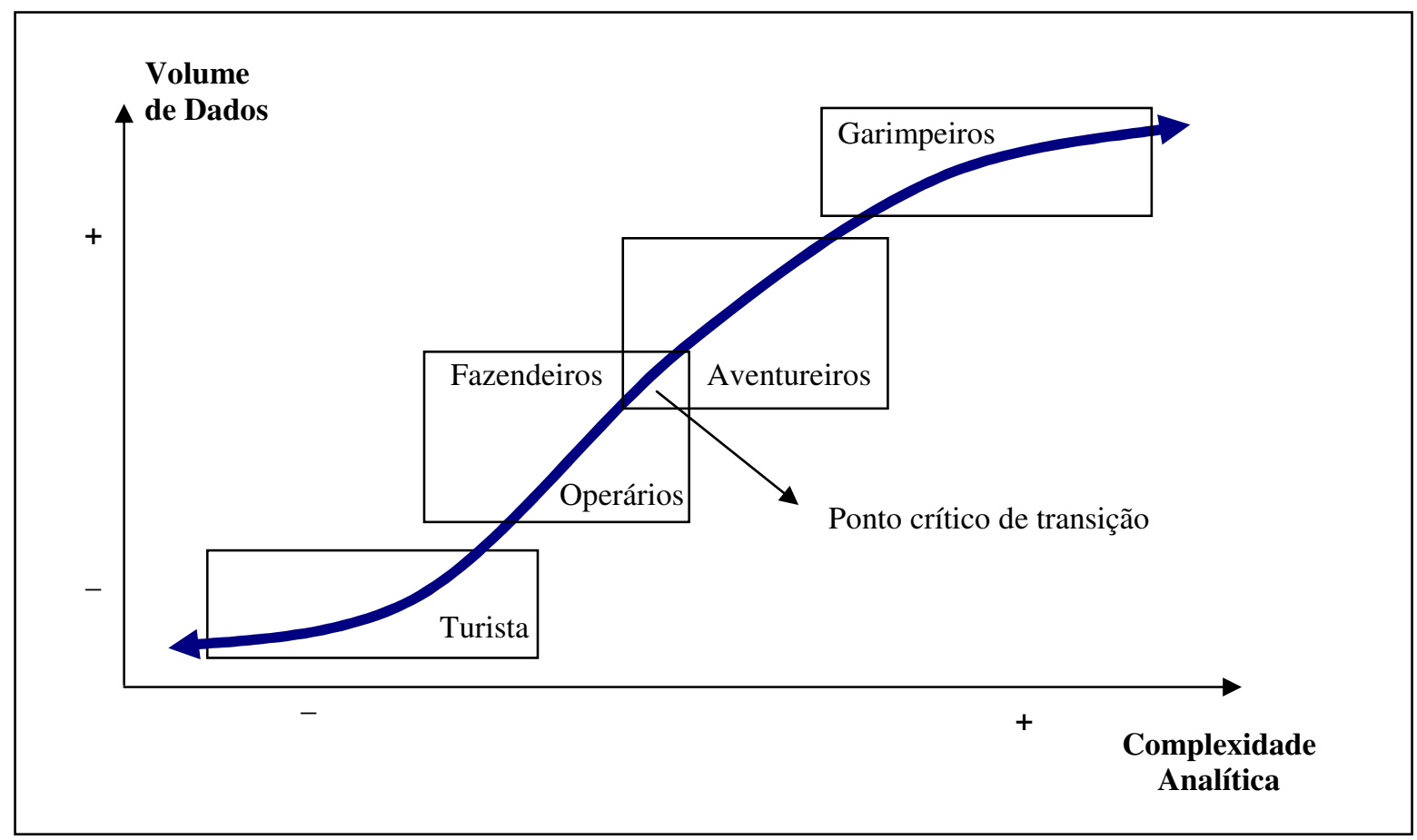

Figura 7. Curva de Usuários do BI

Fonte: Adaptado de Imhoff e Pettit (2004, p.10)

\section{Classificação de Eckerson e Nemati et al}

Apesar de uma abordagem similar, Eckerson (2009, p.5) também colabora com a questão, pois concentra e aprofunda seus esforços principalmente no papel desempenhado pelos diferentes usuários finais. Para o autor, em primeiro lugar existe uma separação fundamental entre dois grandes grupos considerando o conhecimento técnico e as responsabilidades dentro do fluxo de informação. Assim, existem (1) os produtores de informação ou usuários avançados (cerca de $20 \%$ da população da organização), responsáveis pela criação de relatórios e pelas análises mais complexas e (2) os consumidores de informação ou usuários casuais (os $80 \%$ restantes da população), responsáveis por utilizar os relatórios criados e pelas análises mais simples.

Para Nemati et al (2010, p.19) os produtores de informação têm amplo conhecimento técnico, seus requisitos são mais dinâmicos, complexos e flexíveis e, portanto, são mais exigentes sob o ponto-de-vista da análise. De acordo com o papel que desempenham, Eckerson (2009, p.11) destaca quatro tipos de produtores: (1) analistas de negócio (business analysts): são usuários de negócio experientes que utilizam dados para identificar tendências, solucionar problemas e 
elaborar planos, (2) super usuários (super users): são usuários com conhecimento técnico suficiente para construir relatórios esporádicos necessários para sua área, (3) modeladores analíticos (analytical modelers): são usuários que criam modelos matemáticos e utilizam a mineração de dados para previsão ou para encontrar novos conhecimentos e (4) desenvolvedores de TI (IT report developers): são usuários que constroem as ferramentas mais complexas e treinam os demais usuários avançados.

Nemati et al (2010, p.18), por outro lado, têm uma visão mais simples, pois observam apenas dois grupos de produtores de informação: (1) analistas de negócio (business analysts), responsáveis pelos domínios de informação e criação dos relatórios e consultas esporádicas demandadas pelas áreas de negócio (portanto, englobam não só a categoria de analistas de negócios definida por Eckerson, mas também a dos super usuários) e (2) desenvolvedores de TI (data warehouse IT team), responsáveis pela extração, transformação, integração e disponibilização dos dados e pela criação da camada semântica e a parte mais complexa de acesso à informação (a mesma categoria sugerida por Eckerson). O trabalho de Nemati et al, portanto, ignora a evolução dos modelos preditivos e da mineração de dados e não oferece um terceiro conjunto de produtores de informação similar a categoria de modeladores analíticos de Eckerson, usuários que seriam responsáveis ao lado dos analistas de negócio pela exploração dos dados através de modelos quantitativos e aplicação de técnicas de mineração.

Em ambas as visões (de Eckerson e Nemati et al), chama a atenção o fato dos autores incluírem os desenvolvedores de TI como uma categoria específica de usuários avançados. É conhecido que grande parte das ferramentas de BI necessita de uma equipe técnica para o levantamento de requisitos, desenho, construção e implantação da solução, mas normalmente estes desenvolvedores não são tratados como usuários finais, mesmo porque muitos deles sequer são recursos fixos contratados diretamente pela organização. De qualquer forma, os autores consideram que eventualmente estes desenvolvedores participam ou colaboram no fluxo da informação, fornecendo aquilo que os demais grupos não têm, ou seja, o amplo conhecimento técnico nas funcionalidades.

Em relação aos consumidores de informação (ou usuários casuais), Nemati et al (2010, p.18) destacam que estes usuários têm pouco conhecimento técnico e normalmente não têm a necessidade de utilizar funcionalidades mais complexas, preferindo ferramentas fáceis de usar e com interfaces gráficas agradáveis e interatividade apuradas. Apesar de Eckerson não 
oferecer uma segregação deste tipo de usuário, com base nos diferentes papéis desempenhados, Nemati et al (2010, p.18) sugerem então três grupos de usuários básicos para consumidores de informação: (1) Usuários Administrativos, utilizam os relatórios préformatados e normalmente agregados para executar suas atividades cotidianas, sem envolvimento ou análises profundas; (2) Tomadores de Decisão, demandam informações com relevância e praticidade, mas também exigem análise e predição para definir cursos, estratégias e ações; e (3) Entidades Externas, necessitam de relatórios normalmente padronizados para fins regulatórios ou fiscais.

Além de promover a discussão da classificação, Eckerson também oferece uma visão particular para o tema da correspondência entre usuários e ferramentas, ilustrada na figura 8 a seguir. Para o autor, "a classificação de usuários define tipos de usuários de acordo com necessidades de informação e mapeia-os nas [diferentes] tecnologias de BI" (ECKERSON, 2009, p.4). Curiosamente, as ferramentas variadas destacadas por Eckerson são muito similares as descritas anteriormente, mas sua classificação em relação à complexidade é ligeiramente diferente (os painéis de informação estão, por exemplo, num nível intermediário) e um pouco confusa.

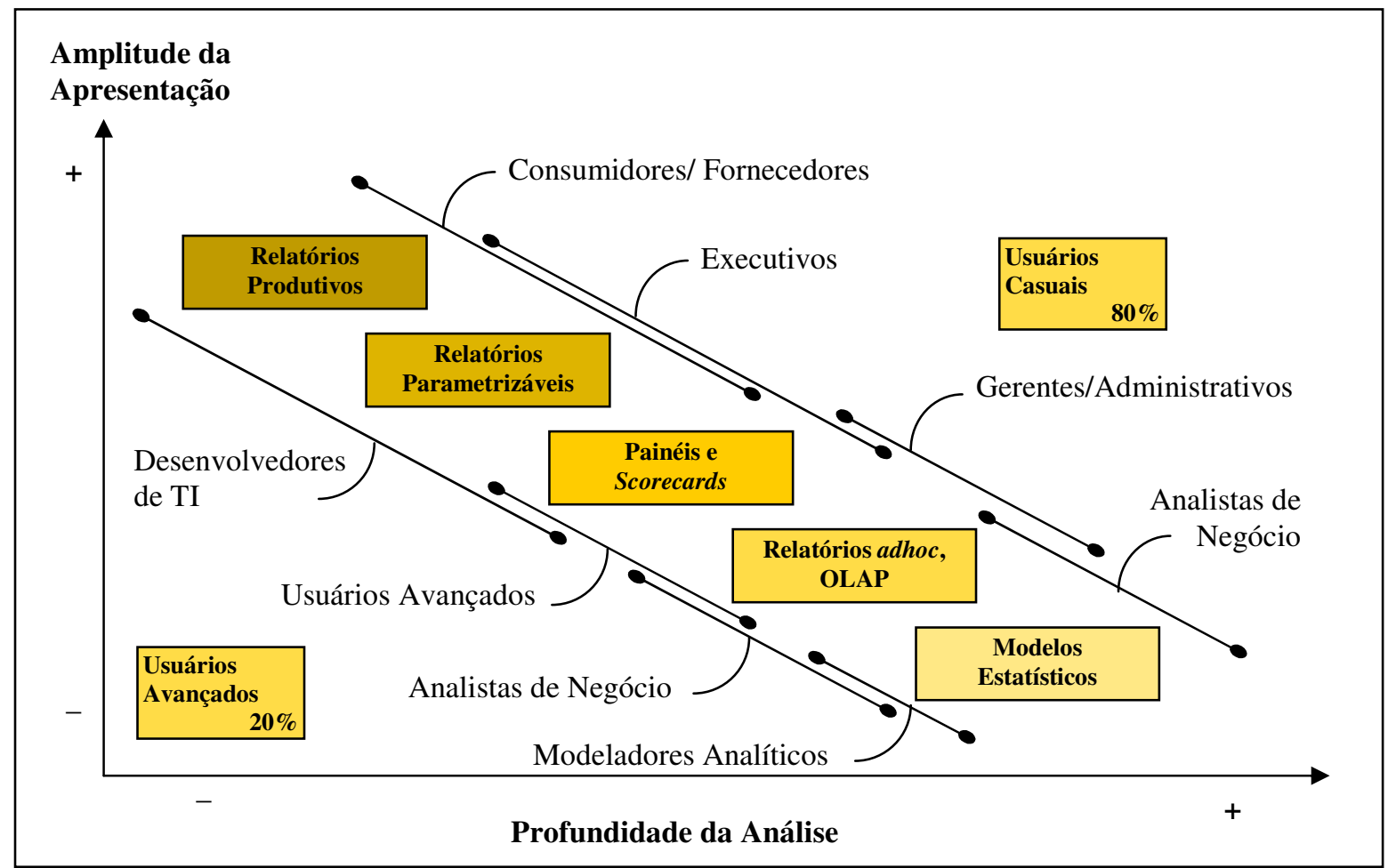

Figura 8. Mapeamento de Tipos de Usuários e Tipos de Ferramentas de BI

Fonte: Adaptado de Eckerson (2009, p.4) 


\subsubsection{Estilos Cognitivos}

O raciocínio de Nemati et al (2010, p.18) de que o conhecimento dos tipos de usuário é uma condição fundamental para o sucesso de uma aplicação de Business Intelligence é corroborado por outros autores na literatura do tema de Sistemas de Informação, como é o caso de Ford (2000 apud ESTIVALETE et al, 2009, p.1), que alerta que este tipo de preocupação pode contribuir para o desenvolvimento de sistemas mais adaptados aos usuários, gerando maior satisfação dos indivíduos e melhores resultados para as organizações.

As divisões de usuários anteriormente abordadas de acordo com as demandas, requerimentos, interesses e habilidades técnicas sugeridas por Nemati et al também estão bastante amadurecidas e consolidadas na literatura e são comumente utilizadas nas organizações. Contudo, elas parecem omitir pelo menos uma variável importante da equação, uma das características mais importantes dos indivíduos que fazem uso das soluções de BI (independente das funcionalidades), o chamado estilo cognitivo. Este parece ser um ponto particularmente importante, pois, como destaca Steiger (2010, p.1), as decisões são, em última análise, tomadas com base no modelo mental das pessoas e, desta forma, para aprimorar a qualidade dessas decisões através de Sistemas de Apoio à Decisão é preciso desenvolver ferramentas que levem este modelo em consideração e de maneira apropriada.

\section{Definição}

Para Felder et al (2002, p.3), cada indivíduo tem sua forma particular de aprender e de interpretar o mundo, os dados e as informações que o cercam, formas que refletem forças, fraquezas, habilidades e interesses específicos. Avaliando particularmente um curso de graduação de Engenharia, por exemplo, os autores verificam que devido a estas diferenças pessoais, nem todos reagem igualmente às abordagens de ensinamento utilizadas e algumas pessoas têm maiores chances de sucesso em determinadas disciplinas do que outras. A visão dos autores em relação às diferenças pessoais é derivada da psicologia e está fundamentada nos estudos de Carl Jung sobre personalidades. 
Acerca deste assunto, Casado (1998, p.34) corrobora a explicação de Felder et al esclarecendo que “(...) diferenças entre as características das pessoas ocasionam diferenças nas suas formas de encarar o mundo e de buscar soluções para seus problemas." De fato, isso pode ser observado em muitas circunstâncias do cotidiano das pessoas, não só nas aulas de graduação de engenharia como sugerem Felder et al, mas também na tomada de decisão e na utilização de sistemas de informação, foco deste trabalho.

Como abordam Keen e Scott Morton (1978, p.73), autores da área de sistemas de informação, indivíduos têm características, estratégias e habilidades pessoais, estilos particulares que são mais efetivos em alguns contextos do que em outros, estilos que influenciam substancialmente os produtos do processo de decisão. Tendo isto em vista, os autores sugerem que "qualquer forma de auxílio analítico deve ser consistente com o estilo do usuário" (KEEN e SCOTT MORTON, 1978, p.73). Esta opinião é similar a de Venkatraman (1987, p.5), para quem “(...) o valor da informação é diferente para diferentes pessoas devido à estrutura mental de cada um" e a de Eckerson (2009, p.4), para quem a questão central do BI está em reconhecer se as ferramentas e métodos são os mais indicados para cada tipo de pessoa responsável pelas diferentes análises.

Bawden e Robinson (2009, p.184) complementam este pensamento esclarecendo que não adequar o volume e a forma de apresentação dos dados ao modelo cognitivo dos usuários e ao uso esperado podem resultar na chamada ansiedade informacional. Segundo os autores, esta é uma patologia recente que se refere à condição de stress ocasionada pela incapacidade de acessar, entender e/ou utilizar as informações necessárias, seja pelo excesso ou falta de dados, pela organização ou apresentação inadequadas ou simplesmente pela dificuldade ou inabilidade de entendimento (BAWDEN e ROBINSON, 2009, p.185).

Outros autores como Agarwal e Karahanna (2000), Ford (2000), Amiel e Sargent (2004), Taylor (2004), Chen, Ghinea e Macredie (2006) e Chakraborty, Hu e Cui (2008), conforme destacam Estivalete et al (2009, p.1), também discorrem sobre os estilos cognitivos e seu relacionamento com os sistemas de informação, demonstrando a relevância do tema dentro do mundo de SI. E como se não bastassem essas opiniões, Mann et al (1991, p.142) alertam que diferentes pesquisas empíricas avaliam como pessoas com diferentes estilos cognitivos têm preferências diferentes em relação quantidade de dados, nível de consolidação, tipo de 
informação (quantitativa ou qualitativa) e forma de apresentação, tópicos genéricos que fazem parte das diferentes funcionalidades dos SIG, SAD, SIE e, conseqüentemente, do BI.

Dentro do campo de estudo da Psicologia, o termo "estilo cognitivo" foi supostamente introduzido por Allport em 1937 para descrever o modo típico ou habitual de uma pessoa resolver problemas, pensar, perceber e lembrar. Apesar de, no campo da psicologia, o termo ainda estar cercado de debate e discussão e ser considerado elusivo, pois muitos autores o entendem como um sinônimo para estilo de aprendizagem (RIDING e CHEEMA, 1991, p.194), no referencial estudado, o sentido parece ser mais uniforme.

De acordo com Kogan (1976 apud KIRTON, 1989, p.4), estilo cognitivo é a maneira pela qual os indivíduos adquirem, armazenam, recuperam e transformam a informação, opinião similar a de Hayes e Allinson (1998 apud ESTIVALETE et al, 2009, p.2) e Ford (2000 apud ESTIVALETE et al, 2009, p.1), que destacam o conceito como a forma particular de processamento da informação e resolução de problemas. Segundo Kirton (1989, p.2), o estilo cognitivo é diferente de capacidade cognitiva (normalmente associada à inteligência do indivíduo), porque depende de uma série de aspectos adicionais como fatores ambientais, tipo do problema, objetivo estratégico, clima social, habilidades pessoais, experiência, persistência dentre outros. Para o autor, portanto, não há um estilo melhor do que outro, mas um estilo mais adaptado a determinadas situações do que outras (KIRTON, 1989, p.2).

De acordo com Curry (1983 apud RIDING e CHEEMA, 1991, p.195), o estilo cognitivo (ou de aprendizagem) pode ser representado por um modelo de três camadas onde a primeira, e mais interna trata da personalidade, que controla as demais; a segunda e intermediária, trata da dimensão do processamento da informação; e, a terceira e mais externa, trata da interação das outras dimensões com o ambiente externo. Para Kirton (1989, p.1), os processos cognitivos refletem então a interação entre a natureza do ambiente físico, do panorama social e dos atributos dos indivíduos, resultando em diferentes manifestações de criatividade, formas de resolução de problemas e tomada de decisão.

$\mathrm{Na}$ literatura de Sistemas de Informação, a discussão dos estilos cognitivos e de suas influências neste campo não é recente. Já em 1978, por exemplo, Keen e Scott Morton (1978, p.50) referenciavam uma série de pesquisadores preocupados com o tema. Além disso, eles abordam a questão como parte de uma preocupação maior, a ciência comportamental dentro 
da realidade dos SAD e alertam para a grande influência que os diferentes estilos e estruturas cognitivas dos gerentes tinham sobre o desenho, a implementação e o uso de sistemas, corroborando a necessidade de uma abordagem mais próxima da teoria da decisão do que dos sistemas de informação (KEEN e SCOTT MORTON, 1978, p.6).

Nesta literatura mais direcionada a sistemas, o estilo cognitivo refere-se então à “(...) forma sistemática e persuasiva de organização de pensamentos das pessoas", a como os dados são percebidos e então são convertidos em conhecimento (MANN et al, 1991, p.141). Refere-se às diferenças individuais de personalidade, habilidades e experiência que, conseqüentemente, resultam em diferentes modos de processar e interpretar informações, de resolver problemas, de tomar decisões e de utilizar os sistemas que apóiam estas atividades (KEEN e SCOTT MORTON, 1978, p.63).

Apesar de antigo, porém, o assunto parece ter recebido pouca atenção das organizações, talvez por sua complexidade e dificuldade de análise, talvez pela viabilidade ou custo. A motivação de Venkatraman (1987, p.5), que é compartilhada por diversos autores do BI, de fornecer a informação correta para a pessoa adequada, no formato certo e no tempo correto, deveria levar em conta os estilos cognitivos, mas parece haver poucas diretrizes operacionais para o tema, os estudos são incompletos ou inconsistentes e outros fatores também têm influência na tomada de decisão (MANN et al, 1991, p.143).

\section{Tipologia de Estilos Cognitivos}

Infelizmente não parece existir na literatura uma tipologia particular para diferenciar os estilos cognitivos. Entretanto, segundo o que se pode interpretar de alguns autores avaliados, é possível derivar esta diferenciação de outros tópicos intimamente relacionados onde essas "classificações" existem e são suficientemente maduras e consolidadas.

Considerando a definição de Curry (1983 apud RIDING e CHEEMA, 1991, p.195), por exemplo, a dimensão mais interna e independente do estilo cognitivo é a personalidade do indivíduo e, dessa forma, seria possível considerar o primeiro como um desdobramento do segundo. As afirmações de Kirton $(1989$, p.4) também revelam uma relação muito próxima entre o estilo cognitivo e a personalidade, pois segundo o autor, Messick e Guilford “(...) 
assumem que estilos são baseados em preferências individuais na maneira de organizar e processar informações, são consistentes com as diferenças individuais e são congeniais com o indivíduo, pois se desenvolvem em torno dos traços da personalidade subjacentes." (KIRTON, 1989, p.4). Em outras palavras, o entendimento do estilo cognitivo depende do conhecimento da personalidade.

Parindo desta premissa, as tipologias relacionadas a tipos psicológicos e personalidades (assim como seus mecanismos de avaliação) podem ser utilizadas para definir e esclarecer o estilo cognitivo dos usuários. Na bibliografia de referência é possível encontrar pelo menos duas abordagens particularmente relevantes, cada qual com seu instrumento de pesquisa definido, aplicado e validado internacionalmente. A primeira tipologia é aquela abordada pela Teoria da Adaptação-Inovação de Kirton, baseada primeiramente em iniciativas no campo da Administração, mas posteriormente aplicada em pesquisas que envolveram sistemas de informação. A segunda é aquela definida pela Teoria dos Tipos Psicológicos de Jung, aprimorada por Myers e Briggs, mais difundida, genérica e aceita tanto na academia quanto nas organizações. Estas duas tipologias são detalhadas a seguir, apesar de a segunda ser a escolhida para a pesquisa de campo por motivos que serão expostos adiante.

De qualquer forma, é importante alertar que há críticas à utilização de tipologias deste gênero. De acordo com Kolb (1984, p.63), por exemplo, “(...) categorizações de pessoas tais como as representadas pelos tipos psicológicos podem facilmente se tornar estereótipos que tendem a banalizar a complexidade humana e assim acabam negando a individualidade humana ao invés de caracterizá-la." Além disso, o autor entende que os tipos não raro oferecem uma conotação fixa e estática para a personalidade das pessoas, dando uma visão fatalista para o desenvolvimento e mudança dos indivíduos (KOLB, 1984, p.63).

\section{Teoria da Adaptação-Inovação}

Segundo Estivalete et al (2009, p.2), “(...) após a conclusão de que as pessoas produzem soluções qualitativamente diferentes para problemas semelhantes, e que isso tem implicações críticas para o seu ajuste na organização", Kirton oferece sua visão particular do assunto propondo que diferentes indivíduos adotam estilos preferenciais de criatividade, resolução de problemas e tomada de decisão, indicando uma escala contínua com dois extremos: a 
preferência por fazer melhor (o perfil adaptador) ou por fazer diferente (o perfil inovador) (ESTIVALETE et al, 2009, p.3; KIRTON, 1989, p.7). As diferenças básicas entre estes dois grupos são resumidas no quadro 3 a seguir.

\begin{tabular}{|c|c|}
\hline Adaptadores & Inovadores \\
\hline $\begin{array}{l}\text { Caracterizados pela precisão, confiança, } \\
\text { eficiência, ordenação, prudência, disciplina e } \\
\text { conformidade. }\end{array}$ & $\begin{array}{l}\text { Vistos como indisciplinados, pensadores, } \\
\text { desconcentrados, abordando tarefas por } \\
\text { ângulos inesperados. }\end{array}$ \\
\hline $\begin{array}{l}\text { Preocupados em resolver problemas } \\
\text { secundários gerados pelos paradigmas atuais. }\end{array}$ & $\begin{array}{l}\text { Procuram por problemas e vias alternativas de } \\
\text { solução, desviando dos paradigmas atuais. }\end{array}$ \\
\hline $\begin{array}{l}\text { Procuram soluções para problemas por meio } \\
\text { de formas previamente tentadas e entendidas. }\end{array}$ & $\begin{array}{l}\text { Questionam os problemas e elaboram } \\
\text { premissas concomitantemente, manipulando } \\
\text { os problemas. }\end{array}$ \\
\hline $\begin{array}{l}\text { Reduzem problemas com melhorias e maior } \\
\text { eficiência, com o máximo de continuidade e } \\
\text { estabilidade. }\end{array}$ & $\begin{array}{l}\text { São catalisadores em grupos estabelecidos, } \\
\text { irreverentes de suas visões consensuais. } \\
\text { Vistos como abrasivos, criam dissonâncias. }\end{array}$ \\
\hline $\begin{array}{l}\text { Vistos como estáveis, conformes, seguros e } \\
\text { dependentes. }\end{array}$ & $\begin{array}{l}\text { Vistos como instáveis, teóricos, não raro } \\
\text { choca seus oponentes. }\end{array}$ \\
\hline $\begin{array}{l}\text { Suscetíveis a estabelecer objetivos conforme } \\
\text { os meios. }\end{array}$ & $\begin{array}{l}\text { Na busca por objetivos, tratam os meios } \\
\text { convencionais com pouca consideração. }\end{array}$ \\
\hline $\begin{array}{l}\text { Parecem insensíveis ao tédio, parecem } \\
\text { capazes de manter a alta precisão em longos } \\
\text { períodos de trabalhos detalhados. }\end{array}$ & $\begin{array}{l}\text { Capazes de trabalhar com rotinas detalhadas } \\
\text { apenas por curtos espaços de tempo. }\end{array}$ \\
\hline $\begin{array}{l}\text { São autoridades dentro de estruturas } \\
\text { estabelecidas. }\end{array}$ & $\begin{array}{l}\text { Tendem a controlar as situações não } \\
\text { estruturadas. }\end{array}$ \\
\hline $\begin{array}{l}\text { Raramente desafiam as regras e quando o } \\
\text { fazem, é de modo cauteloso e com o apoio } \\
\text { assegurado. }\end{array}$ & $\begin{array}{l}\text { Normalmente desafiam as regras, com pouco } \\
\text { respeito para os costumes passados. }\end{array}$ \\
\hline $\begin{array}{l}\text { Tendem a duvidar de si mesmos. Reagem às } \\
\text { críticas com aparente conformidade. São } \\
\text { vulneráveis às pressões sociais e à autoridade. }\end{array}$ & $\begin{array}{l}\text { Aparentam ter poucas dúvidas de si, e não } \\
\text { precisam do consenso para estarem certos de } \\
\text { suas opiniões, mesmo quando confrontados. }\end{array}$ \\
\hline
\end{tabular}

\section{Quadro 3. Características dos Adaptadores e dos Inovadores}

Fonte: Tradução de Kirton (1989, p.8-9)

Uma característica particular e preponderante do adaptador habitual quando enfrentando um problema é aceitar e utilizar os paradigmas (teorias, práticas e os pontos-de-vista) costumeiros e reconhecidos (KIRTON, 1989, p.6). Baseados nas observações de Gallivan, Estivalete et al (2009, p.2) destacam que estes indivíduos dão preferência para a manutenção do status quo, sem desafiar as suposições básicas implícitas. Por outro lado, segundo Kirton (1989, p.6) uma 
característica peculiar do inovador habitual é deslocar-se do problema e dos modelos existentes, buscando uma solução alternativa e fugindo das limitações e barreiras impostas por eles. Baseados nas observações de Gallivan, Estivalete et al $(2009$, p.2) esclarecem que estes indivíduos dão preferência por mudanças radicais, são cercados de riscos e são menos tolerantes a rotinas fixas.

Apesar da observação de Drucker (1969 apud KIRTON, 1989, p.5) de que as organizações tendem a preferir a abordagem adaptativa, a conclusão imediata das observações de Kirton é de que ambos os tipos são vitais para a sobrevivência de qualquer organização. Enquanto o perfil inovador, ilustrado talvez pela figura do empreendedor, assume riscos e oferece novas idéias e alternativas sendo ideal para crises imprevistas (inclusive evitando-as), o perfil adaptador, ilustrado pelo gestor, contribui com a continuidade e a execução das atividades a qualquer momento, focando na eficiência e disciplinas necessárias no mundo dos negócios.

De fato, os dois estilos se complementam. Quando colaborando em parceria com inovadores, os adaptadores oferecem estabilidade, ordem e continuidade, mantém a cooperação e a coesão do grupo e proporcionam a base segura para o lado imprevisível e arriscado dos inovadores. Por outro lado, estes oferecem novas formas de encarar as realidades, quebrando paradigmas desnecessários ou ineficazes dos adaptadores, proporcionando mudanças radicais sem as quais as organizações não poderiam se reinventar e sobreviver (KIRTON, 1989, p.9).

Esta afirmação confirma que a dicotomia adaptação-inovação como estilo cognitivo é apenas uma dimensão do processo cognitivo que não deve ser considerada pejorativa e laudatória, assim como tampouco busca medir o nível intelectual ou a capacidade cognitiva. Pelo contrário, ela procura entender a pessoa e seu comportamento em diferentes situações (KIRTON, 1989, p.5) e dessa forma não há estilos melhores ou piores, apenas maneiras distintas de lidar com as circunstâncias que são propostas.

Com base na teoria descrita o autor desenvolveu então um instrumento de pesquisa chamado KAI, Inventário de Adaptação-Inovação (ou Kirton Adaption-Innovation Inventory) para distinguir operacionalmente o estilo cognitivo preferencial do indivíduo. Ele é composto por 32 itens (cada um com uma escala de 1 a 5), resultando numa medida mínima de 32 pontos (o perfil adaptador extremo) ou máxima de 160 pontos (o perfil inovador extremo). De acordo 
com as aplicações empíricas de seu criador, a distribuição das observações entre estes dois extremos (adaptação/inovação) respeita uma distribuição normal.

\section{Teoria dos Tipos de Personalidade}

De acordo com Casado (1998, p.13), "a necessidade e a utilidade do entendimento das peculiaridades dos seres humanos (...) vem sendo uma busca constante e de muito tempo", voltada principalmente “(...) à utilização produtiva das diferenças.” Apesar de remontar à Antiguidade Clássica, com as idéias e conceitos de importantes pensadores gregos, as principais evoluções nos estudos das diferenças de personalidades e comportamentos dentro do campo da Psicologia ocorreram na era Contemporânea, fundamentados sobre os conceitos de Freud, Fromm, Jung e outros.

Na opinião de Freud, Pai da Psicanálise, a explicação das diferenças pessoais está na sexualidade dos indivíduos. Partindo desta hipótese, o médico austríaco contribui com duas tipologias de personalidade muito importantes para estudos subseqüentes, detalhadas a seguir com base nas observações de Casado (1998, p.14-15). Em primeiro lugar, estabelece o conceito psicanalítico da fixação, elucidando que as características dos indivíduos são um reflexo direto da satisfação excessiva ou da frustração dos estágios de desenvolvimento durante a infância. Basicamente, seriam três fases: a oral, marcada pela dependência, onde a tendência é receber; a anal, marcada pelo controle, onde a tendência é reter; e a fálica, marcada pela autoridade, onde a tendência é a disputa de poder. Em segundo lugar, Freud também proporciona a tipologia da libido (a força dos instintos sexuais), dividindo as pessoas em eróticas, voltadas para o amor e sob influência do id (inconsciente), narcísicas, voltadas para a auto-preservação e sob influência do ego (pré-consciente) e obsessivas, voltadas para o medo e sob a influência do superego (consciência).

Ao contrário de Freud, Fromm entende que as “(...) as diferenças pessoais são primordialmente decorrentes da interação entre pais e filhos, influenciadas pelo grupo cultural a que pertencem" (CASADO, 1998, p.15). Para ele, existem cinco tipos de indivíduos: receptivos, exploradores, acumuladores, mercantis e produtivos, muitos dos quais guardam semelhanças com as características de cada um dos estágios de desenvolvimento propostos por Freud. 
Outro discípulo dissidente de Freud, Jung aprofunda-se no entendimento da natureza humana, estudando as diferenças entre indivíduos e seus traços de personalidade, trabalho que resultou no livro "Tipos de Personalidade", publicado pela primeira vez em 1920. Nele o autor aborda três escalas básicas as quais dá os nomes de tipo geral de disposição, tipo funcional perceptivo e tipo funcional judicativo, onde trabalha com conceitos binários, opostos e complementares que descrevem preferências das personalidades dos indivíduos.

Os Tipos Gerais de Disposição tratam genericamente da forma como o indivíduo se relaciona com o mundo e consigo mesmo, portanto, referem-se à “(...) direção do interesse e da energia colocada no caminho, seja para o objeto ou, contrariamente, para o sujeito" (CASADO, 1998, p.35). Neste sentido há duas possibilidades opostas: a Extroversão (E) e a Introversão (I). Na extroversão, "os interesses [e atenções] fluem principalmente para o mundo exterior das ações, objetos e pessoas" (FELDER et al, 2002, p.3) e a determinação dominante é exercida por forças externas, o que resulta numa maior exposição do indivíduo e de seus sentimentos (CASADO, 1998, p.37). De modo complementar e distinto, na introversão "os interesses [e atenções] fluem principalmente para o mundo interior de conceitos e idéias" (FELDER et al, 2002, p.3), a elaboração de conclusões e reações ocorre interna e intimamente, as determinações são subjetivas e isoladas da exposição (CASADO, 1998, p.40).

Para explicar a enorme diferença entre pessoas dentro destes dois tipos gerais, Jung delineia quatro funções adicionais que procuram esclarecer a função psíquica preferencial de cada indivíduo (LENZI, 2008, p.59). Assim, os Tipos Funcionais Psíquicos refletem as habilidades, aptidões e tendências aplicadas na percepção (isto é, na captação das informações do mundo) e no julgamento (isto é, na interpretação e na tomada de decisão). Quanto à função perceptiva (chamada de irracional), há duas possibilidades opostas: a Sensação (S) e a Intuição $(\mathrm{N})$. Na sensação "a tendência é perceber fatos imediatos, reais e práticos da experiência e da vida (FELDER et al, 2002, p.3), portanto, a captação se dá principalmente pelos cinco órgãos dos sentidos e está concentrada em aspectos concretos, quantificáveis e com ação analítica (CASADO, 1998, p.43). Na intuição, por outro lado, "a tendência é perceber possibilidades, relacionamentos e significados de experiências" (FELDER et al, 2002, p.3), portanto, a captação se dá percebendo além dos cinco sentidos (sexto sentido), de forma mais abstrata, até certo ponto mais caótica e com ação sintética (CASADO, 1998, p.4344). Quanto à função judicativa, há duas possibilidades opostas: o Pensamento (T) e o 
Sentimento (F). No pensamento "a tendência é julgar ou tomar decisões racionalmente, de modo lógico, objetivo e impessoal" (FELDER et al, 2002, p.3), uma abordagem intelectual e até cetro ponto fria, uma vez que desconsidera conseqüências emocionais das ações e foca no que se deve fazer (CASADO, 1998, p.44). No sentimento, ao contrário, "a tendência é julgar ou tomar decisões de modo subjetivo, pessoal e emocional" (FELDER et al, 2002, p.3), conferindo uma abordagem mais emocional às decisões, focando no que se quer fazer (CASADO, 1998, p.45).

Em meados da década de 1960, baseadas sobre as visões do autor em relação ao tema, duas pesquisadoras americanas (Myers e Briggs) contribuíram para a tipologia de Jung incluindo uma quarta escala que trata do tipo de atitude que o indivíduo tem frente ao mundo. Esta postura em relação mundo na verdade reflete a preferência ou maior influência da função psíquica perceptiva ou judicativa. Segundo Myers e Briggs (1962 apud KOLB, 1984, p.80), "na prática, esta preferência é um sub-produto da escolha de qual o processo, dentre os dois elegidos (Intuição/Sensação e Pensamento/Sensação), regerá a vida do individuo.” Em outras palavras, há duas possibilidades opostas: o Julgamento (J) e a Percepção (P). No julgamento a "tendência é viver de forma planejada e decidida" (FELDER et al, 2002, p.4), procurando controlar o mundo a sua volta, estabelecendo rotina e aversão aos riscos. Por outro lado, na percepção "a tendência é viver de forma espontânea e flexível” (FELDER et al, 2002, p.4), procurando adaptar-se ao mundo, aceitando mais os riscos e mudanças no dia-a-dia. O quadro 4 a seguir resume as características das 4 funções.

\begin{tabular}{|l|l|l|}
\hline $\begin{array}{l}\text { Onde você } \\
\text { concentra sua } \\
\text { atenção }\end{array}$ & $\begin{array}{l}\text { Extroversão (E): Preferência por tirar } \\
\text { energia do mundo exterior das pessoas, } \\
\text { atividades ou coisas. }\end{array}$ & $\begin{array}{l}\text { Introversão (I): Preferência por tirar } \\
\text { energia do mundo interior das idéias, } \\
\text { emoções ou impressões pessoais. }\end{array}$ \\
\hline $\begin{array}{l}\text { A forma como } \\
\text { você capta } \\
\text { informações }\end{array}$ & $\begin{array}{l}\text { Sensação (S): Preferência por obter } \\
\text { informações através dos cinco sentidos e } \\
\text { observar aquilo que é real. }\end{array}$ & $\begin{array}{l}\text { Intuição (N): Preferência por obter } \\
\text { informações através do "sexto sentido", } \\
\text { observando o que pode ser. }\end{array}$ \\
\hline $\begin{array}{l}\text { A forma como } \\
\text { você toma decisões }\end{array}$ & $\begin{array}{l}\text { Pensamento (P): Preferência por } \\
\text { organizar e estruturar as informações } \\
\text { para tomar decisões de maneira lógica e e } \\
\text { objetiva. }\end{array}$ & $\begin{array}{l}\text { Sentimento (S): Preferência por } \\
\text { organizar e estruturar as informações } \\
\text { para tomar decisões de maneira pessoal } \\
\text { e orientada para valores. }\end{array}$ \\
\hline $\begin{array}{l}\text { Como você lida } \\
\text { com o mundo } \\
\text { externo }\end{array}$ & $\begin{array}{l}\text { Julgamento (J): Preferência por ter uma } \\
\text { vida organizada e planejada. }\end{array}$ & $\begin{array}{l}\text { Percepção (P): Preferência por ter uma } \\
\text { vida espontânea e flexível. }\end{array}$ \\
\hline
\end{tabular}

\section{Quadro 4. Características dos Tipos Psicológicos}

Fonte: Adaptação de Hirsh e Kummerow (1998, p.4) 
Existem várias formas de identificar os tipos psicológicos de acordo com a teoria de Jung e, conseqüentemente, várias formas de identificar estilos de aprendizagem e estilos cognitivos. Todavia, como explicam Casado (1998, p.60), Felder et al (2002, p.3) e Kolb (1984, p.80), o instrumento de análise mais conhecido e aplicado para este fim é o MBTI, Indicador de Tipos de Myers e Briggs (ou Myers-Briggs Type Indicator), que é baseado nas quatro escalas dicotômicas de Jung (os tipos gerais de disposição mais as duas funções psíquicas) e Myers e Briggs (estilo de vida).

Apesar do reconhecimento internacional do instrumento, há algumas ressalvas. A principal delas é que o MBTI foi elaborado sobre padrões culturais anglo-saxônicos e, assim, seus resultados podem apresentar vieses ou incoerências, principalmente em realidades distintas da americana como, por exemplo, nas culturas latinas ou asiáticas. Considerando este ponto, Casado (1998) desenvolveu no início dos anos 1990 um instrumento similar em conteúdo, forma e objetivo ao MBTI, mas orientado para a realidade brasileira, ao qual deu o nome de DTP - Diagnóstico de Tipo Psicológico. Genericamente, o resultado de uma pessoa no DTP (assim como no MBTI) descreve sua personalidade em determinadas situações, permitindo categorizar o indivíduo dentro de um estilo particular, mesmo que não seja perfeitamente preciso ou não avalie a mudança de estilo durante todo o processo de decisão (MANN et al, 1991, p.144).

Sob o ponto-de-vista operacional, o DTP é um questionário composto de 150 questões onde o respondente deve escolher apenas uma dentre duas opções exibidas e, assim como no MBTI, seu resultado final é o tipo psicológico do indivíduo identificado por quatro letras (uma para cada escala avaliada) e quatro valores que representam a intensidade de cada uma destas quatro escalas. Ele é um instrumento testado por meio de técnicas científicas, com validade comprovada de conteúdo e de constructo, aplicado em instituições de ensino e organizações, o que lhe garante uma posição de destaque dentre as ferramentas de identificação de Tipos Psicológicos Junguianos. Pelos motivos elucidados acima, assim como pela conveniência e gratuidade do DTP para pesquisas acadêmicas, este é o instrumento utilizado para o levantamento empírico desta pesquisa (em detrimento do MBTI ou do KAI de Kirton). 


\section{3. $\quad$ Síntese Bibliográfica}

No quadro 5 a seguir é apresentada uma breve síntese dos referenciais bibliográficos abordados; seu objetivo primordial é indicar os principais aspectos verificados até este ponto, orientando os trabalhos empíricos.

\begin{tabular}{|c|c|c|}
\hline Conceito / Tema & Definição & Principais Autores \\
\hline $\begin{array}{l}\text { Business } \\
\text { Intelligence }\end{array}$ & $\begin{array}{l}\text { "Conjunto de metodologias e } \\
\text { tecnologias para coleta, armazenamento, } \\
\text { análise e acesso a dados para auxiliar } \\
\text { usuários a tomar melhores decisões de } \\
\text { negócio" (KEYES, 2006, p.155). }\end{array}$ & $\begin{array}{l}\text { Luhn (1958), Power (2003; 2007), } \\
\text { Keyes (2006), Rud (2009), Kahn et al } \\
\text { (2009), Roze (2002), Davenport (2006), } \\
\text { Arnott (2008), Gartner Group (2011), } \\
\text { dentre outros. }\end{array}$ \\
\hline $\begin{array}{l}\text { Funcionalidades } \\
\text { de apresentação de } \\
\text { BI }\end{array}$ & $\begin{array}{l}\text { "Permitem pessoas a acessar e analisar } \\
\text { dados" (HOWSON, 2008, p.1), tais } \\
\text { como: Painéis de Informação, Relatórios } \\
\text { Pré-Definidos, Relatórios Ad hoc, } \\
\text { Relatórios OLAP, Modelos Preditivos e } \\
\text { Mineração. }\end{array}$ & $\begin{array}{l}\text { Howson (2008), Silvers (2008), Nemati } \\
\text { et al (2010), Gartner Group (2011), } \\
\text { Turban (2008), Keyes (2006), Ballard et } \\
\text { al (1996), Kimball e Ross (2002), Inmon } \\
\text { (2002), dentre outros. }\end{array}$ \\
\hline $\begin{array}{l}\text { Principais } \\
\text { Preocupações } \\
\text { Humanas do BI }\end{array}$ & $\begin{array}{l}\text { Informações e Usuários; } \\
\text {. Ferramentas e Usuários; } \\
\text {. Capacitação; } \\
\text {. Facilidade de Uso; } \\
\text {. Cultura Analítica; }\end{array}$ & $\begin{array}{l}\text { Keen e Scott Morton (1978), Scheps } \\
\text { (2008), Brunson (2005), Eckerson } \\
\text { (2009), Silvers (2008), Davenport } \\
\text { (2006), Gartner Group (2011), Avgerou } \\
\text { (2001), dentre outros. }\end{array}$ \\
\hline $\begin{array}{l}\text { Aspectos para } \\
\text { Classificação de } \\
\text { Usuários de BI }\end{array}$ & $\begin{array}{l}\text { Conhecimento Técnico; } \\
\text {. Necessidade da Informação; } \\
\text {. Papel Desempenhado; } \\
\text {. Responsabilidade; }\end{array}$ & $\begin{array}{l}\text { Ponniah (2001), Imhoff e Pettit (2004), } \\
\text { Assis (2010), Nemati et al (2010), } \\
\text { Eckerson (2009), dentre outros. }\end{array}$ \\
\hline $\begin{array}{l}\text { Estilos Cognitivos } \\
\text { (Tipos } \\
\text { Psicológicos) }\end{array}$ & $\begin{array}{l}\text { Preferências das personalidades dos } \\
\text { indivíduos descritas através de } 4 \\
\text { dicotomias de Jung e Myers e Briggs: } \\
\text { Extroversão vs Introversão, Sensação vs } \\
\text { Intuição, Pensamento vs Sentimento e } \\
\text { Julgamento vs Percepção. }\end{array}$ & $\begin{array}{l}\text { Casado (1998), Felder et al (2002), } \\
\text { Lenzi (2008), Kolb (1984), Kirton } \\
\text { (1989) e Estivalete et al (2009). }\end{array}$ \\
\hline
\end{tabular}

Quadro 5. Síntese dos Principais Temas do Marco Teórico 


\section{MÉTODO DE PESQUISA}

Considerando a questão-problema e os objetivos propostos e o apoio do referencial bibliográfico discutido, a abordagem escolhida para a pesquisa empírica é a qualitativa do tipo Estudo de Caso, isto é, pesquisa que “(...) investiga um fenômeno contemporâneo dentro de um contexto real de vida, especialmente quando os limites entre o fenômeno e o contexto não estão claramente definidos" (YIN, 2001, p.32). A seguir são abordados os principais aspectos deste tipo particular de abordagem, a justificativa detalhada para tal escolha, o delineamento da pesquisa e uma breve descrição da principal técnica de coleta utilizada.

\subsection{Estudo de Caso}

Para Denzin e Lincoln (2005, p.17), a Pesquisa Qualitativa é “(...) uma atividade situada que localiza o observador no mundo" e consiste de “(...) um conjunto de práticas materiais e interpretativas que dão visibilidade ao mundo." Ela envolve uma abordagem naturalista e interpretativa do contexto, pois seus pesquisadores estudam o objeto em seus cenários naturais, procurando analisar, entender e interpretar os fenômenos em termos dos significados que as pessoas lhes conferem (DENZIN e LINCOLN, 2005, p.17). Strauss e Corbin complementam esta definição ao afirmarem que as pesquisas qualitativas são "qualquer tipo de pesquisa que chega às suas conclusões por meios distintos de procedimentos estatísticos ou outros meios de quantificação" (STRAUSS e CORBIN, 1990 apud SOUZA, 2000, p.73).

Existem diferentes tipos de pesquisas qualitativas, mas quatro delas têm maior usabilidade no campo da Administração de Empresas, a saber: os Estudos de Caso, as Pesquisas-Ação, os Estudos Etnográficos e as Pesquisas Documentais. A aplicação de cada um destes métodos depende de uma série de fatores como tema, contexto e objetivo da pesquisa, técnica de coleta empregada, além de outros aspectos relacionados com o campo de estudo sob avaliação.

O Estudo de Caso, por sua vez, é um tipo de pesquisa qualitativo que “(...) investiga um fenômeno contemporâneo dentro de um contexto real de vida, especialmente quando os limites entre o fenômeno e o contexto não estão claramente definidos” (YIN, 2001, p.32). Para Godoy (1995, p.25), é “(...) um tipo de pesquisa cujo objetivo é uma unidade que se 
analisa profundamente (...)", visando “(...) o exame detalhado de um ambiente, de um simples sujeito ou de uma situação em particular”. De opinião similar, Martins e Theóphilo (2009, p.62) caracterizam o método “(...) pela descrição, compreensão e interpretação de fatos e fenômenos (...) cujo objetivo é o estudo de uma unidade social que se analisa profunda e intensamente."

Uma definição concisa e que engloba as afirmativas acima é aquela do dicionário MerriamWebster; ela descreve este método como "uma análise intensiva de uma unidade individual (como uma pessoa ou comunidade) enfatizando fatores de desenvolvimento em relação ao ambiente" (MERRIAM-WEBSTER, 2009 apud FLYVBJERG, 2011, p.301). Apesar de simples, esta definição é considerada completa por Flyvbjerg (2011, p.301), pois, na opinião do autor, aborda pelo menos quatro dos aspectos mais importantes de um Estudo de Caso: a intensidade da análise, a unidade de pesquisa, os fatores de desenvolvimento e a relação com o ambiente e o contexto.

Ao contrário do que se possa pensar, uma pesquisa qualitativa como um Estudo de Caso não é o oposto da pesquisa quantitativa, mas um método com forma e enfoque específicos que visa a contribuição acadêmica através de métodos racionais e indutivos com o objetivo de entender, analisar, interpretar e explicar os fenômenos de nosso dia-a-dia, uma forma de investigar que “(...) preserva as características holísticas e significativas dos eventos da vida real" (YIN, 2001, p.21). Genericamente, ele trata da observação não participativa e análise limitada - normalmente através de entrevistas e análise de documentos, mas intensiva de uma ou múltiplas unidades sociais, procurando compreender o mecanismo de funcionamento, os motivos e as causas dos fenômenos observados (GODOY, 1995, p.25). Ainda que essencialmente qualitativos, Godoy (1995, p.26) esclarece também que os Estudos de Caso podem conter dados de abordagem tipicamente quantitativa para esclarecer alguma questão ou tópico da investigação, mesmo que a análise estatística seja pouco sofisticada e robusta.

Avaliando a literatura de referência, é possível encontrar diferentes categorizações dos Estudos de Caso de acordo com algumas de suas particularidades, como o propósito a que é aplicado, o número de casos que são avaliados, a singularidade deles e o enfoque como são abordados. Como é de se esperar, algumas destas caracterizações se sobrepõem. 
Com base nessas categorizações e observando as particularidades desta pesquisa é possível ainda afirmar que este Estudo de Caso é do tipo explanatório, pois avalia situações nas quais a unidade de análise não apresenta um conjunto simples e claro de resultados; instrumental, pois a motivação está na crença de que este caso pode colaborar para o entendimento de uma idéia mais ampla; simples, pois tem apenas um sujeito sob análise que representa uma oportunidade única de estudo; típico, pois parece ser convencional e usual frente ao referencial adotado; e incorporado, pois são observadas diferenças entre os componentes de uma mesma unidade de análise, mas com a finalidade de obter maiores informações a respeito do todo. De qualquer forma, esta pesquisa também tem um caráter exploratório e quantitativo na medida em que, dentro das limitações metodológicas, procura avaliar a existência do relacionamento entre duas variáveis, isto é, o estilo cognitivo e a preferência por determinada funcionalidade de BI.

Para Yin (2001, p.28), “embora o Estudo de Caso seja uma forma distintiva de investigação empírica, muitos pesquisadores demonstram certo desprezo com a estratégia”, considerando-a como "menos desejável” ou menos aceitável como abordagem de pesquisa. Flyvbjerg (2011, p.302) concorda com esta visão, afirmando que o método é geralmente menosprezado ou até ignorado dentro da comunidade cientifica. De acordo com Yin (2001, p.28-30), isso normalmente ocorre por três motivos: em primeiro lugar, há uma corrente de críticos que vê pouco rigor metodológico nesta estratégia, talvez influenciados pela própria confusão existente entre o método de pesquisa e o método de ensino de Estudo de Caso; em segundo lugar, trata-se de um método indutivo que não normalmente permite alcançar generalizações ou conclusões definitivas; e, em terceiro lugar, como exigem profundidade e uma análise minuciosa, os Estudos de Caso podem tomar muito tempo para sua realização.

Flyvbjerg (2011, p.302) aprofunda-se nesta temática, discutindo cinco mal-entendidos (ou críticas) dos Estudos de Caso. O primeiro deles é que conhecimentos teóricos e genéricos são mais valiosos do que os conhecimentos concretos de um caso; o segundo é que não se pode generalizar com base em um caso individual e, deste modo, um caso não poderia contribuir para desenvolvimento científico; o terceiro é que o Estudo de Caso é mais útil para gerar hipóteses e em fases iniciais exploratórias de estudo, enquanto outros métodos são mais adequados para teste de hipóteses e efetiva construção de teorias; a quarta é que este método apresenta um viés na verificação, ou seja, tem a tendência para confirmar as premissas e propostas do pesquisador; a quinta e última é que não raro é difícil sintetizar e desenvolver 
proposições gerais e teorias com base no caso específico. O trabalho de Flyvbjerg é especialmente interessante, pois contrapõe cada uma dessas incompreensões com argumentos sólidos e coerentes, fortalecendo o Estudo de Caso como método de pesquisa.

Apesar desta discussão em torno da validade do Estudo de Caso, ele é um método que atualmente é aplicado em uma grande parte das pesquisas empíricas apresentadas em diferentes publicações acadêmicas do campo das ciências sociais (FLYVBJERG, 2011, p.302). Ele tem uma particular aplicabilidade no campo da Administração de Empresas e é oportuno na medida em que cumpre com os objetivos mais básicos da pesquisa científica, isto é, dá explicações sobre a realidade e gera novos conhecimentos. De qualquer forma, para garantir sua qualidade e rigor metodológico e, conseqüentemente, sua validade e confiabilidade, Yin destaca quatro testes fundamentais que devem ser seguidos, descritas no quadro 6 abaixo.

\begin{tabular}{|l|l|}
\hline $\begin{array}{l}\text { Validade } \\
\text { de Constructo }\end{array}$ & $\begin{array}{l}\text { - Utiliza fontes múltiplas de evidências; } \\
\text { - Estabelece encadeamento de evidências; } \\
\text { - O rascunho do relatório é revisado por informantes-chave; }\end{array}$ \\
\hline $\begin{array}{l}\text { Validade } \\
\text { Interna }\end{array}$ & $\begin{array}{l}\text { - Faz adequação ao padrão; } \\
\text { - Faz construção da explanação; } \\
\text { - Faz análise de séries temporais; }\end{array}$ \\
\hline $\begin{array}{l}\text { Validade } \\
\text { Externa }\end{array}$ & - Utiliza lógica de replicação em estudos de múltiplos casos; \\
\hline Confiabilidade & $\begin{array}{l}\text { - Utiliza protocolo de estudo de caso; } \\
\text { - Desenvolve banco de dados para o estudo de caso; }\end{array}$ \\
\hline
\end{tabular}

Quadro 6. Testes Fundamentais do Estudo de Caso

Fonte: Adaptação de Yin (2001, p.55)

\subsection{Justificativa do Método}

Segundo Alves-Mazzotti (2006, p.639) “(...) o maior problema de grande parte dos trabalhos apresentados como Estudos de Caso é que eles não se caracterizam como tal.” Para a autora, muitos trabalhos dizem utilizar este método apenas porque se concentram em apenas uma unidade de análise ou porque têm um número reduzido de sujeitos, sem as justificativas 
suficientes para sua utilização, tanto na escolha do método como na escolha do caso (ALVESMAZZOTTI, 2006, p.639). Por esta razão é explicada a seguir a opção por esta abordagem.

A escolha pelo método qualitativo é similar àquela destacada por Souza (2000) em sua pesquisa dos Sistemas de Gestão Integrada. Para o autor, a pesquisa desta natureza é justificável quando objetiva a ampliação dos conhecimentos a respeito de um objeto, “(...) buscando novos aspectos envolvidos e novas relações entre eles e aspectos levantados na literatura, procurando-se delinear modelos teóricos que descrevam o fenômeno" (SOUZA, 2000, p.73). Assim como os Sistemas de Gestão Integrada na época de seu estudo, as aplicações de Business Intelligence estabeleceram apenas recentemente um campo de estudos, isto porque tratam de um tema de estudos relativamente novo, essencialmente pragmático e praticamente inexplorado sob o ponto-de-vista acadêmico, onde existe uma carência de conhecimentos registrados e com um mínimo de rigor metodológico.

A escolha pelo método de Estudo de Caso para esta dissertação em particular se baseia nas três condições indicadas por Yin (2001, p.24) para a utilização desta estratégia, isto é, o tipo dos objetivos e a questão de pesquisa, o controle do pesquisador sobre os eventos comportamentais efetivos e o foco no momento dos fenômenos históricos ou contemporâneos.

Em primeiro lugar, os objetivos propostos e a questão-problema são do tipo "como" e tem o objetivo genérico de avaliar, entender e explicar de que maneira as organizações tratam dos diferentes usuários analíticos e sua relação com as diferentes ferramentas de aplicações de Business Intelligence. Para Yin (2001, p.25), estes tipos de questão - que se preocupam com o "como" e "por que" - levam ao uso de Estudos de Caso e Experimentos, pois “(...) lidam com ligações operacionais que necessitam ser traçadas ao longo do tempo, em vez de serem encaradas como meras repetições ou incidências." Se, por outro lado, a preocupação fosse com incidências e predominâncias, em confirmar ou refutar hipóteses com um embasamento estatístico, a estratégia mais indicada seria a do Levantamento (ou survey).

Em segundo lugar, quanto ao controle sobre eventos comportamentais, Yin (2001, p.27) destaca que no Estudo de Caso não é possível manipular variáveis de estudo de modo direto, sistemático e preciso como, por exemplo, nos Experimentos (é justamente neste aspecto onde se encontra a principal diferença entre estes dois métodos). A própria forma de coleta do Estudo de Caso (observação, análise documental e entrevistas) pode ser considerada passiva, 
o que corrobora esta opinião de controle inexistente dos eventos comportamentais nesta estratégia de pesquisa. Esta dissertação e seu tema de pesquisa são claramente uma ilustração desta condição, na medida em que, além da complexidade e da quantidade de variáveis envolvidas, não se pode isolar e analisar individualmente alguns dos aspectos avaliados a fim de entendê-los ou explicá-los, como é o caso em concreto da cultura analítica, por exemplo.

Finalmente, quanto ao foco no momento, o Estudo de Caso examina acontecimentos contemporâneos, ao contrário das pesquisas históricas e documentais. Novamente, o Business Intelligence é um tema relativamente recente, faz parte do cotidiano das grandes corporações e é foco de investimentos e de cobrança por resultados cada vez mais intensos na maior parte das organizações nos últimos anos. Além disso, como destacam diferentes autores, a análise de questões relacionadas aos usuários destas aplicações é um trabalho relevante na atualidade.

Assim, o Estudo de Caso é o método “(...) mais adequado quando se procura responder questões do tipo 'como' e 'por que', quando o fenômeno estudado é contemporâneo (isto é, ainda está ocorrendo) e quando há pouca ou nenhuma possibilidade de controlar os fatores envolvidos" (SOUZA, 2000, p. 65-66), características desta pesquisa.

\subsection{Delineamento da Pesquisa}

Uma vez definido o Estudo de Caso como método de pesquisa a ser utilizado, para construir um trabalho sólido é especialmente importante trabalhar cinco componentes centrais: a questão-problema, as proposições do estudo, sua unidade de análise, a lógica que une os dados às proposições e os critérios para se interpretar as descobertas (YIN, 2001, p.42). Estes componentes tratam de forma lógica os objetivos, conectando-os aos dados coletados e estes às conclusões do estudo, facilitando o entendimento da pesquisa e de seus achados. A seguir é analisado cada um destes aspectos de acordo com a bibliografia de referência.

\subsubsection{Questão de Pesquisa e Proposições de Pesquisa}

A questão-problema de uma pesquisa serve como orientação para os esforços do pesquisador, pois estabelece o rumo geral dos estudos, isto é, a direção do desenvolvimento real do 
trabalho, seja do referencial bibliográfico, da coleta e da análise dos dados ou dos resultados. Dada sua transcendência, os efeitos negativos observados na ausência de um problema claramente estabelecido ou bem estruturado podem ser devastadores, inviabilizando a pesquisa.

As proposições de pesquisa, por outro lado, destinam atenção para os aspectos que devem ser examinados dentro do escopo do estudo Yin (2001, p.42) ou como explica Souza (2000, p.67) “(...) são afirmações que estabelecem, de certa maneira, relações teóricas entre os fatores que estão sendo estudados.” Contudo, estas afirmações “(...) não podem ser consideradas hipóteses da pesquisa, pois não haverá comprovação estatística" (SOUZA, 2000, p. 68). Além disso, as proposições são uma consequiência direta do levantamento bibliográfico, pois devem estar fundamentadas sobre autores e literaturas especializadas e consistentes.

\subsubsection{Unidade de Análise}

Segundo Yin (2001, p.43), a unidade de análise refere-se ao problema fundamental que é tratado pela pesquisa, isto é, relaciona-se profundamente à maneira como as questões iniciais da pesquisa foram formuladas e definidas. A princípio pode tratar de um indivíduo, um conjunto e uma entidade, enfoques mais definidos ou, por outro lado, pode tratar de eventos ou fenômenos, como decisões, programas de vários tipos e processos de implementação em empresas (YIN, 2001, p.44).

Para Alves-Mazzotti (2006, p.639) um erro freqüente dos pesquisadores que dizem realizar um Estudo de Caso é que eles aplicam um questionário ou fazem entrevistas em determinado sujeito, sem explicitar o motivo da escolha, dando a impressão de que a opção é randômica e baseada em conveniência ou praticidade. Em outras palavras, o sujeito escolhido "(...) não apresenta qualquer interesse em si, é apenas um local disponível para a coleta de dados" (ALVES-MAZZOTTI, 2006, p.639), o que, por conseguinte, afeta diretamente a consistência do estudo e a relevância de suas observações e conclusões. Seguindo este raciocínio, é importante justificar a escolha do sujeito particular, ponto que é retomado mais adiante. 


\subsubsection{Ligação entre Dados e Proposições}

A ligação entre dados e proposições é o tópico do Estudo de Caso que trata genericamente da apresentação do caso propriamente dito e das observações coletadas. Há duas preocupações centrais relacionadas a este assunto: a primeira trata do encadeamento lógico das observações em relação ao escopo do estudo e às proposições teóricas previamente estabelecidas (também chamado de 'encadeamento de evidências') e a segunda trata amarração entre as idéias e interpretações da análise e o desenvolvimento do texto com sentido e consistência.

Em relação ao encadeamento lógico, Yin (2001, p.47) descreve que a associação entre prática e teoria no Estudo de Caso pode ser construída de diferentes formas, mas uma das estratégias gerais (inclusive a preferível na opinião do autor) é basear-se nas proposições teóricas ou, como indica Souza (2000, p.78), o modelo analítico-linear. Assim, Yin sugere apresentar o caso seguindo as orientações definidas com base no referencial teórico que originaram e guiaram o Estudo de Caso até o momento e que, por conseguinte, definem a prioridade e a relevância dos temas de análise (YIN, 2001, p.133) e garantem o atendimento dos objetivos e questões de pesquisa.

Em relação à amarração entre as idéias, segundo Yin uma das técnicas mais promissoras e desejáveis é 'adequação ao padrão', abordagem pela qual “(...) várias partes da mesma informação do mesmo caso podem ser relacionadas à mesma proposição teórica” (YIN, 2001, p.47), permitindo então a comparação e confrontação de “(...) um padrão fundamentalmente empírico com outro de base prognóstica" (YIN, 2001, p.136). Outra técnica interessante é a ‘construção da explanação’ que se propõe a explicar através da narrativa um fenômeno e um conjunto de elos causais (muitos deles complexos e difíceis de avaliar) em relação a ele (YIN, 2001, p. 140).

\subsubsection{Critérios para Interpretar os Resultados}

Dos cinco componentes de um Estudo de Caso, os dois últimos são os mais complexos de definir e de entender entre outros motivos porque de acordo com Yin (2002, p. 48) o estado atual da ciência não fornece orientação detalhada para eles, principalmente para o caso dos critérios. 
Enquanto a ligação entre dados e proposições pode ser realizada de diversas formas e ainda há diferentes métodos e técnicas aplicáveis conforme abordado anteriormente, "normalmente, não há uma maneira precisa de se estabelecer os critérios para a interpretação das descobertas" (YIN, 2001, p.47). Esta inclusive é uma das desvantagens que foram brevemente apontadas anteriormente para o Estudo de Caso, pois como exemplo de uma pesquisa qualitativa “(...) que chega às suas conclusões por meios distintos de procedimentos estatísticos ou outros meios de quantificação" como afirmam Strauss e Corbin (1990 apud SOUZA, 2000, p.73), é difícil, por exemplo, definir o grau de confiança das observações em relação às adequações. Neste sentido e com base nas orientações de Yin (2001, p.47-48), o que se espera é que as análises sejam realizadas de forma clara e suficiente e de que as descobertas sejam interpretadas considerando sempre o padrão (como comparação ou confrontação).

\subsection{Técnicas de Coleta de Dados}

Existem diversas técnicas que podem ser utilizadas para a coleta de dados das pesquisas qualitativas, como a observação, análise de textos e documentos, entrevistas, focus group dentre outros. Normalmente as técnicas estão associadas ao método de pesquisa, isto é, a observação é mais comumente utilizada em estudos etnográficos e a análise de textos em pesquisas documentais.

No caso particular dos Estudos de Caso, Yin (2001, p.107) descreve seis técnicas fundamentais de coleta de evidências (documentação, registro em arquivos, entrevistas, observação direta, observação participante e artefatos físicos) cada qual com seus pontos fortes e pontos fracos. Independente da técnica, o autor alerta para três princípios básicos que podem aprimorar a coleta e podem garantir a validade do Estudo de Caso: utilizar diferentes fontes de evidências a fim de permitir sua posterior triangulação, criar um banco de dados das observações e manter o ‘encadeamento de evidências’ (YIN, 2001, p.119-129).

De qualquer forma, a maior parte dos Estudos de Caso utiliza as entrevistas como técnica principal. Apesar das desvantagens atribuídas às entrevistas, como vieses (respostas tendenciosas dos entrevistados de acordo com interesses), imprecisões ou omissões 
(propositais ou não) e reflexões (como dizer o que o entrevistador quer ouvir) (YIN, 2001, p.108), elas são uma técnica essencial, pois são fontes primárias de coleta, ricas em informações, opiniões e interpretações das quais podem ser extraídos conhecimentos imprevistos e extremamente relevantes.

Principalmente neste tipo de técnica de coleta é imprescindível que o pesquisador esteja preparado e que siga algumas orientações básicas que lhe permitam conduzir adequadamente um Estudo de Caso, atingindo um resultado consistente e confiável. Para Yin (2001, p.79), “(...) as exigências que um Estudo de Caso faz em relação ao intelecto, ao ego e às emoções de uma pessoa são muito maiores do que qualquer outra estratégia de pesquisa" e complementa, afirmando que as “(...) habilidades [pessoais do pesquisador] raramente receberam atenção dedicada no passado" (YIN, 2001, p.80). Algumas destas habilidades estão descritas no quadro 6 da página a seguir.

A importância destas habilidades para um Estudo de Caso demonstra a complexidade deste tipo de pesquisa e desmistifica a visão simplista e ingênua não raro disseminada na academia; demonstra, inclusive, a importância de praticar e de utilizar de modo recorrente o Estudo de Caso com o objetivo de desenvolver e aprimorar essas habilidades.

Os conhecimentos e as experiências acadêmicas e profissionais do autor desta dissertação, conquistados ao longo de anos como estudante e consultor de soluções de BI, colaboraram para o desenvolvimento de uma grande parte destas habilidades desejadas. Apesar destes conhecimentos e experiências por si só não garantirem a qualidade do pesquisador, é plausível aceitar que ele é minimamente capacitado para exercer este papel, conduzindo a pesquisa de campo proposta. 


\begin{tabular}{|c|c|}
\hline $\begin{array}{l}\text { O pesquisador deve ter } \\
\text { conhecimento dos temas } \\
\text { abordados... }\end{array}$ & $\begin{array}{l}\text { O pesquisador deve ter um conhecimento do tema sob } \\
\text { investigação para executar seu trabalho com destreza e } \\
\text { confiança e para poder questionar e obter informações } \\
\text { relevantes para o estudo. }\end{array}$ \\
\hline $\begin{array}{l}\text { O pesquisador deve ter um } \\
\text { conhecimento prévio do sujeito... }\end{array}$ & $\begin{array}{l}\text { Antes de iniciar a coleta, o pesquisador deve saber do que trata a } \\
\text { situação que irá avaliar, deve saber de antemão qual o contexto } \\
\text { e as particularidades do caso, a fim de traçar estratégias e } \\
\text { abordagens adequadas. }\end{array}$ \\
\hline $\begin{array}{l}\text { O pesquisador deve escolher as } \\
\text { pessoas certas... }\end{array}$ & $\begin{array}{l}\text { O pesquisador deve saber quem são os principais indivíduos } \\
\text { envolvidos no caso e seus esforços devem estar concentrados } \\
\text { nessas pessoas que realmente vão trazer informações pertinentes } \\
\text { para o tema. }\end{array}$ \\
\hline $\begin{array}{l}\text { O pesquisador deve fazer boas } \\
\text { perguntas... }\end{array}$ & $\begin{array}{l}\text { De nada adianta ter um conhecimento prévio e escolher as } \\
\text { pessoas certas, se os questionamentos não são realizados } \\
\text { adequadamente; as perguntas devem ser pertinentes, relevantes } \\
\text { e críticas, instigando e motivando o entrevistado a responder. }\end{array}$ \\
\hline $\begin{array}{l}\text { O pesquisador deve ser um bom } \\
\text { ouvinte... }\end{array}$ & $\begin{array}{l}\text { Não basta fazer as perguntas corretas nos momentos adequados, } \\
\text { é preciso estar atento para ouvir as respostas e saber interagir } \\
\text { com o entrevistado; a atenção ao que o interlocutor diz é } \\
\text { essencial para abrir novas portas e obter informações } \\
\text { interessantes e inesperadas. }\end{array}$ \\
\hline $\begin{array}{l}\text { O pesquisador deve ser flexível e } \\
\text { respeituoso... }\end{array}$ & $\begin{array}{l}\text { O pesquisador deve ter jogo de cintura, adaptando-se a cada } \\
\text { situação e/ou pessoa; a flexibilidade também está relacionada à } \\
\text { utilização de artifícios que permitam com que as mensagens } \\
\text { sejam entendidas. }\end{array}$ \\
\hline $\begin{array}{l}\text { O pesquisador deve ser imparcial e } \\
\text { não deve ter preconceitos... }\end{array}$ & $\begin{array}{l}\text { Mesmo com opiniões diferentes, o pesquisador deve estar atento } \\
\text { para não se deixar levar por seus preconceitos, mantendo-se } \\
\text { imparcial; a falta de receptividade das respostas pode retrair o } \\
\text { entrevistado. }\end{array}$ \\
\hline
\end{tabular}

Quadro 7. Habilidades de um Pesquisador de Estudo de Caso

Fonte: Adaptação de Yin (2001, p.80-85). 


\section{CONDUÇÃO DA PESQUISA}

Orientado pelos cinco componentes do Estudo de Caso abordados no tópico de delineamento de pesquisa, descreve-se a seguir a questão e as proposições desta pesquisa, além da unidade de análise e sua justificativa e os demais tópicos sugeridos por Yin. Em seguida são detalhados os aspectos operacionais e a condução da pesquisa propriamente dita.

\subsection{Questão-Problema e Proposições de Pesquisa}

Como destacado na parte inicial deste manuscrito e com a finalidade de orientar o restante da dissertação no atendimento dos objetivos propostos, a questão central desta pesquisa é:

\section{Existe uma relação entre os estilos cognitivos dos usuários analíticos e sua escolha por determinadas funcionalidades disponíveis em aplicações de Business Intelligence?}

Fundamentadas sobre a literatura de referência e destacando a ligação lógica com cada um dos objetivos sugeridos inicialmente, as proposições de pesquisa são:

\section{Proposição I}

As organizações caracterizam e diferenciam seus usuários de soluções analíticas com base nos papéis que desempenham, nas informações que demandam e nas maneiras como consomem e analisam as informações (ECKERSON, 2009, p.4), ou seja, através da combinação de um ou mais aspectos abaixo:

- Conhecimento técnico (limitado, intermediário e avançado);

- Cargo ou nível hierárquico (executivos, gerentes, analistas);

- $\quad$ Necessidade de informação (consolidada, detalhada);

- $\quad$ Papel desempenhado (produtor ou consumidor); 
Esta proposição é baseada nas observações, distinções e classificações propostas por Ponniah (2001) e Eckerson (2009) e Nemati et al (2010), avaliadas no Marco Teórico desta obra.

Esta proposição está logicamente relacionada com o objetivo de analisar como as organizações caracterizam os usuários de soluções analíticas, isto é, como entendem, diferenciam e tratam os diferentes públicos alvo.

\section{Proposição II}

As aplicações de Business Intelligence presentes dentro das organizações oferecem uma variedade de funcionalidades de apresentação e análise. Baseada nas diferentes técnicas de apresentação e análise de BI sugeridas por diversos autores, dentre eles Gartner Group (2011), Nemati et al (2010), Silvers (2008) e Turban et al (2008 apud AGHA KHAN et al, 2009) e complementada por outros autores da bibliografia de referência, estas funcionalidades podem ser agrupadas da seguinte forma:

- $\quad$ Painéis de informação (ou dashboards);

- Relatórios pré-formatados (isto é, relatórios prontos para uso);

- Relatórios ad hoc (isto é, relatórios ocasionais que o próprio usuário pode criar);

- Relatórios OLAP (isto é, tabelas dinâmicas e cubos);

- Relatórios baseados em Modelos Preditivos e Mineração de Dados;

Elas são apresentadas por ordem de complexidade (daquelas mais simples e limitadas para as mais complexas) sob o ponto-de-vista de facilidade de uso e amplitude de análise para o usuário final, sendo desconsideradas as dificuldades de desenvolvimento.

Esta premissa está logicamente relacionada com o objetivo de entender como ocorre a associação entre os usuários e as diversas ferramentas disponíveis de BI e seu objetivo essencial é declarar de forma explícita justamente o que compõe a variável 'funcionalidades de BI'. Considera-se esta premissa uma das proposições de estudo uma vez que ela também deve ser avaliada na organização em análise e verificada e comprovada nas entrevistas. 
Duas observações são importantes nesta proposição. A primeira delas é a discussão resultante da inclusão dos métodos preditivos e mineração de dados na listagem de funcionalidades de apresentação e análise de BI. O grande argumento neste caso é de que estas ferramentas são dificilmente acessadas diretamente por usuários e normalmente acabam utilizando alguma das outras formas de apresentação como intermediário. Entretanto, são duas funcionalidades que permitem uma análise de dados diferenciada e elaborada, que corroboram o conceito de Business Intelligence no sentido de criar novos conhecimentos.

A segunda observação diz respeito a como tratar os métodos preditivos e a mineração de dados, isto é, considerá-los separadamente ou como uma entidade única dentro da pesquisa. Apesar da diferenciação sugerida no Marco Teórico com base em dois argumentos (complexidade e conhecimento a priori), na pesquisa optou-se por tratá-los em conjunto, pois não parece existir uma distinção pragmática e evidente entre os dois para a maioria dos usuários, talvez pelo estágio de maturidade destas ferramentas ainda não ser muito avançado em muitas organizações no Brasil. Esta união foi promovida após os primeiros testes de questionários e discussões iniciais com entrevistas e recursos experientes de BI.

\section{Proposição III}

Dentro das organizações, a associação entre os usuários e as funcionalidades é realizada tanto de maneira formal quanto informal, mas não é uma preocupação significante dentro das estratégias e ações de BI das organizações brasileiras. Esta associação é influenciada por diversos fatores:

- Conhecimento técnico do usuário;

- $\quad$ Características pessoais do usuário;

- Cargo ou nível hierárquico do usuário;

- $\quad$ Papel desempenhado pelo usuário;

- $\quad$ Tipo da informação que o usuário necessita;

- $\quad$ Nível de detalhamento da informação que o usuário necessita;

- $\quad$ Objetivo que o usuário quer atender;

- Cultura e outros aspectos organizacionais; 
Mais uma vez esta proposição é baseada nas observações, distinções e classificações propostas por Ponniah (2001) e Eckerson (2009) e Nemati et al (2010), complementadas com a vivência e experiência do pesquisador desta obra em projetos de Business Intelligence.

Esta proposição está logicamente relacionada com o objetivo de entender como ocorre a associação entre estes grupos de usuários e as diversas ferramentas disponíveis, como as organizações lidam com este relacionamento e como o consideram em suas estratégias e ações de BI a fim de obter melhores resultados, assim como de avaliar se na opinião das organizações, o estilo cognitivo do usuário é de fato uma variável relevante para o entendimento dos usuários e para a definição de ferramentas adequadas, dentro das práticas e soluções de BI.

\section{Proposição IV}

Existe uma relação entre o estilo cognitivo dos usuários analíticos e sua escolha por determinadas funcionalidades disponíveis em aplicações de Business Intelligence, isto é, pessoas com determinadas características de personalidade preferem determinados tipos de funcionalidades por se ajustarem melhor a sua forma de raciocinar e de decidir.

Com base na pesquisa de Felder et al (2002), são realizadas as seguintes sugestões considerando as quatro dicotomias provenientes da teoria dos tipos psicológicos.

A. Indivíduos introvertidos (I) têm uma maior preferência por ferramentas como relatórios OLAP e que envolvam modelos preditivos e mineração de dados, uma vez que estes instrumentos permitem uma maior interação com o mundo mais abstrato dos conceitos e das idéias. Por outro lado, indivíduos extrovertidos (E) têm uma maior preferência por ferramentas como painéis e relatórios pré-formatados.

B. Indivíduos intuitivos $(\mathrm{N})$ também têm uma maior preferência por ferramentas como relatórios OLAP e que envolvam modelos preditivos e mineração de dados, uma vez que eles dão mais espaço para a captação de informações através da descoberta e, portanto, da intuição e da experiência. Por outro lado, indivíduos sensitivos (S), com forte influência 
dos cinco sentidos, têm uma maior preferência por ferramentas como painéis e relatórios pré-formatados que já apresentam fatos concretos à mão.

C. Não há distinções claras e significativas entre indivíduos do tipo pensamento (P) e sentimento $(\mathrm{F})$.

D. Indivíduos do tipo percepção (P) têm uma maior preferência por ferramentas como relatórios OLAP e que envolvam modelos preditivos e mineração de dados, porque sua ênfase é coletar o maior número de informações para tomar suas decisões. Por outro lado, indivíduos do tipo judicativo (J) têm uma maior preferência por painéis e relatórios préformatados, pois lhes permitem tomar decisões mais rápidas e ordenadas. É possível que a função estilo de vida esteja profundamente relacionada com o atual momento do respondente e do seu cargo, isto é, pessoas em posições mais altas na hierarquia organizacional devem apresentar-se mais judicativas, por exemplo.

Esta proposição está logicamente relacionada com o objetivo de verificar, dentro das limitações metodológicas, se existe a relação proposta entre os estilos cognitivos dos usuários analíticos e sua escolha por determinadas funcionalidades disponíveis em aplicações de Business Intelligence.

\section{Proposição V}

As principais preocupações relacionadas com usuários dentro do Business Intelligence com base em Luhn (1958), Scheps (2008), Brunson (2005), Keyes (2006), dentre outros autores avaliados no Marco Teórico, são:

- $\quad$ Associação entre informações e usuários;

- Associação entre ferramentas e usuários;

- Capacitação técnica e funcional;

- $\quad$ Facilidade de uso das ferramentas;

- Cultura analítica da organização; 
Esta proposição está logicamente relacionada com o objetivo de examinar dentro das organizações como os temas relacionados a usuários são abordados e identificar a importância que elas outorgam às diversas preocupações relacionadas na literatura de referência.

\subsection{Unidade de Análise}

Neste trabalho, a unidade de análise refere-se ao processo de definição, associação e relacionamento entre usuários de BI e as diversas funcionalidades destes aplicativos. A partir desta definição da unidade de análise, é possível afirmar que este é um Estudo de Caso instrumental, pois a motivação está na crença de que o estudo pode colaborar para o entendimento de uma idéia mais ampla e incorporado, dado que são observadas diferenças entre os componentes da mesma unidade que servem o propósito de obter maiores informações a respeito do todo. Em relação ao número de casos onde a unidade de análise será avaliada, este Estudo de Caso é simples e típico, pois, em primeiro lugar, tem apenas um sujeito que representa uma oportunidade única de estudo e, em segundo lugar, este sujeito parece ser convencional e usual, servindo como ilustração do referencial adotado.

O sujeito escolhido para ser avaliado pertence ao setor bancário brasileiro e é uma organização privada que está entre os cinco maiores no país neste ramo de atividade. Por solicitação expressa dos entrevistados e dos representantes da entidade, o nome da instituição é omitido, sendo substituída em toda a dissertação apenas por Banco Alfa, uma descrição fictícia. Como esta organização é o resultado de uma fusão, eventualmente podem ser mencionadas as instituições de origem, isto é, Bancos Beta e Gama, ambos os nomes fictícios.

A opção por uma organização do setor bancário deve-se principalmente às características peculiares desta indústria, que lhe conferem um contexto propício para o estudo, isto é, é um mercado extremamente dinâmico, altamente competitivo e lucrativo, focado em resultados e, ao mesmo tempo, limitado por rígidos controles e regulamentações legais (UBIPARIPOVIĆ e ĐURKOVIĆ, 2011, p.23). Suas necessidades tecnológicas e informacionais são variadas e afetam desde a automatização de processos e desenvolvimento de novos produtos, segmentos e mercados à administração de riscos operacionais, segurança da informação e atendimento a diversas normas e regras nacionais e internacionais. Estas demandas, em conjunto com a própria natureza do negócio que hoje é praticamente virtual, se traduzem numa dependência 
essencial da tecnologia da informação (muito mais do que se observa em outras indústrias) e exigem organizações com uma postura moderna, receptiva, proativa e prática em relação à tecnologia, um fator crítico para responder adequadamente a sofisticação, flexibilidade e complexidade demandadas.

Particularmente no Brasil, as maiores instituições bancárias ilustram este cenário, pois têm utilizado intensamente a TI “(...) para interligar todas as suas agências em nível nacional, para processar um número muito grande de transações e atender uma quantidade de clientes, dentro e fora das agências, de forma rápida, segura e, muitas vezes, personalizada" (ALBERTIN, 1999, p.54). Em comparação com outros setores, Faria e Maçada (2011, p.441) afirmam que “(...) o mercado bancário [brasileiro] é o maior consumidor de produtos e serviços de TI" com um orçamento total para a TI que supera os R $\$ 16$ bilhões em 2008 e investimentos da ordem de $\mathrm{R} \$ 6,4$ bilhões.

Além das necessidades relacionadas ao negócio, outro fator que diferencia os bancos em geral e lhes confere um interesse especial em tecnologia (especialmente em soluções de Business Intelligence) é o grande volume de dados de transações e clientes que é coletado diariamente e que, de alguma maneira, deve ser processado e analisado e deve auxiliar nas decisões e gerar resultados práticos. Analisar o resultado de um novo produto de crédito, avaliar riscos potenciais de inadimplência, comparar resultados do banco por segmentos, associar os produtos adequados aos clientes corretos e criar modelos econométricos para tomar decisões estratégicas são apenas alguns exemplos de atividades que exigem de uma organização bancária um conhecimento e desenvolvimento analítico mais avançado das funcionalidades oferecidas pelo BI. Em outras palavras, como a informação é um ativo essencial para a sobrevivência a curto, médio e longo prazo de uma organização bancária, o nível de maturidade destas instituições tende a ser mais alto do que se observa em outros segmentos da economia, o que pode se traduzir numa visão mais ampla e mais rica para o estudo em questão.

Além disso, os grandes volumes de dados não só exigem equipamentos e soluções tecnológicas de ponta, com recursos variados e alto desempenho, mas uma equipe equilibrada e capacitada de recursos humanos que viabilizem a transformação desta profusão de dados em informações relevantes e novos conhecimentos. Neste caso, a quantidade de recursos dedicados ao Business Intelligence dentro de um banco de grande porte permite avaliar a 
existência de uma relação entre o estilo cognitivo dos usuários e sua escolha por funcionalidades destas aplicações num conjunto amostral relativamente homogêneo e até certo ponto representativo (um dos objetivos declarados no início desta obra).

A escolha pelo sujeito desta pesquisa, o Banco Alfa, baseia-se então nos critérios supramencionados: é uma organização com postura moderna, receptiva, proativa e prática em relação à tecnologia, identificada como sofisticada, inovadora e avançada e com uma posição de destaque dentro do mercado brasileiro; é uma instituição financeira de grande porte que encara a informação como um ativo essencial e que tem uma ampla, capacitada e dedicada equipe analítica que agregar valor; e, finalmente, é uma corporação resultante de uma fusão recente de outros bancos, o que garante uma variável adicional extremamente interessante para a análise que se deseja realizar. A priori, considera-se o Banco Alfa como um sujeito típico no sentido de que é convencional e usual na forma como lida com a unidade de análise, apesar de seu nível de maturidade de BI ser mais avançado que grande parte das organizações - o que poderia lhe conferir um caráter mais excepcional e não usual.

\subsection{Ligação entre Dados e Proposições}

Em relação ao encadeamento lógico, opta-se nesta dissertação por apresentar uma sequiência de tópicos gerais do caso (mais amplos e genéricos) a fim de familiarizar o leitor ao contexto do sujeito de análise, para então abordar e aprofundar-se nos temas específicos e detalhados das proposições. Espera-se, desta forma, uma construção lógica que preserve o contexto e que permita ao leitor acompanhar a interpretação e as conclusões do autor, relacionando estas às proposições iniciais e mantendo o ‘encadeamento de evidências' (YIN, 2001, p.127; SOUZA, 2000, p.78).

Portanto, em primeiro lugar são apresentadas características do setor bancário brasileiro, uma breve história do sujeito e uma revisão concisa da área de Tecnologia da Informação e de Business Intelligence da organização; e, em segundo lugar, são descritas separadamente as observações e as análises de cada uma das cinco proposições sugeridas anteriormente.

Em relação à amarração entre as idéias, esta dissertação combina aspectos de 'adequação ao padrão' e de 'construção da explanação'. Em primeiro lugar, porque ao início de cada um dos 
tópicos abordados no Estudo de Caso (daqueles relacionados com as proposições) é indicado o padrão prognóstico relevante (se existir) a fim de permitir a análise frente ao padrão. Em segundo lugar, porque a cada um dos tópicos, observações, opiniões e interpretações levantadas pelos diferentes métodos de coleta e pelas diferentes fontes são mescladas pela narrativa e sempre que possível são estabelecidos elos causais entre estes insumos de modo a dar sentido lógico e garantir a coesão e coerência do texto.

\subsection{Critérios para Interpretar os Resultados}

Buscando uma maior qualidade e rigor das interpretações e como não há um referencial claro definido para este tópico, a alternativa do autor desta obra é atentar e atender ao menos os quatro testes fundamentais de validade e confiabilidade destacados por Yin para um Estudo de Caso. Além disso, como alerta Souza (2000, p.80) em seu estudo, toma-se um cuidado especial na geração de conclusões, evitando-se qualquer tipo de generalizações, tendo em conta que os resultados não podem ser generalizados nem de maneira estatística (o enfoque não é quantitativo) e nem de maneira analítica (o Estudo de Caso não é múltiplo).

Assim, em relação à validade de construto, observam-se as seguintes orientações: são utilizadas fontes múltiplas de coleta de evidências visando a triangulação, a saber, pesquisa documental, entrevistas em profundidade, questionários individuais e inclusive um levantamento de proporções reduzidas; é construído o encadeamento de evidências de forma lógica e considerando as proposições definidas a priori; foram desenvolvidos instrumentos de pesquisa específicos para cada fonte de coleta, revisados por informante chave com conhecimento não só da unidade de análise, mas do sujeito; estes instrumentos foram aplicados pelo próprio pesquisador, que também se responsabilizou pelo tratamento e análise dos resultados.

Em relação à validade interna, conforme destacado anteriormente houve uma preocupação com a amarração de idéias e conceitos, procurando um misto entre a técnica da 'adequação ao padrão' e a 'construção da explanação'. Como não se trata de um Estudo de Caso múltiplo, a validade externa não pode ser totalmente garantida, contudo, o material gerado para a realização do Estudo de Caso único permite a realização de futuras replicações. 
Finalmente, em relação à confiabilidade, durante a pesquisa de campo houve a construção de um protocolo estruturado (alguns dos elementos deste protocolo encontram-se nos anexos ao final desta obra) e também houve uma preocupação com processamento e armazenamento dos registros e informações coletadas ao longo da pesquisa. Os dados foram coletados de forma estruturada e posteriormente organizados em relatórios ou arquivos em bases de dados, principalmente os resultados do questionário e do Diagnóstico de Tipos Psicológicos aplicados no levantamento.

\subsection{Coleta de Dados}

\section{Entrevistas}

Nas entrevistas semi-estruturadas e em profundidade realizadas durante a pesquisa de campo, o instrumento de pesquisa foi um roteiro construído a partir do referencial teórico abordado anteriormente (em anexo ao final desta obra). Ele é composto por questões abertas organizadas por tópicos de acordo com as proposições e os objetivos de pesquisa. Ao contrário de outras pesquisas, o roteiro não era encaminhado com antecedência aos entrevistados; o objetivo desta estratégia era dar maior flexibilidade tanto para o pesquisador quanto para o entrevistado, permitindo a adaptação dos questionamentos de acordo com as características de cada respondente, o andamento mais natural e informal da entrevista e a observação e a captura de respostas mais espontâneas e inesperadas (ou pelo menos não preparadas).

A princípio o público-alvo das entrevistas durante a pesquisa de campo era composto de gerentes de áreas com algum tipo de envolvimento com as ferramentas de Business Intelligence, isto é, recursos da organização responsáveis pela direção das políticas de BI e pelas principais decisões relacionadas com as ferramentas analíticas. Deste modo buscou-se o contato com áreas de negócio, onde se encontram os usuários finais destas funcionalidades, áreas técnicas, onde se encontram os desenvolvedores responsáveis por atender as demandas, e eventuais áreas mediadoras, onde se encontram os recursos responsáveis por intermediar e traduzir os requisitos e conceitos de negócio em especificações técnicas (por exemplo, equipes de projeto de implementações). Visando construir um recorte mais completo, 
representativo e compreensível do caso, procurou-se então complementar este público-alvo inicial de três formas. Em primeiro lugar, buscou-se a opinião de entrevistados de outros níveis hierárquicos dentro organograma da instituição, ou seja, por um lado superintendentes com uma visão mais estratégica do tema e, por outro, coordenadores ou analistas com uma visão mais operacional. Em segundo lugar, como o sujeito da pesquisa é um banco de grande porte, com participação em diferentes segmentos e com uma vasta estrutura organizacional, procurou-se contar com opiniões de diferentes áreas a fim de avaliar se existem diferenças fundamentais de encarar o assunto em pauta. Em terceiro lugar, procurou-se a opinião imparcial de um recurso externo, mas com experiência e vivência do Banco Alfa, visando a validação das informações coletadas e a eliminação de vieses e exageros positivos ou negativos - uma forma de triangulação.

Tendo em vista as premissas do público-alvo declaradas, foram realizadas seis entrevistas em profundidade que duraram de 1 a 2 horas, distribuídas da seguinte forma: 1 superintendente, 1 gerente, 3 analistas e 1 consultor externo. Alguns destes colaboradores eram de áreas técnicas (Diretoria de Business Intelligence), outros de áreas de negócio (Diretoria de Controladoria e Diretoria de Crédito Empresas), e ainda houve aqueles que estavam alocados a projetos específicos. Por solicitação dos próprios entrevistados, os nomes são omitidos de modo a garantir o anonimato, sendo utilizados os códigos destacados no quadro 8 a seguir, identificando as diferentes respostas. Para dar riqueza à análise dos dados, permitindo algumas interpretações do leitor, a primeira letra do código refere-se ao cargo do entrevistado (superintendente, gerente ou analista) e a segunda letra refere-se à área (negócio ou TI).

\begin{tabular}{|c|c|c|c|}
\hline $\begin{array}{c}\text { Código do } \\
\text { Entrevistado }\end{array}$ & Cargo & Área & $\begin{array}{c}\text { Experiência } \\
\text { Profissional }\end{array}$ \\
\hline ST1 & Superintendente de TI & Business Intelligence & 18 anos, 4 no Alfa \\
\hline GN1 & Gerente de Negócio & Controladoria & 12 anos, 12 no Alfa \\
\hline AN1 & Analista de Negócio & Controladoria & 3 anos, 2 no Alfa \\
\hline AN2 & Analista de Negócio & Crédito Empresas & 8 anos, 6 no Alfa \\
\hline AT1 & Analista de TI & Business Intelligence & 25 anos, 15 no Alfa \\
\hline CE1 & Consultor Externo & - & 13 anos, 2 no Alfa
\end{tabular}

Quadro 8. Perfil dos Entrevistados 
Todas as entrevistas foram agendadas previamente e respeitaram a disponibilidade de tempo do respondente. Elas foram realizadas pelo próprio pesquisador, individualmente e no local de trabalho de cada entrevistado ao longo dos meses de junho e julho de 2012. Com duração média de uma hora e meia, foram gravadas e posteriormente transcritas, servindo de base para a análise de dados.

\section{Levantamento}

Com a finalidade de avaliar um dos objetivos estabelecidos inicialmente, isto é, verificar se existe uma relação entre estilos cognitivos e a preferência por determinada funcionalidade de Business Intelligence, também fez parte desta pesquisa a realização de um levantamento simplificado, de caráter exploratório e baseado numa amostra não probabilística e não representativa da população. De acordo com Godoy (1995, p.26), ainda que essencialmente qualitativos, os Estudos de Caso também podem comportar abordagens tipicamente quantitativas para esclarecer alguma questão ou tópico da investigação, mesmo que a análise estatística seja pouco sofisticada e robusta.

Inicialmente, considerando o referencial teórico coletado, foram definidos e construídos dois questionários. O primeiro deles, chamado de 'Questionário Business Intelligence' (em anexo ao final da obra), foi montado com base nas variáveis levantadas na bibliografia mais técnica sobre este tema particular e seu objetivo primordial era identificar qual a funcionalidade preferencial do respondente dentre as cinco opções genéricas encontradas com o apoio da literatura: painéis de informação (ou dashboards), relatórios pré-formatados (isto é, relatórios prontos para uso), relatórios ad hoc (isto é, relatórios ocasionais que o próprio usuário pode criar), relatórios OLAP (isto é, tabelas dinâmicas e cubos) e relatórios baseados em Modelos Preditivos e Mineração de Dados.

Como explicitado na matriz de variáveis e indicadores (representada no quadro 9 da próxima página), o questionário também procurava identificar características gerais do respondente, descobrir o nível de conhecimento e freqüência de uso de cada uma destas funcionalidades e avaliar na opinião do indivíduo quais aspectos influenciam mais ou menos a escolha pelas diferentes funcionalidades de apresentação. 


\begin{tabular}{|c|c|}
\hline Variáveis & Indicadores \\
\hline $\begin{array}{l}\text { Características Gerais do Respondente; } \\
\text {. Idade e sexo } \\
\text {. Grau de Instrução e Formação Acadêmica } \\
\text {. Experiência Profissional (dentro e fora da organização) } \\
\text {. Cargo e Área atuais }\end{array}$ & $\begin{array}{l}\text { Anos (contínua), sexo (ordinal } \\
\text { dicotômica), grau de instrução (ordinal), } \\
\text { formação (ordinal), experiência } \\
\text { (contínua), cargo (ordinal) e área } \\
\text { (ordinal) }\end{array}$ \\
\hline $\begin{array}{l}\text { Conhecimento nas Funcionalidades de BI: } \\
\text {. Painéis de informação } \\
\text {. Relatórios pré-formatados } \\
\text {. Relatórios ad hoc (ocasionais) } \\
\text {. Relatórios OLAP } \\
\text {. Relatórios de Modelos Preditivos e Mineração de Dados }\end{array}$ & Nota em escala de 10 pontos (ordinal) \\
\hline $\begin{array}{l}\text { Freqüiência de Uso das Funcionalidades de BI: } \\
\text {. Painéis de informação } \\
\text {. Relatórios pré-formatados } \\
\text {. Relatórios ad hoc (ocasionais) } \\
\text {. Relatórios OLAP } \\
\text {. Relatórios de Modelos Preditivos e Mineração de Dados }\end{array}$ & Nota em escala de 10 pontos (ordinal) \\
\hline $\begin{array}{l}\text { Preferência por Funcionalidade de BI: } \\
\text {. Painéis de informação } \\
\text {. Relatórios pré-formatados } \\
\text {. Relatórios ad hoc (ocasionais) } \\
\text {. Relatórios OLAP } \\
\text {. Relatórios de Modelos Preditivos e Mineração de Dados }\end{array}$ & $\begin{array}{l}\text { Múltipla escolha } \\
\text { (ordinal) }\end{array}$ \\
\hline $\begin{array}{l}\text { Aspectos de Influência da Escolha: } \\
\text {. Papel ou função desempenhado pelo usuário final } \\
\text {. Tipo da informação } \\
\text {. Necessidade de negócio do usuário final } \\
\text {. Conhecimento técnico do usuário final } \\
\text {. Nível de detalhamento da informação } \\
\text {. Características pessoais do usuário final } \\
\text {. Cultura analítica da organização }\end{array}$ & $\begin{array}{l}\text { Ranking de } 1 \text { a } 7 \\
\text { (ordinal, postos) }\end{array}$ \\
\hline
\end{tabular}

\section{Quadro 9. Matriz de Variáveis e Indicadores do Questionário}

Com base nestes critérios e com o apoio de um site especializado em questionários eletrônicos, foi criado pelo pesquisador um questionário online de 15 questões (de diferentes formatos), todas de preenchimento obrigatório e que seguiram boas práticas de elaboração de questionários como evitar questões abstratas, utilizar uma linguagem acessível, seguir um padrão lingüístico, incluir explicações claras sobre conceitos ou ferramentas, etc.. Uma versão inicial do questionário foi testada e revisada com um usuário chave. Um dos resultados desta revisão foi justamente o tratamento combinado dos métodos preditivos e a mineração de dados, uma vez que não há uma distinção pragmática e evidente entre os dois para a maioria dos usuários. Também se discutiu a própria eliminação por completo destas ferramentas do questionário, pois invariavelmente utilizam alguma das outras formas de apresentação; 
contudo, para fins de conhecimento e exploração, julgou-se mais interessante manter a variável no questionário. O tempo de resposta aproximado é de 5 minutos.

O segundo questionário, o 'Diagnóstico de Tipos Psicológicos' (ou simplesmente DTP), é um instrumento de pesquisa elaborado pela Prof. Dra. Tânia Casado em 1998 cujo objetivo primordial é identificar o tipo psicológico de um indivíduo baseado no modelo teórico proposto por Jung e posteriormente complementado por Myers e Briggs. Assim, é um instrumento similar em conteúdo, forma e objetivo ao internacionalmente conhecido MBTI, mas orientado para a realidade brasileira, o que lhe confere um papel de destaque no país. Além disso, é uma ferramenta testada por meio de técnicas científicas, com validade comprovada de conteúdo e de constructo, aplicada com sucesso em diversas instituições de ensino e organizações e para fins acadêmicos como em teses e dissertações, por exemplo, em JACOBSOHN (2003) e LENZI (2008).

De modo simplificado, o DTP é um questionário online de 150 questões genéricas sobre situações de cotidianas onde o respondente deve optar por apenas uma dentre duas opções exibidas. Assim como no MBTI, seu resultado final é o tipo psicológico do indivíduo identificado por quatro letras (uma para cada escala avaliada) e quatro valores que representam a intensidade de cada uma destas quatro escalas. O resultado global descreve a personalidade e as preferências entre aspectos do respondente em determinado contexto, mas não é perfeitamente preciso, pois varia dependendo de diferentes questões ambientais. $\mathrm{O}$ importante é destacar que este resultado não mede nível intelectual ou capacidade cognitiva, apenas procura esclarecer o comportamento nas diferentes situações propostas e, dessa forma, não deve ser considerado pejorativo ou laudatório. O tempo de resposta neste caso é de 30 a 40 minutos.

O público-alvo do levantamento foi um desafio particular, uma vez que há uma quantidade considerável de variáveis independentes envolvidas, sobre as quais o pesquisador não tem controle e que poderiam influir negativamente nos resultados, principalmente numa amostra de proporções reduzidas. Além disso, a fim de obter conclusões significantes era preciso que o número de observações fosse grande o suficiente para permitir análises estatísticas devido à quantidade de variáveis envolvidas. 
Em relação ao primeiro tema, levantou-se primeiramente a questão da influência do cargo dos respondentes sobre a preferência, pois tratar respostas de diretores e supervisores (cargos executivos) da mesma forma que estagiários ou analistas inexperientes (cargos operacionais) poderia gerar potenciais anomalias. Por este motivo optou-se em concentrar os esforços numa equipe intermediária de analistas plenos e seniores. Em segundo lugar levantou-se a questão do impacto da área dos respondentes sobre a preferência, decorrente não só das diferenças entre equipes de negócio ou técnicas, mas da própria diferença entre as áreas da organização (como, por exemplo, uma diretoria de crédito e uma de cobrança): cada área tem suas particularidades que influem no modo de pensar e agir, o que dificulta as análises e pode fragilizar conclusões. Neste caso optou-se por selecionar respondentes de apenas uma área (no caso a Diretoria de Crédito Empresas) e que, além disso, faziam parte da equipe híbrida responsável pela mediação entre negócio e TI, visando perfis com um equilíbrio entre o conhecimento de negócio e o conhecimento técnico. De forma similar, também se levantou a questão da influência da instituição sobre a preferência, decorrente, por exemplo, das diferenças de cultura organizacional: um banco de investimento pode priorizar ou indiretamente incentivar ferramentas e funcionalidades diferentes daquelas de um banco de varejo. Por isso (e pela evidente restrição de tempo) optou-se por concentrar o levantamento apenas no sujeito do Estudo de Caso, o Banco Alfa.

De forma resumida, procurou-se então um público minimamente homogêneo a fim de evitar ao máximo variáveis sobre as quais não se tinha controle e, além disso, um público mais extenso, onde fosse possível obter uma amostra representativa que permitisse encontrar conclusões minimamente significantes. Deste modo, o público-alvo (isto é, a população deste levantamento) era composto pelos analistas de sistemas da Diretoria de Crédito para Empresas do Banco Alfa, equipe com 59 pessoas.

Uma vez definido o público-alvo foi estabelecido o contato oficial com a área selecionada e realizou-se a apresentação da pesquisa (através de carta anexa a dissertação), assim como dos questionários que seriam aplicados, demonstrando que não seriam abordados tópicos confidenciais ou de exposição pessoal. Além disso, para incentivar a participação dos respondentes, acordou-se com o representante do banco que após a conclusão dos questionários o resultado do Diagnóstico de Tipo de Personalidade seria encaminhado individualmente, de forma gratuita e sigilosa para cada participante da pesquisa (o modelo se encontra em anexo). 
Como os dois questionários já existiam em sua versão eletrônica e online (no caso do DTP é necessário criar previamente usuários e senhas para a participação efetiva), o procedimento de coleta foi inteiramente eletrônico, atendendo assim uma das restrições impostas pelo banco de não afetar o cotidiano de trabalho. No início de maio foi encaminhado para os participantes um correio eletrônico com as orientações gerais da pesquisa (em anexo ao final da obra) com dois endereços eletrônicos para acesso e preenchimento dos questionários. Em meados de maio e início de junho foram encaminhados lembretes aos participantes que não haviam participado e os questionários permaneceram em aberto até o final de junho de 2012, isto é, por um período de dois meses. Ao final da coleta foi iniciado o tratamento dos dados, a começar pela conversão das respostas do DTP nos tipos psicológicos. 


\section{ESTUDO DE CASO}

A seguir são apresentadas as principais observações do Estudo de Caso. Em primeiro lugar são apresentadas características do setor bancário brasileiro, uma breve história do Banco Alfa, com uma revisão concisa da Tecnologia da Informação e do Business Intelligence no setor e na organização (inclusive tratando da proposição II). Em seguida são descritas separadamente as observações e as análises de acordo com cada uma das demais proposições sugeridas anteriormente.

\subsection{Setor Bancário no Brasil}

\subsubsection{Histórico do Setor Bancário}

Apesar da fundação do primeiro banco brasileiro ter ocorrido de forma prematura em 1808, quando o país se tornou a sede da Coroa devido à fuga da Família Real Portuguesa para o país (BANCO DO BRASIL, 2010, p.14), a rigor não de pode falar de um sistema bancário estabelecido, nem mesmo subdesenvolvido, durante todo o século XIX (COSTA, 2010, p.6). De certa forma este cenário era o reflexo direto de uma economia arcaica, essencialmente extrativista e agrária, caracterizada “(...) por dificuldades decorrentes da escassez de meio circulante e da inexistência de um mercado de capitais desenvolvido" (FIGUEIREDO FILHO, 2005, p.22).

Apenas no início do século XX, com a abertura financeira ao exterior e o surgimento das condições institucionais mínimas necessárias (COSTA, 2010, p.8), o setor bancário de fato iniciou sua evolução dentro do país. Contudo, foi uma infância atribulada, pois a primeira metade do novo século foi marcada por fortes instabilidades e oscilações internacionais em decorrência da Primeira Guerra Mundial (1914 a 1918) e da Crise de 1929 que afetaram profundamente as economias em todo o mundo. A evasão de capitais estrangeiros nestes eventos e o fim das experiências com o padrão-ouro acabaram motivando a articulação de uma nova estratégia para o setor, fundamentada na imposição de uma reserva de mercado a favor de bancos nacionais, na flexibilização da legislação propiciando a criação de novas 
instituições e na participação de bancos públicos para o desenvolvimento e fomento da economia (COSTA, 2010, p.9-12). Nesta época, aproveitando-se dos incentivos e das poucas barreiras de entradas, surgiram os principais bancos brasileiros e, segundo Costa (2010, p.15), observou-se uma fase competitiva dentro do setor com o número de instituições dobrando num período de apenas cinco anos (de 354 instituições em 1940 para 663 em 1944).

Este período inicial rico em experimentações proporcionou “(...) certo grau de experiência, um ambiente propício e o reconhecimento da necessidade de aperfeiçoamento da regulamentação bancária, monetária e cambial no Brasil" (FIGUEIREDO FILHO, 2005, p.31). Assim, o início da segunda metade do século XX foi marcado pelo desenvolvimento de mecanismos de controle e monitoração do setor, visando definir e obviamente aplicar regras mais rígidas (como exigências de reservas bancárias) e restrições legais para práticas até então aceitáveis e corriqueiras (COSTA, 2010, p.18-19). Um exemplo disso foi a própria criação da Superintendência da Moeda e do Crédito (SUMOC), instituição antecessora do Banco Central. Apesar de ter como objetivo definir uma política monetária com vistas para o controle da inflação, pois a economia brasileira passava por dificuldades decorrentes do descontrole dos gastos públicos e aceleração inflacionária, a SUMOC era a autoridade central e regulatória do setor bancário, responsável pelas “(...) políticas de controle dos meios de pagamento, do sistema bancário e do crédito com vistas à estabilidade monetária" (FIGUEIREDO FILHO, 2005, p.55). Neste mesmo período também ocorreram a expansão geográfica da rede nacional de agências bancárias e a concentração do setor: o número de instituições caiu das 663 em 1944 para 328 em 1964 e, mais tarde, 106 em 1974 (COSTA, 2010, p.16).

Ao contrário das décadas anteriores, a de 1960 foi um período particularmente agitado para o setor bancário, reflexo direto do momento histórico no qual o país estava imerso. Em 1964, o Brasil sofria com os efeitos negativos do crescimento da inflação, do descontrole de gastos públicos e do desequilíbrio econômico instaurado (BANCO DO BRASIL, 2010, p.190; ERCOLIN, 2009, p.21), além da instabilidade social vivida nas ruas. "Agitações estudantis e operárias, revoltas militares e invasões de terra eclodiam pelo território nacional" (BANCO DO BRASIL, 2010, p.190) e, temendo pelas instituições e pelos poderes constitucionais, ocorreu o golpe militar de 31 de março de 1964. Para o setor bancário, o golpe culminou na reforma bancária de 1964 e no processo de "repressão financeira" que tratou da reformulação e reorganização do sistema nacional bancário (e de suas principais instituições), 
modernizando-o e fortalecendo-o (COSTA, 2010, p.25). Apesar da ampliação das exigências e controles da época, para os grandes bancos já estabelecidos o período teve um saldo positivo, pois induziu a uma maior concentração das instituições, possibilitou a criação de grupos conglomerados, estimulou a internacionalização dos bancos nacionais e, principalmente, resultou numa situação extremamente lucrativa uma vez que o problema da inflação não foi de fato solucionado (COSTA, 2010, p.25-27).

Após 24 anos, a regulamentação bancária foi novamente alterada na Constituição de 1988. Observou-se então um processo de liberalização do setor, com o fim da exigência da cartapatente (autorização do Banco Central para operação de novos bancos), o fim da reserva de mercado (portanto, abertura ao capital externo) e a formalização dos bancos de atuação múltipla (com permissão para exercer praticamente qualquer serviço financeiro) (COSTA, 2010, p.16). Mas para Ferreira (2005, p.10), “a nova legislação, aliada a um quadro macroeconômico de alta inflação, ao qual as instituições financeiras souberam se adequar e tirar proveito, permitiu um crescimento da indústria bancária que aumentou sua participação na renda nacional"; em outras palavras, um período de ouro para o mercado financeiro, apesar de dramático para o restante da economia brasileira, com a aceleração da inflação e a dificuldade do governo em se financiar.

Este cenário persistiu até a implantação do Plano Real no segundo semestre de 1994, que “(...) reduziu a inflação drasticamente e, com ela, a receita dos bancos" (FERREIRA, 2005, p.11). "A perda dessas receitas [relacionadas com a inflação], aliada a práticas administrativas que dificultavam a adaptação ao novo ambiente econômico tornou diversas instituições bastante frágeis", resultando numa crise bancária sem precedentes. Dentre os impactos mais marcantes deste choque, destacam-se: a liquidação de grandes bancos privados nacionais, como o Econômico e Nacional que quebraram e o Bamerindus que foi comprado em 1995; a privatização de bancos públicos estaduais, como o Banespa no Estado de São Paulo; a reestruturação patrimonial das instituições financeiras públicas federais; o aumento na concentração bancária em decorrência da insolvência de algumas instituições; e a desnacionalização bancária com a entrada progressiva de grandes grupos internacionais, como o HSBC e Banco Santander (COSTA, 2010, p.34; FERREIRA, 2005, p.10).

Durante esta difícil transição, um período de readequação ao novo padrão, os bancos tiveram de se reinventar e de se modernizar, revendo suas estratégias, seus produtos e inclusive seus 
processos. Obviamente, em alguns casos foi necessária a participação e articulação do governo através do Programa de Estímulo à Reestruturação e ao Fortalecimento do Sistema Financeiro Nacional (PROER), principalmente no período que sucedeu a entrada em vigor do Plano Real. Contudo, num curto espaço de tempo, os grandes bancos brasileiros (assim como os novos estrangeiros) adequaram-se a este novo cenário, promovendo a popularização bancária e a expansão do crédito (além do aumento da rentabilidade através de economias de escala obtidas através de fusões e aquisições) (COSTA, 2010, p.38), colaborando para o amadurecimento do setor bancário e conseqüentemente do sistema financeiro nacional.

Atualmente o setor bancário brasileiro é extremamente dinâmico, altamente competitivo e lucrativo, apesar das limitações com os rígidos controles e regulamentações legais nacionais e internacionais. Também é o maior, o mais desenvolvido e mais rico dentro da América Latina, com aproximadamente 180 instituições (bancos múltiplos, comerciais, de desenvolvimento, de investimento e caixas econômicas) (COSTA, 2010, p.17), 20 mil agências, 13 mil postos bancários e 180 mil caixas automáticos (ATMs) (FEBRABAN, 2011, p.4-8). De acordo com números recentemente divulgados pela Febraban (2011, p.5-6), em conjunto, estas cerca de 180 instituições são responsáveis por aproximadamente 56 bilhões de transações bancárias realizadas por 141 milhões de contas correntes, 153 milhões de cartões de crédito e 38 milhões de clientes com acesso ao internet banking.

\subsubsection{Tecnologia da Informação no Setor Bancário}

O setor bancário brasileiro também é dos mais inovadores e avançados tecnologicamente não só na América Latina, mas no mundo; é uma indústria onde se observa uma ampla utilização e aplicação de informática e tecnologias diversas de telecomunicações, o que faz dela um referencial de informatização de status comparável (em alguns casos, muito superior) a países desenvolvidos (DINIZ, 2004, p.55). No país, as maiores instituições têm utilizado intensamente a TI “(...) para interligar todas as suas agências em nível nacional, para processar um número muito grande de transações e atender uma quantidade de clientes, dentro e fora das agências, de forma rápida, segura e, muitas vezes, personalizada" (ALBERTIN, 1999, p.54). 
Na verdade, a Tecnologia da Informação é um dos principais fatores que viabilizaram o desenvolvimento da indústria bancária no Brasil, sendo considerada uma das forças que tem acelerado as principais mudanças no setor (ALBERTIN, 1999, p.54). Em pouco mais de 50 anos, tornou-se uma força vital e irreversível no cotidiano dos bancos, gerando um quadro de dependência maciça, ilimitada e sem precedentes. Hoje, a natureza do negócio bancário é praticamente virtual, o que exige das organizações uma postura moderna, receptiva, proativa e prática em relação à tecnologia, um fator crítico para responder adequadamente a sofisticação, flexibilidade e complexidade demandadas e, certamente, uma barreira de entrada para novos concorrentes no setor, o que explica a tendência de manutenção na concentração. Evidentemente, dois aspectos importantes possibilitaram este avanço tecnológico dos bancos: em primeiro lugar, a receptividade do brasileiro no sentido de adotar novas tecnologias mesmo envolvendo recursos e riscos financeiros e, em segundo lugar, a cooperação entre os próprios bancos concorrentes em busca de um objetivo comum (KASSAB, 2011, p.62).

Segundo Kassab (2011, p.38-39), a aplicação da tecnologia da informação nos bancos do Brasil iniciou-se nos anos 1960, mais precisamente em 1964, em virtude das novas demandas processuais e da expansão territorial exigidas com a reforma bancária do período. Neste primeiro período (que durou até meados de 1970), houve a introdução gradual da computação nas atividades operacionais e administrativas com a finalidade principal de apoiar o processamento centralizado de dados (KASSAB, 2011, p.38). Em outras palavras, a TI estava concentrada na automatização de processos e no controle centralizado das atividades em escala nacional, viabilizando a expansão territorial. Apesar da resistência inicial como explica Diniz (2004, p.56), com a liderança de Olavo Setúbal e Amador Aguiar, Itaú e Bradesco, respectivamente, foram os principais pioneiros na adoção e aplicação dos primeiros computadores ao negócio, demonstrando uma postura visionária em relação à tecnologia que se mantém até hoje.

A segunda onda, que durou de meados de 1970 a meados de 1980, foi “(...) caracterizada pelo surgimento de tecnologias mais fáceis para se trabalhar, como os minicomputadores e microcomputadores que permitiam distribuir o processamento, automatizar as agências bancárias e aumentar a velocidade das transações” (KASSAB, 2011, p.58). De acordo com Kassab (2011, p.59), neste período a TI passou a ocupar um papel essencial no cotidiano dos bancos tornando-se uma peça chave para alcançar os objetivos e cumprir as estratégias. Neste período "acreditava-se que, quanto mais automatizado fosse um banco, mais clientes ele 
conseguiria" (DINIZ, 2004, p.57). Além disso, a falta de produtos adequados aos requisitos e as medidas governamentais sobre o mercado tecnológico nacional, resultaram na criação de empresas associadas aos bancos, mas concentradas em eletrônica, computação e programação, cujo objetivo era desenvolver novos produtos e soluções tecnológicas para a realidade brasileira (como, por exemplo, a Itautec).

A terceira onda, iniciada com a redemocratização, é marcada pelos planos do governo de controle de inflação e pela abertura do mercado tecnológico brasileiro. Se, por um lado, as novas normas e padrões de cada pacote de medidas exigiam dos bancos e de suas áreas de TI adaptabilidade, flexibilidade e agilidade no atendimento dos novos requisitos, por outro contribuíram para o amadurecimento de estruturas, processos e metodologias de TI (KASSAB, 2011, p.90), a ponto de permitir o início da comoditização e terceirização no setor (KASSAB, 2011, p.97). A maior pressão neste período era para projetos que tivessem como objetivo a eficiência operacional e a redução de custos com o processamento transacional, o que também resultou numa redução dramática do número de funcionários (DINIZ, 2004, p.57-58).

Finalmente, a quarta onda teve início em 1994, com a implantação do Plano Real (e o controle da inflação no país), o processo de globalização financeira e econômica, inclusive com a entrada de bancos estrangeiros no Brasil após a eliminação de barreiras e, praticamente ao mesmo tempo, o advento da internet e o início de sua utilização pelo público brasileiro. "A popularização dos computadores pessoais ao longo dos anos noventa (...)", assim como as facilidades da internet e do mundo virtual levaram “(...) ao surgimento dos conceitos de home banking e office banking" (DINIZ, 2004, p.58). A capacidade de assimilar e utilizar a tecnologia em conjunto com as forças do mercado “(...) acabaram selecionando os bancos que foram sobrevivendo e adquirindo o controle sobre os demais, e, nesse caso, a história e trajetória percorridas pelo Bradesco e pelo Itaú desde os anos 1960 fizeram a diferença, tornando-os os dois grandes bancos privados nacionais, atualmente em operação no Brasil" (KASSAB, 2011, p.118).

Hoje, “(...) o mercado bancário é o maior consumidor de produtos e serviços de TI” no país (FARIA e MAÇADA, 2011, p.441) com um orçamento total para a TI que supera os R 22 bilhões em 2010 (infra-estrutura, hardware, telecomunicações, programas internos e externos e outros), representando um crescimento de $15 \%$ em relação ao ano anterior (FEBRABAN, 
2011, p.9). Além disso, o internet banking já representa $23 \%$ do total de transações, realizadas por cerca de 40 milhões de clientes; o mobile banking, acesso a operações bancárias através de dispositivos moveis e celulares, também demonstra a receptividade das novas tecnologias no país: em apenas dois anos registra pouco mais de 2 milhões de contas (FEBRABAN, 2011, p.9).

A figura 9 a seguir ilustra as fases da automação bancária no Brasil, destacando algumas evoluções importantes no período.

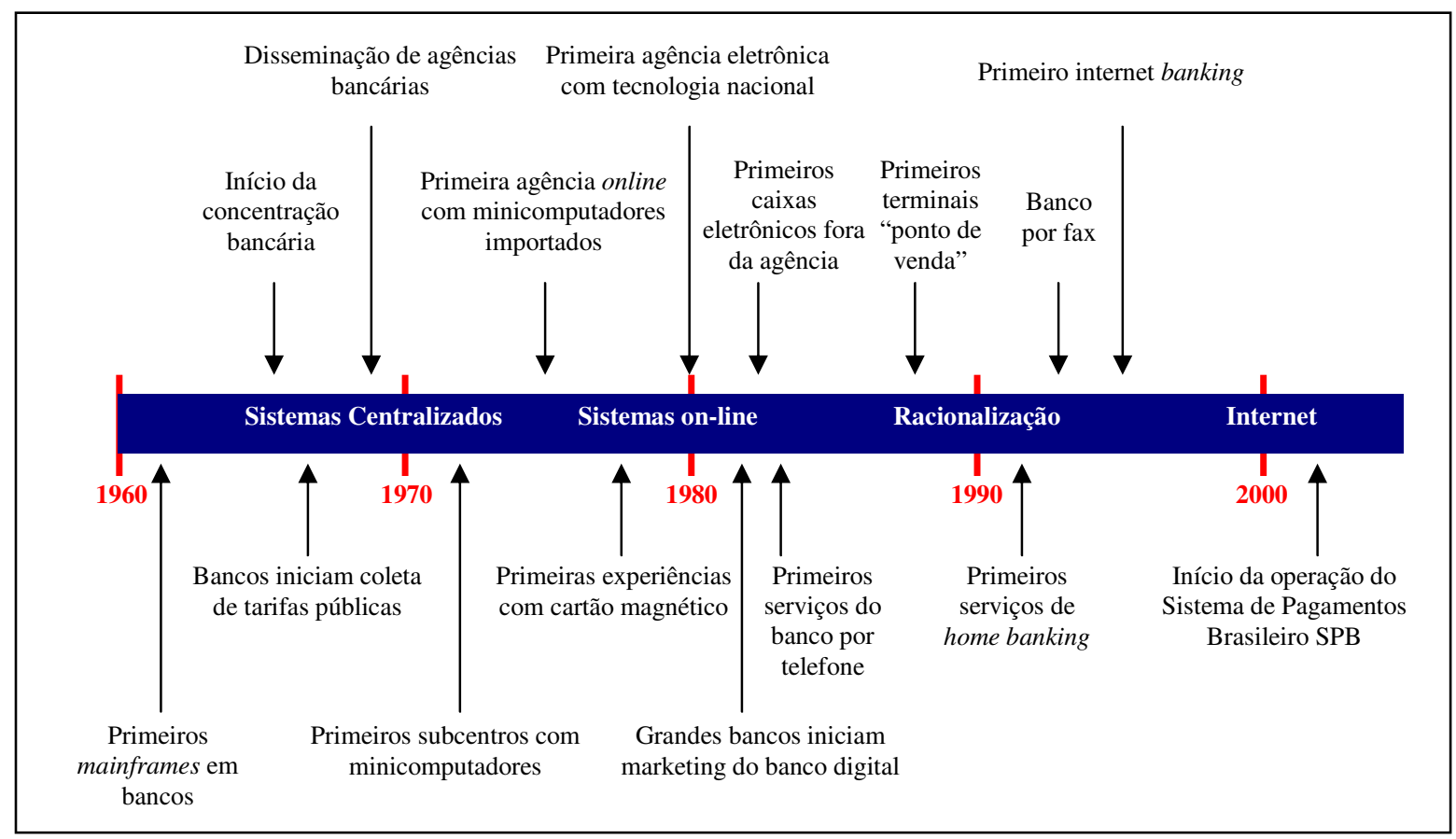

Figura 9. Fases da Automação Bancária no Brasil

Fonte: Diniz (2004, p.58)

\subsection{O Banco Alfa}

De forma resumida e procurando manter o anonimato da organização, é possível afirmar que o Banco Alfa é uma instituição consolidada e integrada no cenário bancário brasileiro, apesar da recente fusão pela qual passou. Está entre os maiores bancos múltiplos no Brasil em patrimônio líquido e ativo total e também está entre os maiores bancos do mundo pelo critério de valor de mercado. É uma das organizações mais rentáveis no país e conta com uma ampla 
e diversificada carteira de produtos e serviços: atua como banco comercial (inclusive no private banking), banco de investimento, gestor de fundos imobiliários, segurador (com produtos de previdência e capitalização), financiador e credor de pessoas físicas e jurídicas, dentre outros. É preocupado com temas como cultura, terceiro setor e sustentabilidade e também é destacado sob o ponto-de-vista de governança corporativa.

\subsubsection{Business Intelligence na Organização}

Antes da análise do BI na organização, é interessante recuperar o quadro 8 abaixo já apresentado a fim de recordar o perfil dos entrevistados e facilitar a leitura.

\begin{tabular}{|c|c|c|c|}
\hline $\begin{array}{c}\text { Código do } \\
\text { Entrevistado }\end{array}$ & Cargo & Área & $\begin{array}{c}\text { Experiência } \\
\text { Profissional }\end{array}$ \\
\hline ST1 & Superintendente de TI & Business Intelligence & 18 anos, 4 no Alfa \\
\hline GN1 & Gerente de Negócio & Controladoria & 12 anos, 12 no Alfa \\
\hline AN1 & Analista de Negócio & Controladoria & 3 anos, 2 no Alfa \\
\hline AN2 & Analista de Negócio & Crédito Empresas & 8 anos, 6 no Alfa \\
\hline AT1 & Analista de TI & Business Intelligence & 25 anos, 15 no Alfa \\
\hline CE1 & Consultor Externo & - & 13 anos, 2 no Alfa
\end{tabular}

\section{Quadro 8. Perfil dos Entrevistados}

As soluções de Business Intelligence dentro do Banco Alfa remontam em alguns casos ao final da década de 1970, quando os conceitos ainda embrionários de Sistemas de Informação Gerencial e, posteriormente, de Sistemas de Apoio à Decisão chegaram ao Brasil e foram aplicados em soluções pontuais dentro da instituição. A disseminação dentro da organização e a aplicação em massa destes sistemas, entretanto, apenas ocorreram a partir da década de 1990, quando a tecnologia avançou em desempenho e em funcionalidades e as preocupações operacionais foram controladas. De fato, nas décadas anteriores (de 1960 a 1980) os esforços das áreas de Tecnologia de Informação dos dois bancos eram praticamente monopolizados por ações relacionadas a sistemas de informação e infra-estruturas transacionais, focados no processamento de operações e integração de dados de uma extensa rede de agências. 
Hoje, porém, a área de BI é vital dentro do Banco Alfa, pois na opinião de ST1 (um executivo do banco) "ela alavanca a receita, reduz custos e riscos e otimiza os recursos da organização". A instituição compreende a necessidade, vê benefícios estratégicos na utilização do BI e tem a maturidade suficiente para saber que alinhamento estratégico com o negócio é imprescindível para o sucesso destas aplicações. Particularmente sobre o tema de maturidade - uma premissa para a escolha desta instituição para o Estudo de Caso, ST1 acredita que comparativamente com outras empresas e outros setores (o entrevistado tem histórico em outras indústrias), não só o Alfa, mas o setor bancário tem um grau de maturidade relativamente alto sob o ponto-devista analítico por cinco motivos básicos: grande volume de dados, grande volume de usuários, tipo do negócio, inserção tecnológica e esclarecimento das pessoas ("os clientes internos têm mais certeza do que querem").

De fato, algumas das surpresas deste entrevistado ao entrar na organização foram "(...) o tamanho, as proporções e os impactos das bases de dados e das necessidades de BI". Segundo ST1, "estima-se que cerca de 10 mil colaboradores façam uso direta ou indiretamente dos dados de inteligência da empresa"; o que pode parecer um número exagerado é confirmado por projetos de Business Intelligence reconhecidos e premiados dentro do setor.

GN1 e AN1, dois representantes da área de negócios, também corroboram a opinião de que a instituição entende o BI como vital e de que enxerga os dados e as informações como ativos essenciais do negócio. Também consideram que a organização e seus colaboradores anseiam poder investigar estas informações, principalmente no cenário atual onde "a rastreabilidade dos dados leva tempo e é custosa". Na verdade, na opinião destes entrevistados, o Alfa "já utiliza fortemente seus recursos informacionais, mas gostaria de utilizá-los com mais intensidade e profundidade", proporcionando resultados mais detalhados e precisos, o que, conseqüentemente, resultaria em produtos mais prezados pelos usuários. Em outras palavras, o objetivo prático é facilitar as análises mais convencionais e dar mais tempo aos analistas para se concentrar nas novas demandas e na descoberta de novos conhecimentos, principalmente através das funcionalidades de mineração de dados, objetivo de médio prazo da maior parte das áreas que trabalham com o BI dentro da organização.

Sob o ponto-de-vista administrativo, dentro do Banco Alfa a área de Business Intelligence responde hierarquicamente à área de Tecnologia de Informação e é bastante centralizada, inclusive fisicamente. A área é responsável pela parte técnica do BI, isto é, administração de 
bancos de dados, ferramentas e métodos, definindo infra-estrutura, modelos de dados, funcionalidades e acessos (resumidamente a governança de $\mathrm{BI}$ ) e também é responsável pelos desenvolvimentos técnicos de necessidades das áreas funcionais, ou seja, construção e acompanhamento de novos produtos de BI.

De qualquer forma, segundo a explicação dos diversos entrevistados (sejam técnicos ou de negócio), pode-se dizer que a responsabilidade é compartilhada com as diferentes áreas de negócio, pois estas são as intermediárias das soluções analíticas, construindo os relatórios e painéis para os usuários finais da corporação. Assim, sob o ponto-de-vista do BI funcional, a organização é totalmente descentralizada. Cada uma das áreas funcionais de análise tem sua equipe de BI dedicada que além de ser responsável por analisar as informações, deve definir novas necessidades analíticas, entendendo e traduzindo em aspectos técnicos as necessidades do cliente que serão construídas pela equipe técnica. Segundo ST1, "não há outra forma de se organizar e administrar com sucesso um BI das proporções do Banco Alfa"; pois a centralização técnica do BI “(...) garante governança, controle sobre a informação e iniciativas únicas e corporativas, ao mesmo tempo em que evita o risco operacional, coíbe fraudes e facilita auditorias", aspectos importantes num banco desta magnitude e importância; a descentralização funcional do BI, por outro lado, “(....) permite que as necessidades sejam entendidas por equipes dedicadas que apresentam o conhecimento do negócio", o que enriquece as soluções e diminui consideravelmente os problemas de comunicação entre TI e negócio.

Obviamente há desvantagens e algumas insatisfações com este modelo, como admite ST1, pois a centralização técnica "aumenta a burocracia e o tempo de atendimento das solicitações". O primeiro aspecto está relacionado com a priorização de atividades, isto é, a necessidade de definir quais iniciativas são mais importantes para o negócio, o que pode impedir ou limitar oportunidades. Mas este aspecto, também pode ser encarado como positivo de acordo com ST1, pois "controla a grande maioria de pedidos intempestivos (em muitos casos irrelevantes e desnecessários) e exige do cliente um estudo de custo/benefício da necessidade". O segundo aspecto está relacionado ao óbvio limite de recursos e custos da área técnica, o que impede de tratar todas as demandas simultaneamente. De qualquer forma, em geral os usuários e intermediários de BI "estão em sua grande maioria satisfeitos com os produtos de informação que a área de TI oferece", principalmente com a qualidade e o serviço. 
Sob o ponto-de-vista operacional, atualmente o ambiente de BI do Banco Alfa conta com exemplos de utilização de todas as funcionalidades descritas no Marco Teórico, desde os painéis de informação à mineração de dados. Obviamente, o uso depende da necessidade de cada área: enquanto a Diretoria de Crédito Empresas precisa construir modelos preditivos e fazer uso da mineração de dados para elaborar estratégias consistentes de retorno e risco, na Diretoria de Controladoria esta necessidade ainda é sutil. As ferramentas homologadas que são utilizadas também dependem de cada área e de cada necessidade, mas em geral, os relatórios OLAP e pré-formatados são viabilizados por produtos como Cognos e Microstrategy (com algumas iniciativas inclusive em andamento), enquanto os relatórios $a d$ $h o c$ e aqueles que envolvem métodos preditivos e mineração são viabilizados pelos produtos da SAS. Segundo AN2, também "há muitos relatórios em SQL montados sobre as bases, cujos dados são posteriormente exportados para ferramentas como o Microsoft Excel”, onde são posteriormente manipuladas pelas equipes analíticas para, por exemplo, a construção de painéis.

Apesar de não ser um tema presente no escopo inicial de estudo, outro tópico interessante mencionado recorrentemente nas entrevistas foi a fusão que deu origem ao Banco Alfa e os impactos para o BI, uma vez que a integração representou um importante desafio para todos os colaboradores entrevistados. Como declarado nas primeiras comunicações oficiais, o processo de união entre as instituições foi liderado por uma equipe de integração, que supervisionou as atividades de diferentes frentes de trabalho, criadas para mapear processos e identificar as melhores práticas de cada instituição, com o objetivo de escolher de forma criteriosa os melhores modelos. GN1 acredita que este plano também foi aplicado no caso do $\mathrm{BI}$, pois se "avaliaram os modelos mais fortes e robustos, valorizando os recursos mais qualificados (tanto de pessoas quanto de processos) e a sinergia dos pontos fortes”. Para ST1 o processo de integração foi executado "(...) com muito planejamento e cuidado, procurando respeitar as culturas, as instituições, os processos e, sobretudo, as pessoas de cada instituição". No caso particular do BI, ao contrário da opinião de AT1 cujo entendimento é de que o Banco Gama era mais desenvolvido neste aspecto, ST1 acredita que "tanto em maturidade, quanto em conceitos e problemas as duas organizações eram parelhas"; fato é que "a fusão procurou tirar o máximo das duas instituições de origem" e, neste sentido, o entrevistado entende que o processo foi bem sucedido. 


\subsection{Caracterização e Distinção de Usuários de Soluções Analíticas}

Como explorado no Marco Teórico, diversos autores destacam a importância do lado humano para o sucesso das aplicações de BI. Como afirma Howson (2008, p.1), por exemplo, sem pessoas capacitadas para interpretar a informação e agir sobre ela, o Business Intelligence é incapaz de atingir qualquer resultado. Em outras palavras, a tecnologia é apenas o meio, mas nunca pode ser o fim. Assim, a primeira análise deste tópico procura avaliar como a organização sob análise encara esta preocupação com o tema humano e se de fato é na prática um fator crítico assim como sugerem os autores na teoria.

Apesar de concordar com a afirmação supramencionada, para o entrevistado AT1, por exemplo, dentro do banco esta preocupação humana não é devidamente reconhecida, desenvolvida e compartilhada porque entre outros motivos a organização ainda se encontra num estágio inicial de maturidade, concentrada em discussões mais básicas e com foco mais pragmático. Certamente esta impressão está relacionada à fusão recente dos bancos e ao longo processo de integração vivido nos últimos anos - este ponto-de-vista bastante crítico parece ser comum a alguns colaboradores mais antigos provenientes do Banco Gama, para quem a fusão foi encarada com mais reservas e limitações. Ainda segundo AT1 - cuja experiência profissional é de mais de 20 anos no Banco Gama - "no momento da união o Banco Beta não estava tão avançado quanto o Banco Gama nos temas analíticos, sendo inclusive caótico em alguns aspectos" (por exemplo, sem uma clara governança de BI). De qualquer forma, apesar de considerar a instituição até certo ponto imatura, após quatro anos de integração, a opinião de AT1 é de que o cenário está mudando para melhor e de que a instituição está avançando no tema. Além disso, entende que muitas das dificuldades não são específicas ou particulares de sua área, nem da organização ou do setor; "tratam de desafios genéricos como integridade de dados e dificuldades de entendimento entre negócios e TI”, aspectos também estudados no meio acadêmico.

Para os entrevistados GN1 e AN1, por outro lado, a afirmação inicial de que o lado humano é importante é adequada, válida e relevante, não só pessoalmente, mas dentro da organização também. Eles acreditam, no entanto, que "os aspectos humanos dentro do BI tratam de questões abstratas e complexas, difíceis de equalizar e quantificar" e com um grande número de variáveis envolvidas, fatores que, em conjunto, fazem do assunto um tema confuso e 
complicado de se trabalhar. Ao contrário da declaração inicial, porém, quando questionados sobre os principais fatores críticos de sucesso de aplicações de BI, os entrevistados GN1 e AN1 concentraram-se em diferentes tópicos técnicos, mas muito poucos humanos, a saber: (1) Flexibilidade, isto é, a solução deve permitir modificações, melhorias e/ou ajustes com facilidade e agilidade (diminuindo custos e tempo de desenvolvimento), pois as demandas do negócio são dinâmicas; (2) Estabilidade, ou seja, a solução deve ser confiável e deve estar disponível para o usuário sempre que este precisar; (3) Timing, isto é, as informações devem ser apresentadas na periodicidade correta e no momento adequado, de modo a serem úteis para o usuário, caso contrário, perdem o objetivo e não atendem a necessidade do negócio; (4) Tempestividade, isto é, dados devem ser os mais atuais e recentes possíveis de modo a dar o embasamento necessário para a tomada de decisões; (5) Rastreabilidade, ou seja, solução deve ser permitir a visualização dos dados nos seus níveis mais granulares e deve ser possível rastrear a informação a sua origem para construir análises lógicas e críticas; (6) Desempenho, isto é, solução deve atender adequadamente os requisitos não funcionais do usuário final quanto ao tempo de resposta e processamento; e (7) Alinhamento, ou seja, solução deve estar alinhada com os conceitos da organização, não só nos objetivos, mas principalmente nos conceitos de negócio.

De acordo com os entrevistados, ferramentas de BI que não atentem para estes fatores podem resultar em soluções equivocadas ou inadequadas, que não atendem a área de negócio e que, portanto, não tem utilidade. Mas como pode ser visto, o tema de usuários e o lado humano das aplicações foram omitidos desta lista. Posteriormente estes tópicos foram abordados na entrevista, mas não de forma espontânea, o que demonstra que o tema no nível operacional e gerencial não está dentro do rol de preocupações chave.

Contudo esta interpretação também foi confirmada no nível estratégico. Avaliando a opinião de ST1, um executivo da instituição com experiência em outros setores industriais, não parece haver de fato uma atenção específica com o tema em discussão, pois existem outras dificuldades mais relevantes e urgentes que o BI deve balancear, segundo a opinião do entrevistado. Para ST1, as principais preocupações com o Business Intelligence sob o pontode-vista estratégico “(...) estão relacionadas em basicamente demonstrar seu valor (benefícios) e justificar os seus custos"; de qualquer forma, em comparação com outros setores em que atuou, ST1 entende que o Banco Alfa é uma organização madura sob o ponto-de-vista analítico, que valoriza a informação e a considera um ativo vital para o sucesso a longo prazo. 
Enfim, com base na opinião dos entrevistados a impressão é de que as preocupações com usuários das aplicações de BI destacadas por Eckerson ainda são um tema pouco abordado e discutido, avaliado apenas informalmente e muitas vezes relegado a um segundo plano, seja por sua relevância discutível ou pela dificuldade prática de tratar o assunto e as variáveis que o compõem. Curiosamente, apesar do tema humano não fazer parte da agenda formal da instituição, segundo o entrevistado ST1, por exemplo, "os usuários estão em sua grande maioria satisfeitos com os produtos de BI que a área de TI oferece, principalmente com a qualidade e o serviço".

Particularmente em relação à distinção de usuários de soluções analíticas, de acordo com Eckerson (2009, p.4) as organizações caracterizam estes usuários com base nos papéis que desempenham, nas informações que demandam e nas maneiras como consomem e analisam as informações, ou seja, através da combinação de um ou mais aspectos abaixo:

- Conhecimento técnico (limitado, intermediário e avançado);

- Cargo ou nível hierárquico (executivos, gerentes, analistas);

- $\quad$ Necessidade de informação (consolidada, detalhada);

- $\quad$ Papel desempenhado (produtor ou consumidor);

Neste aspecto, não há um consenso claro entre os entrevistados. Para ST1, o aspecto mais importante e essencial (talvez o único pelo que se pode interpretar da opinião do entrevistado) é o tipo de necessidade de informação. Em outras palavras, "ao definir uma ferramenta, devese observar a demanda de negócio, considerando as características da solicitação e a dinâmica dos processos de cada área, isto é, o que se quer fazer e aonde se quer chegar". Para os demais entrevistados, como, por exemplo, GN1, a caracterização dos usuários é realizada informalmente considerando o prioritariamente o conhecimento dos usuários (tanto de negócio quanto o técnico) e os perfis de acesso e segurança a informação de cada usuário. Outro fator que certamente influência na caracterização dos usuários na opinião de GN1 é o cargo ou a função. Para AT1, a principal forma de caracterizar os usuários (e também os desenvolvedores) é a capacidade e o conhecimento técnico e indiretamente e sem ter sido explicitamente citadas, a necessidade do negócio e o papel desempenhado. 
Como resumiu GN1, "é difícil desvincular os fatores, pois todos influenciam, têm relacionamento entre si e um peso similar". Esta declaração encontra fundamento inclusive no levantamento exploratório que é detalhado a seguir, pois mesmo numa amostra reduzida, não houve um fator que se destacou ou, por outro lado, um fator que foi excluído por completo. $\mathrm{Na}$ verdade, como afirmam os entrevistados, o objetivo é atender a demanda do cliente considerando todos os aspectos possíveis. Talvez esta dificuldade em lidar com o tema na prática seja um dos motivos que colaborem para que a caracterização de usuários seja informal e indireta, sem uma orientação clara. Assim como é realizado em outras empresas, a caracterização acaba considerando aspectos mais operacionais e práticos como os perfis de acesso à informação e a possibilidade ou não de uso da funcionalidade, de acordo com o pedido de cada cliente.

\subsection{Associação entre os usuários e as funcionalidades de BI}

Antes de avaliar a associação, é fundamental tratar a segunda variável da análise, isto é, as funcionalidades de BI, conforme sugerido na proposição II. Com base nas particularidades descritas por diferentes autores, dentre eles Gartner Group (2011, p.10-11), Nemati et al (2010, p.19-21), Silvers (2008, p.209-218) e Turban et al (2008 apud AGHA KHAN et al, 2009, p.2) e o que pode ser observado em diversas soluções de BI de organizações, foram destacas cinco categorias genéricas de funcionalidades típicas de apresentação e análise do BI, a saber: painéis de informação (ou dashboards), relatórios pré-formatados (isto é, relatórios prontos para uso), relatórios ad hoc (isto é, relatórios ocasionais que o próprio usuário pode criar), relatórios OLAP (isto é, tabelas dinâmicas e cubos) e Relatórios baseados em Modelos Preditivos e Mineração de Dados. Estas categorias estão ordenadas de forma crescente de acordo com a complexidade de uso e entendimento para os usuários finais.

A fim de validar as categorias e interpretar corretamente as observações, todos os entrevistados foram questionados sobre a divisão, inclusive o consultor CE1. Todos foram bastante consistentes na confirmação de que a divisão de funcionalidades proposta é aceitável, corroborando a divisão proposta. ST1 inclusive destacou que dentro da organização podem ser observadas todas as funcionalidades, com maior ou menor intensidade dependendo da área, do conhecimento e das necessidades, confirmando na prática a proposição. A ordenação por complexidade também foi confirmada por AT1, AN2, ST1 e CE1, mas para GN1 e AN1 
houve alguma dificuldade de entendimento. Mesmo alertados para o fato de que a complexidade era de uso e entendimento do usuário final, estes colaboradores construíram sua opinião tendo como base os desafios da implementação técnica de algumas das funcionalidades, talvez por seu envolvimento atual num projeto de implantação.

Embora inicialmente o conjunto de respostas seja positivo, é preciso destacar que foram observados alguns fatos inconsistentes relacionadas com os conceitos de algumas dessas funcionalidades, assim como ocorre na literatura de apoio. Um exemplo ocorreu com os painéis de informação, pois para ST1 esta funcionalidade deve apresentar informações detalhadas de indicadores, com possibilidades de drilldown para o fim de rastrear informações particulares, o que é um mecanismo típico de relatórios OLAP. Para com GN1, também houve alguma confusão para distinguir os conceitos de relatórios ad hoc (que podem ser construídos sobre uma base pré-definida) e relatórios pré-formatados (que podem ser consumidos diretamente e sem customizações com apenas poucas possibilidades de interação).

Quanto à associação entre os usuários e as funcionalidades, isto é, como ocorre o relacionamento entre os usuários e as diversas ferramentas disponíveis, ST1 explica que “(...) ninguém é mais capacitado para tomar esta decisão do que os profissionais técnicos". Segundo o entrevistado, uma vez entendida a necessidade, os requisitos, a expectativa, os objetivos e os critérios de usabilidade exigidos, os analistas técnicos são aqueles que detêm o conhecimento técnico das funcionalidades e que podem saber qual a melhor ferramenta para cada demanda, o que os torna os principais responsáveis por realizar esta associação (o que normalmente ocorre de modo informal). Na opinião de ST1, "um usuário não pode escolher ou ter preferência por funcionalidades", pois normalmente desconhecem as opções técnicas que podem existir e quais são aquelas que melhor respondem as suas necessidades. GN1 concorda com esta visão, insinuando inclusive que a escolha não pode ficar inteiramente na mão do usuário, pois os critérios de escolha, embora na maioria das vezes sejam racionais, também podem ser incoerentes ou inclusive emocionais e resultarem em produtos que posteriormente podem não cumprir os objetivos propostos. Este cenário parece particularmente válido quando a iniciativa é um novo desenvolvimento numa área ainda imatura sob o ponto-de-vista analítico. 
De qualquer forma, como afirma $\mathrm{AN} 1$, as opiniões do usuário não são tão veladas ou reprimidas como poderia ser interpretado pela declaração anterior (mesmo em novos projetos). O risco de fracasso, desuso ou esquecimento devido ao não atendimento de expectativas faz com que o processo de seleção da ferramenta seja realizado de maneira paulatina, com o uso de protótipos e com alguma participação de usuários, conforme confirmam os recursos com responsabilidades operacionais e gerenciais. De acordo com GN1, em primeiro lugar, em um projeto novo analistas técnicos e de requisitos entendem as necessidades funcionais e não funcionais do cliente; em seguida, as ferramentas existentes e homologadas pela área técnica são apresentadas através de workshops com todos os envolvidos, inclusive com a presença dos usuários de negócio, indicando as opções existentes, viabilidade, vantagens e desvantagens de cada funcionalidade, não só das cinco categorias discutidas, mas também dos próprios produtos de mercado (como, por exemplo, Cognos, SAS, etc); finalmente, apesar de não definirem ou escolherem diretamente, os usuários declaram suas preferências e dão orientações, insumos avaliados pela equipe técnica sobre os quais são desenvolvidos protótipos.

De certa forma este processo pode ser entendido como uma formalização da associação no caso dos novos produtos analíticos. Neste processo, segundo GN1, é considerada uma série de aspectos, mas principalmente as necessidades, os conhecimentos técnicos e, um fator imprevisto, que é o alinhamento conceitual, ou seja, o conhecimento de negócio e da modelagem a fim de não gerar informações equivocadas sob o ponto-de-vista semântico, pois existe uma grande preocupação em relação à disseminação de informações incorretas ou inverossímeis.

Por outro lado, no caso de aplicações já estabelecidas, é possível afirmar que os usuários acabam escolhendo a funcionalidade por conta própria, desde que elas estejam préconfiguradas para tal (por exemplo, ter um modelo dimensional disponível para construir relatórios OLAP). Além de usuários de negócio minimamente capacitados, existem alguns analistas que tem o conhecimento técnico dentro das áreas para instruir e direcionar dúvidas. Neste caso, AT1 entende que além dos aspectos já abordados, "as características pessoais têm uma importante participação na preferência da funcionalidade'. De acordo com GN1, neste caso, a escolha de qual funcionalidade (das disponíveis) deve suprir a necessidade da área cabe inteiramente à equipe de negócio e ao gestor. 
De forma geral, portanto, seja em novas aplicações ou em aplicações já estabelecidas, os fatores que foram mais mencionados durante as entrevistas para o tema da associação foram: conhecimento técnico do usuário, conhecimento de negócio do usuário, características pessoais do usuário, cargo ou nível hierárquico do usuário, papel desempenhado pelo usuário, tipo da informação necessária, objetivo que a atender. Não foram mencionados nível de detalhamento, tampouco cultura e outros aspectos organizacionais.

Procurando avaliar indiretamente a associação entre usuários (características pessoais, principalmente) e as funcionalidades, foi proposto um exercício simples com os entrevistados: questionou-se qual dentre as cinco categorias de funcionalidade era a preferida do respondente, assim como os motivos para esta escolha. Para AN1, um analista com menos experiência, os Relatórios OLAP foram a funcionalidade preferida, pois significam “(...) a possibilidade de relacionar informações e, a partir disto, gerar decisões e ações sobre os fatos observados". Outro analista, este com mais experiência, AT1 também preferiu os relatórios OLAP, pois “(...) dão mais liberdade ao usuário para realizar análises e investigações graças às funcionalidades que oferecem"; em outras palavras, o entrevistado dá muito valor para ferramentas de exploração. Curiosamente, na opinião de AT1, a maioria de gestores de sua área tem cada vez mais interesse por este tipo de funcionalidade, também preferindo os relatórios OLAP pelas possibilidades de exploração avançadas. Ao contrário dos analistas, contudo, para o executivo entrevistado a preferência eram os painéis de informação, pois “(...) apresentam informações consolidadas e permitem um rápido entendimento do tema em discussão". Como superintendente, ST1 explicou que precisa otimizar seu tempo e suas decisões devem ser rápidas. Como ouvinte de uma apresentação, por exemplo, ele gosta de materiais assertivos e diretos, preferencialmente no formato de pontos, evitando textos longos ou descritivos, o que segundo ele é compartilhado por outros executivos da organização.

Assim, particularmente na opinião de ST1, a escolha parece estar completamente associada ao momento atual de carreira e cargo do entrevistado. $\mathrm{Na}$ verdade, para este entrevistado os usuários típicos de cada uma das funcionalidades destacadas estão relacionados com os objetivos de cada ferramenta, mas em maior intensidade com o nível hierárquico da pessoa, isto é, a posição atual da carreira de cada usuário. Para ele, painéis atendem as necessidades de executivos, Relatórios OLAP e ad hoc as de analistas, enquanto a mineração e os modelos preditivos atendem as demandas de analistas mais técnicos, algo condizente com as divisões de usuários vistas anteriormente. 
Com base em todos os pontos descritos, nota-se que a associação entre usuários e funcionalidades é informal, leva em consideração diversos fatores e é informalmente realizada de formas diferentes por cada desenvolvedor/analista. A opinião do tema depende muito de cada entrevistado e cada área, o que demonstra que o tema não tem muita relevância, nem critérios claros definidos; além disso, estas opiniões parecem estar particularmente relacionadas com o nível hierárquico dos entrevistados.

\subsection{Relação entre Estilo Cognitivo e Preferência por Funcionalidades de BI}

Especificamente em relação à influência do estilo cognitivo sobre a preferência e escolha das funcionalidades de BI em aplicações já estabelecidas, AT1 entende que é um tema importante a ser considerado, pois, para ele, é perceptível que "alguns usuários têm um perfil mais investigativo e analítico, enquanto outros têm um perfil mais generalista e superficial; alguns lidam melhor com tabelas, enquanto outros preferem gráficos e informações mais consolidadas". AN2, GN1 e AN1 também entendem e vêem diferentes comportamentos na análise de informações de acordo com a personalidade e consideram que este aspecto pessoal influencia na utilização das ferramentas.

Contudo, é um tema difícil de trabalhar. Em primeiro lugar, porque como explica AT1 "respeitar as demandas e características de cada usuário poderia resultar em diversas funcionalidades diferentes", apesar de ele concordar que grande parte das demandas já são atendidas pelas 5 categorias de funcionalidades existentes. Em segundo lugar, porque como explicam GN1 e AN1 "é muito difícil captar e interpretar estas características pessoais e convertê-las em uma regra clara de preferência”, tornando o tema praticamente impossível de ser trabalhado em tempo hábil no cotidiano das áreas. Em terceiro lugar, é complicado quantificar o benefício marginal que este cuidado traria para as aplicações de BI, o que reabre a discussão da relevância do tema.

Nesta linha mais crítica, para ST1 "as características pessoais de cada usuário (inclusive o estilo cognitivo) não importam muito na escolha de funcionalidades". Como explicitado anteriormente, na opinião do entrevistado a necessidade de negócio é dominante sobre quaisquer outros aspectos e, mesmo admitindo existirem diferentes perfis de pessoas, “o 
relacionamento não faz sentido". Para ilustrar esta opinião, o entrevistado inclusive propôs um exemplo prático: um novo gestor que muda de uma área de crédito, por exemplo, para uma área de cobrança. Para ST1, é o novo gestor que se ajusta as necessidades da nova área e não o inverso, pois objetivos, necessidades e problemas referem-se ao negócio, a área e aos seus processos específicos, permanecendo, portanto, quase sempre iguais e independentes do usuário, o que resulta em métodos e ferramentas praticamente constantes. Em outras palavras, o entrevistado entende que existe a influência do perfil, mas não a acha dominante ou relevante; esta opinião não é compartilhada pelos recursos operacionais, que consideram uma visão utópica, pois na prática, cada gestor tem um perfil específico e acaba priorizando e determinando aqueles formatos que melhor lhe convém.

Independentemente da opinião dos entrevistados, para avaliar o objetivo estabelecido inicialmente de verificar se existe uma relação entre estilos cognitivos e a preferência por determinada funcionalidade de Business Intelligence, decidiu-se pela realização de um levantamento de proporções reduzidas, cujo tratamento e análises são descritas a seguir.

\subsubsection{Análise das Variáveis de Pesquisa}

Como dito anteriormente, o público-alvo deste levantamento são os analistas (juniores, plenos e seniores) da Diretoria de Crédito para Empresas do Banco Alfa, um conjunto homogêneo sob o ponto-de-vista de cargos e papéis, composto por uma equipe de 59 recursos capacitados e usuários de aplicativos de BI na organização. Ao final da coleta foi observada uma taxa de participação de $42 \%$, ou seja, 25 pessoas interagiram com os questionários, participando de alguma forma da pesquisa. A quantidade e a taxa de respostas são encaradas inicialmente como satisfatórias, considerando que a comunicação com os participantes durante a coleta foi realizada inteiramente de forma eletrônica em virtude das restrições impostas pelo banco com a finalidade de manter o anonimato dos participantes. Um fator que certamente colaborou para incentivar os respondentes a participar da pesquisa foi o fato de receberem a resposta do Diagnóstico de Tipos Psicológicos ao final da participação. Com isso, alguns participantes acabaram preenchendo os questionários até mesmo fora do horário comercial ou das dependências do banco. 
Contudo, se o número de participantes a princípio é positivo, sob o ponto-de-vista estatístico a amostra (que não é probabilística) tampouco pode ser considerada representativa, o que restringe quaisquer extrapolações ou achados definitivas, mesmo que alguns autores, como indicam Corder e Foreman (2009, p.2), defendam amostras de apenas 20 observações para encontrar conclusões estatisticamente aceitáveis. Além disso, não é possível realizar uma validação da amostra para confirmar se ela é minimamente condizente com a população, isto é, avaliar se as distribuições do conjunto de observações são similares aos do universo selecionado, pois não se tem as informações mínimas necessárias para esta análise.

Em relação ao número de respostas válidas, no questionário BI foram obtidas 23 respostas válidas (39\%), portanto, 2 participantes não acessaram o instrumento (mesmo com a insistência do pesquisador e inclusive a prorrogação no prazo de coleta); no DTP foram obtidas apenas 19 respostas válidas (32\%), uma vez que 6 participantes não acessaram ou interromperam o questionário em algum momento. Esta disparidade entre o número de respostas entre os dois questionários pode ser justificada por dois motivos: o primeiro é que os instrumentos eram logicamente diferentes, residiam em sites separados e tinham formatos e orientações específicas, o que, em conjunto, pode ser encarado como um aborrecimento adicional para o participante. A alternativa de combinar os questionários foi avaliada durante a fase de planejamento da coleta, contudo, foi descartada, pois poderia trazer riscos de exposição indevida para o DTP. O segundo motivo é que de acordo com a opinião de um dos participantes, apesar de o DTP ser um questionário "simples de entender, bem elaborado e bastante interessante", a combinação entre o extenso número de questões (150) e a longa duração (entre 30 e 45 minutos) de preenchimento acabava desmotivando alguns respondentes a participar da pesquisa. Assim, considerando apenas aqueles participantes que responderam os dois questionários satisfatoriamente, a amostra utilizada para avaliar o relacionamento entre BI e estilos cognitivos é composta de apenas 17 respostas válidas, pouco menos de um terço (ou 29\%) da população, abaixo do número proposto por Corder e Foreman.

Avaliando inicialmente os 23 participantes do Questionário BI (39\% da população), é possível realizar uma análise de cada um dos indicadores previamente estabelecidos. Em relação às características demográficas da amostra, $56 \%$ são homens e $44 \%$ mulheres, $74 \%$ têm formação em exatas, confirmando a preferência por recursos que genericamente têm como ponto forte o raciocínio lógico, e $26 \%$ em humanas, $52 \%$ têm grau superior completo e $44 \%$ 
já realizaram pelo menos uma pós-graduação (strictu ou latu senso), dados ilustrados na figura 10 abaixo.

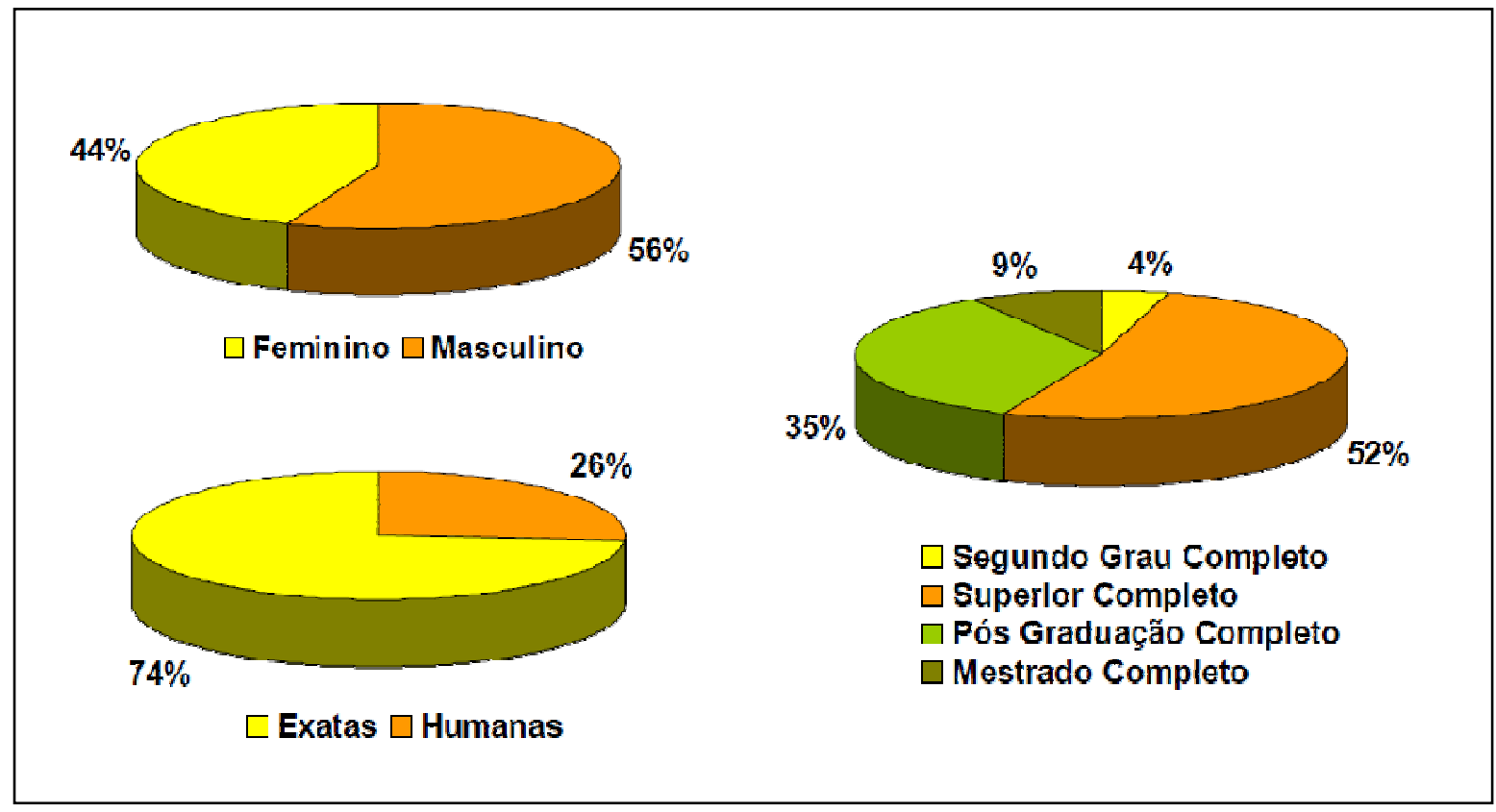

Figura 10. Características Demográficas da Amostra

A média de idade dos respondentes é cerca de 30 anos, com 10 anos em média de experiência profissional (incluindo estágios) e 5 anos em média de experiência dentro do Banco Alfa (incluindo eventual estágio). Como era esperado numa população de analistas, a amostra é composta por uma maioria de pessoas jovens (na faixa dos 30 anos), mas com um grau de experiência razoável. Obviamente a questão do cargo influi na média de idade, mas também deve se considerar o fato da dependência tecnológica da área, o que requer e motiva recursos mais propensos ao tema, característica marcante nas novas gerações que têm adentrado no mercado de trabalho nos últimos anos. Na tabela 1 a seguir são destacados alguns indicadores.

\begin{tabular}{|c|c|c|c|}
\hline Indicador & Idade & Exp. Profissional & Exp. Organização \\
\hline Média & 30,8 & 9,7 & 4,2 \\
\hline Desvio Padrão & 8,7 & 8,6 & 5,0 \\
\hline Mediana & 28,0 & 5,0 & 2,0 \\
\hline Moda & 25,0 & 4,0 & 1,0 \\
\hline Máximo & 54,0 & 35,0 & 20,0 \\
\hline Mínimo & 21,0 & 2,0 & 1,0 \\
\hline$n$ & 23,0 & 23,0 & 23,0 \\
\hline
\end{tabular}

Tabela 1. Características Demográficas da Amostra 
Em relação aos temas associados ao BI, a primeira análise é a das respostas de conhecimento. Mesmo estando baseadas nas opiniões dos próprios participantes, as notas dadas indicam basicamente que se trata de um conjunto amostral com relativa experiência no tema, pois além da maioria das respostas se concentrarem nas faixas de conhecimento 'razoável' e 'alto', pelo menos $75 \%$ dos respondentes afirmam ter conhecimento acima de 'razoável' (exceto modelos preditivos e mineração) e pelo menos $50 \%$ afirmam ter conhecimento 'alto' ou 'muito alto' (exceto modelos preditivos e mineração), como destacado na tabela 2 a seguir.

\begin{tabular}{|l|r|r|r|r|r|}
\hline Funcionalidade & Nenhum & \multicolumn{1}{|c|}{ Pouco } & Razoável & \multicolumn{1}{c|}{ Alto } & Muito Alto \\
\hline Painéis de Informação & $17,4 \%$ & $8,7 \%$ & $34,8 \%$ & $34,8 \%$ & $4,3 \%$ \\
\hline Relatórios Pré-Formatados & $4,3 \%$ & $8,7 \%$ & $30,4 \%$ & $39,1 \%$ & $17,4 \%$ \\
\hline Relatórios ad hoc & $8,7 \%$ & $17,4 \%$ & $26,1 \%$ & $43,5 \%$ & $4,3 \%$ \\
\hline Relatórios OLAP & $4,3 \%$ & $13,0 \%$ & $26,1 \%$ & $47,8 \%$ & $8,7 \%$ \\
\hline Relatórios c/ Mineração de Dados & $17,4 \%$ & $21,7 \%$ & $30,4 \%$ & $30,4 \%$ & $0,0 \%$ \\
\hline
\end{tabular}

Tabela 2. Distribuição de Conhecimento por Funcionalidade

Se por um lado as notas limitam conclusões absolutas da amostra devido à subjetividade individual de cada respondente, combinadas, elas permitem comparações relativas entre as funcionalidades que são bastante confiáveis. Assim, como era esperado, nos relatórios que envolvem modelos preditivos e mineração de dados o grau de conhecimento dos respondentes é menor quando comparado ao das outras funcionalidades, pois pelo menos $40 \%$ afirmam ter 'pouco' ou 'nenhum' conhecimento e não há nenhum participante que considere seu conhecimento como 'muito alto', conforme figura 11 abaixo. Esta observação está relacionada à alta complexidade envolvida nesta opção, não só tecnológica, mas estatística.

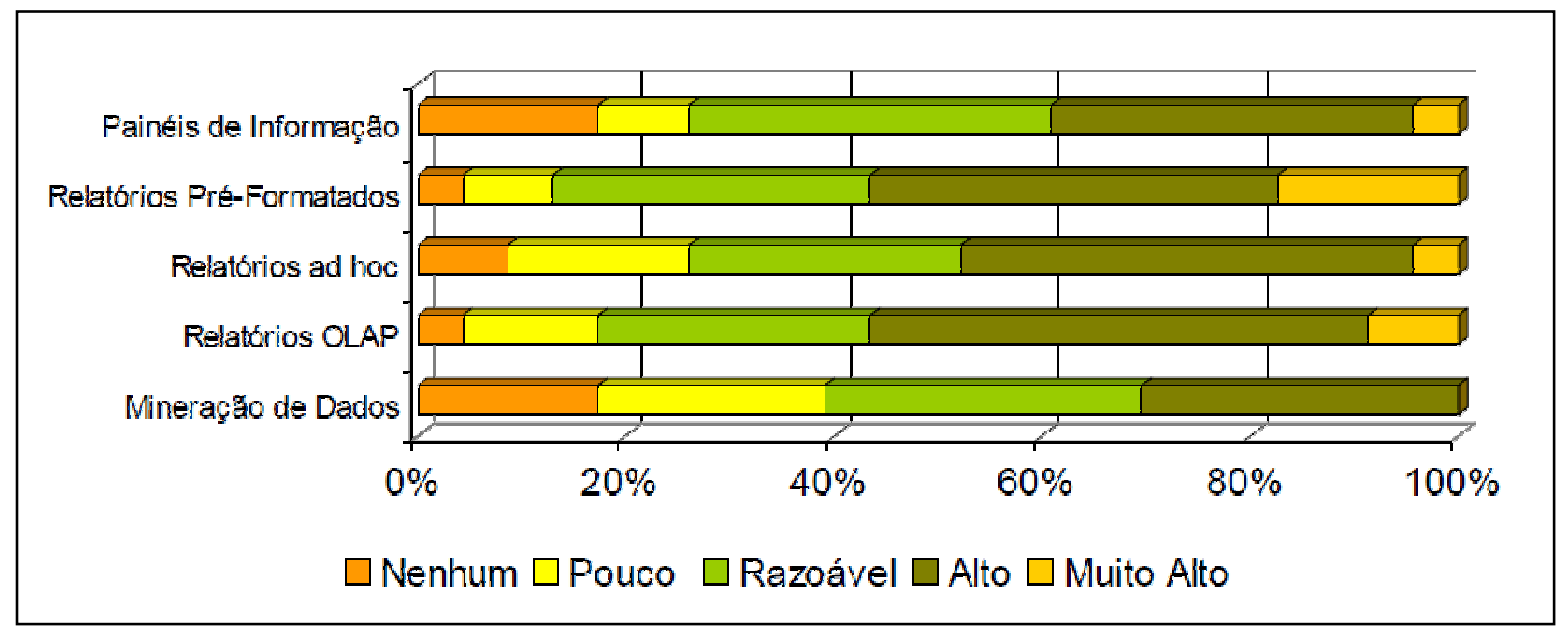

Figura 11. Grau de Conhecimento por Funcionalidade 
Observando as médias e medianas das notas dadas para cada funcionalidade e lembrando que elas podem variar de zero a dez, também é possível verificar que os relatórios pré-formatados (média 6,6 e mediana 8,0) e os relatórios OLAP (média 6,3 e mediana 7,0) são aqueles nos quais os usuários indicaram maior conhecimento. Por outro lado, os relatórios com modelos preditivos e mineração de dados (média 4,1 e mediana 5,0) e os painéis de informação (média 5,0 e mediana 6,0) são aqueles onde indicaram menor conhecimento. Há dois fatos surpreendentes nestes números. O primeiro deles é que, apesar de terem o maior número de respostas 'nenhum' conhecimento, a média dos relatórios com modelos preditivos e mineração de dados é relativamente alta, apenas 1 ponto abaixo dos painéis, por exemplo. $\mathrm{O}$ segundo fato é que, ao contrário do que se esperava, o grau de conhecimento dos painéis de informação é consideravelmente baixo. Há uma maior concentração de respostas dentro do 'razoável', mas comparando os painéis com as demais funcionalidades, poucos respondentes declararam ter conhecimento 'muito alto'; pelo ao contrário, muitos afirmaram não ter 'nenhum' conhecimento. Esta é uma observação importante no sentido de corroborar que o entendimento da funcionalidade Painel de informação dentro da organização estudada é diferente daquele oferecido anteriormente no Marco Teórico.

A segunda análise é a das respostas de utilização e, conforme tabela 3 a seguir, elas parecem mostrar que os usuários da área analisada utilizam os recursos de que dispõe adequadamente.

\begin{tabular}{|l|r|r|r|r|r|}
\hline Funcionalidade & Não usa & \multicolumn{1}{c|}{ Pouco } & Razoável & \multicolumn{1}{c|}{ Alto } & Muito Alto \\
\hline Painéis de Informação & $17,4 \%$ & $13,0 \%$ & $26,1 \%$ & $30,4 \%$ & $13,0 \%$ \\
\hline Relatórios Pré-Formatados & $8,7 \%$ & $13,0 \%$ & $8,7 \%$ & $34,8 \%$ & $34,8 \%$ \\
\hline Relatórios ad hoc & $21,7 \%$ & $17,4 \%$ & $26,1 \%$ & $21,7 \%$ & $13,0 \%$ \\
\hline Relatórios OLAP & $8,7 \%$ & $4,3 \%$ & $17,4 \%$ & $43,5 \%$ & $26,1 \%$ \\
\hline Mineração de Dados & $39,1 \%$ & $34,8 \%$ & $13,0 \%$ & $13,0 \%$ & $0,0 \%$ \\
\hline
\end{tabular}

Tabela 3. Distribuição de Utilização por Funcionalidade

Assim como no conhecimento, a maioria das respostas se concentra nas faixas de freqüência de uso 'razoável' e 'alto' (exceto para mineração), sendo que pelo menos $70 \%$ dos respondentes afirmam utilizar com alguma frequiência painéis, relatórios pré-formatados e relatórios OLAP. Naqueles que envolvem modelos preditivos e mineração de dados observase justamente o contrário, isto é, $75 \%$ dos usuários afirmam utilizar esta funcionalidade numa frequiência baixa, sendo que $40 \%$ nunca a utilizam, conforme figura 12 da próxima página. 


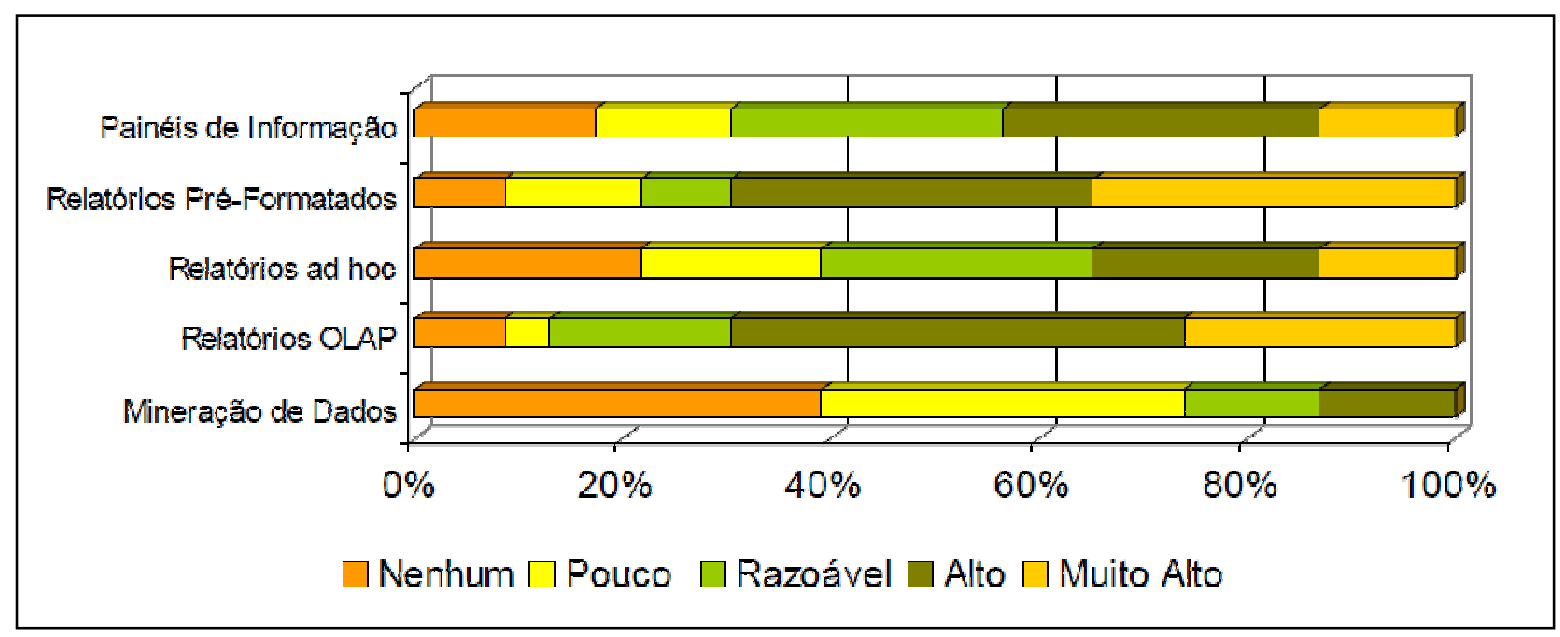

Figura 12. Freqüência de Utilização por Funcionalidade

Observando as médias e medianas das notas dadas para cada funcionalidade, é possível verificar que os relatórios OLAP (média 7,2 e mediana 8,0) e os relatórios pré-formatados (média 6,7 e mediana 8,0) são aqueles nos quais os usuários indicaram maior freqüência de uso. Por outro lado, os relatórios com modelos preditivos e mineração de dados (média 2,5 e mediana 2,0) e os relatórios ad hoc (média 4,6 e mediana 5,0) são aqueles onde indicaram menor frequiência de uso. Em conjunto com as distribuições, a média da mineração confirma que a funcionalidade é um trabalho mais específico e de uma equipe limitada; também pode ser resultado da opinião de entrevistados que declararam não ter tempo hábil para as análises mais elaboradas e profundas que a mineração oferece, pois estão imersos nas tarefas operacionais do cotidiano que exigem a maior parte de seus esforços e atenção.

Para avaliar as correlações entre as respostas de conhecimento e freqüência, em primeiro lugar é avaliada a normalidade de cada variável, uma vez que esta é uma premissa quando se testam hipóteses de correlações (SPSS, 1997, p.146). Como regra prática indicada por SPSS (1997, p.28), devem ser rejeitadas hipóteses de normalidade de variáveis sempre que a razão entre as medidas de simetria (skewness) e de inclinação (kurtosis) de sua distribuição pelos respectivos desvios padrão estiverem fora do intervalo - 2 e 2 (ambas medidas estão centradas no zero). Avaliando a tabela de valores sob este prisma, a única variável que não pode ter sua distribuição considerada como normal é a freqüência de uso de relatórios OLAP; nas demais a hipótese de normalidade é aceitável, mesmo com uma quantidade limitada de respostas, conforme tabela 4 da próxima página. 


\begin{tabular}{|l|r|r|r|r|r|r|}
\hline & Skew & Desvio & Razão & \multicolumn{1}{|c|}{ Kurt } & Desvio & Razão \\
\hline Conhecimento & & & & & & \\
\hline Painéis de Informação & $-0,582$ & 0,481 & $-1,209$ & $-0,681$ & 0,935 & $-0,728$ \\
\hline Relatórios Pré-Formatados & $-0,708$ & 0,481 & $-1,471$ & $-0,047$ & 0,935 & $-0,051$ \\
\hline Relatórios ad hoc & $-0,359$ & 0,481 & $-0,746$ & $-0,989$ & 0,935 & $-1,058$ \\
\hline Relatórios OLAP & $-0,921$ & 0,481 & $-1,914$ & 0,390 & 0,935 & 0,417 \\
\hline Mineração de Dados & $-0,143$ & 0,481 & $-0,297$ & $-1,479$ & 0,935 & $-1,583$ \\
\hline Freqüência de Uso & & & & & & \\
\hline Painéis de Informação & $-0,263$ & 0,481 & $-0,546$ & $-1,065$ & 0,935 & $-1,140$ \\
\hline Relatórios Pré-Formatados & $-0,876$ & 0,481 & $-1,820$ & $-0,593$ & 0,935 & $-0,635$ \\
\hline Relatórios ad hoc & 0,072 & 0,481 & 0,149 & $-1,315$ & 0,935 & $-1,407$ \\
\hline Relatórios OLAP & $-1,369$ & 0,481 & $-2,844$ & 1,393 & 0,935 & 1,491 \\
\hline Mineração de Dados & 0,823 & 0,481 & 1,709 & $-0,671$ & 0,935 & $-0,717$ \\
\hline
\end{tabular}

Tabela 4. Teste de Normalidade de Conhecimento e Freqüência de Uso

Confirmadas as normalidades e partindo da premissa que uma amostra de 23 observações é suficiente, conforme Warner (2008 apud CORDER e FOREMAN, 2009, p.2), verifica-se então a correlação entre as respostas de conhecimento e freqüência de uso. Basicamente, a correlação mede a força de uma associação linear entre duas variáveis (SPSS, 1997, p.145). Apesar de indicar algum tipo de relacionamento entre as variáveis, um alto coeficiente de correlação (no caso utilizou-se o coeficiente de Pearson) não representa necessariamente a existência de uma relação de causa e efeito entre elas, portanto, não se podem concluir quaisquer causalidades.

Avaliando a correlação entre conhecimento e freqüência de uso destacadas na tabela 5 da próxima página, observam-se altos e significantes coeficientes (ao nível de 0,01) entre todas as funcionalidades, principalmente para painéis $(0,717)$, relatórios pré-formatados $(0,767)$ e relatórios ad hoc $(0,712)$; também são significantes, mas não tanto, para mineração $(0,528)$ e relatórios $\operatorname{OLAP}(0,558)$, mesmo que neste último caso não atenda totalmente a premissa de distribuição normal na amostra colhida. Com base nestes números é possível afirmar que para a amostra colhida existe uma forte e positiva corelação entre conhecimento e uso, o que faz sentido lógico, pois quanto mais se conhece, mais se usa e quanto mais se usa, mais se conhece. Além disso, como demonstra a tabela 5 nos campos marcados, observam-se outras correlações interessantes e significantes (ao nível de 0,01 ) como o conhecimento entre painéis e relatórios pré-formatados $(0,647)$ e painéis e relatórios com mineração de dados $(0,621)$, assim como entre relatórios pré-formatados e relatórios ad hoc $(0,620)$ e relatórios préformatados e $\operatorname{OLAP}(0,624)$. 


\begin{tabular}{|c|c|c|c|c|c|c|c|c|c|c|}
\hline & \multicolumn{5}{|c|}{ Conhecimento } & \multicolumn{5}{|c|}{ Freqüência de Uso } \\
\hline & Painel & Pré-F & ad hoc & OLAP & Miner & Painel & Pré-F & ad hoc & OLAP & Miner \\
\hline \multicolumn{11}{|l|}{ Conhecimento } \\
\hline \multirow{2}{*}{ Painéis de Informação } & 1,000 & 0,647 & 0,546 & 0,499 & 0,621 & 0,717 & 0,643 & 0,212 & 0,249 & 0,136 \\
\hline & - & 0,001 & 0,007 & 0,015 & 0,002 & 0,000 & 0,001 & 0,332 & 0,252 & 0,536 \\
\hline \multirow{2}{*}{ Relatórios Pré-Formatados } & & 1,000 & 0,620 & 0,624 & 0,404 & 0,579 & 0,767 & 0,208 & 0,533 & $-0,037$ \\
\hline & & - & 0,002 & 0,001 & 0,056 & 0,004 & 0,000 & 0,340 & 0,009 & 0,866 \\
\hline \multirow{2}{*}{ Relatórios ad hoc } & & & 1,000 & 0,521 & 0,453 & 0,271 & 0,594 & 0,712 & 0,252 & 0,282 \\
\hline & & & - & 0,011 & 0,030 & 0,210 & 0,003 & 0,000 & 0,245 & 0,193 \\
\hline \multirow{2}{*}{ Relatórios OLAP } & & & & 1,000 & 0,495 & 0,387 & 0,408 & 0,146 & 0,558 & 0,254 \\
\hline & & & & - & 0,016 & 0,068 & 0,054 & 0,506 & 0,006 & 0,242 \\
\hline \multirow{2}{*}{ Mineração de Dados } & & & & & 1,000 & 0,542 & 0,232 & $-0,001$ & 0,151 & 0,528 \\
\hline & & & & & - & 0,008 & 0,287 & 0,997 & 0,491 & 0,010 \\
\hline \multicolumn{11}{|l|}{ Freqüência de Uso } \\
\hline \multirow{2}{*}{ Painéis de Informação } & & & & & & 1,000 & 0,492 & 0,055 & 0,450 & 0,371 \\
\hline & & & & & & - & 0,017 & 0,803 & 0,031 & 0,081 \\
\hline \multirow{2}{*}{ Relatórios Pré-Formatados } & & & & & & & 1,000 & 0,519 & 0,289 & $-0,198$ \\
\hline & & & & & & & - & 0,011 & 0,182 & 0,366 \\
\hline \multirow{2}{*}{ Relatórios ad hoc } & & & & & & & & 1,000 & 0,082 & 0,172 \\
\hline & & & & & & & & - & 0,708 & 0,432 \\
\hline \multirow{2}{*}{ Relatórios OLAP } & & & & & & & & & 1,000 & 0,287 \\
\hline & & & & & & & & & - & 0,184 \\
\hline \multirow{2}{*}{ Mineração de Dados } & & & & & & & & & & 1,000 \\
\hline & & & & & & & & & & - \\
\hline
\end{tabular}

Tabela 5. Coeficiente de Pearson entre Conhecimento e Freqüência de Uso

A terceira análise é a das preferências de funcionalidades dos respondentes dentre as cinco opções sugeridas. Conforme figura 13 da próxima página, quase $57 \%$ dos entrevistados declararam sua preferência pelos Relatórios OLAP, enquanto 22\% preferem relatórios ad hoc, 17\% Painéis de Informação e apenas 4\% Relatórios que envolvem Modelos Preditivos e Mineração de Dados. Apesar de serem os mais utilizados de acordo com a média de frequiência de uso, os Relatórios Pré-Formatados não são a preferência de nenhum dos respondentes, provavelmente por sua característica pouco maleável e flexível, fatores que são muito prezados pelos usuários de ferramentas de BI, conforme pôde ser constatado nas entrevistas. 


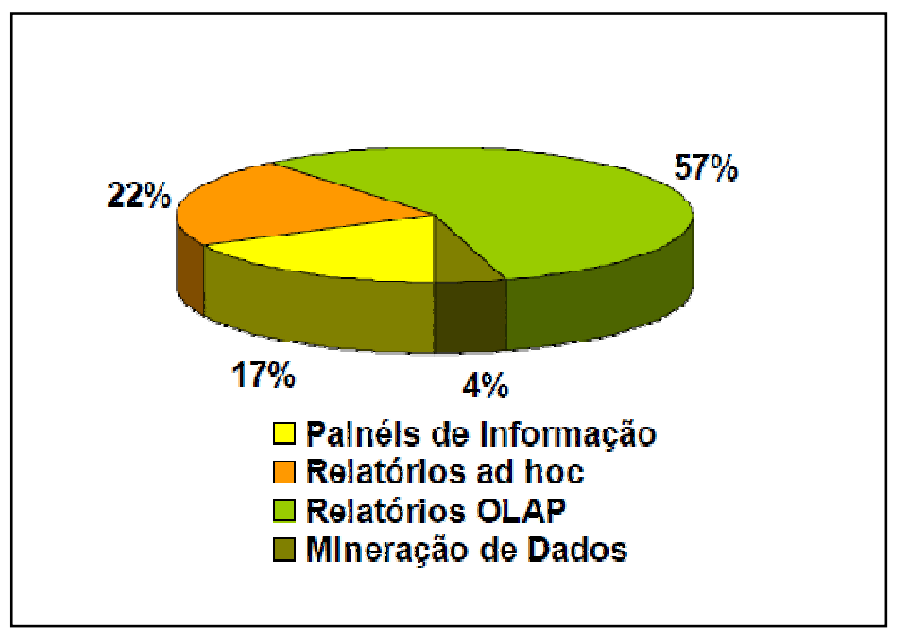

Figura 13. Preferência por Funcionalidades

A última análise individual do questionário BI é verificar a opinião dos respondentes sobre os aspectos que mais influenciam a preferência pelas diferentes funcionalidades de apresentação de BI. Pelo que se pode constatar das respostas dos participantes (numa amostra composta por apenas 19 observações válidas, pois em 4 casos esta pergunta não foi respondida), não há uma explicação que tenha uma preponderância indiscutível sobre as outras. Por um lado este fato pode ser explicado pela própria característica da pergunta - o respondente era obrigado a classificar de 1 (influi muito) a 7 (influi pouco) sem repetir números; por outro lado, pode ser explicado pela própria distribuição das respostas, que nos permitem afirmar que todas as razões apresentadas contribuem para um usuário preferir uma funcionalidade em vez de outra.

De qualquer forma, as duas razões que apresentam respostas de modo geral mais próximas do 'influi muito’ são 'tipo de informação' (nota média 3,47, lembrando que o mais alto era 1,00), e 'características pessoais do usuário final' (nota média 3,58), que representa trata justamente do estilo cognitivo dos usuários. Ao contrário, as duas razões que parecem influir menos na opinião dos participantes são a 'cultura analítica da organização' (nota média 4,47) e 'Papel ou função desempenhado pelo usuário final' (nota média 4,37). Tendo em vista que a diferença é de apenas um ponto, é possível conceber que, na opinião em conjunto da amostra, todos os motivos podem ser encarados como influenciadores com um peso muito similar. A figura 14 da próxima página ilustra algumas das observações supramencionadas. 


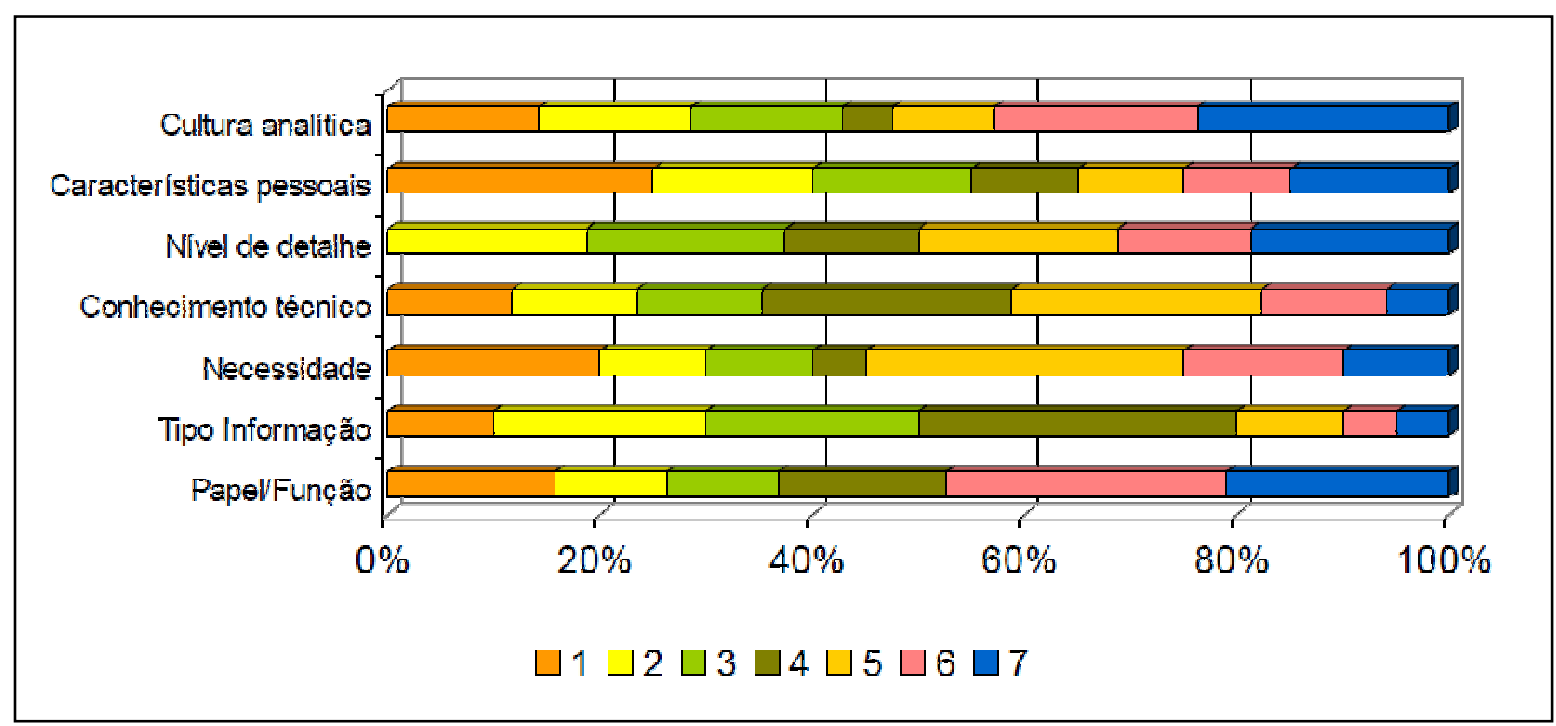

Figura 14. Grau de Influência na Escolha

Quanto ao Diagnóstico de Tipos Psicológicos, em primeiro lugar é possível afirmar que as 19 respostas estão distribuídas de forma homogênea nas dicotomias Extroversão (E) / Introversão (I), Sensação (S) / Intuição (N), Julgamento (J) / Percepção (P), com as observações praticamente divididas entre cada preferência; apenas na dicotomia Pensamento (T) / Sentimento (F) há um ligeiro desvio para as pessoas do primeiro tipo como pode ser visto na figura 15 a seguir.

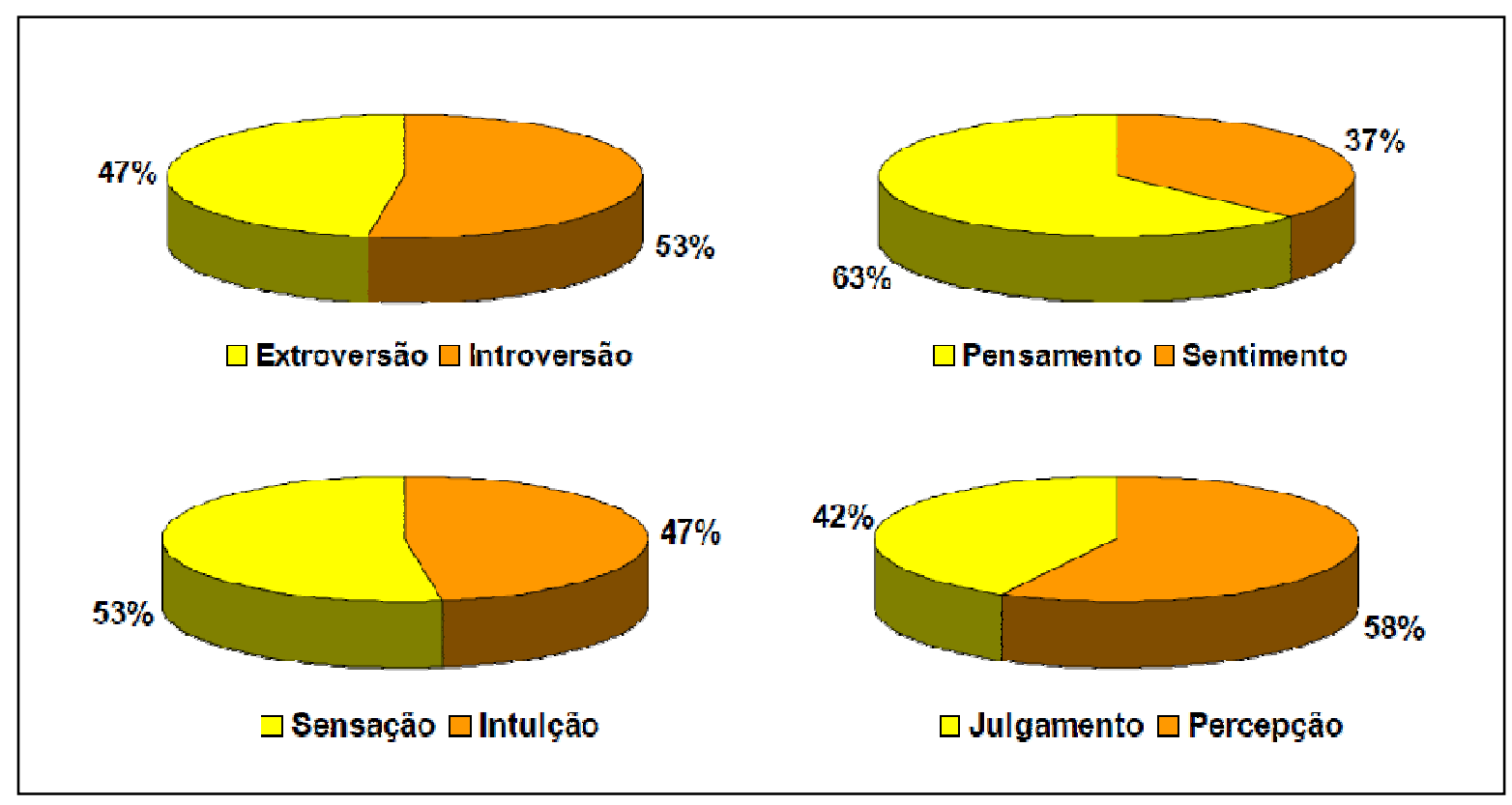

Figura 15. Distribuição dos Respondentes de acordo com as Funções Jungianas 
Além disso, como ilustra a tabela 6 a seguir, observou-se na amostra respondentes de pelo menos treze dos dezesseis tipos psicológicos descritos por Myers e Briggs, isto é, o conjunto total de tipos resultante da permuta das 4 dicotomias possíveis. Este é um cenário positivo porque, além das chances matemáticas remotas disto ocorrer, esperava-se que numa área relacionada com tecnologia e voltada de capacidades analíticas, alguns tipos psicológicos incidissem mais do que outros. Duas explicações podem ser propostas para este fato: a primeira é uma extrapolação do que autores como Casado sugerem, isto é, de que todos os tipos psicológicos têm pontos fortes, benefícios e diferenciais a oferecer, inclusive dentro do mundo particular do BI; a segunda é de que os conhecimentos sobre os Tipos Psicológicos aplicados à administração ainda são pouco disseminados e pouco utilizados na identificação e seleção de recursos, principalmente na composição de equipes operacionais e analíticas, lembrando que conclusões em relação aos tipos devem ser tomadas com parcimônia, pois não são exatas ou definitivas.

\begin{tabular}{|r|r|l|r|}
\hline Tipo & Respondentes & Tipo & Respondentes \\
\hline ESTJ & 1 & ISTJ & 1 \\
\hline ESTP & 2 & ISTP & 3 \\
\hline ESFJ & 2 & ISFJ & 0 \\
\hline ESFP & 0 & ISFP & 1 \\
\hline ENTJ & 2 & INTJ & 1 \\
\hline ENTP & 1 & INTP & 1 \\
\hline ENFJ & 0 & INFJ & 1 \\
\hline ENFP & 1 & INFP & 2 \\
\hline
\end{tabular}

Tabela 6. Tipos Psicológicos dos Respondentes

\subsubsection{Análise da Relação entre Tipo Psicológico e Escolha por Funcionalidade}

Uma vez avaliadas todas as variáveis individuais das observações coletadas, é possível então realizar as verificações necessárias para confirmar ou rejeitar a hipótese de que existe de uma relação entre o estilo cognitivo de um indivíduo e a sua preferência ou escolha por determinada funcionalidade de BI. Para atingir este objetivo, optou-se pela análise separada de cada uma das funções dicotômicas de Jung, assim como realizado por Lenzi (2008, p.95), o que diminui a complexidade dos cálculos estatísticos e, ao mesmo tempo, permite alcançar um melhor entendimento dos achados, além de estar alinhado com as proposições realizadas anteriormente. 
Ao iniciar esta análise, porém, a primeira questão que deve ser tratada é a escolha do método estatístico adequado para a avaliação, uma vez que não podem ser utilizadas as correlações medidas pelos coeficientes de Pearson (como realizado anteriormente na relação entre conhecimento e uso) ou de Spearman. Esta impossibilidade é uma conseqüência direta do não atendimento das premissas básicas dos testes paramétricos, isto é, variáveis contínuas (a preferência é uma variável nominal, assim como as quatro escalas dicotômicas dos tipos psicológicos), distribuiçõos normais (como são nominais, nenhuma apresenta este tipo de distribuição) e tamanho mínimo da amostra maior que 20 (foram obtidas apenas 17 respostas completas) (CORDER e FOREMAN, 2009, p.1-2). Desta forma, as possibilidades de análise ficam restritas a testes chamados de não paramétricos ou livres de distribuição, mais especificamente ao Teste Qui-Quadrado (Chi-Square Test) ou Teste Exato de Fischer (Fischer Exact Test), conforme Corder e Foreman (2009, p.4).

Fundamentalmente, o teste Qui-Quadrado de independência “(...) usa dados da amostra para testar a hipótese de que não há associação estatística entre duas categorias (...)”, determinando “(...) o quão bem as proporções da amostra se ajustam as proporções especificadas na hipótese nula" (CORDER e FOREMAN, 2009, p.168). De forma prática então, o primeiro passo para realizar o teste Qui-Quadrado é definir as hipóteses nulas. Nesta pesquisa, estas hipóteses declaram de forma simples que não há associação entre as duas categorias (tipos psicológicos e preferências), portanto, a preferência por determinada funcionalidade é independente do estilo cognitivo. Em outras palavras, o resultado esperado e desejado é que estas hipóteses nulas sejam rejeitadas, afirmando a existência da relação.

- H1 $1_{0}$ : Não há associação entre Tipo Geral de Disposição (Extrovertido/Introvertido) e a preferência por funcionalidade de BI;

- H2 $2_{0}$ : Não há associação entre Tipo Funcional Perceptivo (Sensação/Intuição) e a preferência por funcionalidade de BI;

- H3 $3_{0}$ : Não há associação entre Tipo Funcional Judicativa (Pensamento/Sentimento) e a preferência por funcionalidade de BI;

- H40 : Não há associação entre Tipo de Atitude (Percepção/Julgamento) e a preferência por funcionalidade de BI; 
O segundo passo é a construção das tabelas de freqüência observadas e esperadas (tabelas de contingência), que permitem posteriormente encontrar o quadrado das diferenças e chegar ao coeficiente do Qui-Quadrado de Pearson. Detalhes em relação à fórmula de cálculo podem ser verificados em Corder e Foreman (2009). O resultado está detalhado na tabela 7 abaixo.

\begin{tabular}{|c|c|c|c|c|}
\hline & Ad hoc & OLAP & Painel & Total \\
\hline $\mathrm{E}$ & 2,00 & 6,00 & 1,00 & 9,00 \\
\hline 1 & 1,00 & 4,00 & 3,00 & 8,00 \\
\hline \multirow[t]{2}{*}{ Total } & 3,00 & 10,00 & 4,00 & $17,0 \mathrm{C}$ \\
\hline & ad hoc & OLAP & Painel & Total \\
\hline $\mathrm{N}$ & 1,00 & 5,00 & 2,00 & 8,00 \\
\hline S & 2,00 & 5,00 & 2,00 & 9,00 \\
\hline \multirow[t]{2}{*}{ Total } & 3,00 & 10,00 & 4,00 & 17,00 \\
\hline & ad hoc & OLAP & Painel & Total \\
\hline $\mathrm{F}$ & 2,00 & 4,00 & 0,00 & 6,00 \\
\hline$T$ & 1,00 & 6,00 & 4,00 & $11,0 \mathrm{C}$ \\
\hline \multirow[t]{2}{*}{ Total } & 3,00 & 10,00 & 4,00 & 17,00 \\
\hline & ad hoc & OLAP & Painel & Total \\
\hline $\mathrm{J}$ & 2,00 & 4,00 & 2,00 & 8,00 \\
\hline $\mathrm{P}$ & 1,00 & 6,00 & 2,00 & 9,00 \\
\hline Total & 3,00 & 10,00 & 4,00 & 17,00 \\
\hline
\end{tabular}

\begin{tabular}{|c|c|c|c|c|}
\hline & ad hoc & OLAP & Painel & Total \\
\hline$E$ & 1,59 & 5,29 & 2,12 & 9,00 \\
\hline 1 & 1,41 & 4,71 & 1,88 & 8,00 \\
\hline \multirow[t]{2}{*}{ Total } & 3,00 & 10,00 & 4,00 & 17,00 \\
\hline & ad hoc & OLAP & Painel & Total \\
\hline $\mathrm{N}$ & 1,41 & 4,71 & 1,88 & 8,00 \\
\hline$s$ & 1,59 & 5,29 & 2,12 & 9,00 \\
\hline \multirow[t]{2}{*}{ Total } & 3,00 & 10,00 & 4,00 & 17,00 \\
\hline & ad hoc & OLAP & Painel & Total \\
\hline$F$ & 1,06 & 3,53 & 1,41 & 6,00 \\
\hline $\mathrm{T}$ & 1,94 & 6,47 & 2,59 & 11,00 \\
\hline \multirow[t]{2}{*}{ Total } & 3,00 & 10,00 & 4,00 & 17,00 \\
\hline & ad hoc & OLAP & Painel & Total \\
\hline $\mathrm{J}$ & 1,41 & 4,71 & 1,88 & 8,00 \\
\hline$P$ & 1,59 & 5,29 & 2,12 & 9,00 \\
\hline Total & 3,00 & 10,00 & 4,00 & 17,00 \\
\hline
\end{tabular}

Tabela 7. Frequiências Observadas e Esperadas I

Antes mesmo de realizar o cálculo, contudo, já é possível identificar visualmente que não há contrastes acentuados na tabela de freqüências observadas. Grande parte dos valores está distribuída de forma similar (e, em alguns casos, de forma simétrica) entre as dicotomias psicológicas. A única diferença clara aparece entre indivíduos Sentimento $(F)$ e indivíduos Pensamento (T) para os painéis e, além disso, os relatórios ad hoc não parecem ter qualquer importância na discussão, pois são apenas três observações que sempre ficam divididas igualmente.

Apesar deste panorama inicial, os coeficientes são calculados e avaliados a seguir, considerando 2 graus de liberdade e um nível de risco/significância de 0,05, isto é, chance de 95\% de que as diferenças estatísticas observadas sejam reais (CORDER e FOREMAN, 2009, p.170). O valor de referência para rejeitar as hipóteses nulas neste cenário é de 7,38, ou seja, coeficientes Qui-Quadrado com valores calculados menores que 7,38 resultam na confirmação das hipóteses nulas de inexistência de relacionamento e independência das variáveis; valores maiores (ou iguais), resultam na rejeição das hipóteses. 
Como se pode observar na tabela 8 a seguir, nenhum dos coeficientes ficou acima do valor de referência $(7,38)$ - o maior foi 3,57 , portanto, as hipóteses nulas são confirmadas. Isto significa dizer que, de acordo com o teste Qui Quadrado a um nível de significância de 0,05, na amostra selecionada não há associação entre nenhuma das dicotomias de tipos psicológicos e a preferência por funcionalidade de BI e, por conseguinte, tampouco há relação entre os estilos cognitivos e a preferência por funcionalidade de BI. Ficam deste modo refutadas as proposições sugeridas inicialmente.

\begin{tabular}{|l|r|r|r|}
\hline & Valor E/ & Graus Lib & Sig. Assim. \\
\hline Pearson Chi-Square & 1,680 & 2 & 0,432 \\
\hline Likelihood Ratio & 1,730 & 2 & 0,421 \\
\hline Linear-by-Linear Association & 1,273 & 1 & 0,259 \\
\hline Cramer's V & 0,314 & & 0,432 \\
\hline N of Valid Cases & 17 & & \\
\hline
\end{tabular}

\begin{tabular}{|r|r|r|}
\hline Valor F/T & Graus Lib & Sig. Assim. \\
\hline 3,572 & 2 & 0,168 \\
\hline 4,795 & 2 & 0,091 \\
\hline 3,287 & 1 & 0,070 \\
\hline 0,458 & & 0,168 \\
\hline 17 & & \\
\hline
\end{tabular}

\begin{tabular}{|l|r|r|r|}
\hline & Valor N/S & Graus Lib & Sig. Assim. \\
\hline Pearson Chi-Square & 0,275 & 2 & 0,871 \\
\hline Likelihood Ratio & 0,281 & 2 & 0,869 \\
\hline Linear-by-Linear Association & 0,153 & 1 & 0,696 \\
\hline Cramer's V & 0,127 & & 0,871 \\
\hline N of Valid Cases & 17 & & \\
\hline
\end{tabular}

\begin{tabular}{|r|r|r|}
\hline Valor P/J & Graus Lib & Sig. Assim. \\
\hline 0,677 & 2 & 0,713 \\
\hline 0,684 & 2 & 0,710 \\
\hline 0,121 & 1 & 0,728 \\
\hline 0,200 & & 0,713 \\
\hline 17 & & \\
\hline
\end{tabular}

Tabela 8. Resultados Teste Qui Quadrado de Pearson

Há, entretanto, um ponto de atenção: como o número total de observações da amostra é reduzido, existem algumas freqüências esperadas nas tabelas de contingência que são menores do que 5. De acordo com alguns pesquisadores, esta situação pode ser considerada uma contravenção a uma das poucas premissas do cálculo do Qui-Quadrado e pode resultar em achados distorcidos ou enganosos (SPSS, 1997, p.67), discussão que pode suscitar dúvidas sobre a validade das conclusões supramencionadas. Deste modo, é aconselhável realizar também o Teste Exato de Fischer, utilizado para “(...) analisar dados discretos de amostras pequenas e independentes, podendo ser nominais ou ordinais" (CORDER e FOREMAN, 2009, p.170).

Apesar deste teste ser possível em tabelas de contingência até 6x6, inclusive com o apoio de ferramentas, ele é realizado mais comumente nas tabelas $2 \times 2$, devido aos grandes números resultantes das multiplicações de permutações que compõem a fórmula de cálculo. Além disso, como o cálculo também considera conjuntos com desvios mais extremos, quando há 
mais de duas linhas e colunas é preciso decidir como mensurar estes desvios da hipótese nula, isto é, quais conjuntos são mais extremos que o observado (MCDONALD, 2008, p.64), o que também aumenta a complexidade das análises. Detalhes em relação à fórmula de cálculo podem ser verificados em Corder e Foreman (2009) e em McDonald (2008).

Tendo em vista simplificar os cálculos e as análises, portanto, optou-se por converter a matriz original 3x2 em 2x2, eliminando a coluna dos relatórios ad hoc da análise. Este procedimento é justificável devido à distribuição bastante simétrica das respostas nos 4 cenários, desde que as conclusões sejam restritas aos dois conjuntos restantes (SPSS, 1997, p.67). Cogitou-se a princípio a idéia de agrupar as três observações com os relatórios OLAP ou com os painéis de informação de modo a não reduzir o número de observações; porém, como o entendimento de alguns dos entrevistados em relação a estas funcionalidades difere do exposto no Marco Teórico, qualquer artifício seria discutível. As tabelas $2 \times 2$ resultantes são ilustradas abaixo na tabela 9.

\begin{tabular}{|c|c|c|c|c|c|c|c|}
\hline & OLAP & Painel & Total & & OLAP & Painel & Total \\
\hline & 6,00 & 1,00 & 7,00 & $\mathrm{E}$ & 5,00 & 2,00 & 7,00 \\
\hline & 4,00 & 3,00 & 7,00 & 1 & 5,00 & 2,00 & 7,00 \\
\hline Total & 10,00 & 4,00 & 14,00 & Total & 10,00 & 4,00 & 14,00 \\
\hline & OLAP & Painel & Total & & OLAP & Painel & Total \\
\hline $\mathrm{N}$ & 5,00 & 2,00 & 7,00 & $\mathrm{~N}$ & 5,00 & 2,00 & 7,00 \\
\hline$s$ & 5,00 & 2,00 & 7,00 & $\mathrm{~s}$ & 5,00 & 2,00 & 7,00 \\
\hline Total & 10,00 & 4,00 & 14,00 & Total & 10,00 & 4,00 & 14,00 \\
\hline & OLAP & Painel & Total & & OLAP & Painel & Total \\
\hline$F$ & 4,00 & 0,00 & 4,00 & $F$ & 2,86 & 1,14 & 4,00 \\
\hline $\mathrm{T}$ & 6,00 & 4,00 & 10,00 & $\mathrm{~T}$ & 7,14 & 2,86 & 10,00 \\
\hline Total & 10,00 & 4,00 & 14,00 & Total & 10,00 & 4,00 & 14,00 \\
\hline & OLAP & Painel & Total & & OLAP & Painel & Total \\
\hline J & 4,00 & 2,00 & 6,00 & $\mathrm{~J}$ & 4,29 & 1,71 & 6,00 \\
\hline$p$ & 6,00 & 2,00 & 8,00 & $\mathrm{P}$ & 5,71 & 2,29 & 8,00 \\
\hline Total & 10,00 & 4,00 & 14,00 & Total & 10,00 & 4,00 & 14,00 \\
\hline
\end{tabular}

Tabela 9. Freqüências Observadas e Esperadas II

Assim como no Qui-Quadrado, as hipóteses nulas são as de que não há associação entre as variáveis (preferência e dicotomias psicológicas). Nesta nova apresentação, visualmente já é possível aceitar a hipótese nula no caso dos indivíduos Intuição $(\mathrm{N})$ e Sensação $(\mathrm{S})$, pois não há diferença entre as freqüências observadas e esperadas. De qualquer forma, as probabilidades são calculadas e avaliadas a seguir. 
Como se pode observar na tabela 10 a seguir, independente do método ( 2 tailed ou 1 tailed) nenhuma das probabilidades ficou abaixo no nível de significância de 0,05, portanto, conforme sugerem Corder e Foreman (2009, p.183), todas as hipóteses nulas são confirmadas, isto é, não há relação entre as variáveis avaliadas, isto é, não há associação entre nenhuma das dicotomias de tipos psicológicos e a preferência por funcionalidade de BI. De acordo com o Teste Exato de Fischer, ficam refutadas as proposições sugeridas inicialmente, especificamente para relatórios OLAP e Painéis de Informação.

\begin{tabular}{|l|r|r|}
\hline & $\begin{array}{c}\text { Exact Sig. } \\
\text { (2sid) }\end{array}$ & $\begin{array}{c}\text { Exact Sig. } \\
\text { (1sid) }\end{array}$ \\
\hline E/I & 0,559 & 0,280 \\
\hline N/S & 1,000 & 0,720 \\
\hline F/T & 0,085 & 0,070 \\
\hline J/P & 1,000 & 0,594 \\
\hline N of Valid Cases & 14 & \\
\hline
\end{tabular}

Tabela 10. Resultados Teste Exato de Fischer

\subsection{Principais Preocupações com usuários no BI}

A última análise trata genericamente das principais preocupações da organização em relação aos usuários de Business Intelligence. A princípio, com base no levantamento do Marco Teórico, foram encontrados cinco tópicos fundamentais cujo objetivo era direcionar esta discussão, a saber: associação entre informações e usuários, associação entre ferramentas e usuário, capacitação técnica e funcional, facilidade de uso das ferramentas e cultura analítica da organização.

Certamente o tópico mais abordado nas entrevistas em profundidade foi justamente o do relacionamento entre funcionalidades e usuários, uma vez que um dos objetivos desta pesquisa era avaliar até que ponto os estilos cognitivos são considerados nesta associação. Para Keyes (2006, p.100), combinar adequadamente as diversas ferramentas que o BI oferece com os usuários finais certos é um dos principais fatores de sucesso de uma aplicação deste tipo. Apesar dos entrevistados concordarem com a afirmação, na prática pouco parece ser feito neste sentido; pois mesmo aquelas características mais recorrentes na literatura de referência e nas políticas das organizações são limitadas, recaindo normalmente sobre o 
conhecimento técnico implícito do usuário. E como foi visto nos pontos anteriores, apesar do tema dos estilos cognitivos até ser reconhecido pela maioria dos entrevistados como um aspecto influenciador, ele parece ter pouca relevância no cotidiano e na estratégia da organização em análise, seja pela dificuldade de tratamento ou pelo custo/benefício desconhecido. Com base em outras experiências inclusive em outras indústrias, este parece ser o cenário típico na grande maioria das organizações brasileiras, inclusive naquelas em que a maturidade analítica é bastante avançada.

Quanto ao tema abordado por Luhn (1958, p.315) sobre o relacionamento entre informação e usuários, isto é, a distribuição de informações particulares baseada numa relação com os requerimentos, desejos e interesses dos usuários, pode-se dizer que praticamente não foi contemplado durante as entrevistas. Isto ocorreu por dois motivos: em primeiro lugar, o tópico foi ofuscado pelo tema do relacionamento entre ferramentas e usuários, ficando num segundo plano quando eventualmente foi abordado pelo entrevistado; em segundo lugar, este relacionamento é realizado de forma já estabelecida com base no perfil de acesso dos usuários que considera definições atreladas com as políticas de segurança de informação da organização, portanto, uma questão decidida sobre a qual não parece haver muito espaço para discussão.

Dentre os três tópicos restantes, o mais abordado espontaneamente foi o da capacitação. provavelmente porque é aquele que é insistentemente e explicitamente exigido pelas equipes de administração de mudança das empresas na implantação de novas tecnologias dentro das diferentes metodologias de projeto. De fato, esta é uma preocupação sensata, pois como defende Brunson (2005, p.1), nem a melhor das soluções tecnológicas é eficientemente aproveitada se seus usuários não são educados de forma adequada na sua utilização e entendimento. Para AN1, por exemplo, este tema é uma preocupação essencial, principalmente em projetos, pois afeta a aceitação do produto e, por conseguinte, sua adoção. Infelizmente, é um tema que não raro perde visibilidade perto das decisões tecnológicas, de negócios e de custos das iniciativas, ficando relegado a um segundo plano, o que aumenta os riscos de insatisfação dos usuários. De forma genérica, os diferentes entrevistados reconhecem que a capacitação através de treinamentos é uma das principais formas de vencer a resistência à mudança, um tópico que por si só representa outra preocupação relevante. 
De forma simples, a resistência à mudança trata basicamente da dificuldade normalmente inconsciente dos usuários em aceitar uma nova tecnologia ou conceito, abandonando a zona de conforto em que se encontram, isto é, a tecnologia ou conceito que os atendem e com a qual estão habituados, mesmo que com benefícios e facilidades inferiores a nova opção. Um exemplo ilustrativo está no exemplo detalhado por Diniz (2004, p.56), que explica que num banco particular "as primeiras experiências com o uso de sistemas computadorizados foram acompanhadas por grandes resistências por parte de grupos de profissionais, que sentiam seu trabalho ameaçado". Dentro deste banco, houve uma resistência muito grande dos contadores do banco em relação ao uso de computadores; na década de 1960, por exemplo, "o Chefe da Contabilidade do banco recusou-se a comparecer ao lançamento do sistema de contabilidade computadorizado, para não ser conivente com uma iniciativa "fadada ao fracasso"” (DINIZ, 2004, p.56). Segundo AT1 e ST1, para mitigar esta aversão e oposição às novas aplicações, é preciso “(...) envolvimento dos usuários no desenvolvimento, alinhamento entre negócio e tecnologia, treinamentos para o usuário final, períodos de transição entre o antigo paradigma e o novo e, principalmente, patrocinadores influentes que dêem apoio e se comprometam com o novo".

Um tópico que não foi abordado dentro do referencial bibliográfico, mas que apareceu recorrentemente nas entrevistas e poderia ter um destaque foi o da comunicação entre equipe funcional (de negócios) e equipe técnica. Para ST1, existe uma dificuldade em entender corretamente as demandas de negócio e, posteriormente, em conseguir demonstrar qual o resultado que será alcançado. "Muitas vezes o cliente não está certo do que precisa ou do que quer, nem de qual será o produto final e como ele irá de fato ajudá-lo em suas atividades corriqueiras". Para isso, ST1 destaca que comunicação é fundamental, principalmente na definição de requisitos. É preciso alinhar entendimentos e, neste sentido, o entrevistado insiste de que o uso de protótipos é uma ótima ferramenta para demonstrar o que foi pedido, os benefícios e os resultados esperados frente às expectativas. Ainda sobre a comunicação, ST1 defende que “(...) é importante que as pessoas das áreas de negócio tenham conhecimentos técnicos (e há muitas assim), assim como que a área de TI também tenha conhecimentos de negócio". Para isso, segundo o entrevistado é importante para a organização investir e capacitar recursos mistos e polivalentes, isto é, "pessoas de negócio que discutam tecnologia, assim como pessoas técnicas que saibam falar e entender o negócio”. 
A discussão da facilidade também teve uma atenção particular e também apresentou opiniões bastante diferentes. Para o consultor CE1, as observações de Gartner Group (2011, p.7) de que usuários de negócio de BI têm demandado cada vez mais experiências de uso similares as de outras tecnologias pessoais que tiveram grande difusão nos últimos anos, direcionando as ferramentas para aplicações mais simples, móveis, intuitivas e divertidas são coerentes com o que se observa no mercado, isto é, uma busca por ferramentas com interfaces amigáveis e fáceis de entender e de usar. Para esta tendência colaboram o lançamento de novas ferramentas da Apple como o iPod, iPhone e iPad, que são muito simples de usar; segundo este entrevistado, "não é raro ouvir no levantamento de novos requisitos (não só desta organização em particular), que o usuário deseja funcionalidades similares com as disponíveis nestas ferramentas". GN1 confirma que a facilidade de uso das ferramentas é um tema recorrentemente discutido entre as equipes técnicas e de negócio, na busca de uma interface lógica e amigável. Para balancear esta demanda, além dos workshops onde os usuários participam e avaliam o ferramental utilizado, a transferência de conhecimento para a área de negócio e disseminação de conceitos técnicos e de modelagem através da capacitação devem ser incentivados e cobrados a fim de acelerar a curva de aprendizagem. Para ST1, a facilidade de uso está totalmente relacionada com à resistência à mudança, ou seja, "além da ferramenta ser melhor, ela também deve ser comprovadamente mais fácil de utilizar, caso contrário não é possível convencer o usuário a mudar de tecnologia”. De qualquer forma, na opinião do entrevistado esta questão da facilidade de uso é um tema intrínseco à tecnologia e o que se pode fazer é investir no treinamento e na capacitação. Numa linha um pouco inversa, AT1 entende que este assunto não tem tanta importância, talvez porque ele não veja muito espaço para manobra. Para AT1, no fundo "são os usuários que têm de se adequar à ferramenta, vencer a resistência e sair da zona de conforto". Ele não entende isso como uma imposição da área de TI, mas uma tendência do mercado contra a qual não se pode lutar contra, "um caminho sem volta".

O tópico menos abordado ou ao qual se deu a menor importância durante as entrevistas foi o da cultura, pois, segundo os entrevistados, este aspecto afeta pouco a utilização das ferramentas e aplicações de BI na organização, apesar da observação de Howson (2008, p.183), de que os resultados do BI são limitados, locais e têm um impacto reduzido quando a organização não tem uma cultura que apóie e fomente estas iniciativas. De qualquer forma, de acordo com ST1, o Banco Alfa "é uma instituição madura sob o ponto-de-vista de BI e que tem uma cultura 'analítica e gerencial', pois encara a informação como um ativo da 
organização e incentiva seu uso para a criação de novos conhecimentos e vantagens competitivas". AN1 também acredita que o banco tem uma cultura que valoriza o BI, principalmente quando se compara a outras organizações nas quais teve experiências. Para ele, isso fica claro quando se avalia a governança da informação dentro do Alfa, uma vez que é um aspecto ao qual se dá muita atenção e importância, seja pelos temas relacionados com confidencialidade, seja pela necessidade de alinhar conceitos. Para AN1 a organização não só tem uma cultura analítica, mas tem uma cultura de informação, uma vez que se preocupa com o todo o fluxo de dados ("desde suas origens até seu destino final") e sabe que a qualidade e confiança dos dados ao longo da cadeia são fundamentais para que a informação seja íntegra e coerente para o usuário final. Apesar destes comentários positivos, a organização na opinião de AT1 não pode ser considerada um competidor analítico como prega Davenport (2006), pois a grande maioria de suas áreas ainda utiliza de forma insipiente as funcionalidades de BI (quando estão disponíveis), realizando suas atividades analíticas em planilhas de cálculo. 


\section{CONSIDERAÇÕES FINAIS}

Como abordado nas declarações iniciais deste esforço acadêmico e no Marco Teórico, diversos autores destacam a importância do lado humano para o sucesso das aplicações de Business Intelligence nas organizações. Contudo, o enfoque tecnológico na implantação ou utilização destas ferramentas analíticas ainda é dominante, por vários motivos. Mesmo que uma equipe esteja capacitada intelectualmente dentro da organização para realmente criar a inteligência de negócios de fato sobre o volume de dados atualmente disponível nas grandes organizações é essencial o suporte de um instrumental tecnológico; em conseqüência, qualquer iniciativa de BI é relacionada e normalmente encabeçada pelas áreas de TI das instituições, por equipes com conhecimentos e perfil mais técnico. Além disso, ao contrário de sistemas transacionais que, pelo menos no caso dos bancos brasileiros, foram em grande parte desenvolvidos internamente, os sistemas analíticos de fornecedores são melhores (com mais funcionalidades), são mais maduros, robustos, customizáveis e possibilitam resultados mais rápidos.

No Banco Alfa, este enfoque não é diferente, pois o aspecto tecnológico é ainda dominante; segundo um dos entrevistados, os aspectos humanos não são devidamente reconhecidos, desenvolvidos e compartilhados, nem no nível operacional, nem no nível estratégico. Quando questionados sobre as cinco principais preocupações humanas em relação ao BI - levantadas com o apoio do referencial bibliográfico, os entrevistados demonstraram interesse genuíno apenas no tema da capacitação, que é continuamente abordado pelas equipes de administração de mudança de projetos de implantações de sistemas e sem a qual qualquer iniciativa está comprovadamente fadada ao fracasso. Os demais temas levantados parecem insipientes ou inexistentes pelo que se pode interpretar dos entrevistados, confirmando a visão inicial de que dentro das organizações pouca importância é outorgada a estas diversas preocupações teóricas, seja pela baixa relevância ou pela dificuldade de manejar o tema. Contudo, espontaneamente, dois outros tópicos adicionais foram abordados: em primeiro lugar foi reiterada em diversas entrevistas a preocupação com a resistência à mudança (numa associação com o tema da capacitação), uma discussão que não é particular de sistemas analíticos, mas na adoção de qualquer tipo de sistema, transacional, corporativo ou pessoal. Em segundo lugar, também se insistiu nas dificuldades de comunicação e entendimento entre 
as equipes de negócio e as equipes técnicas, o que talvez demonstre que ainda há temas mais práticos e operacionais sobre os quais as organizações ainda têm que se preocupar.

Mesmo neste cenário, com base na interpretação das observações do Estudo de Caso é possível afirmar que o Banco Alfa é uma organização madura sob o ponto-de-vista de Business Intelligence e um referencial dentro do país. Não obstante, com base nos prérequisitos de Davenport (2006, p.2) e Davenport et al (2005, p.7-9), ainda não é possível considerar o banco como um competidor analítico, pois, apesar de contar com um ambiente tecnológico sustentável, com o acúmulo maciço de dados confiáveis e de qualidade, com estratégias para administração dos dados e com o estímulo da demanda pelos produtos analíticos, ainda falta experiência e conhecimento quantitativo da maioria dos recursos, assim como comprometimento explícito e inabalável da liderança e mudanças de mentalidade e de cultura (como as pessoas pensam, trabalham e são tratadas).

Quanto a entender melhor os usuários das aplicações analíticas e compreender quais são as ferramentas e métodos mais adequados para os diferentes grupos de usuários que usufruem das soluções de Business Intelligence, objetivo central desta pesquisa, os entrevistados demonstraram através de suas opiniões que é um tema complexo e bastante abstrato. Para aqueles que consideram um desafio relevante para o sucesso do BI, tratar os aspectos humanos é uma questão difícil de equalizar e quantificar, pois envolve um grande número de variáveis, fatores que, em conjunto, fazem do assunto um tema confuso e complicado de se trabalhar. De qualquer forma, a avaliação realizada com base nas opiniões dos entrevistados é de que a caracterização dos usuários ocorre de modo informal, indireta e pessoal e leva em consideração os aspectos mais convencionais de diferenciação encontrado nas classificações de Ponniah (2001, p. 326-329), Eckerson (2009, p.5) e Nemati et al (2010, p.19), isto é, o conhecimento técnico, o conhecimento de negócios, a necessidade de negócio e o papel desempenhado.

A associação entre os usuários e as funcionalidades em novas aplicações de BI também é executada de modo informal e indireto pelos profissionais técnicos, mais capacitados para tomar esta decisão uma vez que sabem qual a necessidade do usuário e entendem das possibilidades de cada uma dessas ferramentas. De acordo com alguns entrevistados, usuários não podem escolher ou ter preferências por funcionalidades, pois normalmente desconhecem as opções técnicas que podem existir e quais são aquelas que melhor respondem as suas 
necessidades; o risco é não atingir os objetivos propostos e as expectativas. Por outro lado, no caso de aplicações já estabelecidas, é possível afirmar que os usuários acabam escolhendo a funcionalidade por conta própria, desde elas estejam pré-configuradas para tal (por exemplo, ter um modelo dimensional disponível para construir relatórios OLAP). Neste caso, os entrevistados entendem que além dos aspectos convencionais, o momento da carreira (nível hierárquico) e as características pessoais têm uma importante participação na preferência da funcionalidade, inclusive o estilo cognitivo.

Especificamente em relação à influência do estilo cognitivo sobre a preferência e escolha das funcionalidades de BI em aplicações já estabelecidas, parece haver um contraste de opiniões de acordo com o nível organizacional dos respondentes. Para o executivo entrevistado, as características pessoais de cada usuário (inclusive o estilo cognitivo) não importam na escolha de funcionalidades, pois a necessidade de negócio é dominante sobre quaisquer outros aspectos; por outro lado, para os recursos mais operacionais, esta é uma visão exposta pelo executivo é utópica, uma vez que na prática cada gestor tem um perfil específico e acaba priorizando e determinando formatos que melhor lhe convém. Estes recursos admitem ver diferentes comportamentos na análise de informações de acordo com a personalidade, sendo perceptível que "alguns usuários têm um perfil mais investigativo e analítico, enquanto outros têm um perfil mais generalista e superficial; alguns lidam melhor com tabelas, enquanto outros preferem gráficos e informações mais consolidadas". Não obstante, é um tema difícil de se trabalhar, porque respeitar as demandas e características de cada usuário poderia resultar em diversas funcionalidades diferentes, é muito difícil captar e interpretar estas características pessoais e convertê-las em uma regra clara de preferência e é complicado quantificar o benefício marginal que este cuidado traria para as aplicações de BI.

Além das opiniões de colaboradores, também foi realizado um levantamento limitado de caráter exploratório para verificar se existe uma relação entre estilos cognitivos e a preferência por determinada funcionalidade de Business Intelligence.

Numa amostra de 23 respondentes, todos analistas da Diretoria de Crédito para Empresas do Banco Alfa, observou-se uma equipe jovem, mas com experiência, com um bom conhecimento das funcionalidades de $\mathrm{BI}$, principalmente relatórios pré-formatados e relatórios OLAP, mas com utilização pouco menor, com os relatórios com modelos preditivos e mineração de dados e os relatórios ad hoc sendo os menos usados. Avaliada a correlação 
entre as repostas de conhecimento e uso, é possível afirmar que para a amostra colhida existe uma forte e positiva relação entre os dois temas, o que faz sentido lógico, pois quanto mais se conhece, mais se usa e quanto mais se usa, mais se conhece. Também se verificou que dentre as cinco categorias de funcionalidade de BI destacadas, quase dois terços da amostra dizem preferir Relatórios OLAP, enquanto nenhum declarou preferência pelos Relatórios PréFormatados.

Em relação aos tipos psicológicos ou estilos cognitivos, numa amostra composta de 19 pessoas, os resultados encontrados através do DTP foram relativamente homogêneos entre as quatro dicotomias propostas e observou-se pelo menos treze dos dezesseis tipos psicológicos descritos por Myers e Briggs. Este foi um cenário positivo porque, além das chances matemáticas remotas de ocorrer, esperava-se que numa área relacionada com tecnologia e voltada para capacidades analíticas, alguns tipos psicológicos incidissem mais do que outros. Duas explicações podem ser propostas para este fato: a primeira é uma extrapolação do que autores como Casado sugerem, isto é, de que todos os tipos psicológicos têm pontos fortes, benefícios e diferenciais a oferecer, inclusive dentro do mundo particular do BI; a segunda é de que os conhecimentos sobre os Tipos Psicológicos aplicados à Administração ainda são pouco disseminados, isto é, são raras as áreas e organizações que tiram proveito desta ferramenta e, conseqüentemente, ignoram estes aspectos ao identificar e selecionar recursos para compor suas equipes analíticas.

Para avaliar a relação entre os estilos cognitivos e a preferência por funcionalidades foram realizados dois testes estatísticos não paramétricos (uma vez que são usadas variáveis nominais). Primeiramente no teste Qui-Quadrado nenhum dos coeficientes ficou acima do valor de referência, portanto, na amostra selecionada não existe associação entre nenhuma das dicotomias de tipos psicológicos e a preferência por funcionalidade de BI. Contudo, há um ponto de atenção nesta observação, pois o número total de observações da amostra é diminuto (apenas 17 observações), o pode ser considerada uma contravenção às premissas do cálculo do Qui-Quadrado. Deste modo, também foi executado o Teste Exato de Fischer, utilizado para analisar dados nominais de amostras pequenas, mas neste caso tampouco se encontrou uma relação entre os estilos cognitivos e as funcionalidades.

Surpreendentemente, os resultados negativos achados nesta pesquisa quantitativa simplificada são totalmente contraditórios às opiniões e observações colhidas ao longo do Estudo de Caso, 
o que nos impede de aceitar qualquer conclusão definitiva. Evidentemente um dos motivos que pode explicar esta inconsistência é o próprio fato da amostra (e da população) ser pequena, não significativa e pouco representativa. Entretanto, quando analisamos as duas variáveis envolvidas no estudo, outras explicações podem ser encontradas para as inconsistências. Como o 'Diagnóstico de Tipos Psicológicos' é um instrumento de pesquisa testado e validado, aplicado com sucesso em diversas ocasiões, o questionamento recai então sobre as cinco categorias de funcionalidades propostas: seriam elas a forma mais adequada para averiguar o impacto das personalidades e diferenças pessoais sobre as preferências de BI? Como foi averiguado com os respondentes, todos foram bastante consistentes na confirmação de que tanto a divisão de funcionalidades quanto a ordenação por complexidade proposta eram aceitáveis. Porém, além das inconsistências explícitas em relação a estas funcionalidades não só entre os próprios respondentes (como, por exemplo, no caso dos painéis de informação), mas também nos autores apontados na literatura de apoio, pode haver muitas mais incoerências implícitas que não puderam ser avaliadas no Estudo de Caso, muito menos no levantamento. Em outras palavras, é muito provável que a variável de preferência das funcionalidades não tenha atendido o objetivo desejado, pois não havia um conjunto de conceitos homogêneos entre os respondentes e o próprio pesquisador quanto às ferramentas. Neste sentido, o que talvez possa ser concluído é que os estilos cognitivos têm algum tipo de influência nas preferências analíticas, mas não necessariamente sobre a escolha de funcionalidades disponibilizadas pelas ferramentas.

\subsection{Limitações da Pesquisa}

O Banco Alfa conta com quase 100 mil funcionários, dos quais praticamente $10 \%$ têm algum tipo de envolvimento com ferramentas de BI. Construir um cenário completo e que considere todas as realidades é praticamente inviável, mesmo que um dos entrevistados seja um executivo que esteja profundamente relacionado com o tema. Assim, é importante destacar que as opiniões e interpretações descritas neste Estudo de Caso, assim como as considerações e conclusões da pesquisa estão totalmente limitadas às Diretorias de Controladoria e de Crédito Empresas.

Se não é possível extrapolar os achados desta pesquisa para toda a instituição, é inaceitável qualquer conclusão estatística generalizada, assim como afirma Souza (2000, p.80). O fato da 
escolha do método ter sido o Estudo de Caso único e explanatório, com o objetivo de entender, analisar e explicar os fenômenos relacionados com o tema de pesquisa impede que suas observações sejam generalizadas.

Além disso, o estudo está completamente baseado na opinião dos entrevistados e dos respondentes do levantamento, isto é, percepções subjetivas sobre os vários tópicos discutidos que podem apresentar parcialidades, influências e pré-conceitos; também podem faltar fatos relevantes, seja por esquecimento não intencional ou de forma proposital justificada com as preocupações de confidencialidade de informações. Além disso, as próprias interpretações do pesquisador podem sofrer destes mesmos vieses.

\subsection{Implicações, Contribuições e Recomendações}

Após a análise do caso e o levantamento inicial, a primeira e mais fundamental implicação desta obra foi dar continuidade às observações dos diferentes autores avaliados no Marco Teórico, aprimorando o entendimento dos temas humanos de BI, inclusive dos usuários das ferramentas analíticas e seu relacionamento com as diferentes funcionalidades.

Como declaram Elbashir et al (2008, p.136), o Business Intelligence é um assunto recente que tem ganhado cada vez mais importância e investimentos dentro das organizações pela profusão de benefícios que pode gerar para a organização que o aplica adequadamente. Entretanto, apesar das inúmeras vantagens, aparentemente poucas organizações parecem ter usufruído plenamente delas (WILLIAMS e WILLAMS, 2007, p.1), demonstrando que ainda há muita coisa para desvendar e estudar. Além disso, é um assunto cujo desenvolvimento e utilização dentro das organizações são baseados na prática, com pouca discussão teórica. Neste sentido, esta pesquisa contribui com o corpo de conhecimento acadêmico do tema, debatendo sob o ponto-de-vista acadêmico uma série de achados. Espera-se expandir os conhecimentos atuais no tópico, colaborando dentro das limitações para o êxito destas soluções, com resultados mais positivos e menos frustrantes tanto para usuários e organizações.

Este trabalho poderia ser futuramente complementado e aprimorado com estudos alternativos sobre a variável que mede as funcionalidades. Como foi dito anteriormente, as inconsistências 
de conceitos ou a própria inexistência de relacionamento com os estilos cognitivos motivam que novas alternativas sejam estudadas, pois a influência do estilo cognitivo descrita na teoria também é vivenciada pela maioria das pessoas que trabalham com BI. Neste sentido e com base nas observações dos entrevistados, uma alternativa interessante seria substituir e simplificar a variável de ferramentas, utilizando uma perspectiva similar a de Mann et al (1991, p.142), que declaram que pessoas com diferentes estilos cognitivos têm preferências diferentes em relação quantidade de dados, nível de consolidação, tipo de informação (quantitativa ou qualitativa) e forma de apresentação. Essa afirmação é condizente com a opinião dos entrevistados de que é perceptível que "alguns usuários têm um perfil mais investigativo e analítico, enquanto outros têm um perfil mais generalista e superficial; alguns lidam melhor com tabelas, enquanto outros preferem gráficos e informações mais consolidadas". 


\section{REFERÊNCIAS BIBLIOGRÁFICAS}

ALBERTIN, Alberto Luiz. Comércio Eletrônico: um Estudo no Setor Bancário. Revista de Administração Contemporânea (RAC). Rio de Janeiro: ANPAD, v.3, n.1, p.47-70, Jan/Abr 1999.

ALVES-MAZZOTTI, Alda Judith. Usos e Abusos dos Estudos de Caso. Cadernos de Pesquisa. São Paulo: Fundação Carlos Chagas, v.36, n.129, p.637-651, set/dez 2006.

ARNOTT, David. Success Factors for Data Warehouse and Business Intelligence Systems. Proceedings of the Australasian Conference on Information Systems (ACIS). Christchurch: [?], 19th ACIS, p.55-65, December 2008.

ASSIS, Sergio Luiz de Oliveira. Inteligência de Negócios - O Ambiente da Inteligência de Negócios. Material didático da disciplina EAD-5941, oferecida pelo Programa de PósGraduação em Administração da Faculdade de Economia, Administração e Contabilidade da Universidade de São Paulo, 2010.

ATRE, Shaku. The Top 10 Critical Challenges for Business Intelligence Success. Computerworld. [?]: Computerworld Custom Publishing, 2003.

AVGEROU, Chrisanthi. The Significance of Context in Information Systems and Organizational Change. Info Systems Journal. [?]: Blackwell Science Ltd, i.11, p.43-63, 2001.

BAARS, Henning; KEMPER, Hans-George. Management Support with Structured and Unstructured Data-An Integrated Business Intelligence Framework. Information Systems Management. [?]: Taylor \& Francis Group, v.25, p.132-148, 2008.

BALLARD, Chuck; FARELL, Daniel M.; GUPTA, Amit; MAZULE, Carlos; VOHNIK, Stanislav. Dimensional Modeling: In a Business Intelligence Environment. Armonk: IBM Red Books, 1996. 
BANCO CENTRAL DO BRASIL. 50 maiores bancos e o consolidado do Sistema Financeiro Nacional. 2012. Disponível em: http://www4.bcb.gov.br/top50/port/top50.asp

BANCO DO BRASIL, DIRETORIA DE MARKETING E COMUNICAÇÕES DO. História do Banco do Brasil. Belo Horizonte: Del Rey, Fazenda Comunicação e Marketing, $2^{\mathrm{a}}$ edição, 2010.

BAWDEN, David Bawden; ROBINSON, Lyn. The dark side of information: overload, anxiety and other paradoxes and pathologies. Journal of Information Science. [?]: [?], v.35, n.2, p.180-191, 2009.

BERNHARDT, Douglas C. 'I want it fast, factual, actionable': tailoring competitive intelligence to executive's needs. Long Range Planning. Vienna: Strategic Planning Society, v.27, n.1, p.11-24, 1994.

BLANCO, Sylvie; CARON-FASAN, Marie-Laurence; LESCA, Humbert. Developing capabilities to create collective intelligence within organizations. Journal of Competitive Intelligence and Management. Alexandria: Society of Competitive Intelligence Professionals, v.1, n.1, p.80-92, 2003.

BLANCO, Sylvie; LESCA, Humbert. Business Intelligence: Integrating Knowledge Into The Selection Of Early Warning Signals. ECIS Proceedings: ECIS Workshop on Knowledge Management. Saclay: CEA Centre, June 1998.

BRUNSON, Duffie. Top 10 Trends in Business Intelligence and Data Warehousing for 2005 Revisited. BeyeNETWORK, June 2005. Disponível em: http://www.b-eyenetwork.com/view/998

BRYDON, Michael; GEMINO, Andrew. You've Data Mined. Now What? Communications of the Association for Information Systems. Berkeley: The Berkeley Electronic Press, v.22, a.33, p.603-617, June 2008.

CARR, Nicholas G. IT Doesn't Matter. Harvard Busines s Review. Boston: Harvard Business School Publishing Corporation, May, p.5-12, 2003. 
CASADO, Tania. Tipos psicológicos: uma proposta de instrumento para diagnóstico do potencial humano nas organizações. Tese (Doutorado em Administração) do Programa de Pós Graduação em Administração, Departamento de Administração, Faculdade de Economia, Administração e Contabilidade da Universidade de São Paulo. São Paulo, 1998.

CASTELLS, Manuel. A Era da Informação - Volume I: A Sociedade em Rede. São Paulo: Paz e Terra, $8^{\text {a }}$ edição, 2005.

CHOO, Chun Wei. Information Management for the Intelligent Organization: The Art of Scanning the Environment. Medford: Information Today, 3rd edition, 2001.

CODY, W. F.; KREULEN, J. T.; KRISHNA, V.; SPANGLER, W. S. The integration of business intelligence and knowledge management. IBM Systems Journal. [?]: ABI/INFORM Global, v.41, n.4, p.697-713, 2002.

CORDER, Gregory W.; FOREMAN, Dale I. Nonparametric Statistics for NonStatisticians. New York: John Wiley \& Sons, 2009.

COSTA, Fernando Nogueira. Origem do capital bancário no Brasil: o caso RUBI. Texto 106 para discussão do Instituto de Economia da Universidade Estadual de Campinas, UNICAMP, 2002.

COSTA, Fernando Nogueira. Fases Históricas do Sistema Bancário Brasileiro. Material didático de disciplina oferecida pelo Instituto de Economia da Universidade Estadual de Campinas, UNICAMP, 2010.

DAVENPORT, Thomas H. Competing On Analytics. Harvard Business Review. Boston: Harvard Business School Publishing, p.1-9, January 2006.

DAVENPORT, Thomas H; COHEN, Don; JACKOBSON, Al. Competing On Analytics. Working Knowledge Research Center. Babson Park: Babson Eecutive Education, p.1-10, May 2005. 
DENZIN, Norman K., LINCOLN, Yvonna S. The SAGE Handbook of Qualitative Research. 3rd ed. Thousand Oaks: SAGE Publications, 2005.

DINIZ, Eduardo H. Cinco Décadas de Automação. GV Executivo. São Paulo: Fundação Getúlio Vargas, v.3, n.3, p.55-60, ago/out 2004.

ECKERSON, Wayne W. Beyond Reporting: Delivering Insights with Next-Generation Analytics. TDWI Best Practices Report. Renton: The Data Warehousing Institute, 2009.

ECKERSON, Wayne W. The Keys to Enterprise Business Intelligence: Critical Success Factors. Renton: The Data Warehousing Institute, 2005.

ELBASHIR, Mohamed Z.; COLLIER, Philip A.; DAVERN, Michael J. Measuring the effects of business intelligence systems: The relationship between business process and organizational performance. International Journal of Accounting Information Systems. [?]: Elsevier, v.9, p.135-153, 2008.

ERCOLIN, Tiago Mayoral. Evolução da Estrutura do Mercado Bancário e de Crédito do Brasil no Período de 2001 a 2007. Dissertação (Mestrado em Ciências) do Programa de Pós Graduação em Economia Aplicada da Escola Superior de Agronomia Luiz Queiroz. Piracicaba: 2009.

ESTIVALETE, Vania de Fátima Barros; LÖBLER; Mauri Leodir; VISENTINI, Monize Sâmara; ANDRADE, Taís de. Estilos Cognitivos e Teoria Unificada de Aceitação e Uso da Tecnologia (UTAUT): Verificando Influências na Intenção de Uso dos Sistemas de Informação. Anais do XXXIII Encontro da ANPAD. São Paulo: ANPAD, Setembro de 2009.

FARIA, Fernando de Abreu; MAÇADA, Antonio Carlos Gastaud. Impacto dos Investimentos em TI no Resultado Operacional dos Bancos Brasileiros. Revista de Administração de Empresas. São Paulo: RAE, v.51, n.5, p.440-457, set/out 2011.

FEBRABAN, Federação Brasileira de Bancos. CIAB 2011 - A Tecnologia Além da Web. CIAB 2011. São Paulo: FEBRABAN, Junho 15-17, 2011. 
FERREIRA, Caio Fonseca. Estrutura, Concorrência e Performance do Setor Bancário em um Mercado Heterogêneo. . Tese (Doutorado em Economia) do Programa de Pós Graduação em Economia, Departamento de Economia, Faculdade de Economia, Administração e Contabilidade da Universidade de São Paulo. São Paulo, 2005.

FELDER, R. M.; FELDER, G. N.; DIETZ, E. J. The Effects of Personality Type on Engineering Student Performance and Attitudes. Journal of Engineering Education. [?]: [?], v.91, n.1, p.3-17, 2002.

FIGUEIREDO FILHO, João Sydney de. Política Monetária, Cambial e Bancária no Brasil sob a Gestão do Conselho da Sumoc, de 1945 a 1955. Dissertação (Mestrado em Economia) do Programa de Pós Graduação em Economia da Universidade Federal Fluminense, Niterói, 2005.

FLEISHER, Craig S.; BENSOUSSAN, Babette E. Strategic and competitive analysis: methods and techniques for analyzing business competition. New Jersey: Prentice Hall, 2002.

FLYVBJERG, Bent. Case Study. In: DENZIN, Norman K.; LINCOLN, Yvonna S. The SAGE Handbook of Qualitative Research. 4th ed. Thousand Oaks: SAGE Publications, 2011.

GARTNER GROUP INC. Magic Quadrant for Business Intelligence Platforms. Stamford: Gartner, January 2011.

GILAD, Ben. The Future of Competitive Intelligence. Competitive Intelligence Magazine. Alexandria: SCIP, v.11, n.5, p.21-25, September-October 2008.

GODOY, Arilda Schmidt. Pesquisa Qualitativa: Tipos Fundamentais. Revista de Administração de Empresas. São Paulo: RAE, v.35, n.3, p.20-29, 1995.

HIRSH, Sandra K.; KUMMEROW, Jean. M. Introduction to Type in Organizations. [?]: CPP Inc., 3rd edition, 1998. 
HOWSON Cindy. BI scorecard: Excel integration. InformationWeek. Manhasset: UBM's Techweb, May 2004.

HOWSON, Cindi. Successful Business Intelligence: Secrets to Making BI a Killer App. New York: McGraw-Hill, 2008.

IGBARIA, Magid; SPRAGUE Jr, Ralph H.; BASNET, Chuda; FOULDS, Les. The impact and benefits of a DSS: The case of FleetManager. Information \& Management. [?]: Elsevier, v.31, p. 215-225, 1996.

IMHOFF, Claudia; PETTIT, Ray. The Critical Shift to Flexible Business Intelligence: What Every Marketer Wants - And Needs - From Technology. [?]: Intelligent Solutions. 2004.

INMON, William H. Building the Data Warehouse. New York: John Wiley \& Sons, $3^{\text {rd }}$ edition, 2002.

JACKSON, Joyce. Data Mining: A Conceptual Overview. Communications of the Association for Information Systems. Berkeley: The Berkeley Electronic Press, v.8, p.267296, June 2002.

JACOBSOHN, Liliana Vasconcellos. A Contribuição do e-learning no Desenvolvimento de Competências do Administrador: Considerando o Estilo de Aprendizagem do Aluno de Graduação. Dissertação (Mestrado em Administração) do Programa de Pós Graduação em Administração, Departamento de Administração, Faculdade de Economia, Administração e Contabilidade da Universidade de São Paulo. São Paulo, 2003.

KASSAB, Cláudio. Um Estudo da Gênese das Dynamic Capabilities: O Caso da Tecnologia Bancária no Brasil. Dissertação (Mestrado em Administração) do Programa de Pós Graduação em Administração da Escola de Administração de Empresas de São Paulo da Fundação Getúlio Vargas. São Paulo, 2011. 
KEEN, Peter G. W. Decision Support Systems and the Marginal Economic of Effort. Sloan School of Management Working Paper. Cambridge: Massachusetts Institute of Technology (MIT), n.1089, p.1-32,1979.

KEEN, Peter G. W. Value Analysis: Justifying Decision Support Systems. MIS Quarterly. Minneapolis: Management Information Systems Research Center, p.1-15, March, 1981.

KEEN, Peter G. W; SCOTT MORTON, Michael S. Decision Support Systems: An Organizational Perspective. Reading: Addison-Wesley Publishing, 1978.

KEYES, Jessica. Knowledge Management, Business Intelligence and Content Management: The IT practitioner's Guide. Boca Raton: Auerbach Publications, 2006.

KHAN, Agha Muhammad Ali; AMIN, Nadia; LAMBROU, Nick. Drivers and Barriers to Business Intelligence Adoption: A Case of Pakistan. Proceedings of the European and Mediterranean Conference on Information Systems (EMCIS) 2010. Abu Dhabi: EMCIS, April 12-13, 2009.

KIMBALL, Ralph; ROSS, Margy. The Data Warehouse Toolkit: the complete guide to dimensional modeling. New York: John Wiley \& Sons, 2nd edition, 2002.

KIRTON, Michael. Adaptors and Innovators: Styles of Creativity and Problem Solving. London: Routledge, 1989.

KOHAVI, Ron; ROTHLEDER, Neal J.; SIMOUDIS, Evangelos. Emerging Trends in Business Analytics. Communications of the ACM. New York: Association for Computing Machinery (ACM), v.45, i.8, p.45-48, August 2002.

KOLB, David A. Experimental Learning: Experience as the Source of Learning and Development. New Jersey: Prentice Hall, 1984.

KUMAR, Ram L. Understanding DSS value: an options perspective. Omega International Journal of Management Science. London: Pergamon Press, v.27, p.295-304, 1999. 
LAUDON Kenneth C.; LAUDON, Jane P. Management Information Systems: Managing the Digital Firm. Prentice Hall, 9th edition, 2005.

LAUDON Kenneth C.; LAUDON, Jane P. Management Information Systems: Managing the Digital Firm. Prentice Hall, 12th edition, 2012.

LENZI, Fernando César. Os Empreendedores Corporativos nas Empresas de Grande Porte dos Setores Mecânico, Metalúrgico e de Material Elétrico/Comunicação em Santa Catarina: Um Estudo da Associação entre Tipos Psicológicos e Competências Empreendedoras Reconhecidas. Tese (Doutorado em Administração) do Programa de Pós Graduação em Administração, Departamento de Administração, Faculdade de Economia, Administração e Contabilidade da Universidade de São Paulo. São Paulo, 2008.

LOVEMAN, Thomas H. Diamonds in the Data Mine. Harvard Business Review. Boston: Harvard Business School Publishing, p.109-113, May 2003.

LUHN, Hans Peter. A Business Intelligence System. IBM Journal of Research and Development. Yorktown Heights: IBM, v.2, i.4, p. 314-319, October, 1958.

MANN, Robert I.; WATSON, Hugh J.; CHENEY, Paul H.; GALLAGHER, Charles A. Incorporação do Estilo Cognitivo do Usuário Através de Hardware e Software para DSS. In: SPRAGUE Jr, Ralph H.; WATSON, Hugh J. (Org.). Sistemas de apoio à decisão: colocando a teoria em prática. Rio de Janeiro: Editora Campus, p.141-155, 1991.

MARTINS, Gilberto Andrade; THEÓPHILO, Carlos Renato. Metodologia da Investigação Científica para Ciências Sociais Aplicadas. São Paulo: Atlas, 2009.

MATTHEWS, Robin; SHOEBRIDGE, Anthony. EIS A Guide for Executives. Long Range Planning. London: Pergamon Press, v.25, n.6, p.94-101, 1992.

MAXIMIANO, Antonio Cesar Amaru. Teoria Geral da Administração: da revolução urbana à revolução digital. São Paulo: Editora Atlas, $6^{\text {a }}$ edição, 2006. 
MCDONALD, John H. Handbook of Biological Statistics. Baltimore: Sparky House Publishing, 2008.

MCGAUGHEY, Ronald E.; GUNASEKARAN, Angappa. Enterprise Resource Planning (ERP): Past, Present and Future. International Journal of Enterprise Information System. Hershey: IGI Publishing, v.3, n.3, p.23-35, 2007.

MCLEOD Jr, Raymond; JONES, Jack William. Executive Information Systems: Where Have We Been, Where Are We Now, and Where Are We Going? Proceedings of the 23rd Annual Hawaii International Conference on System Sciences (HICSS). Kailua-Kona: HICSS, v.3, p.153-159, January 1990.

MODY, Meera. Key Intelligence Topics (KITs) in Competitive Intelligence and Global Business In: FLEISHER, Craig S.; BLENKHORN, David L. Competitive Intelligence and Global Business. Wesport: Praeger Publishers, 2005.

NEGASH, Solomon. Business Intelligence. Communications of the Association for Information Systems. [?]: Association for Information Systems (AIS), v.13, p.177-195, 2004.

NEMATI; Hamid; EARLE, Brad; AREKAPUDI, Satya; MAMANI, Sanjay. Do Users GO Both Ways? BI User Profiles Fit BI Tools. International Journal of Business Intelligence Research. Hershey: IGI Global, v.1, i.3, p.15-33, July-September, 2010.

OLAP COUNCIL. 1997. Disponível em: http://www.olapcouncil.org/research/resrchly.htm

PAULI, Sergi. Interpretação e Subjetividade na Inteligência Competitiva. Anais do XIII Seminário em Administração (SEMEAD). São Paulo: Programa de Pós-Graduação em Administração da Faculdade de Economia, Administração e Contabilidade da Universidade de São Paulo, p.1-14, Setembro, 2010.

PONNIAH, Paulraj. Data Warehouse Fundamentals: A Comprehensive Guide for IT Professionals. New York: John Wiley \& Sons, 2001. 
POWER, Daniel J. A Brief History of Decision Support Systems v2.8. DSSResources.COM. May, 2003. Disponível em: http://dssresources.com/history/dsshistoryv28.html.

POWER, Daniel J. A Brief History of Decision Support Systems v4.0. DSSResources.COM. March, 2007. Disponível em: http://dssresources.com/history/dsshistory.html.

RANJAN, Jayanthi. Business Intelligence: Concepts, Components, Techniques and Benefits. Journal of Theoretical and Applied Information Technology. Ipswich: EBSCO Publishing, v.9, n.1, p.60-70, 2009.

RIDING, Richard; CHEEMA, Indra. Cognitive Styles - An Overview and Integration. Educational Psychology. London: Routledge, v.11, n.3-4, p.193-215, 1991.

ROZE, Catherine M. SAP BW certification: a business information warehouse study guide. Hoboken: John Wiley \& Sons, 2002.

RUD, Olivia Parr. Business Intelligence Success Factors: Tools for Aligning Your Business in the Global Economy. John Wiley \& Sons. New Jersey: 2009.

SAAYMAN, Andrea; PIENAAR, Jaco; DE PELSMACKER, Patrick; VIVIERS, Wilma; CUYVERS, Ludo; MULLER, Marie-Luce; JEGERS, Marc. Competitive Intelligence: Construct exploration, validation and equivalence. Aslib Proceedings: New Information Perspective. Bingley: Emerald Group Publishing, v.60, n.4, p.383-411, 2008.

SANTOS, Sandra C.; ALMEIDA, Fernando C. Os Diferentes Conceitos, Interpretações e Aplicações da Inteligência Competitiva. Revista Científica da FAI. Santa Rita do Sapucaí: Faculdade de Administração e Informática, v.9, n.1, p.46-58, 2009.

SCHEPS, Swain. Business Intelligence for Dummies. Hoboken: Wiley Publishig, 2008.

SCIP (Strategy and Competitive Intelligence Professionals). 2009. Disponível em: http://www.scip.org/content.cfm?itemnumber=2226\&navitemnumber=2227 
SILVERS, Fon. Building and Maintaining a Data Warehouse. Boca Raton: Auerbach Publications, 2008.

SOUZA. Cesar Alexandre de. Sistemas integrados de gestão empresarial: estudos de caso de implementação de sistemas ERP. Dissertação (Mestrado em Administração) do Programa de Pós Graduação em Administração, Departamento de Administração, Faculdade de Economia, Administração e Contabilidade da Universidade de São Paulo. São Paulo, 2000.

SOUZA. Cesar Alexandre de; SACCOL, Amarolinda Zanela. Sistemas ERP no Brasil: Teoria e Caos. São Paulo: Atlas, 2003.

SPRAGUE Jr, Ralph H. A Framework for the Development of Decision Support Systems. MIS Quarterly. Minneapolis: Management Information Systems Research Center, v.4, n.4, p.1-26, December 1980.

SPSS Inc. SPSS Base 7.5 Applications Guide. Chicago: SPSS Inc. 1997.

STEIGER, David. Decision Support as Knowledge Creation: a Business intelligence design theory. International Journal of Business Intelligence Research. Hershey: IGI Publishing, v.1, n.1, p.29-47, January-March 2010.

TURBAN, Efraim; RAINER JR, R. Kelly; POTTER, Richard E. Administração da Tecnologia da Informação. Rio de Janeiro: Editora Campus, 2005.

TURBAN, Efraim; SCHAEFFER, Donna M. Uma comparação entre sistemas de informação para executivos, DSS e sistemas de informação gerencial. In: SPRAGUE Jr, Ralph H.; WATSON, Hugh J. (Org.). Sistemas de apoio à decisão: colocando a teoria em prática. Rio de Janeiro: Editora Campus, p.345-362, 1991.

VEDDER, Richard G.; VANECEK, Michael T.; GUYNES, C. Stephen; CAPPEL, James J. $\mathrm{CEO}$ and $\mathrm{CIO}$ Perspectives on Competitive Intelligence. Communications of the ACM. New York: Association for Computing Machinery (ACM), v.42, i.8, p.109-116, August 1999. 
UBIPARIPOVIĆ, Bogan; ĐURKOVIĆ, Emina. Application of Business Intelligence in the Banking Industry. Management Information Systems. [?]: [?], v.6, n.4, p.23-30, 2011.

VENKATRAMAN, Santosh S. DSS: Is It just an Alias for MIS? ACM SIGCPR Computer Personnel. New York: ACM, v.12, n.2, p.4-11, 1989.

WARMOUTH, Michael T; YEN, David. A Detailed Analysis of Executive Information Systems. International Journal of Information Management. [?]: Butterworth-Heinemann, v.12, p.192-208, 1992.

WATSON, Hugh J. Business Intelligence - Past, Present, and Future. Communications of the Association for Information Systems. [?]: Association for Information Systems (AIS), v.25, i.1, a.39, p.487-510, November 2009.

WILLIAMS, Steve; WILLIAMS, Nancy. The Business Value of Business Intelligence. Business Intelligence Journal. Renton: The Data Warehousing Institute, v.8, n.3, p.1-11, November, 2003.

WILliaMS, Steve; WILliaMS, Nancy. The Profit Impact of BI. San Francisco: Morgan Kaufmann Publishers, 2007.

YEOH, William; KORONIOS, Andy; GAO, Jing. Managing the implementation of business intelligence systems: a critical success factors framework. International Journal of Enterprise Information Systems. Hershey: IGI Publishing, v.4, n.3, p.79-94, 2008.

YERMISH, Ira; MIORI, Virginia; YI, John; MALHOTRA, Rashmi; KLIMBERG, Ronald. Business Plus intelligence Plus technology equals Business intelligence. International Journal of Business Intelligence Research. Hershey: IGI Publishing, v.1, n.1, p.48-63, January-March 2010.

YIN, Robert K. Estudo de Caso: Planejamento e Métodos. 2a edição. Porto Alegra: Bookman, 2001. 
YONG, Chu Shao. Do Executive Information System (EIS) a Inteligência de Negócios (BI). São Paulo: Fundação Getúlio Vargas, 2009. 


\section{ANEXOS}

A seguir são apresentados os seguintes anexos na íntegra e conforme descritos no decorrer desta dissertação:

- $\quad$ Roteiro para Entrevista (2 páginas);

- Questionário Business Intelligence (4 páginas);

- $\quad$ Carta de Apresentação da Pesquisa (1 página);

- $\quad$ Orientação para Participação na Pesquisa (1 página);

- Resultado do Diagnóstico de Tipos Psicológicos (1 página); 


\section{Roteiro para Entrevista}

Nome:

Área:

Cargo:

Experiência:

\section{Introdução:}

Apesar do enfoque essencialmente tecnológico dado ao Business Intelligence, diversos autores destacam a importância do lado humano para o sucesso destas aplicaçōes. Sem pessoas capacitadas para interpretar a informaçāo e agir sobre ela, o BI é incapaz de atingir qualquer resultado, ou seja, a tecnologia é apenas o meio, mas nunca pode ser o fim. Nem a melhor das soluçōes tecnológicas é eficientemente aproveitada se seus usuários nāo săo educados de forma adequada na sua utilização e entendimento.

O objetivo primordial do BI é fornecer a informação certa para a pessoa adequada, dentro do tempo esperado e no formato correto, através do canal mais apropriado. Para cumprir este comple xo desafio, a questāo central está em compreender quais as ferramentas e métodos são mais adequados para os diferentes grupos de usuários que usufruem das soluçōes de Business Intelligence. Entender os diferentes públicos alvo, os papéis que desempenham, as informaçōes que demandam $\mathrm{e}$ as maneiras como consomem e analisam as informaçōes permite que as estratégias e decisōes em relação ao BI sejam aprimoradas dentro das organizaçōes, garantindo resultados mais positivos, com menos frustração e insatisfação tanto pelo lado de TI, quanto pelo lado do ne gócio.

\section{Objetivo:}

Analisar como as organizaçōes caracterizam os usuários de soluçōes analíticas (como o Business Intelligence), isto é, como entendem e tratam os diferentes públicos alvo com base nos papéis que desempenham, nas informaçōes que demandam e nas maneiras como consomem e analisam estas informaçōes, procurando, desta forma, entender como lidam com essas distinçōes e como as consideram em suas estratégias e açōes de BI;

\section{Bloco L. Relevância (objetivo 1)}

(1) Business Intelligence: tecnologia ou pessoas?

(2) Pessoalmente, você considera que e sta é uma preocupação válida (usuários)?

(3) Dentro da sua organizaçāo, voố considera que este tema é válido?

(4) É um fator crítico para o êxito das aplicaçōes? Qual a satisfaçăo dos usuários?

\section{Bloco II. Caracterização do Usuário (objetivo 1)}

(1) Como a sua organização caracteriza/diferencia os usuários de Business Intelligence?

(2) Quais os fatores que sāo levados em consideração nesta distinçāo? Falta algum?

(3) Existe uma estratégia clara e definida sob este ponto de vista? É possível existir? 
Bloco III. Relacionamento entre usuários e funcionalidades (objetivo 2)

(1) É aceitável a divisão de funcionalidades de apresentação e análise sugerida? Faltou alguma, sobrou alguma, estão adequadamente ordenadas por complexidade?

Painéis de Informaçāo (ou Dashboard)

Relatórios Pré-Formatados (isto é, re latórios prontos para uso)

Relatórios ad hoc (isto é, relatórios que o próprio usuário pode criar)

Relatórios OLAP (istoé, tabelas dinâmicas e cubos)

Relatórios baseados em Modelos Preditivos e Mineração de Dados

(2) Como sua organização associa os diversos usuários de BI e as diferentes funcionalidades disponibilizadas por estas aplicaçōes?

(3) No questionário você precisou ordenar os aspectos que você entende que mais influenciam a escolha do usuário por uma funcionalidade. Explique sua opiniāo.

1 Características pessoais do usuário final

2 Conhecimento técnico do usuário final

3 Papel ou funçăo desempenhado pelo usuário final

4 Nível de detalhamento da informaçāo

5 Tipo da informaçāo

6 Necessidade de ne gócio do usuário final

7 Cultura analítica da organização

(4) Sua preferência particular săo os relatórios OLAP. Por quê? Explique sua opiniāo.

(5) Qual o usuário típico de cada uma das funcionalidades destacadas acima?

\section{Bloco IV. Estilo Cognitivo (objetivo 4)}

A maioria dos estudos concentra seus esforços de entendimento dos usuários nas necessidades de informaçāo e capacidades técnicas, características essenciais no contexto organizacional. O estilo cognitivo normalmente nāo é considerado devido a sua complexidade e subjetividade. Ele trata da diferença entre personalidades de usuários que resultam em distintas formas de interpretação de dados e de tomada de decisão e que, por conseguinte, podem significar distintas preferências por ferramentas de análise e apresentaçăo de dados.

(1) Você acha que este relacionamento faz sentido? Procure lembrar de situaçōes em que você esteve certo de que este relacionamento existia ou, pelo contrário, não existia.

(2) Você acha que ele é importante (relacionar com a III.2)?

(3) Sua organização considera de alguma forma esta variável (mesmo que informal)?

\section{Bloco V. Preocupações com Usuários (objetivo 5)}

(1) Qual(is) a(s) principal(is) dificuldade(s) relacionada(s) com pessoas no BI?

A associaçāo entre usuários e informaçōes;

A associaçăo entre usuários e ferramentas;

A importância da capacitação;

A discussäo da facilidade de uso;

Filosofia e cultura analítica; 
Questionário Business Intelligence

Página $1 / 4$

\section{Questionário BI}

O questionário que voce está prestes a responder está dividido em dois blocos: o primeiro bloco aborda questCes gerais e o segundo avalia sua opiniao em relaça a temas de Business Intelligence.

Nà há tempo determinado para a conclusăo do questionário, mas acredíz-se que vocé leve aproximadamente 5 minutos para preenchê-lo por completo. Para garantir uma pesquisa legitima e com resultados confíaveis, é importante ler com cuidado e atença as perguntas, respondendo conforme as orientaçes de cada questao. Alençac, pois uma vez que você mude de página, nao será mais possivel retornar às anteriores. Além disso, lembre-se de que nâo há respostas certas ou erradas, mas sua opiniao para os diferentes temas abordados.

Reserve um horário e um local tranquilo para responder este questionário, preferencialmente fora do horário de trabalho. Responda-o sem irterrupçes sempre no mesmo computador e navegador para nao correr o risco de perder respostas ou ter de recomeçar.

Para receber gratuitamente o resultado de seu tipo psicológico informe o endereço eletrônico no inicio do questionário e complate-o até no máximo 15/07/2012.

Desde já agradeço sua participaçà e comprometimento com a pesquisa. Qualquer dúvida ou cpiriao, por favor ente em contato pelo endereço eletrônico.

Muito obrigado,

Sergi Pauli

email: serniausp.br

Clique em "seguinte" para iniciar. 
Questionário Business Intelligence

Página 2/4

\section{Bloco I. Informaçøes Gerais}

Informe seu login (recebido por email com 8 digitos):

1. Qualé a sua idade?

2. Qualé o seu gênero? (mútipla escolha)

$\square$ Masculino
$\square$ Feminino

3. Qualé o seu grau de instruçao? (mútipla escolha)

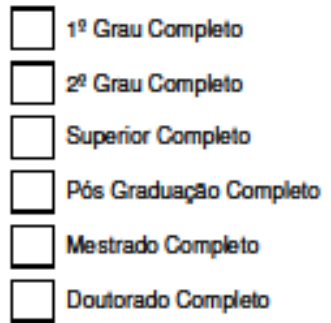

4. Qualé a sua formaça acadêmica predominante? (mútipla escolha)

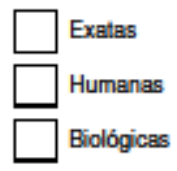

5. Quartos anos de experiência profissional (incluindo estágios) voce tem?

6. Quartos anos de experiância profissional (incluindo estágios) voce tem nesta organizaçao?

7. Qualé o seu cargo atual?

8. Qual é a sua diretoria/gerência atual?

9. Se deseja receber gratuitamente o resultado do DTP informe um e-mail. 
Questionário Business Intelligence

Página 3/4

Bloco II. Funcionalidades de Apresentaçá de BI

1. Qualé o seu grau de conhecimento das funcionalidades de apresentaçao de BI (Business Intelligence) abaixo indicadas? Dê uma nota de 0 (nenhum conhecimento) a 10 (total conhecimento) para cada uma das linhas abaixo.

\begin{tabular}{|l|l|}
\hline Painéis de Informaçao (ou Dashboard) & \\
\hline Relatórios Pré-Formatados (isto é, relatórios prontos para uso) & \\
\hline Relatórios ad hoc (isto é, relatórios que o próprio usuário pode criar) & \\
\hline Relatórios OLAP (isto é, tabelas dinâmicas e cubos) & \\
\hline Relatórios baseados em Modelos Predívos e Mineraçăo de Dados & \\
\hline
\end{tabular}

2. Qualé a sua frequência de uso das funcionalidades de apresentaçao de BI (Business Intelligence) abaixo indicadas? De uma nota de 0 (nao utilizo nunca) a 10 (uso frequentemente) para cada uma das linhas abaixo

\begin{tabular}{|l|l|}
\hline Painéis de Informaçao (ou Dashboard) & \\
\hline Relatórios Pré-Formatados (isto é, relatórios prontos para uso) & \\
\hline Relatórios ad hoc (isto é, relatórios que o próprio usuário pode criar) & \\
\hline Relatórios OLAP (isto é, tabelas dinâmicas e cubos) & \\
\hline Relatórios baseados em Modelos Predfivos e Mineraça de Dados & \\
\hline
\end{tabular}

3. Dentre as funcionalidades de apresentaçao de BI (Business Intelligence) abaixo indicadas, qual á a sua preferência? Ao responder, procure pensar naquela funcionalidade que voce mais gosta e se identifica independente de outros fatores influenciadores. (múltipla escolha)

\begin{tabular}{|l|l|}
\hline Painéis de Informaçao (ou Dashboard) & \\
\hline Relatórios Pré-Formatados (isto é, relatórios prontos para uso) & \\
\hline Relatórios ad hoc (isto é, relatónios que o próprio usuário pode criar) & \\
\hline Relatórios OLAP (isto é, tabelas dinâmicas e cubos) & \\
\hline Relatórios baseados em Modelos Predtivos e Mineraçao de Dados & \\
\hline
\end{tabular}

4. Em sua opiniaq quais dos aspectos abaixo influenciam mais a preferência pelas dferentes funcionalidade de apresentaça de BI (Business Intelligence)? Classifique em ordem crescente as opços abaixo (1 para maior influência a 7 para menor influência).

\begin{tabular}{|l|l|}
\hline Papel ou funçao desempenhado pelo usuário final & \\
\hline Tipo da informaçåo & \\
\hline Necessidade de negócio do usuário final & \\
\hline Conhecimento técrico do usuário final & \\
\hline Nivel de detalhamento da informaçåo & \\
\hline Características pessoais do usuário final & \\
\hline Cultura analitica da organizaçao & \\
\hline
\end{tabular}


Questionário Business Intelligence

Página 4/4

Parabéns, você respondeu o questionário alé o fim. Você já pode iniciar a outra parte, o Diagnóstico. Os resultados do DTPQ será devolvidos a você posteriormente no endereço eletrônico que voc\& informou no inicio deste questionário.

Agradeço sua participaça e comprometimento com a pesquisa. Qualquer dúvida ou opiniac, por favor entre em contato pelo endereço elatronico.

Muito obrigado,

Sergi Pauli

email: sacriausp.br

Clique em "concluido" para encerrar. 
Carta de Apresentação da Pesquisa

Prezado,

Sou aluno do curso de Mestrado em Administraçáo de Empresas do PPGA FEA USP (Programa de PósGraduaçāo em Administraçāo da Universidade de Sāo Paulo) e estou neste momento elaborando a dissertaçâo, um requisito obrigatório para a obtençâo do titulo.

Meu estudo está relacionado à área de Sistemas de Informaçấo e seu objetivo essencial é avaliar se existe uma relaçāo entre o estilo cognitivo do usuário - identificado pelo tipo de personalidade - e sua preferência pelas diferentes funcionalidades de Business Intelligence. Para identificar esta relaçâo e confirmar ou refutar sua validade é preciso realizar um levantamento (survey) que permita coletar um conjunto mínimo de dados e executar análises estatisticas. Trata-se, portanto, de uma pesquisa quantitativa realizada através de um questionário fechado, respondido direta $\Theta$ individualmente por usuários de BI, disponibilizado em meio digital e com tempo de resposta aproximado de 30 minutos.

Como muitas outras variáveis afetarn a preferência do usuário por determinada ferramenta, um requisito importante para avaliar isoladamente a influência do tipo de personalidade é aplicar o questionário num conjunto relativamente homogêneo de pessoas, isto é, usuários de uma mesma área, de um mesmo nível de instruçấo e de cargos equivalentes. Além disso, para que as conclusóes sejam válidas, é necessário um conjunto relativamente extenso e que tenha um conhecimento relativamente uniforme das diferentes funcionalidades de Business Intelligence.

Pelas informaçōes que pude levantar, acredito que dentro do ltaú, uma organizaçáo madura e referência sob o ponto de vista de Bl, sua área apresenta as características descritas acima e, por este motivo, gostaria de contar com sua permissāo e endosso na aplicaçáo deste questionário aos seus subordínados neste próximo mês de março. É importante destacar que a pesquisa nāo aborda qualquer tema que possa ser considerado confidencial ou sigiloso pela organizaçáa ou pelos respondentes. Apesar de individual, pessoal $\Theta$, obviamente, voluntário, as respostas sáo avaliadas exclusivamente pelo pesquisador e apenas de forma agregada de forma a alcançar conclusōes para o grupo.

Para incentivar a participaçáo, após a conclusáo e o tratamento das respostas será oferecido de forma gratuita $\theta$ confidencial o tipo de personalidade de cada participante. Ele será obtido através do Diagnóstico de Tipo de Personalidade, instrumento confiável e fidedigno elaborado pela Prof. Dra. Tânia Casado, titular da Universidade de Sáo Paulo, e já utilizado com sucesso em diversos cursos de graduaçáo e pós. graduaçāo da USP e da FIA, além de diferentes organizaçóes.

Desde já agradeço sua colaboraçâo e ałençấo e fico a disposiçāo para esclarecer quaisquer dúvidas e detalhar o procedimento $e$ as necessidades relacionadas com a coleta, caso esta seja aprovada. 
Prezado(a),

Você foi selecionado(a) para responder uma pesquisa de Mestrado sobre Business Inteligence, condurida por um aluno da Pós-Graduaçào da USP. Para participar, siga as orientaçdes ao final desta mensagem.

Estes questionários sào anônimos $\Theta$ individuais $\Theta$ o interesse da pesquisa está na análise dos dados agregados, isto $\dot{e}$, as respostas säo confidenciais e seräo avaliadas de forma consolidada exclusivamente pelo pesquisador e para fins acadêmicos.

O tempo estimado para a conclusäo dos dois questionários é de 30 minutos. Por favor, leia com atençào as perguntas, respondendo conforme as orientaçöes de cada questäo. Atençẫo, pois uma vez que você mude de página, näo será mais possível retornar às anteriores.

Reserve um horário e um local tranquilo para responder os questionários, preferencialmente fora do horário de trabalho. Responda 0 sem interrupçdes sempre no mesmo computador e navegador para näo correr o risco de perder as respostas.

Para receber gratuitamente o resultado de seu tipo psicológico é necessário informar o endereço eletrônico no inicio do primeiro questionário e completar ambos até 15/07/2012.

Desde já agradeço sua participaçào e comprometimento com a pesquisa. Qualquer dúvida ou opinião, por favor entre em contato pelo endereço eletrônico.

Muito obrigado,

Sergi Pauli

email: sercianuso.br

\section{Orientap̧es:}

Questionário BI

Link: https//www. surveymonkey.com/s/SQ6DZ6G

Login: procurar seu login na lista abaixo

Senha: USP (é a mesma para todos)

Diagnóstico de Tipo Psicológico (DTPQ)

Link: http://www.tipoconsultores.com.brisisquest/

Login: procurar seu login na lista abaixo

Senha: procurar sua senha na lista abaixo

No DTP, cada usuário tem seu login e senha, utilize apenas o seu. Atenção, pois existem 5 enunciados diferentes ao longo do teste e näo há como voltar para responder. Se ocorrer algum erro, entre em contato para que uma nova senha seja providenciada, pois ela é de uso único.

\begin{tabular}{|l|l|l|}
\hline \multicolumn{1}{|c|}{ Nome } & \multicolumn{1}{c|}{ Login } & \multicolumn{1}{c|}{ Senha } \\
\hline Respondente 01 & sp_sra01 & sra01 \\
\hline Respondente 02 & sp_sra02 & sra02 \\
\hline Respondente 03 & sp_sra03 & sra03 \\
\hline Respondente XX & sp_sraXX & sraXX \\
\hline
\end{tabular}


Resultado do Diagnóstico de Tipos Psicológicos

Página 1/1

RESULTADO DO DLAGNÓSTICO DE TIPOS PSICOLÓGICOS

Definiçao:

O objetivo do DTP' é identificar o tipo psicológico de um individuo baseado no modelo lećrico proposto por Jung e posteriormente complementado por Myers-Briggs. Com base nas respostas indíviduais fornecidas no questionário online, o instrumerto avalia a pessoa em quatro escalas dicotômicas, indicando como resultado global um fipo online, o instrumerto avaia a pessoa em

Este resultado global descreve sua personalidade e suas preferências em delerminado contexto, mas nao é perfeitamente preciso, pois pode variar dependendo de diferentes questoes ambiertais ou do seu momento atual de vida. 0 resultado nâ mede nivel intelectual ou capacidade cognitiva, apenas procura esclarecer seu comportamerto nas diferentes situaçes propostas e, dessa forma nalo deve ser considerado pejorativo ou laudatório. Em outras palavras, nâo há estilo melhor ou pior, cada qual tem seus pontos forles e seus pontos a melhorar, o importarte é utilizar a ferramenta para se conhecer melhor e se deservolver.

\section{Resultado do DTP:}

Com base nas suas respostas, seu tipo psicológico é o ESFP. Entenda o que ele sigrifica:

Preferencia 1. Seu foco de atençao: Extrovertido (E)

Seus interesses e atençes fluem principalmente para o mundo exterior das açes, objetos e pessoas e a determinaçao dominante é exercida por forças externas, resultando em maior exposiçac, inclusive de sentimentos.

Preferência 2. Sua forma de captar informaçđes: Sensaçao (S)

Sua tendência é perceber fatos imediatos, reais e práticos da experiência e da vidą portarto, a captaça se dá principalmente pelos cinco órgalos dos sentidos e está concentrada em aspectos concretos e quantífić́veis.

Preferencia 3. Sua forma de interpretar e tomar decisces: Sentimento (F)

Sua tendência é julgar ou tomar decisరes de modo subjetivo, pessoal e emocional, levantando em conta valores e preocupaçoes humanas, conferindo uma abordagem mais emocional às decisces.

Preferência 4. Sua forma de lidar com o mundo exterior: Percepcăo (P)

Sua tendância é viver de forma espontânea e flexivel, procurando adaptar-se ao mundo, aceitando mais os riscos e mudanças no dia-dia e mantendo suas opços em aberto.

Clareza nas Preferências:

Com base nas suas respostas também é possivel avalar qualo claras sao essas preferências:

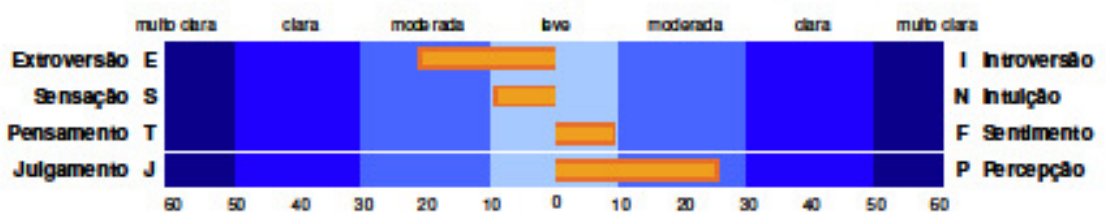

Estas barras sao meras posiçoes de referência que indicam o quâo consistente voce foi ao responder as perguntas propostas para cada préerência. Em outras palavras, elas nâo medem necessariamente a intensidade rem significam que voce nao apresenta caracteristicas da alternativa oposta.

\section{Pontos Fortes do Tipo ESFP:}

Entusiasmados, adaptáveis e divertidos:

Amigáveis, alegres e sociáveis;

Comunicativos, cooperativos e despreocupados;

Tolerantes e agradáveis.

\footnotetext{
1 O DTP foi elaborado pela Prof. Dra. Tânia Casado, peolossora do Departamento de Administrapăo da FEA USP, 6 uma berramenta lestada por meio de b́cricas cientficas, com validade oomprovada de conbúdo e co conetructo, aplicado com
} sucesso em diversas insthuiços de ensino e organizapoes. 